\title{
ESC Guidelines for the diagnosis and treatment of acute and chronic heart failure 2012
}

\section{The Task Force for the Diagnosis and Treatment of Acute and Chronic Heart Failure 2012 of the European Society of Cardiology. Developed in collaboration with the Heart Failure Association (HFA) of the ESC}

Authors/Task Force Members: John J.V. McMurray (Chairperson) (UK)*, Stamatis Adamopoulos (Greece), Stefan D. Anker (Germany), Angelo Auricchio (Switzerland), Michael Böhm (Germany), Kenneth Dickstein (Norway), Volkmar Falk (Switzerland), Gerasimos Filippatos (Greece), Cândida Fonseca (Portugal), Miguel Angel Gomez-Sanchez (Spain), Tiny Jaarsma (Sweden), Lars Køber (Denmark), Gregory Y.H. Lip (UK), Aldo Pietro Maggioni (Italy), Alexander Parkhomenko (Ukraine), Burkert M. Pieske (Austria), Bogdan A. Popescu (Romania), Per K. Rønnevik (Norway), Frans H. Rutten (The Netherlands), Juerg Schwitter (Switzerland), Petar Seferovic (Serbia), Janina Stepinska (Poland), Pedro T. Trindade (Switzerland), Adriaan A. Voors (The Netherlands), Faiez Zannad (France), Andreas Zeiher (Germany).

ESC Committee for Practice Guidelines (CPG): Jeroen J. Bax (CPG Chairperson) (The Netherlands), Helmut Baumgartner (Germany), Claudio Ceconi (Italy), Veronica Dean (France), Christi Deaton (UK), Robert Fagard (Belgium), Christian Funck-Brentano (France), David Hasdai (Israel), Arno Hoes (The Netherlands), Paulus Kirchhof (Germany/UK), Juhani Knuuti (Finland), Philippe Kolh (Belgium), Theresa McDonagh (UK), Cyril Moulin (France), Bogdan A. Popescu (Romania), Željko Reiner (Croatia), Udo Sechtem (Germany), Per Anton Sirnes (Norway), Michal Tendera (Poland), Adam Torbicki (Poland), Alec Vahanian (France), Stephan Windecker (Switzerland).

Document Reviewers: Theresa McDonagh (CPG Co-Review Coordinator) (UK), Udo Sechtem (CPG Co-Review Coordinator) (Germany), Luis Almenar Bonet (Spain), Panayiotis Avraamides (Cyprus), Hisham A. Ben Lamin (Libya), Michele Brignole (Italy), Antonio Coca (Spain), Peter Cowburn (UK), Henry Dargie (UK), Perry Elliott (UK), Frank Arnold Flachskampf (Sweden), Guido Francesco Guida (Italy), Suzanna Hardman (UK), Bernard lung

\footnotetext{
* Corresponding author. Chairperson: Professor John J.V. McMurray, University of Glasgow G12 8QQ, UK. Tel: +44 1413303479 , Fax: +44 141 330 6955, Email: john.mcmurray@ glasgow.ac.uk

Other ESC entities having participated in the development of this document:

Associations: European Association for Cardiovascular Prevention \& Rehabilitation (EACPR), European Association of Echocardiography (EAE), European Heart Rhythm Association (EHRA), European Association of Percutaneous Cardiovascular Interventions (EAPCl)

Working Groups: Acute Cardiac Care, Cardiovascular Pharmacology and Drug Therapy, Cardiovascular Surgery, Grown-up Congenital Heart Disease, Hypertension and the Heart, Myocardial and Pericardial Diseases, Pulmonary Circulation and Right Ventricular Function, Thrombosis, Valvular Heart Disease

Councils: Cardiovascular Imaging, Cardiovascular Nursing and Allied Professions, Cardiology Practice, Cardiovascular Primary Care

The content of these European Society of Cardiology (ESC) Guidelines has been published for personal and educational use only. No commercial use is authorized. No part of the ESC Guidelines may be translated or reproduced in any form without written permission from the ESC. Permission can be obtained upon submission of a written request to Oxford University Press, the publisher of the European Heart Journal and the party authorized to handle such permissions on behalf of the ESC.

Disclaimer. The ESC Guidelines represent the views of the ESC and were arrived at after careful consideration of the available evidence at the time they were written. Health professionals are encouraged to take them fully into account when exercising their clinical judgement. The guidelines do not, however, override the individual responsibility of health professionals to make appropriate decisions in the circumstances of the individual patients, in consultation with that patient, and where appropriate and necessary the patient's guardian or carer. It is also the health professional's responsibility to verify the rules and regulations applicable to drugs and devices at the time of prescription.

(C) The European Society of Cardiology 2012. All rights reserved. For permissions please email: journals.permissions@oup.com
} 


\section{(France), Bela Merkely (Hungary), Christian Mueller (Switzerland), John N. Nanas (Greece), Olav Wendelboe Nielsen (Denmark), Stein Ørn (Norway), John T. Parissis (Greece), Piotr Ponikowski (Poland).}

The disclosure forms of the authors and reviewers are available on the ESC website www.escardio.org/guidelines

\section{Table of Contents}

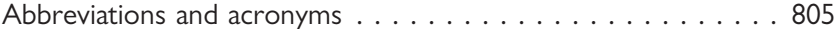

1. Preamble . . . . . . . . . . . . . . . . . . . . 8 807

2. Introduction . . . . . . . . . . . . . . . . . . 808

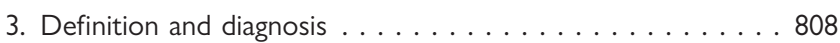

3.1 Definition of heart failure . . . . . . . . . . . . 808

3.2 Terminology related to left ventricular ejection fraction. 808

3.3 Terminology related to the time-course of heart failure 809

3.4 Terminology related to the symptomatic severity of heart

failure . . . . . . . . . . . . . . . . 809

3.5 Epidemiology, aetiology, pathophysiology, and natural

history of heart failure . . . . . . . . . . . . . 810

3.6 Diagnosis of heart failure . . . . . . . . . . . . . . . . . . . . . 810

3.6 .1 Symptoms and signs . . . . . . . . . . . . . 810

3.6.2 General diagnostic tests in patients with suspected heart failure . . . . . . . . . . . . . 811

3.6.3 Essential initial investigations: echocardiogram,

electrocardiogram, and laboratory tests . . . . . . . . 811

3.6.4 Natriuretic peptides . . . . . . . . . . . . . . . . 811

3.6.5 Chest X-ray . . . . . . . . . . . . . . . . . 813

3.6.6 Routine laboratory tests . . . . . . . . . . . . 813

3.6.7 Algorithm for the diagnosis of heart failure . . . . . 815

4. The role of cardiac imaging in the evaluation of patients with

suspected or confirmed heart failure . . . . . . . . . . . 816

4.1 Echocardiography. . . . . . . . . . . . . . . . . . 816

4.1.1 Assessment of left ventricular systolic dysfunction . 816

4.1.2 Assessment of left ventricular diastolic dysfunction . 816

4.2 Transoesophageal echocardiography . . . . . . . . 816

4.3 Stress echocardiography . . . . . . . . . . . . . . . . . . . . 818

4.4 Cardiac magnetic resonance . . . . . . . . . . . . 818

4.5 Single-photon emission computed tomography and

radionuclide ventriculography . . . . . . . . . . . . . . . . . . . 819

4.6 Positron emission tomography imaging . . . . . . . . . 819

4.7 Coronary angiography . . . . . . . . . . . . . . . . . . 819

4.8 Cardiac computed tomography. . . . . . . . . . . . . . 819

5. Other investigations . . . . . . . . . . . . . . . . . . . 819

5.1 Cardiac catheterization and endomyocardial biopsy . . . 819

5.2 Exercise testing . . . . . . . . . . . . . . . . 820

5.3 Genetic testing . . . . . . . . . . . . . . . . . 820

5.4 Ambulatory electrocardiographic monitoring . . . . . . 820

6. Prognosis . . . . . . . . . . . . . . . . . . . 820

7. Pharmacological treatment of heart failure with reduced

ejection fraction (systolic heart failure) . . . . . . . . . . 820

7.1 Objectives in the management of heart failure . . . . . 820
7.2 Treatments recommended in potentially all patients with systolic heart failure . . . . . . . . . . . . . . . . 820

7.2.1 Angiotensin-converting enzyme inhibitors and beta-blockers. . . . . . . . . . . . . . . . . . . . . . . 820

7.2.2 Mineralocorticoid/aldosterone receptor antagonists . . . . . . . . . . . . . . . . . . . . 823

7.2.3 Other treatments recommended in selected patients with systolic heart failure . . . . . . . . . . . . . . . . . . . . 825 825

7.2.4 Angiotensin receptor blockers . . . . . . . . . . . . 825

7.2 .5 Ivabradine . . . . . . . . . . . . . . . . . . . . . 825

7.2.6 Digoxin and other digitalis glycosides . . . . . . . . 826

7.2.7 Combination of hydralazine and isosorbide

dinitrate . . . . . . . . . . . . . . . 826

7.2.8 Omega-3 polyunsaturated fatty acids . . . . . . . 826

7.3 Treatments not recommended (unproven benefit) . . . 827

7.3.1 3-Hydroxy-3-methylglutaryl-coenzyme A reductase inhibitors ('statins') . . . . . . . . . . . . . . . . . 827

7.3 .2 Renin inhibitors . . . . . . . . . . . . . . . . . . 827

7.3 .3 Oral anticoagulants . . . . . . . . . . . . . . . . . 827

7.4 Treatments not recommended (believed to cause harm) 827

7.5 Diuretics . . . . . . . . . . . . . . . . . . . . . . 828

8. Pharmacological treatment of heart failure with 'preserved' ejection fraction (diastolic heart failure) . . . . . . . . . . 828 9. Non-surgical device treatment of heart failure with reduced ejection fraction (systolic heart failure) . . . . . . . . . . . . . 829

9.1 Implantable cardioverter-defibrillator . . . . . . . . . . . 829

9.1.1 Secondary prevention of sudden cardiac death . . . 829

9.1.2 Primary prevention of sudden cardiac death . . . . . 829

9.2 Cardiac resynchronization therapy . . . . . . . . . . 830

9.2.1 Recommendations for cardiac resynchronization therapy where the evidence is certain . . . . . . . . 831

9.2.2 Recommendations for cardiac resynchronization

therapy where the evidence is uncertain . . . . . . . . . 831

10. Arrhythmias, bradycardia, and atrioventricular block in patients with heart failure with reduced ejection fraction and heart failure with preserved ejection fraction . . . . . . . 832

10.1 Atrial fibrillation . . . . . . . . . . . . . . . . 832

10.1.1 Rate control . . . . . . . . . . . . . . . 832

10.1.2 Rhythm control . . . . . . . . . . . . . . . . . . 833

10.1.3 Thrombo-embolism prophylaxis . . . . . . . . . . . . . . . . . . . . . . 334

10.2 Ventricular arrhythmias . . . . . . . . . . . . . . 834

10.3 Symptomatic bradycardia and atrioventricular block . . 835 
11. Importance and management of other co-morbidity in heart failure with reduced ejection fraction and heart failure with preserved ejection fraction . . . . . . . . . . . . . . 837

11.1 Heart failure and co-morbidities . . . . . . . . . 837

11.2 Anaemia . . . . . . . . . . . . . . . . . . . . . 837

11.3 Angina . . . . . . . . . . . . . . . . . 837

11.4 Asthma: see chronic obstructive pulmonary disease . . 837

11.5 Cachexia . . . . . . . . . . . . . . . . . . . 837

11.6 Cancer . . . . . . . . . . . . . . . . . . . . . 837

11.7 Chronic obstructive pulmonary disease . . . . . . . . 837

11.8 Depression . . . . . . . . . . . . . . . . . . . . . . . . . . . . . . . . . . . . .

11.9 Diabetes . . . . . . . . . . . . . . . . . . . . . 838

11.10 Erectile dysfunction . . . . . . . . . . . . . . . 839

11.12 Gout . . . . . . . . . . . . . . . . . . . . . . . . . . 839

11.13 Hyperlipidaemia . . . . . . . . . . . . . . . . . . . . 839

11.14 Hypertension . . . . . . . . . . . . . . . . . . . . 839

11.14 Iron deficiency . . . . . . . . . . . . . . . . . . 840

11.15 Kidney dysfunction and cardiorenal syndrome . . . . 840

11.16 Obesity . . . . . . . . . . . . . . . . . . . . . . . . 840

11.17 Prostatic obstruction . . . . . . . . . . . . . . . 840

11.18 Renal dysfunction . . . . . . . . . . . . . . . . 840

11.19 Sleep disturbance and sleep-disordered breathing . . 840

12. Acute heart failure . . . . . . . . . . . . . . . . . 840

12.1 Initial assessment and monitoring of patients . . . . . . 841

12.2 Treatment of acute heart failure . . . . . . . . . . 841

12.2.1 Pharmacological therapy. . . . . . . . . . . . . . . 841

12.2.2 Non-pharmacological/non-device therapy . . . . . 843

12.3 Invasive monitoring . . . . . . . . . . . . . . . . . 847

12.3.1 Intra-arterial line . . . . . . . . . . . . . . . . 847

12.3.2 Pulmonary artery catheterization . . . . . . . . . 847

12.4 Monitoring after stabilization . . . . . . . . . . . . . 847

12.5 Other in-patient assessments . . . . . . . . . . . . . . . . . . . . . . . . . . .

12.6 Readiness for discharge . . . . . . . . . . . . . . . . . . . . . . . . 847

12.7 Special patient populations . . . . . . . . . . . . . . 847

12.7.1 Patients with a concomitant acute coronary

syndrome . . . . . . . . . . . . . . . . . 847

12.7.2 Isolated right ventricular failure . . . . . . . . . 848

12.7.3 Acute heart failure with 'cardiorenal syndrome' . . 848

12.7.4 Perioperative acute heart failure . . . . . . . . . 848

12.7.5 Peripartum cardiomyopathy . . . . . . . . . . 848

12.7.6 Adult congenital heart disease . . . . . . . . . . 848

13. Coronary revascularization and surgery, including valve

surgery, ventricular assist devices, and transplantation . . . . . 848

13.1 Coronary revascularization . . . . . . . . . . . . . . 848

13.2 Ventricular reconstruction . . . . . . . . . . . . . . . 849

13.3 Valvular surgery . . . . . . . . . . . . . . . . . . . . 849

13.3.1 Aortic stenosis . . . . . . . . . . . . . . . . . . . . 849

13.3.2 Aortic regurgitation . . . . . . . . . . . . . . . . . 849

13.3.3 Mitral regurgitation . . . . . . . . . . . . . . . . . . 849

13.4 Heart transplantation . . . . . . . . . . . . . . . 850

13.5 Mechanical circulatory support . . . . . . . . . . . 850

13.5.1 End-stage heart failure . . . . . . . . . . . . 851
13.5.2 Acute heart failure 851

14. Holistic management, including exercise training and multidisciplinary management programmes, patient monitoring, and palliative care . . . . . . . . . . . . . . . 852

14.1 Exercise training . . . . . . . . . . . . . . 852

14.2 Organization of care and multidisciplinary management

programmes . . . . . . . . . . . . . . . . . . . 853

14.3 Serial natriuretic peptide measurement . . . . . . . . 854

14.4 Remote monitoring (using an implanted device) . . . . 854

14.5 Remote monitoring (no implanted device) . . . . . . . 854

14.6 Structured telephone support . . . . . . . . . . . . . . 854

14.7 Palliative/supportive/end-of-life care . . . . . . . . . . 854

15. Gaps in evidence . . . . . . . . . . . . . . . . . . . . . 854

15.1 Diagnosis . . . . . . . . . . . . . . . . . . . 854

15.2 Co-morbidity . . . . . . . . . . . . . . . . . . . . . . 854

15.3 Non-pharmacological, non-interventional therapy . . . . 855

15.4 Pharmacological therapy . . . . . . . . . . . . . . . . . . . . . . . . . . . . .

15.5 Devices . . . . . . . . . . . . . . . . . . . . . 855

15.6 Acute heart failure . . . . . . . . . . . . . . . . 855

15.7 End-of-life care. . . . . . . . . . . . . . . . . . . . 855

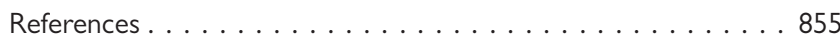

\section{Abbreviations and acronyms}

$\begin{array}{ll}\text { ACE } & \text { angiotensin-converting enzyme } \\ \text { ACHD } & \text { adult congenital heart disease } \\ \text { AF } & \text { atrial fibrillation } \\ \text { AF-CHF } & \text { Atrial Fibrillation and Congestive Heart Failure } \\ \text { AHF } & \text { acute heart failure } \\ \text { AIRE } & \text { Acute Infarction Ramipril Efficacy } \\ \text { ARB } & \text { angiotensin receptor blocker } \\ \text { ARR } & \text { absolute risk reduction } \\ \text { ATLAS } & \text { Assessment of Treatment with Lisinopril And } \\ & \text { Survival } \\ \text { AV } & \text { atrioventricular } \\ \text { AVP } & \text { arginine vasopressin } \\ \text { BEAUTIFUL } & \text { MorBidity-mortality EvAlUaTion of the } \text { I }_{f} \text { inhibi- } \\ & \text { tor ivabradine in patients with coronary disease } \\ \text { BEST } & \text { and left ventricULar dysfunction } \\ \text { BiVAD } & \text { Beta-Blocker Evaluation of Survival Trial } \\ \text { BNP } & \text { bi-ventricular assist device } \\ \text { b.P.m. } & \text { B-type natriuretic peptide } \\ \text { BTC } & \text { beats per minute } \\ \text { BTD } & \text { bridge to candidacy } \\ \text { BTR } & \text { bridge to decision } \\ \text { BTT } & \text { bridge to recovery } \\ \text { CABG } & \text { bridge to transplantation } \\ \text { CAD } & \text { coronary artery bypass graft } \\ \text { CARE-HF } & \begin{array}{l}\text { coronary artery disease } \\ \text { CCB }\end{array} \\ & \text { calcium-channel blocker } \\ & \end{array}$


$\mathrm{CHA}_{2} \mathrm{DS}_{2}$-VASc Cardiac failure, Hypertension, Age $\geq 75$ (Doubled), Diabetes, Stroke (Doubled)-Vascular disease, Age 65-74 and Sex category (Female)

CHARM Candesartan in Heart Failure: Assessment of Reduction in Mortality and Morbidity

CIBIS II Cardiac Insufficiency Bisoprolol Study

CMR cardiac magnetic resonance

COMET Carvedilol or Metoprolol European Trial

COMPANION Comparison of Medical Therapy, Pacing, and Defibrillation in Heart Failure

CONSENSUS Cooperative North Scandinavian Enalapril Survival Study

COPD chronic obstructive pulmonary disease

COPERNICUS Carvedilol Prospective Randomized Cumulative Survival

CORONA Controlled Rosuvastatin Multinational Trial in Heart Failure

CPAP continuous positive airway pressure

CRT cardiac resynchronization therapy

CRT-D cardiac resynchronization therapy-defibrillator

CRT-P

CT

DEFINITE

DIG

DT

ECG

ECMO

EF

eGFR

ELITE ॥

EMPHASIS-HF

GFR

GISSI-HF

H-ISDN

HAS-BLED

HEAAL

HF

HF-ACTION Heart Failure: A Controlled Trial Investigating Outcomes of Exercise Training

HF-PEF

HF-REF

I-PRESERVE

Defibrillators in Non-ischemic Cardiomyopathy

Treatment Evaluation

Digitalis Investigation Group

destination therapy

electrocardiogram

extracorporeal membrane oxygenation

ejection fraction

estimated glomerular filtration rate

Second Evaluation of Losartan in the Elderly Trial

Eplerenone in Mild Patients Hospitalization and Survival Study in Heart Failure

glomerular filtration rate

Gruppo Italiano per lo Studio della Sopravvivenza nell'Infarto miocardico-heart failure

hydralazine and isosorbide dinitrate

Hypertension, Abnormal renal/liver function (1 point each), Stroke, Bleeding history or predisposition, Labile INR, Elderly (>65), Drugs/ alcohol concomitantly (1 point each)

Heart failure Endpoint evaluation of Angiotensin

II Antagonist Losartan

heart failure

heart failure with 'preserved' ejection fraction

heart failure with reduced ejection fraction

Irbesartan in heart failure with preserved systolic function i.v.

IABP

ICD

LA

LBBB

LV

LVAD

LVEF

MADIT-II

MCS

MDCT

MERIT-HF

MRA

MR-proANP

MUSTIC

NIPPV

NNT

NSAID

NYHA

OPTIMAAL

intravenous

intra-aortic balloon pump

implantable cardioverter-defibrillator

left atrial

left bundle branch block

left ventricular

left ventricular assist device

left ventricular ejection fraction

Multicenter Automatic Defibrillator Implantation

Trial II

mechanical circulatory support

multi-detector computed tomography

Metoprolol CR/XL Randomised Intervention

Trial in Congestive Heart Failure

mineralocorticoid receptor antagonist

mid-regional atrial (or A-type) natriuretic peptide

Multisite Stimulation in Cardiomyopathies

non-invasive positive pressure ventilation

number needed to treat

non-steroidal anti-inflammatory drug

New York Heart Association

Optimal Therapy in Myocardial infarction with the Angiotensin II Antagonist Losartan

PEP-CHF

PET

PUFA

RAFT

RALES

RCT

RRR

SAVE

SCD-HeFT

SENIORS

Perindopril for Elderly People with Chronic Heart failure

positron emission tomography

polyunsaturated fatty acid

Resynchronization/Defibrillation for Ambulatory

Heart Failure Trial

Randomised Aldactone Evaluation Study

randomized controlled trial

relative risk reduction

Survival and Ventricular Enlargement

Sudden Cardiac Death in Heart Failure Trial

Study of Effects of Nebivolol Intervention on

Outcomes and Rehospitalization in Seniors

With Heart Failure

SHIFT Systolic Heart failure treatment with the $\mathrm{I}_{f}$ inhibitor ivabradine Trial

SOLVD

SPECT

STICH

TAPSE

TDI

TOE

TRACE

Val-HeFT

VALIANT

$\mathrm{VO}_{2}$
Studies of Left Ventricular Dysfunction

single-photon emission computed tomography

Surgical Treatment for Ischemic Heart Failure

tricuspid annular plane systolic excursion

tissue Doppler imaging

transoesophageal echocardiography

TRAndolapril Cardiac Evaluation

Valsartan Heart Failure Trial

Valsartan In Acute myocardial infarction

maximal oxygen consumption 


\section{Preamble}

Guidelines summarize and evaluate all available evidence at the time of the writing process, on a particular issue with the aim of assisting physicians in selecting the best management strategies for an individual patient, with a given condition, taking into account the impact on outcome, as well as the risk-benefit ratio of particular diagnostic or therapeutic means. Guidelines are no substitutes, but are complements, for textbooks and cover the European Society of Cardiology (ESC) Core Curriculum topics. Guidelines and recommendations should help physicians to make decisions in their daily practice. However, the final decisions concerning an individual patient must be made by the responsible physician(s).

A large number of Guidelines have been issued in recent years by the ESC as well as by other societies and organizations. Because of the impact on clinical practice, quality criteria for the development of guidelines have been established in order to make all decisions transparent to the user. The recommendations for formulating and issuing ESC Guidelines can be found on the
ESC website (http://www.escardio.org/guidelines-surveys/escguidelines/about/Pages/rules-writing.aspx). ESC Guidelines represent the official position of the ESC on a given topic and are regularly updated.

Members of this Task Force were selected by the ESC to represent professionals involved with the medical care of patients with this pathology. Selected experts in the field undertook a comprehensive review of the published evidence for diagnosis, management, and/or prevention of a given condition according to ESC Committee for Practice Guidelines (CPG) policy. A critical evaluation of diagnostic and therapeutic procedures was performed including assessment of the risk-benefit ratio. Estimates of expected health outcomes for larger populations were included, where data exist. The level of evidence and the strength of recommendation of particular treatment options were weighed and graded according to pre-defined scales, as outlined in Tables A and $B$.

The experts of the writing and reviewing panels filled in declarations of interest forms of all relationships which might be perceived as real or potential sources of conflicts of interest. These forms

Table A Classes of recommendations

\begin{tabular}{|c|l|l}
\hline \multicolumn{1}{c|}{$\begin{array}{c}\text { Classes of } \\
\text { recommendations }\end{array}$} & \multicolumn{1}{c}{ Definition } & Suggested wording to use \\
\hline Class I & $\begin{array}{l}\text { Evidence and/or general agreement } \\
\text { that a given treatment or procedure } \\
\text { is beneficial, useful, effective. }\end{array}$ & $\begin{array}{l}\text { Is recommended/is } \\
\text { indicated }\end{array}$ \\
\hline Class II & $\begin{array}{l}\text { Conflicting evidence and/or a } \\
\text { divergence of opinion about the } \\
\text { usefulness/efficacy of the given } \\
\text { treatment or procedure. }\end{array}$ & Should be considered \\
\hline Class IIa & $\begin{array}{l}\text { Weight of evidence/opinion is in } \\
\text { favour of usefulness/efficacy. }\end{array}$ & May be considered \\
\hline Class IIb & $\begin{array}{l}\text { Usefulness/efficacy is less well } \\
\text { established by evidence/opinion. }\end{array}$ & Is not recommended \\
\hline Class III & $\begin{array}{l}\text { Evidence or general agreement that } \\
\text { the given treatment or procedure } \\
\text { is not useful/effective, and in some } \\
\text { cases may be harmful. }\end{array}$ & \\
\hline
\end{tabular}

\section{Table B Levels of evidence}

\begin{tabular}{l|l}
\hline $\begin{array}{l}\text { Level of } \\
\text { evidence A }\end{array}$ & $\begin{array}{l}\text { Data derived from multiple randomized } \\
\text { clinical trials or meta-analyses. }\end{array}$ \\
\hline $\begin{array}{l}\text { Level of } \\
\text { evidence B }\end{array}$ & $\begin{array}{l}\text { Data derived from a single randomized } \\
\text { clinical trial or large non-randomized } \\
\text { studies. }\end{array}$ \\
\hline $\begin{array}{l}\text { Level of } \\
\text { evidence C }\end{array}$ & $\begin{array}{l}\text { Consensus of opinion of the experts andl } \\
\text { or small studies, retrospective studies, } \\
\text { registries. }\end{array}$ \\
\hline
\end{tabular}

were compiled into one file and can be found on the ESC website (http://www.escardio.org/guidelines). Any changes in declarations of interest that arise during the writing period must be notified to the ESC and updated. The Task Force received its entire financial support from the ESC without any involvement from the healthcare industry.

The ESC CPG supervises and coordinates the preparation of new Guidelines produced by Task Forces, expert groups, or consensus panels. The Committee is also responsible for the endorsement process of these Guidelines. The ESC Guidelines undergo extensive review by the CPG and external experts. After appropriate revisions, it is approved by all the experts involved in the Task 
Force. The finalized document is approved by the CPG for publication in the European Heart Journal.

The task of developing ESC Guidelines covers not only the integration of the most recent research, but also the creation of educational tools and implementation programmes for the recommendations. To implement the guidelines, condensed pocket guidelines versions, summary slides, booklets with essential messages, and an electronic version for digital applications (smartphones, etc.) are produced. These versions are abridged and, thus, if needed, one should always refer to the full text version which is freely available on the ESC website. The National Societies of the ESC are encouraged to endorse, translate, and implement the ESC Guidelines. Implementation programmes are needed because it has been shown that the outcome of disease may be favourably influenced by the thorough application of clinical recommendations.

Surveys and registries are needed to verify that real-life daily practice is in keeping with what is recommended in the guidelines, thus completing the loop between clinical research, writing of guidelines, and implementing them into clinical practice.

The guidelines do not, however, override the individual responsibility of health professionals to make appropriate decisions in the circumstances of the individual patients, in consultation with that patient, and, where appropriate and necessary, the patient's guardian or carer. It is also the health professional's responsibility to verify the rules and regulations applicable to drugs and devices at the time of prescription.

\section{Introduction}

The aim of this document is to provide practical, evidence-based guidelines for the diagnosis and treatment of heart failure (HF). The principal changes from the 2008 guidelines ${ }^{1}$ relate to:

(i) an expansion of the indication for mineralocorticoid (aldosterone) receptor antagonists (MRAs);

(ii) a new indication for the sinus node inhibitor ivabradine;

(iii) an expanded indication for cardiac resynchronization therapy (CRT);

(iv) new information on the role of coronary revascularization in $\mathrm{HF}$;

(v) recognition of the growing use of ventricular assist devices; and

(vi) the emergence of transcatheter valve interventions.

There are also changes to the structure and format of the guidelines. Therapeutic recommendations now state the treatment effect supported by the class and level of recommendation in tabular format; in the case of chronic heart failure due to left ventricular (LV) systolic dysfunction, the recommendations focus on mortality and morbidity outcomes. Detailed summaries of the key evidence supporting generally recommended treatments have been provided. Practical guidance is provided for the use of the more important disease-modifying drugs and diuretics. When possible, other relevant guidelines, consensus statements, and position papers have been cited to avoid unduly lengthy text. All tables should be read in conjunction with their accompanying text and not read in isolation.

\section{Definition and diagnosis}

\subsection{Definition of heart failure}

Heart failure can be defined as an abnormality of cardiac structure or function leading to failure of the heart to deliver oxygen at a rate commensurate with the requirements of the metabolizing tissues, despite normal filling pressures (or only at the expense of increased filling pressures). ${ }^{1}$ For the purposes of these guidelines, HF is defined, clinically, as a syndrome in which patients have typical symptoms (e.g. breathlessness, ankle swelling, and fatigue) and signs (e.g. elevated jugular venous pressure, pulmonary crackles, and displaced apex beat) resulting from an abnormality of cardiac structure or function. The diagnosis of HF can be difficult (see Section 3.6). Many of the symptoms of HF are nondiscriminating and, therefore, of limited diagnostic value. ${ }^{2-6}$ Many of the signs of HF result from sodium and water retention and resolve quickly with diuretic therapy, i.e. may be absent in patients receiving such treatment. Demonstration of an underlying cardiac cause is therefore central to the diagnosis of HF (see Section 3.6). This is usually myocardial disease causing systolic ventricular dysfunction. However, abnormalities of ventricular diastolic function or of the valves, pericardium, endocardium, heart rhythm, and conduction can also cause HF (and more than one abnormality can be present) (see Section 3.5). Identification of the underlying cardiac problem is also crucial for therapeutic reasons, as the precise pathology determines the specific treatment used (e.g. valve surgery for valvular disease, specific pharmacological therapy for LV systolic dysfunction, etc.).

\subsection{Terminology related to left ventricular ejection fraction}

The main terminology used to describe HF is historical and is based on measurement of LV ejection fraction (EF). Mathematically, EF is the stroke volume (which is the end-diastolic volume minus the end-systolic volume) divided by the end-diastolic volume. In patients with reduced contraction and emptying of the left ventricle (i.e. systolic dysfunction), stroke volume is maintained by an increase in end-diastolic volume (because the left ventricle dilates), i.e. the heart ejects a smaller fraction of a larger volume. The more severe the systolic dysfunction, the more the EF is reduced from normal and, generally, the greater the end-diastolic and end-systolic volumes.

The EF is considered important in HF, not only because of its prognostic importance (the lower the EF the poorer the survival) but also because most clinical trials selected patients based upon EF (usually measured using a radionuclide technique or echocardiography). The major trials in patients with $\mathrm{HF}$ and a reduced $\mathrm{EF}$ (HF-REF), or 'systolic HF', mainly enrolled patients with an EF $\leq 35 \%$, and it is only in these patients that effective therapies have been demonstrated to date.

Other, more recent, trials enrolled patients with $\mathrm{HF}$ and an EF $>40-45 \%$ and no other causal cardiac abnormality (such as valvular or pericardial disease). Some of these patients did not have an entirely normal EF (generally considered to be $>50 \%$ ) 


\section{Table I Diagnosis of heart failure}

\begin{tabular}{|c|}
\hline The diagnosis of HF-REF requires three conditions to be satisfied: \\
\hline I. Symptoms typical of $\mathrm{HF}$ \\
\hline 2. Signs typical of $\mathrm{HF}^{\mathrm{a}}$ \\
\hline 3. Reduced LVEF \\
\hline The diagnosis of HF-PEF requires four conditions to be satisfied: \\
\hline I. Symptoms typical of HF \\
\hline 2. Signs typical of $\mathrm{HF}^{\mathrm{a}}$ \\
\hline 3. Normal or only mildly reduced LVEF and LV not dilated \\
\hline $\begin{array}{l}\text { 4. Relevant structural heart disease (LV hypertrophy/LA } \\
\text { enlargement) and/or diastolic dysfunction (see Section 4.I.2) }\end{array}$ \\
\hline
\end{tabular}

$\mathrm{HF}=$ heart failure; $\mathrm{HF}-\mathrm{PEF}=$ heart failure with 'preserved' ejection fraction; $\mathrm{HF}-\mathrm{REF}=$ heart failure and a reduced ejection fraction; $L A=$ left atrial; $L V=$ left ventricular; $\mathrm{LVEF}=$ left ventricular ejection fraction.

${ }^{a}$ Signs may not be present in the early stages of HF (especially in HF-PEF) and in patients treated with diuretics (see Section 3.6).

but also did not have a major reduction in systolic function either. Because of this, the term HF with 'preserved' EF (HF-PEF) was created to describe these patients. Patients with an EF in the range $35-50 \%$ therefore represent a 'grey area' and most probably have primarily mild systolic dysfunction. The diagnosis of HF-PEF is more difficult than the diagnosis of HF-REF because it is largely one of exclusion, i.e. potential non-cardiac causes of the patient's symptoms (such as anaemia or chronic lung disease) must first be discounted (Table 1). ${ }^{7,8}$ Usually these patients do not have a dilated heart and many have an increase in LV wall thickness and increased left atrial (LA) size. Most have evidence of diastolic dysfunction (see Section 4.1.2), which is generally accepted as the likely cause of HF in these patients (hence the term 'diastolic HF'). ${ }^{7,8}$

It is important to note that EF values and normal ranges are dependent on the imaging technique employed, method of analysis, and operator. Other, more sensitive measures of systolic function may show abnormalities in patients with a preserved or even normal EF (see Section 4.1.1), hence the preference for stating preserved or reduced EF over preserved or reduced 'systolic function, 9,10

\subsection{Terminology related to the time-course of heart failure}

The terms used to describe different types of HF can be confusing. As described above, in these guidelines the term HF is used to describe the symptomatic syndrome, graded according to the New York Heart Association (NYHA) functional classification (see Section 3.4 and Table 2), although a patient can be rendered asymptomatic by treatment. In these guidelines, a patient who has never exhibited the typical signs or symptoms of HF is described as having asymptomatic LV systolic dysfunction (or whatever the underlying cardiac abnormality is). Patients who have had HF for some time are often said to have 'chronic HF'. A treated patient with symptoms and signs, which have remained generally unchanged for at least a month, is said to be 'stable'. If chronic stable HF deteriorates, the patient may be described as 'decompensated' and this may happen suddenly, i.e. 'acutely', usually leading to hospital admission, an event of considerable prognostic importance. New ('de novo') HF may present acutely, for example as a consequence of acute myocardial infarction or in a subacute (gradual) fashion, for example in a patient who has had asymptomatic cardiac dysfunction, often for an indeterminate period, and may persist or resolve (patients may become 'compensated'). Although symptoms and signs may resolve in the latter patients, their underlying cardiac dysfunction may not, and they remain at risk of recurrent 'decompensation'. Occasionally, however, a patient may have HF due to a problem that resolves completely (e.g. acute viral myopericarditis). Some other patients, particularly those with 'idiopathic' dilated cardiomyopathy, may also show substantial or even complete recovery of LV systolic function with modern disease-modifying therapy [including an angiotensinconverting enzyme (ACE) inhibitor, beta-blocker, and mineralocorticoid receptor antagonist (MRA)]. 'Congestive HF' is a term that is sometimes still used, particularly in the USA, and may describe acute or chronic HF with evidence of congestion (i.e. sodium and water retention). Congestion, though not other symptoms of HF (e.g. fatigue), may resolve with diuretic treatment. Many or all of these terms may be accurately applied to the same patient at different times, depending upon their stage of illness.

\subsection{Terminology related to the symptomatic severity of heart failure}

The NYHA functional classification (Table 2) has been used to select patients in almost all randomized treatment trials in $\mathrm{HF}$ and, therefore, to describe which patients benefit from effective therapies. Patients in NYHA class I have no symptoms attributable to heart disease; those in NYHA classes II, III or IV are sometimes said to have mild, moderate or severe symptoms, respectively.

It is important to note, however, that symptom severity correlates poorly with ventricular function, and that although there is a clear relationship between severity of symptoms and survival, patients with mild symptoms may still have a relatively high absolute risk of hospitalization and death. ${ }^{11-13}$ Symptoms can also change rapidly; for example, a stable patient with mild symptoms can become suddenly breathless at rest with the onset of an arrhythmia, and an acutely unwell patient with pulmonary oedema and NYHA class IV symptoms may improve rapidly with the administration of a diuretic. Deterioration in symptoms indicates heightened risk of hospitalization and death, and is an indication to seek prompt medical attention and treatment. Obviously, improvement in symptoms (preferably to the point of the patient becoming asymptomatic) is one of the two major goals of treatment of HF (the other being to reduce morbidity, including hospital admissions, and mortality).

The Killip classification may be used to describe the severity of the patient's condition in the acute setting after myocardial infarction. $^{14}$ 
Table 2 New York Heart Association functional classification based on severity of symptoms and physical activity

\begin{tabular}{|l|l|}
\hline Class I & $\begin{array}{l}\text { No limitation of physical activity. Ordinary physical } \\
\text { activity does not cause undue breathlessness, fatigue, } \\
\text { or palpitations. }\end{array}$ \\
\hline Class II & $\begin{array}{l}\text { Slight limitation of physical activity. Comfortable at } \\
\text { rest, but ordinary physical activity results in undue } \\
\text { breathlessness, fatigue, or palpitations. }\end{array}$ \\
\hline Class III & $\begin{array}{l}\text { Marked limitation of physical activity. Comfortable at } \\
\text { rest, but less than ordinary physical activity results in } \\
\text { undue breathlessness, fatigue, or palpitations. }\end{array}$ \\
\hline Class IV & $\begin{array}{l}\text { Unable to carry on any physical activity without } \\
\text { discomfort. Symptoms at rest can be present. If any } \\
\text { physical activity is undertaken, discomfort is increased. }\end{array}$ \\
\hline
\end{tabular}

\subsection{Epidemiology, aetiology, pathophysiology, and natural history of heart failure}

Approximately $1-2 \%$ of the adult population in developed countries has HF, with the prevalence rising to $\geq 10 \%$ among persons 70 years of age or older. ${ }^{15}$ There are many causes of HF, and these vary in different parts of the world (Appendix A). At least half of patients with HF have a low EF (i.e. HF-REF). HF-REF is the best understood type of HF in terms of pathophysiology and treatment, and is the focus of these guidelines. Coronary artery disease (CAD) is the cause of approximately two-thirds of cases of systolic HF, although hypertension and diabetes are probable contributing factors in many cases. There are many other causes of systolic HF (Appendix A), which include previous viral infection (recognized or unrecognized), alcohol abuse, chemotherapy (e.g. doxorubicin or trastuzumab), and 'idiopathic' dilated cardiomyopathy (although the cause is thought to be unknown, some of these cases may have a genetic basis). ${ }^{16}$

HF-PEF seems to have a different epidemiological and aetiological profile from HF-REF. ${ }^{17,18}$ Patients with HF-PEF are older and more often female and obese than those with HF-REF. They are less likely to have coronary heart disease and more likely to have hypertension and atrial fibrillation (AF). Patients with HF-PEF have a better prognosis than those with HF-REF (see below). ${ }^{19}$

In patients with LV systolic dysfunction, the maladaptive changes occurring in surviving myocytes and extracellular matrix after myocardial injury (e.g. myocardial infarction) lead to pathological 'remodelling' of the ventricle with dilatation and impaired contractility, one measure of which is a reduced EF. ${ }^{11,20}$ What characterizes untreated systolic dysfunction is progressive worsening of these changes over time, with increasing enlargement of the left ventricle and decline in EF, even though the patient may be symptomless initially. Two mechanisms are thought to account for this progression. The first is occurrence of further events leading to additional myocyte death (e.g. recurrent myocardial infarction). The other is the systemic responses induced by the decline in systolic function, particularly neurohumoral activation.
Two key neurohumoral systems activated in HF are the reninangiotensin-aldosterone system and sympathetic nervous system. In addition to causing further myocardial injury, these systemic responses have detrimental effects on the blood vessels, kidneys, muscles, bone marrow, lungs, and liver, and create a pathophysiological 'vicious cycle', accounting for many of the clinical features of the HF syndrome, including myocardial electrical instability. Interruption of these two key processes is the basis of much of the effective treatment of HF. ${ }^{11,20}$

Clinically, the aforementioned changes are associated with the development of symptoms and worsening of these over time, leading to diminished quality of life, declining functional capacity, episodes of frank decompensation leading to hospital admission (which is often recurrent and costly to health services), and premature death, usually due to pump failure or a ventricular arrhythmia. The limited cardiac reserve of such patients is also dependent on atrial contraction, synchronized contraction of the left ventricle, and a normal interaction between the right and left ventricles. Intercurrent events affecting any of these [e.g. the development of $\mathrm{AF}$ or conduction abnormalities, such as left bundle branch block (LBBB)] or imposing an additional haemodynamic load on the failing heart (e.g. anaemia) can lead to acute decompensation.

Before 1990, the modern era of treatment, $60-70 \%$ of patients died within 5 years of diagnosis, and admission to hospital with worsening symptoms was frequent and recurrent, leading to an epidemic of hospitalization for $\mathrm{HF}$ in many countries. ${ }^{21-23}$ Effective treatment has improved both of these outcomes, with a relative reduction in hospitalization in recent years of $30-50 \%$ and smaller but significant decreases in mortality. ${ }^{21-23}$

\subsection{Diagnosis of heart failure}

\subsubsection{Symptoms and signs}

The diagnosis of HF can be difficult, especially in the early stages. Although symptoms bring patients to medical attention, many of the symptoms of HF (Table 4) are non-specific and do not, therefore, help discriminate between HF and other problems. Symptoms that are more specific (i.e. orthopnoea and paroxysmal nocturnal dyspnoea) are less common, especially in patients with milder symptoms, and are, therefore, insensitive. ${ }^{2-6}$

Many of the signs of HF result from sodium and water retention, and are, therefore, also not specific. Peripheral oedema has other causes as well, and is particularly non-specific. Signs resulting from sodium and water retention (e.g. peripheral oedema) resolve quickly with diuretic therapy (i.e. may be absent in patients receiving such treatment, making it more difficult to assess patients already treated in this way). More specific signs, such as elevated jugular venous pressure and displacement of the apical impulse, are harder to detect and, therefore, less reproducible (i.e. agreement between different doctors examining the same patient may be poor). ${ }^{2-6}$

Symptoms and signs may be particularly difficult to identify and interpret in obese individuals, in the elderly, and in patients with chronic lung disease. ${ }^{24-26}$

The patient's medical history is also important. HF is unusual in an individual with no relevant medical history (e.g. a potential cause of cardiac damage), whereas certain features, particularly previous myocardial infarction, greatly increase the likelihood of HF in a 


\section{Table 4 Symptoms and signs typical of heart failure}

\begin{tabular}{|c|c|}
\hline Symptoms & Signs \\
\hline Typical & More specific \\
\hline Breathlessness & Elevated jugular venous pressure \\
\hline Orthopnoea & Hepatojugular reflux \\
\hline Paroxysmal nocturnal dyspnoea & Third heart sound (gallop rhythm) \\
\hline Reduced exercise tolerance & Laterally displaced apical impulse \\
\hline $\begin{array}{l}\text { Fatigue, tiredness, increased time } \\
\text { to recover after exercise }\end{array}$ & Cardiac murmur \\
\hline \multicolumn{2}{|l|}{ Ankle swelling } \\
\hline Less typical & Less specific \\
\hline Nocturnal cough & $\begin{array}{l}\text { Peripheral oedema (ankle, sacral, } \\
\text { scrotal) }\end{array}$ \\
\hline Wheezing & Pulmonary crepitations \\
\hline Weight gain (>2 kg/week) & $\begin{array}{l}\text { Reduced air entry and dullness to } \\
\text { percussion at lung bases (pleural } \\
\text { effusion) }\end{array}$ \\
\hline $\begin{array}{l}\text { Weight loss } \\
\text { (in advanced heart failure) }\end{array}$ & Tachycardia \\
\hline Bloated feeling & Irregular pulse \\
\hline Loss of appetite & Tachypnoea (>16 breaths/min) \\
\hline $\begin{array}{l}\text { Confusion } \\
\text { (especially in the elderly) }\end{array}$ & Hepatomegaly \\
\hline Depression & Ascites \\
\hline Palpitations & Tissue wasting (cachexia) \\
\hline Syncope & \\
\hline
\end{tabular}

patient with appropriate symptoms and signs. ${ }^{2-5}$ These points highlight the need to obtain objective evidence of a structural or functional cardiac abnormality that is thought to account for the patient's symptoms and signs, to secure the diagnosis of HF (see below).

Once the diagnosis of HF has been made, it is important to establish the cause, particularly specific correctable causes (Appendix A). Symptoms and signs are important in monitoring a patient's response to treatment and stability over time. Persistence of symptoms despite treatment usually indicates the need for additional therapy, and worsening of symptoms is a serious development (placing the patient at risk of urgent hospital admission and death) and merits prompt medical attention.

\subsubsection{General diagnostic tests in patients with suspected heart failure}

In view of the difficulty in grading the evidence for diagnostic tests, all diagnostic recommendations have been given an arbitrary evidence level of $\mathrm{C}$.

\subsubsection{Essential initial investigations: echocardiogram, electrocardiogram, and laboratory tests}

The echocardiogram and electrocardiogram (ECG) are the most useful tests in patients with suspected HF. The echocardiogram provides immediate information on chamber volumes, ventricular systolic and diastolic function, wall thickness, and valve function. $^{7-10,27-34}$ This information is crucial in determining appropriate treatment (e.g. an ACE inhibitor and beta-blocker for systolic dysfunction or surgery for aortic stenosis). Echocardiography is discussed in detail later (see Section 4). The ECG shows the heart rhythm and electrical conduction, i.e. whether there is sinoatrial disease, atrioventricular (AV) block, or abnormal intraventricular conduction (see Table 5). These findings are also important for decisions about treatment (e.g. rate control and anticoagulation for AF, pacing for bradycardia, or CRT if the patient has LBBB) (see Section 9.2 on treatment). The ECG may also show evidence of LV hypertrophy or $\mathrm{Q}$ waves (indicating loss of viable myocardium), giving a possible clue to the aetiology of HF. HF is very unlikely (likelihood $<2 \%$ ) in patients presenting acutely and with a completely normal ECG. ${ }^{2,3,35-38}$ In patients with a non-acute presentation, a normal ECG has a somewhat lower negative predictive value (likelihood $<10-14 \%$ ).

The information provided by these two tests will permit an initial working diagnosis and treatment plan in the majority of patients. Routine biochemical and haematological investigations are also important, partly to determine whether renin-angiotensin-aldosterone blockade can be initiated safely (renal function and potassium) and to exclude anaemia (which can mimic or aggravate HF) and because they provide other, useful information (see Section 3.6.6).

Other tests are generally only required if the diagnosis remains unclear (e.g. if echocardiographic images are suboptimal or if an unusual cardiac cause, or a non-cardiac cause, of the patient's condition is suspected) or if further evaluation of the underlying cause of the patient's cardiac problem is indicated (e.g. perfusion imaging or angiography in suspected CAD or endomyocardial biopsy in certain infiltrating diseases of the myocardium). Special tests are discussed in more detail in Sections 4 and 5.

\subsubsection{Natriuretic peptides}

Because the signs and symptoms of HF are so non-specific, many patients with suspected HF referred for echocardiography are not found to have an important cardiac abnormality. Where the availability of echocardiography is limited, an alternative approach to diagnosis is to measure the blood concentration of a natriuretic peptide, a family of hormones secreted in increased amounts when the heart is diseased or the load on any chamber is increased (e.g. by $A F$, pulmonary embolism, and some non-cardiovascular conditions, including renal failure). ${ }^{39-42}$ Natriuretic peptide levels also increase with age, but may be reduced in obese patients. ${ }^{26} \mathrm{~A}$ normal natriuretic peptide level in an untreated patient virtually excludes significant cardiac disease, making an echocardiogram unnecessary (investigation for a non-cardiac cause of the patient's problems is likely to be more productive in such patients). ${ }^{39,42}$ The use of natriuretic peptides as a 'rule-out' test in the diagnosis of $\mathrm{HF}$ is discussed in detail elsewhere. ${ }^{39-50}$ Multiple studies have examined the threshold concentration that excludes HF for the 


\section{Recommendations for the diagnostic investigations in ambulatory patients suspected of having heart failure ${ }^{c}$}

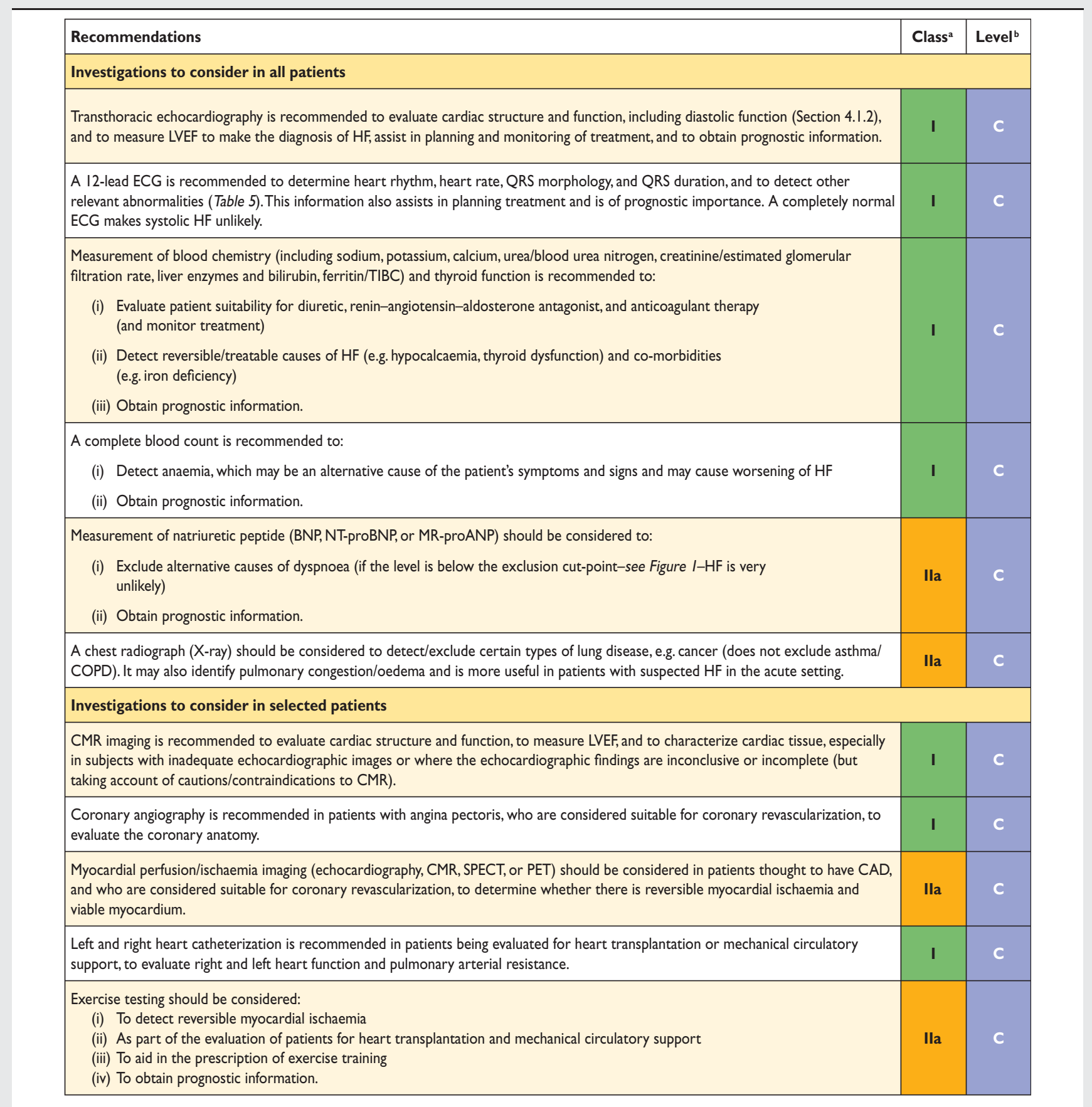

$\mathrm{BNP}=\mathrm{B}$-type natriuretic peptide; $\mathrm{CAD}=$ coronary artery disease; $\mathrm{CMR}=$ cardiac magnetic resonance; $\mathrm{COPD}=$ chronic obstructive pulmonary disease; $\mathrm{ECG}=$ electrocardiogram; $\mathrm{HF}=$ heart failure; $\mathrm{LV}=$ left ventricular; $\mathrm{LVEF}=$ left ventricular ejection fraction; $\mathrm{MR}$-proANP = mid-regional pro atrial natriuretic peptide; NT-proBNP = N-terminal pro B-type natriuretic peptide; $\mathrm{PET}=$ positron emission tomography; SPECT = single photon emission computed tomography; TIBC = total iron-binding capacity.

${ }^{a}$ Class of recommendation.

bLevel of evidence.

'This list is not exhaustive and other investigations are discussed in the text. Additional investigations may be indicated in patients with suspected acute HF in the emergency department/ hospital, including troponins and D-dimer measurement and right heart catheterization.

two most commonly used natriuretic peptides, B-type natriuretic peptide (BNP) and $\mathrm{N}$-terminal pro B-type natriuretic peptide (NT-proBNP). ${ }^{43-50}$ The exclusion threshold differs for patients presenting with acute onset or worsening of symptoms (e.g. to a hospital emergency department) and those presenting with a more gradual onset of symptoms.

For patients presenting with acute onset or worsening of symptoms, the optimal exclusion cut-off point is $300 \mathrm{pg} / \mathrm{mL}$ 
Table 5 Most common abnormalities on the electrocardiogram in heart failure

\begin{tabular}{|c|c|c|}
\hline Abnormality & Causes & Clinical implications \\
\hline Sinus tachycardia & Decompensated HF, anaemia, fever, hyperthyroidism & $\begin{array}{l}\text { Clinical assessment } \\
\text { Laboratory investigation }\end{array}$ \\
\hline Sinus bradycardia & $\begin{array}{l}\text { Beta-blockade, digoxin, ivabradine, verapamil, diltiazem } \\
\text { Antiarrhythmics } \\
\text { Hypothyroidism } \\
\text { Sick sinus syndrome }\end{array}$ & $\begin{array}{l}\text { Review drug therapy } \\
\text { Laboratory investigation }\end{array}$ \\
\hline $\begin{array}{l}\text { Atrial tachycardia/flutter/ } \\
\text { fibrillation }\end{array}$ & $\begin{array}{l}\text { Hyperthyroidism, infection, mitral valve disease } \\
\text { Decompensated HF, infarction }\end{array}$ & $\begin{array}{l}\text { Slow AV conduction, anticoagulation, pharmacological } \\
\text { cardioversion, electrical cardioversion, catheter ablation }\end{array}$ \\
\hline Ventricular arrhythmias & $\begin{array}{l}\text { Ischaemia, infarction, cardiomyopathy, myocarditis } \\
\text { hypokalaemia, hypomagnesaemia } \\
\text { Digitalis overdose }\end{array}$ & $\begin{array}{l}\text { Laboratory investigation } \\
\text { Exercise test, perfusion/viability studies, coronary angiography, } \\
\text { electrophysiology testing, ICD }\end{array}$ \\
\hline Myocardial ischaemia/infarction & Coronary artery disease & $\begin{array}{l}\text { Echocardiography, troponins, perfusion/viability studies, coronary } \\
\text { angiography, revascularization }\end{array}$ \\
\hline$Q$ waves & $\begin{array}{l}\text { Infarction, hypertrophic cardiomyopathy } \\
\text { LBBB, pre-excitation }\end{array}$ & Echocardiography, perfusion/viability studies, coronary angiography \\
\hline LV hypertrophy & $\begin{array}{l}\text { Hypertension, aortic valve disease, hypertrophic } \\
\text { cardiomyopathy }\end{array}$ & Echocardiography/CMR \\
\hline AV block & $\begin{array}{l}\text { Infarction, drug toxicity, myocarditis, sarcoidosis, genetic } \\
\text { cardiomyopathy (laminopathy, desminopathy), Lyme disease }\end{array}$ & $\begin{array}{l}\text { Review drug therapy, evaluate for systemic disease; family history/ } \\
\text { genetic testing indicated. Pacemaker or ICD may be indicated. }\end{array}$ \\
\hline Low $Q R S$ voltage & Obesity, emphysema, pericardial effusion, amyloidosis & $\begin{array}{l}\text { Echocardiography/CMR, chest X-ray; for amyloidosis consider } \\
\text { further imaging (CMR, } 99 \mathrm{mT} \text { C-DPD scan) and endomyocardial } \\
\text { biopsy }\end{array}$ \\
\hline $\begin{array}{l}\text { QRS duration } \geq 120 \text { ms and } \\
\text { LBBB morphology }\end{array}$ & Electrical and mechanical dyssynchrony & $\begin{array}{l}\text { Echocardiography } \\
\text { CRT-P, CRT-D }\end{array}$ \\
\hline
\end{tabular}

$\mathrm{AV}=$ atrioventricular; $\mathrm{CMR}=$ cardiac magnetic resonance; CRT-P = cardiac resynchronization therapy pacemaker; CRT-D $=$ cardiac resynchronization therapy defibrillator; $\mathrm{ECG}=$ electrocardiogram; HF = heart failure; ICD = implantable cardioverter-defibrillator; $\mathrm{LBBB}=$ left bundle branch block; $\mathrm{LV}=$ left ventricular. $99 \mathrm{mT} \mathrm{c}-\mathrm{DPD}=$ technetium-99m 3,3-diphosphono-1,2-propanodicarboxylic acid.

for NT-proBNP and $100 \mathrm{pg} / \mathrm{mL}$ for BNP. In one other study, mid-regional atrial (or A-type) natriuretic peptide (MR-proANP), at a cut-off point of $120 \mathrm{pmol} / \mathrm{L}$, was shown to be non-inferior to these thresholds for BNP and NT-proBNP in the acute setting. ${ }^{51}$

For patients presenting in a non-acute way, the optimum exclusion cut-off point is $125 \mathrm{pg} / \mathrm{mL}$ for NT-proBNP and $35 \mathrm{pg} / \mathrm{mL}$ for BNP. The sensitivity and specificity of BNP and NT-proBNP for the diagnosis of $\mathrm{HF}$ are lower in non-acute patients. ${ }^{43-50}$

\subsubsection{Chest X-ray}

A chest $X$-ray is of limited use in the diagnostic work-up of patients with suspected HF. It is probably most useful in identifying an alternative, pulmonary explanation for a patient's symptoms and signs. It may, however, show pulmonary venous congestion or oedema in a patient with HF. It is important to note that significant LV systolic dysfunction may be present without cardiomegaly on the chest $\mathrm{X}$-ray.

\subsubsection{Routine laboratory tests}

In addition to standard biochemical [sodium, potassium, creatinine/estimated glomerular filtration rate (eGFR)] and haematological tests (haemoglobin, haematocrit, ferritin, leucocytes, and platelets), it is useful to measure thyroid-stimulating hormone (thyrotropin) as thyroid disease can mimic or aggravate HF (Table 6). Blood glucose is also worth measuring as undiagnosed diabetes is common in patients with HF. Liver enzymes may also be abnormal in HF (important if considering amiodarone or warfarin).

As well as a pre-treatment check, biochemical monitoring is important after the initiation of renin-angiotensin system blockers, while the dose is being up-titrated (see Section 7.2) and during longer term follow-up, especially if an intercurrent illness leading to sodium and water loss occurs (e.g. diarrhoea and vomiting) or another drug that affects sodium and water homeostasis or renal function is started or the dose altered [e.g. nonsteroidal anti-inflammatory drugs (NSAIDs) or diuretics]. Many 
Table 6 Common laboratory test abnormalities in heart failure

\begin{tabular}{|c|c|c|}
\hline Abnormality & Causes & Clinical implications \\
\hline $\begin{array}{l}\text { Renal/kidney impairment } \\
\text { (creatinine }>150 \mu \mathrm{mol} / \mathrm{L} / \mathrm{l} .7 \mathrm{mg} / \mathrm{dL} \text {, } \\
\left.\text { eGFR }<60 \mathrm{~mL} / \mathrm{mim} / 1.73 \mathrm{~m}^{2}\right)\end{array}$ & $\begin{array}{l}\text { Renal disease } \\
\text { Renal congestion } \\
\text { ACE inhibitor/ARB, MRA } \\
\text { Dehydration } \\
\text { NSAIDs and other nephrotoxic drugs }\end{array}$ & $\begin{array}{l}\text { Calculate eGFR } \\
\text { Consider reducing ACE inhibitor/ARB or MRA } \\
\text { dose (or postpone dose up-titration) } \\
\text { Check potassium and BUN } \\
\text { Consider reducing diuretic dose if dehydrated but if renal } \\
\text { congestion, more diuresis may help } \\
\text { Review drug therapy }\end{array}$ \\
\hline $\begin{array}{l}\text { Anaemia }(<13 \mathrm{~g} / \mathrm{dL} / 8.0 \mathrm{mmol} / \mathrm{L} \text { in men, } \\
<12 \mathrm{~g} / \mathrm{dL} / 7.4 \mathrm{mmol} / \mathrm{L} \text { in women })\end{array}$ & $\begin{array}{l}\text { Chronic HF, haemodilution, iron loss or poor } \\
\text { utilization, renal failure, chronic disease, } \\
\text { malignancy }\end{array}$ & $\begin{array}{l}\text { Diagnostic work-up } \\
\text { Consider treatment }\end{array}$ \\
\hline Hyponatraemia $(<135 \mathrm{mmol} / \mathrm{L})$ & $\begin{array}{l}\text { Chronic HF, haemodilution, AVP release, } \\
\text { diuretics (especially thiazides) and other drugs }\end{array}$ & $\begin{array}{l}\text { Consider water restriction, adjusting diuretic dosage } \\
\text { Ultrafiltration, vasopressin antagonist } \\
\text { Review drug therapy }\end{array}$ \\
\hline Hypernatraemia (>150 mmol/L) & Water loss/inadequate water intake & $\begin{array}{l}\text { Assess water intake } \\
\text { Diagnostic work-up }\end{array}$ \\
\hline Hypokalaemia (<3.5 mmol/L) & Diuretics, secondary hyperaldosteronism & $\begin{array}{l}\text { Risk of arrhythmia } \\
\text { Consider ACE inhibitor/ARB, MRA, potassium supplements }\end{array}$ \\
\hline Hyperkalaemia (>5.5 mmol/L) & $\begin{array}{l}\text { Renal failure, potassium supplement, renin- } \\
\text { angiotensin-aldosterone system blockers }\end{array}$ & $\begin{array}{l}\text { Stop potassium supplements/potassium sparing diuretic } \\
\text { Reduce dose of/stop ACE inhibitor/ARB, MRA } \\
\text { Assess renal function and urine } \mathrm{pH} \\
\text { Risk of bradycardia and serious arrhythmias }\end{array}$ \\
\hline Hyperglycaemia (>6.5 mmol/L/II7 mg/dL) & Diabetes, insulin resistance & Evaluate hydration, treat glucose intolerance \\
\hline Hyperuricaemia $(>500 \mu \mathrm{mol} / \mathrm{L} / 8.4 \mathrm{mg} / \mathrm{dL})$ & Diuretic treatment, gout, malignancy & $\begin{array}{l}\text { Allopurinol } \\
\text { Reduce diuretic dose }\end{array}$ \\
\hline Albumin high (>45 g/L) & Dehydration & Rehydrate \\
\hline Albumin low $(<30 \mathrm{~g} / \mathrm{L})$ & Poor nutrition, renal loss & Diagnostic work-up \\
\hline Transaminase increase & $\begin{array}{l}\text { Liver dysfunction } \\
\text { Liver congestion } \\
\text { Drug toxicity }\end{array}$ & $\begin{array}{l}\text { Diagnostic work-up } \\
\text { Liver congestion } \\
\text { Review drug therapy }\end{array}$ \\
\hline Elevated troponins & $\begin{array}{l}\text { Myocyte necrosis } \\
\text { Prolonged ischaemia, severe HF, myocarditis, } \\
\text { sepsis, renal failure }\end{array}$ & $\begin{array}{l}\text { Evaluate pattern of increase (mild increases common in severe HF) } \\
\text { Perfusion/viability studies } \\
\text { Coronary angiography } \\
\text { Evaluation for revascularization }\end{array}$ \\
\hline Elevated creatine kinase & $\begin{array}{l}\text { Inherited and acquired myopathies (including } \\
\text { myositis) }\end{array}$ & $\begin{array}{l}\text { Consider genetic cardiomyopathy (laminopathy, desminopathy, } \\
\text { dystrophinopathy), muscular dystrophies } \\
\text { Statin use }\end{array}$ \\
\hline Abnormal thyroid tests & $\begin{array}{l}\text { Hyper-/hypothyroidism } \\
\text { Amiodarone }\end{array}$ & $\begin{array}{l}\text { Treat thyroid abnormality } \\
\text { Reconsider amiodarone use }\end{array}$ \\
\hline Urine analysis & Proteinuria, glycosuria, bacteria & $\begin{array}{l}\text { Diagnostic work-up } \\
\text { Rule out infection, diabetes }\end{array}$ \\
\hline International normalized ratio $>3.5$ & $\begin{array}{l}\text { Anticoagulant overdose } \\
\text { Liver congestion/disease } \\
\text { Drug interactions }\end{array}$ & $\begin{array}{l}\text { Review anticoagulant dose } \\
\text { Assess liver function } \\
\text { Review drug therapy }\end{array}$ \\
\hline CRP $>10$ mg/L, neutrophilic leukocytosis & Infection, inflammation & Diagnostic work-up \\
\hline
\end{tabular}

$\mathrm{ACE}=$ angiotensin-converting enzyme; $\mathrm{ARB}=$ angiotensin receptor blocker; $\mathrm{AVP}=$ arginine vasopressin; $\mathrm{BNP}=\mathrm{B}$-type natriuretic peptide; $\mathrm{BUN}=$ blood urea nitrogen; $\mathrm{CRP}=\mathrm{C}$-reactive protein; eGFR = estimated glomerular filtration rate; HF = heart failure; MRA = mineralocorticoid receptor antagonist; NSAID = non-steroidal anti-inflammatory drug. 
routine laboratory tests provide valuable prognostic information (see Section 6).

\subsubsection{Algorithm for the diagnosis of heart failure}

An algorithm for the diagnosis of HF or LV dysfunction is shown in Figure 1.
In patients presenting to hospital as an emergency with suspected HF and acute onset of symptoms, early echocardiography is recommended (and immediate echocardiography in shocked or severely haemodynamically compromised patients). If a natriuretic peptide is measured, a high exclusion cut-off point should be used. $^{39-50}$ In patients presenting non-emergently in primary care, or to a hospital outpatient

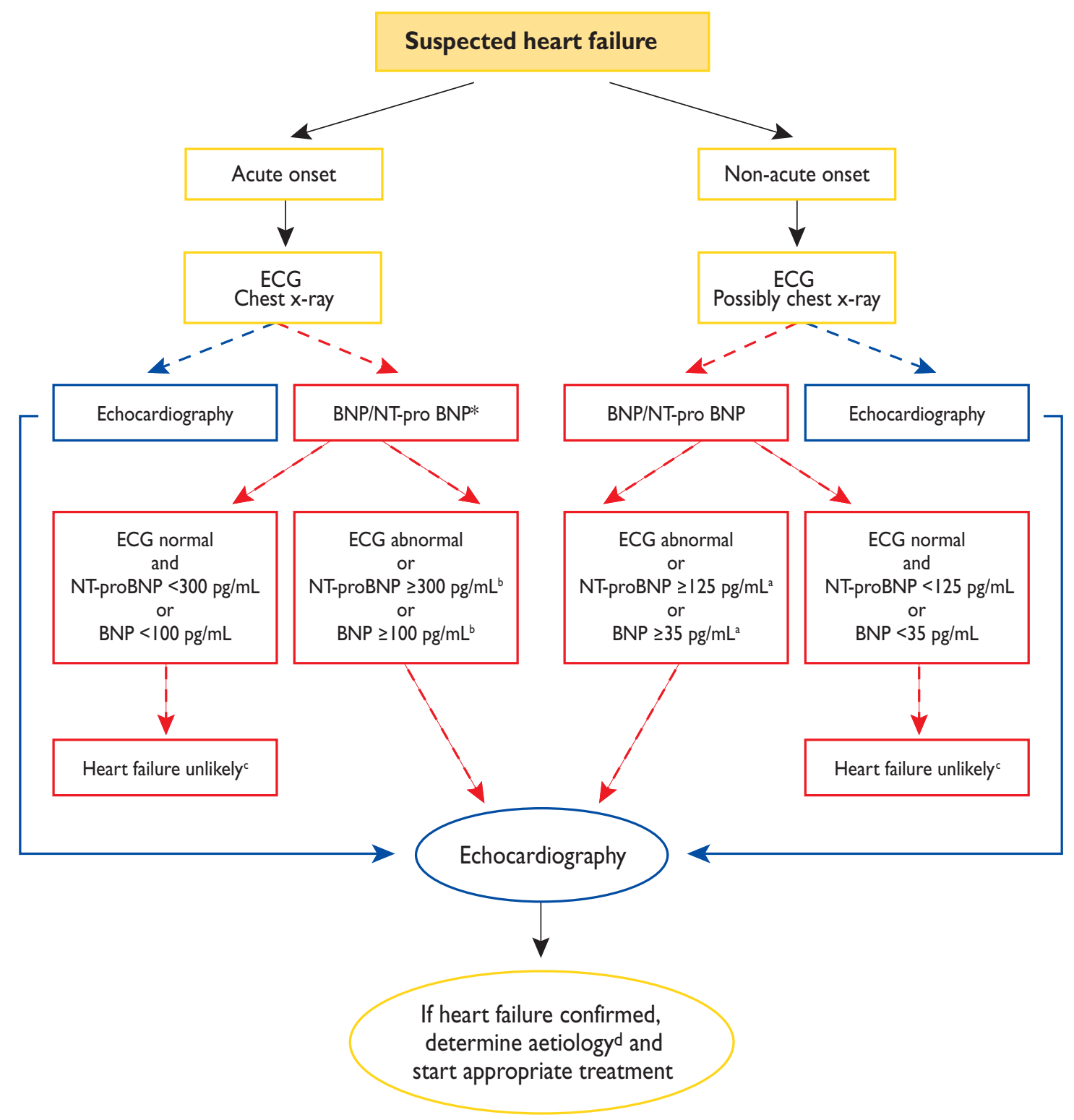

*In the acute setting, MR-proANP may also be used (cut-off point $120 \mathrm{pmol} / \mathrm{L}$, i.e. $<120 \mathrm{pmol} / \mathrm{L}=$ heart failure unlikely).

$\mathrm{BNP}=\mathrm{B}$-type natriuretic peptide; $\mathrm{ECG}=$ electrocardiogram; $\mathrm{HF}=$ heart failure; $\mathrm{MR}$-proANP = mid-regional pro atrial natriuretic peptide;

NT-proBNP = N-terminal pro B-type natriuretic peptide.

${ }^{a}$ Exclusion cut-off points for natriuretic peptides are chosen to minimize the false-negative rate while reducing unnecessary referrals for echocardiography.

${ }^{b}$ Other causes of elevated natriuretic peptide levels in the acute setting are an acute coronary syndrome, atrial or ventricular arrhythmias, pulmonary embolism, and severe

chronic obstructive pulmonary disease with elevated right heart pressures, renal failure, and sepsis. Other causes of an elevated natriuretic level in the non-acute setting are:

old age (>75 years), atrial arrhythmias, left ventricular hypertrophy, chronic obstructive pulmonary disease, and chronic kidney disease.

'Treatment may reduce natriuretic peptide concentration, and natriuretic peptide concentrations may not be markedly elevated in patients with HF-PEF.

dSee Section 3.5 and Appendix A.

Figure I Diagnostic flowchart for patients with suspected heart failure - showing alternative 'echocardiography first' (blue) or 'natriuretic peptide first' (red) approaches. 
clinic, with slow onset of symptoms (and signs) suggestive of HF, an ECG and natriuretic peptide measurement may be used as a means of identifying patients who most need echocardiography (an echocardiogram is indicated if the natriuretic peptide level is above the exclusion threshold/ECG is abnormal). In these patients, a lower exclusion natriuretic peptide cut-off point should be used to prevent a 'false-negative' diagnosis of $\mathrm{HF}^{39-50}$ Patients with a high pre-test likelihood of HF, such as those with a history of myocardial infarction, may be referred directly for echocardiography.

\section{The role of cardiac imaging in the evaluation of patients with suspected or confirmed heart failure}

Imaging plays a central role in the diagnosis of HF and in guiding treatment. Of the several imaging modalities available, echocardiography is the method of choice in patients with suspected HF for reasons of accuracy, availability (including portability), safety, and cost. $^{27-34}$ It may be complemented by other modalities, chosen according to their ability to answer specific clinical questions and taking account of contraindications to, and risks of, specific tests (see Table 7). ${ }^{9,10,52-60}$ All imaging examinations, regardless of type, should be performed only by individuals competent and experienced in the specific technique. ${ }^{32}$

\subsection{Echocardiography}

Echocardiography is a term used here to refer to all cardiac ultrasound imaging techniques, including two-dimensional/threedimensional echocardiography, pulsed and continuous wave Doppler, colour flow Doppler, and tissue Doppler imaging (TDI). 8,27-34,61-64 Echocardiography provides information about cardiac anatomy (e.g. volumes, geometry, mass) and function (e.g. LV function and wall motion, valvular function, right ventricular function, pulmonary artery pressure, pericardium).

\subsubsection{Assessment of left ventricular systolic dysfunction}

LVEF is not an index of contractility as it depends on volumes, preload, afterload, heart rate, and valvular function, and is not the same as stroke volume. Stroke volume may be maintained by LV dilation in a patient with HF-REF, whereas it may be reduced in patients with HF-PEF and concentric LV hypertrophy. EF may also be preserved (and stroke volume reduced) in patients with significant mitral regurgitation. Thus EF must be interpreted in its clinical context.

The recommended echocardiographic method for measurement of EF is the apical biplane method of discs (the modified Simpson's rule). ${ }^{8,27-34,61}$ However, because this method relies on accurate tracing of the endocardial border, use of a contrast agent to better delineate the endocardial border is recommended when image quality is suboptimal (i.e. where $<80 \%$ of the endocardial border is adequately visualized). ${ }^{61}$ The Teichholz and Quinones methods of calculating EF from linear dimensions may result in inaccuracies, particularly in patients with regional
LV dysfunction; the same is true for another technique for assessing LV systolic function-fractional shortening. These and visual assessment of EF ('eye-balling') are not recommended. ${ }^{61}$ Threedimensional echocardiography of adequate quality further improves the quantification of ventricular volumes and EF calculation. ${ }^{62}$ The LV wall motion score index may be an acceptable alternative to EF but is not widely used. Other indices of LV systolic function include AV plane systolic excursion, systolic tissue Doppler velocities, and measurements of deformation (strain and strain rate). Deformation imaging is more sensitive than EF in detecting minor changes in LV systolic function. However, issues of reproducibility and standardization currently limit the routine clinical use of deformation imaging. Stroke volume and cardiac output can also be calculated by measuring the velocity time integral at the LV outflow tract area.

The most common echocardiographic abnormalities seen in patients with $\mathrm{HF}$ and their clinical significance are presented in Table 8.

\subsubsection{Assessment of left ventricular diastolic dysfunction}

LV diastolic dysfunction is thought to be the underlying pathophysiological abnormality in patients with HF-PEF, and thus its identification is fundamental to the diagnosis of this type of $\mathrm{HF}$ (Table 9). 7,8,27-34,63,64 The Doppler echocardiographic diastolic indices commonly measured in patients with HF are shown in Table 9. Of note, normal values for functional echocardiographic indices of LV diastolic dysfunction may also depend on age, heart rate, and body size. ${ }^{63,64}$ Importantly, no single echocardiographic parameter is sufficiently accurate and reproducible to be used in isolation to make a diagnosis of LV diastolic dysfunction. Therefore, a comprehensive echocardiographic examination incorporating all relevant two-dimensional and Doppler data is recommended. ${ }^{8,63,64}$ This should include the evaluation of both structural (LV hypertrophy, LA dilation) and functional abnormalities (Table 1). Tissue Doppler imaging-derived early diastolic myocardial velocities (e'), measured at the mitral annulus, allow the assessment of myocardial relaxation. A normal e' $(>8 \mathrm{~cm} / \mathrm{s}$ septal, $>10 \mathrm{~cm} / \mathrm{s}$ lateral, or $>9 \mathrm{~cm} / \mathrm{s}$ average, measured using real-time pulsed TDI) is very unusual in a patient with HF. The E/e' ratio correlates with LV filling pressure. ${ }^{63,64}$ (Table 9). Thus, echocardiographic evidence of LV diastolic dysfunction may consist of a reduced e' (e' average $<9 \mathrm{~cm} / \mathrm{s}$ ) or an increased E/e' ratio ( $>15$ ), or a combination of these parameters (Table 9). The presence of at least two abnormal measurements and/or AF increases the likelihood of the diagnosis.

\subsection{Transoesophageal echocardiography}

Transoesophageal echocardiography (TOE) is not needed in routine diagnostic assessment unless the transthoracic ultrasound window is inadequate (e.g. because of obesity, chronic lung disease, ventilated patients) and an alternative modality [e.g. cardiac magnetic resonance (CMR) imaging] is not available or applicable.

TOE is, however, valuable in patients with complex valvular disease (especially mitral disease and prosthetic valves), suspected endocarditis, and in selected patients with congenital heart disease. 
Table 7 Possible applications of various imaging techniques in the diagnosis of HF

\begin{tabular}{|c|c|c|c|c|c|c|c|}
\hline & & Echo & CMR & Cath & SPECT & MDCT & PET \\
\hline \multicolumn{8}{|c|}{ Remodelling/dysfunction } \\
\hline \multirow[t]{4}{*}{$\mathrm{LV}:$} & EDV & ++ & +++ & ++ & ++ & ++ & ++ \\
\hline & ESV & ++ & +++ & ++ & ++ & ++ & ++ \\
\hline & EF & ++ & +++ & ++ & ++ & ++ & ++ \\
\hline & Mass & ++ & +++ & - & - & ++ & - \\
\hline \multirow[t]{4}{*}{ RV: } & EDV & ++ & +++ & + & - & ++ & - \\
\hline & ESV & ++ & +++ & + & - & ++ & - \\
\hline & $\mathrm{EF}$ & ++ & +++ & + & - & ++ & - \\
\hline & Mass & ++ & +++ & - & - & ++ & - \\
\hline LV diastolic dysfunction & & +++ & + & +++ & - & - & - \\
\hline Dyssynchrony & & ++ & + & - & + & - & - \\
\hline \multicolumn{8}{|l|}{ Aetiology } \\
\hline \multirow[t]{4}{*}{ CAD: } & Ischaemia & $++++^{a}$ & +++ & $+++b$ & +++ & - & +++ \\
\hline & Hibernation & $++++^{a}$ & $++++^{a}$ & - & +++ & - & +++ \\
\hline & Scar & ++ & +++ & - & ++ & - & ++ \\
\hline & Coronary anatomy & - & - & +++ & - & +++ & - \\
\hline \multirow[t]{2}{*}{ Valvular: } & Stenosis & +++ & + & +++ & - & $++^{c}$ & - \\
\hline & Regurgitation & +++ & ++ & ++ & - & - & - \\
\hline Myocarditis & & + & +++ & $+++d$ & - & - & - \\
\hline Sarcoidosis & & + & +++ & $++^{d}$ & - & - & ++ \\
\hline \multirow[t]{2}{*}{ Hypertrophic CMP: } & $\mathrm{HCM}$ & +++ & ++ & ++ & - & - & - \\
\hline & Amyloidosis & ++ & +++ & $+++^{d}$ & - & - & - \\
\hline \multirow[t]{4}{*}{ Dilated CMP: } & Myocarditis & + & +++ & $++++^{d}$ & - & - & - \\
\hline & Eosinophilic syndromes & + & +++ & $+++d$ & - & - & - \\
\hline & Iron: haemochromatosis & + & +++ & - & - & - & - \\
\hline & Iron: thalassaemia & + & +++ & - & - & - & - \\
\hline ARVC & & ++ & +++ & $+++d$ & - & + & - \\
\hline \multirow[t]{4}{*}{ Restrictive CMP: } & Pericarditis & $++^{e}$ & $++{ }^{f}$ & $++^{e}$ & - & ++8 & - \\
\hline & Amyloidosis & ++ & +++ & $+++^{d}$ & - & - & - \\
\hline & Endomyocardial fibrosis & + & +++ & $+++d$ & - & - & - \\
\hline & Anderson-Fabry & + & + & - & - & - & - \\
\hline Unclassified CMP & Takotsubo-CMP & ++ & ++ & +++ & - & - & - \\
\hline \multicolumn{8}{|l|}{ Main advantages } \\
\hline & & $\begin{array}{l}\text { Wide availability } \\
\text { Portability } \\
\text { No radiation } \\
\text { Relatively low cost }\end{array}$ & $\begin{array}{l}\text { Good quality } \\
\text { images }^{h} \\
\text { No radiation }\end{array}$ & $\begin{array}{l}\text { Good } \\
\text { availability }\end{array}$ & $\begin{array}{l}\text { Good } \\
\text { availability }\end{array}$ & $\begin{array}{l}\text { Reasonable } \\
\text { availability } \\
\text { High quality images }\end{array}$ & $\begin{array}{l}\text { Limited } \\
\text { availability } \\
\text { Good quality } \\
\text { imagesi }\end{array}$ \\
\hline \multicolumn{8}{|l|}{ Main disadvantages } \\
\hline & & $\begin{array}{l}\text { Echo window } \\
\text { needed }\end{array}$ & $\begin{array}{l}\text { Limited availability } \\
\text { Contraindications }{ }^{k} \\
\text { Functional analysis } \\
\text { Image quality } \\
\text { limited if arrhythmia }\end{array}$ & $\begin{array}{l}\text { Radiation } \\
\text { Invasive }\end{array}$ & Radiation & $\begin{array}{l}\text { Radiation } \\
\text { Image quality limited } \\
\text { if arrhythmia }\end{array}$ & $\begin{array}{l}\text { Radiation } \\
\text { Limited } \\
\text { availability }\end{array}$ \\
\hline
\end{tabular}

Selection of a test in daily practice should consider availability, local expertise, advantages/disadvantages, and, in the case of several questions to address, which test could best answer several of them.

$\mathrm{ARVC}=$ arrhythmogenic right ventricular cardiomyopathy; $\mathrm{CAD}=$ coronary artery disease; Cath $=$ cardiac catheterization; $\mathrm{CMP}=$ cardiomyopathy; $\mathrm{CMR}=$ cardiac magnetic resonance; $\mathrm{EDV}=$ end-diastolic volume; $\mathrm{EF}=$ ejection fraction; $\mathrm{ESV}=$ end-systolic volume; $\mathrm{HCM}=$ hypertrophic cardiomyopathy; $\mathrm{LV}=$ left ventricular; $\mathrm{MDCT}=$ multidetector computed tomography; PET = positron emission tomography; RV = right ventricular; SPECT = single photon emission computed tomography.

${ }^{\text {a }}$ tress (dobutamine) imaging.

'Fractional flow reserve or 'Doppler' flow reserve measurements.

Including measurements of aortic annulus for transcatheter aortic valve implantation.

dEndomyocardial biopsy.

eHaemodynamic evaluation (constriction).

${ }^{f}$ Describes disease activity by contrast-enhanced CMR.

${ }^{g}$ Calcifications.

${ }^{\mathrm{h}}$ Good quality irrespective of patient habitus.

'Excellent attenuation correction.

${ }^{\mathrm{k}}$ Foreign metallic bodies in specific locations (e.g. in the eye) and electronic devices (some pacemakers are MR-compatible); relative contraindication: claustrophobia. 
Table 8 Common echocardiographic abnormalities in patients with heart failure

\begin{tabular}{|c|c|c|}
\hline Measurement & Abnormality & Clinical implications \\
\hline \multicolumn{3}{|c|}{ Parameters related to systolic function } \\
\hline LV ejection fraction & Reduced $(<50 \%)$ & LV global systolic dysfunction \\
\hline LV fractional shortening & Reduced $(<25 \%)$ & LV radial systolic dysfunction \\
\hline$L V$ regional function & Hypokinesis, akinesis, dyskinesis & $\begin{array}{l}\text { Myocardial infarction/ischaemia } \\
\text { Cardiomyopathy, myocarditis }\end{array}$ \\
\hline LV end-diastolic size & $\begin{array}{l}\text { Increased }\left(\text { diameter } \geq 60 \mathrm{~mm},>32 \mathrm{~mm} / \mathrm{m}^{2} \text {, }\right. \\
\left.\text { volume }>97 \mathrm{~mL} / \mathrm{m}^{2}\right)\end{array}$ & Volume overload HF likely \\
\hline LV end-systolic size & $\begin{array}{l}\text { Increased }\left(\text { diameter }>45 \mathrm{~mm} />25 \mathrm{~mm} / \mathrm{m}^{2} \text {, }\right. \\
\left.\text { volume }>43 \mathrm{~mL} / \mathrm{m}^{2}\right)\end{array}$ & Volume overload HF likely \\
\hline LV outflow tract velocity time integral & Reduced $(<15 \mathrm{~cm})$ & Reduced LV stroke volume \\
\hline \multicolumn{3}{|c|}{ Parameters related to diastolic function } \\
\hline LV diastolic dysfunction parameters & $\begin{array}{l}\text { Abnormalities of the mitral inflow pattern, } \\
\text { tissue velocities }\left(\mathrm{e}^{\prime}\right) \text { or the E/e'ratio }\end{array}$ & $\begin{array}{l}\text { Indicate LV diastolic dysfunction degree and suggest level of filling } \\
\text { pressure }\end{array}$ \\
\hline Left atrial volume index & Increased (volume $>34 \mathrm{~mL} / \mathrm{m}^{2}$ ) & $\begin{array}{l}\text { Increased LV filling pressure (past or present) } \\
\text { Mitral valve disease }\end{array}$ \\
\hline LV mass index & $\begin{array}{l}\text { Increased: }>95 \mathrm{~g} / \mathrm{m}^{2} \text { in women and } \\
>115 \mathrm{~g} / \mathrm{m}^{2} \text { in men }\end{array}$ & Hypertension, aortic stenosis, hypertrophic cardiomyopathy \\
\hline \multicolumn{3}{|c|}{ Parameters related to valvular function } \\
\hline Valvular structure and function & $\begin{array}{l}\text { Valvular stenosis or regurgitation (especially } \\
\text { aortic stenosis and mitral regurgitation) }\end{array}$ & $\begin{array}{l}\text { May be the cause of HF or a complicating factor or the result of } \\
\mathrm{HF} \text { (secondary mitral regurgitation) } \\
\text { Assess dysfunction severity and haemodynamic consequences } \\
\text { Consider surgery }\end{array}$ \\
\hline \multicolumn{3}{|l|}{ Other parameters } \\
\hline RV function (e.g.TAPSE) & Reduced (TAPSE < $16 \mathrm{~mm}$ ) & RV systolic dysfunction \\
\hline Tricuspid regurgitation peak velocity & Increased $(>3.4 \mathrm{~m} / \mathrm{s})$ & Increased RV systolic pressure \\
\hline Systolic pulmonary artery pressure & Increased (>50 mmHg) & Pulmonary hypertension likely \\
\hline Inferior vena cava & Dilated, with no respiratory collapse & $\begin{array}{l}\text { Increased right atrial pressure } \\
\text { RV dysfunction, volume overload } \\
\text { Pulmonary hypertension possible }\end{array}$ \\
\hline Pericardium & Effusion, haemopericardium, calcification & $\begin{array}{l}\text { Consider tamponade, malignancy, systemic diseases, acute or } \\
\text { chronic pericarditis, constrictive pericarditis }\end{array}$ \\
\hline
\end{tabular}

E/e' = ratio of the mitral inflow E wave to the tissue Doppler e' wave; HF= heart failure; LV = left ventricular; RV = right ventricular; TAPSE $=$ tricuspid annular plane systolic excursion.

TOE is also used to check for thrombus in the left atrial appendage of patients with AF.

\subsection{Stress echocardiography}

Exercise or pharmacological stress echocardiography may be used to identify the presence and extent of inducible ischaemia and to determine whether non-contracting myocardium is viable (see Section 13). ${ }^{34}$ This technique may also be useful in evaluating patients with suspected severe aortic stenosis, reduced EF, and a low transvalvular gradient (see Section 13.3.1). Diastolic stress testing is an emerging procedure to identify HF-PEF in patients with $\mathrm{HF}$ symptoms during physical activity, normal EF, and inconclusive diastolic function parameters at rest. ${ }^{63}$

\subsection{Cardiac magnetic resonance}

$\mathrm{CMR}$ is a non-invasive technique that provides most of the anatomical and functional information available from echocardiography, including evaluation of ischaemia and viability, as well as additional assessments. ${ }^{52,57,65} \mathrm{CMR}$ is regarded as the gold standard with respect to accuracy and reproducibility of volumes, mass, and wall motion. Because CMR yields good image quality in most patients, it is the best alternative imaging modality in patients with non-diagnostic echocardiographic studies.

CMR is particularly valuable in identifying inflammatory and infiltrative conditions, and in predicting prognosis in patients with these (Table 7). ${ }^{65}$ CMR is also useful in the work-up of patients with suspected cardiomyopathy, arrhythmias, suspected cardiac tumours (or cardiac involvement by tumour), or pericardial diseases, and is the imaging method of choice in patients with complex congenital heart disease. ${ }^{66}$

Limitations include lack of availability, inability to image patients with certain metallic implants (including many, but not all, cardiac devices), and cost. Also, the accuracy of functional analysis is limited in patients with atrial arrhythmias. Some patients cannot tolerate the procedure, often because of claustrophobia. Linear gadolinium chelates are contraindicated in individuals with a GFR $<30 \mathrm{~mL} / \mathrm{min} / \mathrm{m}^{2}$ because they cause the rare condition known as nephrogenic systemic fibrosis 
Table 9 Common echocardiographic measures of left ventricular diastolic dysfunction in patients with heart failure

\begin{tabular}{|c|c|c|}
\hline Measurement & Abnormality & Clinical implications \\
\hline $\mathrm{e}^{\prime}$ & $\begin{array}{l}\text { Decreased }(<8 \mathrm{~cm} / \mathrm{s} \text { septal, }<10 \mathrm{~cm} / \mathrm{s} \text { lateral, } \\
\text { or }<9 \mathrm{~cm} / \mathrm{s} \text { average) }\end{array}$ & Delayed LV relaxation \\
\hline$E^{\prime} / e^{\prime}$ ratio ${ }^{a}$ & High (>15) & High LV filling pressure \\
\hline & Low $(<8)$ & Normal LV filling pressure \\
\hline & Intermediate (8-15) & Grey zone (additional parameters necessary) \\
\hline Mitral inflow E/A ratio ${ }^{b}$ & 'Restrictive’ (>2) & High LV filling pressure \\
\hline & & Volume overload \\
\hline & 'Impaired relaxation’ $(<1)$ & Delayed LV relaxation \\
\hline & & Normal LV filling pressure \\
\hline & Normal (I-2) & Inconclusive (may be 'pseudonormal') \\
\hline Mitral inflow during Valsalva manoeuvre & $\begin{array}{l}\text { Change of the 'pseudonormal' to the 'impaired } \\
\text { relaxation' pattern (with a decrease in E/A } \\
\text { ratio } \geq 0.5 \text { ) }\end{array}$ & High LV filling pressure (unmasked through Valsalva) \\
\hline (A pulm-A mitral) duration & $>30 \mathrm{~ms}$ & High LV filling pressure \\
\hline
\end{tabular}

A pulm-A mitral = time difference between pulmonary vein flow A-wave duration and mitral flow A-wave duration; E/A = ratio of early to late diastolic mitral inflow waves; e' = early diastolic velocity of mitral annulus; E/e' = ratio of the mitral inflow E wave to the tissue Doppler e' wave; HF $=$ heart failure; LV $=$ left ventricular.

${ }^{a}$ Different cut-off points exist in different consensus documents; ${ }^{8,63}$ for the cut-off points mentioned in this table both septal and average e' may be used.

${ }^{b}$ Highly variable and unsuitable for diagnosis on its own; largely depending on loading conditions; age-corrected normal values exist. ${ }^{63}$

(this may be less of a concern with newer macrocyclic gadolinium chelates). ${ }^{67,68}$

\subsection{Single-photon emission computed tomography and radionuclide ventriculography}

Single-photon emission computed tomography (SPECT) may be useful in assessing ischaemia and viability if CAD is suspected, and provides prognostic as well as diagnostic information (Table 7). ${ }^{54}$ Gated SPECT can also yield information on ventricular volumes and function, but exposes the patient to ionizing radiation.

\subsection{Positron emission tomography imaging}

Positron emission tomography (PET) [alone or with computed tomography $(\mathrm{CT})$ ] may be used to assess ischaemia and viability, but the flow tracers ( $\mathrm{N}-13$ ammonia or $\mathrm{O}-15$ water) require an on-site cyclotron. ${ }^{58,60,69}$ Rubidium is an alternative tracer for ischaemia testing with PET, which can be produced locally at relatively low cost (Table 7). Lack of availability, radiation exposure, and cost are the main limitations.

\subsection{Coronary angiography}

Coronary angiography should be considered in patients with angina pectoris or a history of cardiac arrest if the patient is otherwise suitable for coronary revascularization. Angiography should also be considered in patients with evidence of reversible myocardial ischaemia on non-invasive testing, especially if the EF is reduced (because coronary artery bypass surgery may be beneficial) (Section 13). Non-invasive assessment of myocardial viability may also be carried out before angiography as some observational data show that coronary angiography may be of little, if any, benefit and may confer considerable risk, in the absence of significant viability. In cases where ischaemia information is lacking, fractional flow reserve gives information about the haemodynamic relevance of lesions. $^{70}$

Coronary angiography may be required, urgently, in selected patients with acute HF (AHF) (shock or acute pulmonary oedema), particularly those with an associated acute coronary syndrome (see Section 12.7.1 and revascularization guidelines ${ }^{71}$ ). Coronary angiography may also be indicated in patients with valve disease when surgical correction is planned.

\subsection{Cardiac computed tomography}

The main use of $\mathrm{CT}$ in patients with $\mathrm{HF}$ is a non-invasive means to visualize the coronary anatomy. ${ }^{59}$ The risk vs. benefit of this procedure should be considered as discussed above, under coronary angiography (Section 4.7).

\section{Other investigations}

\subsection{Cardiac catheterization and endomyocardial biopsy}

In patients with suspected constrictive or restrictive cardiomyopathy, cardiac catheterization used in combination with other noninvasive imaging techniques may help to establish the correct diagnosis (see Table 7). In patients with suspected myocarditis and infiltrative diseases (e.g. amyloidosis, see Table 7), endomyocardial biopsy may be needed to confirm the diagnosis. The use of this procedure is described in detail in other guidelines. ${ }^{72}$ 


\subsection{Exercise testing}

Exercise testing allows objective evaluation of exercise capacity and exertional symptoms, such as dyspnoea and fatigue. ${ }^{73}$ The 6-min walk test and a variety of treadmill and bicycle protocols are available. Gas exchange analysis helps differentiate between cardiac and respiratory causes of dyspnoea, shows whether the anaerobic threshold has been reached, and provides prognostic information (peak oxygen consumption is often measured as part of the assessment of candidates for heart transplantation). A normal exercise capacity in a patient not receiving treatment effectively excludes the diagnosis of symptomatic HF, although it must be remembered that there is a poor correlation between exercise capacity and resting haemodynamic measures, including EF.

\subsection{Genetic testing}

The emerging role of genetic testing in 'idiopathic' dilated and hypertrophic cardiomyopathy is described in detail elsewhere. ${ }^{16}$ Currently this is recommended in patients with dilated cardiomyopathy and AV block or a family history of premature unexpected sudden death, as a prophylactic implantable cardioverterdefibrillator (ICD) may be indicated.

\subsection{Ambulatory electrocardiographic monitoring}

Ambulatory ECG monitoring is valuable in the assessment of patients with symptoms suggestive of an arrhythmia or bradycardia (e.g. palpitations or syncope) and in monitoring ventricular rate control in patients with AF. It is useful for identifying the type, frequency, and duration of atrial and ventricular arrhythmias, silent episodes of ischaemia and bradycardia, and conduction disturbances, which may cause or exacerbate HF.

\section{Prognosis}

Many variables provide prognostic information (Appendix B), although most of this can be obtained from readily available data such as age, aetiology, NYHA class, EF, key co-morbidities (renal dysfunction, diabetes, anaemia, hyperuricaemia), and plasma natriuretic peptide concentration. ${ }^{74-80}$ Clearly these variables change over time, as does prognosis. Assessment of prognosis is particularly important when counselling patients about devices and surgery (including transplantation) and in planning end-of-life care with patients, their family, and caregivers.

\section{Pharmacological treatment of heart failure with reduced ejection fraction (systolic heart failure)}

\subsection{Objectives in the management of heart failure}

The goals of treatment in patients with established HF are to relieve symptoms and signs (e.g. oedema), prevent hospital admission, and improve survival. Although the focus of clinical trials was previously mortality, it is now recognized that preventing HF hospitalization is important for patients and healthcare systems. ${ }^{81}$ Reductions in mortality and hospital admission rates both reflect the ability of effective treatments to slow or prevent progressive worsening of HF. This is often accompanied by reverse LV remodelling and a reduction in circulating natriuretic peptide concentrations. $^{82,83}$

The relief of symptoms, improvement in quality of life, and increase in functional capacity are also of the utmost importance to patients, but they have not been the primary outcome in most trials. ${ }^{84}$ This is in part because they are difficult to measure and partly because some treatments previously shown to improve these outcomes also decreased survival. ${ }^{85,86}$ However, effective pharmacological therapies and CRT improve these outcomes, as well as mortality and hospitalization.

Figure 2 shows a treatment strategy for the use of drugs (and devices) in patients with HF-REF; the recommendations for each treatment are summarized below. Three neurohumoral antagonists-an ACE inhibitor [or angiotensin receptor blocker (ARB)], a beta-blocker, and an MRA — are fundamentally important in modifying the course of systolic HF and should at least be considered in every patient. They are commonly used in conjunction with a diuretic given to relieve the symptoms and signs of congestion. The following text summarizes the evidence supporting the recommendations in this section, in Appendices $C-E$ and in Figure 2. The recommended doses of these disease-modifying medications are given in Table 14. The recommendations given in Section 7.4 summarize drugs that should be avoided in patients with HF-REF.

\subsection{Treatments recommended in potentially all patients with systolic heart failure}

\subsubsection{Angiotensin-converting enzyme inhibitors and beta-blockers}

The pivotal trials with beta-blockers were conducted in patients with continuing symptoms and a persistently low EF, despite treatment with an ACE inhibitor and, in most cases, a diuretic. Despite this, there is consensus that these treatments are complementary and that a beta-blocker and an ACE inhibitor should both be started as soon as possible after diagnosis of HF-REF. This is in part because ACE inhibitors have a modest effect on LV remodelling whereas beta-blockers often lead to a substantial improvement in EF. Furthermore, beta-blockers are anti-ischaemic, are probably more effective in reducing the risk of sudden cardiac death, and lead to a striking and early reduction in overall mortality.

Key evidence supporting the use of angiotensing-converting enzyme inhibitors

- Two key randomized controlled trials [Cooperative North Scandinavian Enalapril Survival Study (CONSENSUS) ${ }^{87}$ and Studies of Left Ventricular Dysfunction (SOLVD)-Treatment] ${ }^{88}$ assigned $\sim 2800$ patients with mild to severely symptomatic $\mathrm{HF}$ to placebo or enalapril. Most were also treated with a diuretic and digoxin, but $<10 \%$ of patients in each trial were treated with a beta-blocker. In CONSENSUS, which enrolled patients 
Diuretics to relieve symptoms/signs of congestion ${ }^{\mathrm{a}}$

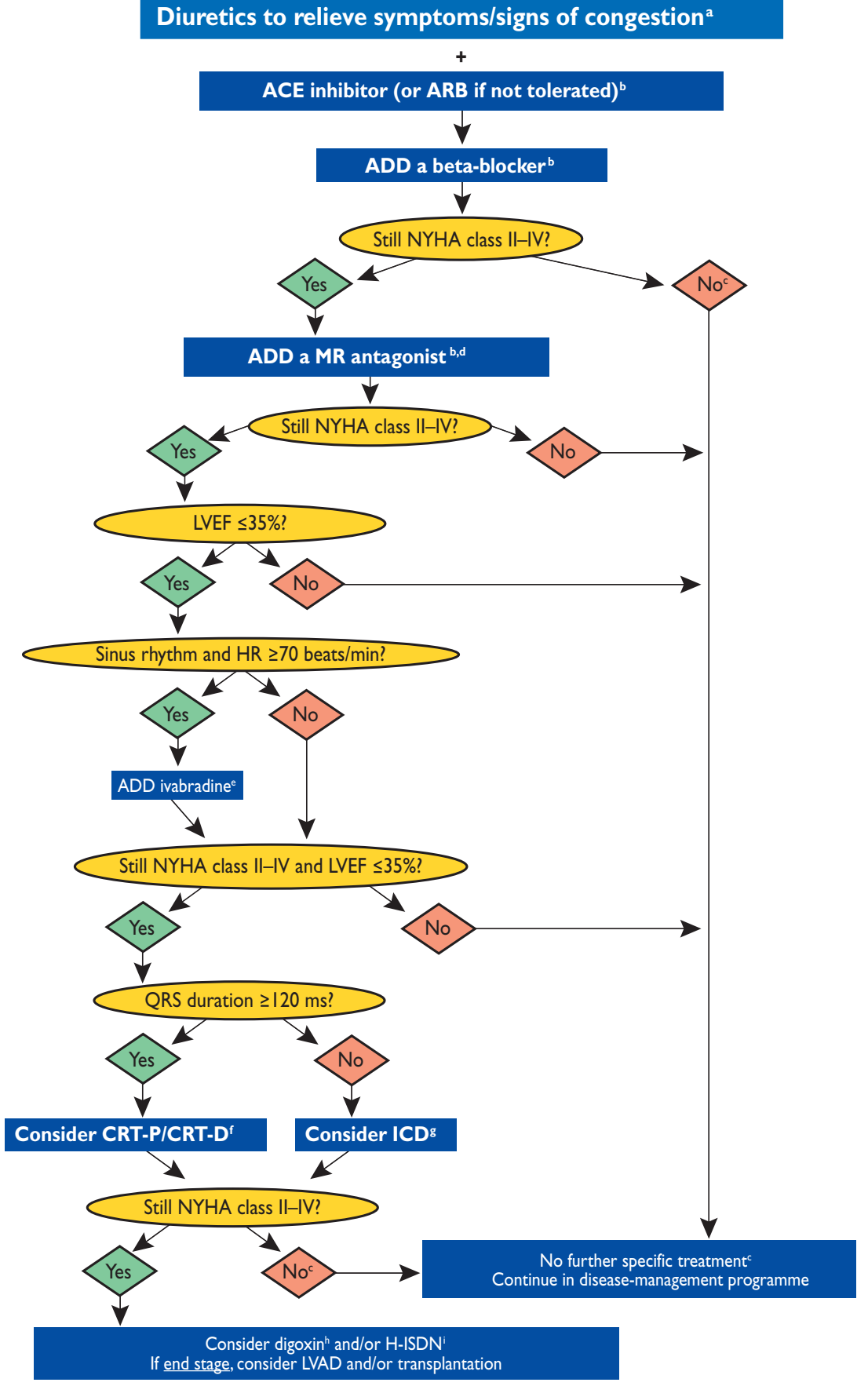

$A C E=$ angiotensin-converting enzyme; $A R B=$ angiotensin receptor blocker; $C R T-D=$ cardiac resynchronization therapy defibrillator; $C$ CRT-P $=$ cardiac resynchronization therapy pacemaker; $\mathrm{H}-\mathrm{ISDN}=$ hydralazine and isosorbide dinitrate; $\mathrm{HR}=$ heart rate; $\mathrm{ICD}=$ implantable cardioverter-defibrillator; $\mathrm{LBBB}=$ left bundle branch block; $\mathrm{LVAD}=$ left ventricular assist device; LVEF = left ventricular ejection fraction; MR antagonist = mineralocorticoid receptor antagonist; NYHA $=$ New York Heart Association.

${ }^{2}$ Diuretics may be used as needed to relieve the signs and symptoms of congestion (see Section 7.5) but they have not been shown to reduce hospitalization or death.

bShould be titrated to evidence-based dose or maximum tolerated dose below the evidence-based dose.

'Asymptomatic patients with an LVEF $\leq 35 \%$ and a history of myocardial infarction should be considered for an ICD.

If mineralocorticoid receptor antagonist not tolerated, an ARB may be added to an ACE inhibitor as an alternative.

e European Medicines Agency has approved ivabradine for use in patients with a heart rate $\geq 75$ b.p.m. May also be considered in patients with a contraindication to a beta-blocker or beta-blocker intolerance.

'See Section 9.2 for details-indication differs according to heart rhythm, NYHA class, QRS duration, QRS morphology and LVEF.

${ }^{8}$ Not indicated in NYHA class IV.

${ }^{\mathrm{h}}$ Digoxin may be used earlier to control the ventricular rate in patients with atrial fibrillation—usually in conjunction with a beta-blocker

'The combination of hydralazine and isosorbide dinitrate may also be considered earlier in patients unable to tolerate an ACE inhibitor or an ARB.

Figure 2 Treatment options for patients with chronic symptomatic systolic heart failure (NYHA functional class II-IV). 


\section{Pharmacological treatments indicated in potentially all patients with symptomatic (NYHA functional class II- IV) systolic heart failure}

\begin{tabular}{|c|c|c|c|}
\hline Recommendations & Class $^{\mathrm{a}}$ & Level $^{\mathrm{b}}$ & $\operatorname{Ref}^{c}$ \\
\hline $\begin{array}{l}\text { An } \mathrm{ACE} \text { inhibitor is } \\
\text { recommended, in addition to } \\
\text { a beta-blocker, for all patients } \\
\text { with an } \mathrm{EF} \leq 40 \% \text { to reduce the } \\
\text { risk of } \mathrm{HF} \text { hospitalization and } \\
\text { the risk of premature death. }\end{array}$ & I & A & $87-91$ \\
\hline $\begin{array}{l}\text { A beta-blocker is } \\
\text { recommended, in addition to } \\
\text { an ACE inhibitor (or ARB if } \\
\text { ACE inhibitor not tolerated), } \\
\text { for all patients with an EF } \\
\leq 40 \% \text { to reduce the risk of HF } \\
\text { hospitalization and the risk of } \\
\text { premature death. }\end{array}$ & I & $\mathbf{A}$ & $92-98$ \\
\hline $\begin{array}{l}\text { An MRA is recommended } \\
\text { for all patients with persisting } \\
\text { symptoms (NYHA class } \\
\text { II-IV) and an } E F \leq 35 \% \text {, despite } \\
\text { treatment with an ACE } \\
\text { inhibitor (or an ARB if an ACE } \\
\text { inhibitor is not tolerated) and } \\
\text { a beta-blocker, to reduce the } \\
\text { risk of HF hospitalization and } \\
\text { the risk of premature death. }\end{array}$ & I & A & 99,100 \\
\hline
\end{tabular}

$\mathrm{ACE}=$ angiotensin-converting enzyme; $\mathrm{ARB}=$ angiotensin receptor blocker; $\mathrm{EF}=$ ejection fraction; $\mathrm{HF}=$ heart failure; $\mathrm{MRA}=$ mineralocorticoid receptor antagonist; NYHA = New York Heart Association.

${ }^{a}$ Class of recommendation.

bevel of evidence.

${ }^{\mathrm{C}}$ References.

with severe HF, 53\% of patients were treated with spironolactone.

- Both of these two RCTs showed that ACE inhibitor treatment reduced mortality [relative risk reduction (RRR) $27 \%$ in CONSENSUS and $16 \%$ in SOLVD-Treatment]. In SOLVDTreatment there was also an RRR of $26 \%$ in HF hospitalization. These benefits were additional to those gained with conventional treatment at that time (i.e. a diuretic, digoxin, and spironolactone).

- The absolute risk reduction (ARR) in mortality in patients with mild or moderate HF (SOLVD-Treatment) was 4.5\%, equating to a number needed to treat (NNT) of 22 to postpone one death (over an average of 41 months). The equivalent figures for severe HF (CONSENSUS) were $14.6 \%$ for ARR and 7 for NNT (over an average of 6 months).

- These findings are supported by a meta-analysis of smaller, short-term, placebo-controlled randomized controlled trials (RCTs), which showed a clear reduction in mortality within only 3 months. ${ }^{89}$ These RCTs also showed that ACE inhibitors improve symptoms, exercise tolerance, quality of life, and exercise performance.

- In the Assessment of Treatment with Lisinopril And Survival (ATLAS) trial, ${ }^{90} 3164$ patients with mainly moderate to severe
HF were randomized to low- or high-dose lisinopril. There was an RRR of $15 \%$ in the risk of death or HF hospitalization in the high-dose lisinopril group compared with the low-dose lisinopril group.

- Additional support for the use of ACE inhibitors comes from an RCT in patients with a low EF but no symptoms of HF ('asymptomatic LV systolic dysfunction') and three large (5966 patients in total) placebo-controlled, randomized, outcome trials in patients with HF, LV systolic dysfunction, or both after acute myocardial infarction. ${ }^{91}$ In the SOLVD-Prevention trial (which randomized 4228 patients with asymptomatic LV systolic dysfunction), there was a $20 \%$ RRR in death or HF hospitalization. In the myocardial infarction trials, which used captopril [Survival and Ventricular Enlargement (SAVE)], ramipril [Acute Infarction Ramipril Efficacy (AIRE)], and trandolapril [TRAndolapril Cardiac Evaluation (TRACE)], there was a $26 \%$ RRR in death and a $27 \%$ RRR in death or HF hospitalization. ${ }^{101}$

- ACE inhibitors occasionally cause worsening of renal function, hyperkalaemia, symptomatic hypotension, cough, and, rarely, angioedema. An ACE inhibitor should only be used in patients with adequate renal function (creatinine $\leq 221 \mu \mathrm{mol} / \mathrm{L}$ or $\leq 2.5 \mathrm{mg} / \mathrm{dL}$ or eGFR $\geq 30 \mathrm{~mL} / \mathrm{min} / 1.73 \mathrm{~m}^{2}$ ) and a normal serum potassium level (see Appendix C).

Practical guidance on how to use ACE inhibitors is given in Appendix C. $^{102}$

Key evidence supporting the use of beta-blockers

- More RCTs have been undertaken with beta-blockers than with ACE inhibitors in patients with HF.

- Three key trials [Cardiac Insufficiency Bisoprolol Study II (CIBIS II), Carvedilol Prospective Randomized Cumulative Survival (COPERNICUS), and Metoprolol CR/XL Randomised Intervention Trial in Congestive Heart Failure (MERIT-HF)] randomized nearly 9000 patients with mild to severely symptomatic HF to placebo or a beta-blocker (bisoprolol, carvedilol, or metoprolol succinate $C R / X L) .{ }^{92-96}$ More than $90 \%$ of the patients were on an ACE inhibitor or ARB.

- Each of these three trials showed that beta-blocker treatment reduced mortality (RRR 34\% in each trial) and HF hospitalization (RRR 28-36\%) within $\sim 1$ year of starting treatment. There was also an also an improvement in self-reported patient wellbeing in COPERNICUS and MERIT-HF. These benefits were additional to those gained with conventional treatment, including an ACE inhibitor.

- The ARR in mortality (after 1 year of treatment) in patients with mild to moderate HF (CIBIS II and MERIT-HF combined) was $4.3 \%$, equating to an NNT (for 1 year to postpone one death) of 23. The equivalent figures for severe HF (COPERNICUS) were ARR 7.1\% and NNT 14.

- These findings are supported by another placebo-controlled RCT [Study of Effects of Nebivolol Intervention on Outcomes and Rehospitalization in Seniors With Heart Failure (SENIORS)] in 2128 elderly ( $\geq 70$ years) patients, 36\% of whom had an LVEF $>35 \%$. Treatment with nebivolol resulted in an RRR of $14 \%$ in the primary composite endpoint of death or cardiovascular hospitalization, but did not reduce mortality. ${ }^{97}$ 
- The findings of these trials were also supported by an earlier programme of studies with carvedilol (US carvedilol studies), a meta-analysis of other small beta-blocker trials, and a placebocontrolled RCT in 1959 patients with an LVEF $\leq 0.40$ after acute myocardial infarction in which the RRR in mortality with carvedilol was $23 \%$ during a mean follow-up of 1.3 years. ${ }^{98}$

- One large RCT [Beta-Blocker Evaluation of Survival Trial (BEST)] with bucindolol, a beta-blocker with partial agonist properties, did not show a significant reduction in mortality, though its findings were generally consistent with the above studies. $^{103}$

- Another RCT [Carvedilol or Metoprolol European Trial (COMET)] showed that carvedilol increased survival compared with short-acting metoprolol tartrate (different from the longacting succinate formulation used in MERIT-HF). ${ }^{104}$

- Beta-blockers should usually be initiated in stable patients, and used only with caution in recently decompensated patients (and only initiated in hospital in these patients). Recently decompensated patients were, however, safely initiated on betablocker treatment in COPERNICUS. ${ }^{105}$

- Continuation of beta-blocker treatment during an episode of decompensation has been shown in an RCT to be safe, although dose reduction may be necessary. ${ }^{106}$ Temporary discontinuation is advised in shocked or severely hypoperfused patients. Re-institution of treatment should be attempted before discharge.

Practical guidance on how to use beta-blockers is given in Appendix D. ${ }^{102}$

\subsubsection{Mineralocorticoid/aldosterone receptor antagonists}

Spironolactone and eplerenone block receptors that bind aldosterone and other corticosteroids, and are best characterized as MRAs. Although patients in the Eplerenone in Mild Patients Hospitalization and Survival Study in Heart Failure (EMPHASIS-HF) ${ }^{100}$ were required to have additional features elevating risk (recent cardiovascular hospitalization or elevated natriuretic peptide concentration), the benefits of MRAs probably extend to all patients with systolic HF, particularly as the two RCTs in chronic HF are supported by an additional RCT in patients with acute myocardial infarction. ${ }^{99,100,107}$

Key evidence supporting the use of mineralocorticoid receptor antagonists

- The Randomized Aldactone Evaluation Study (RALES) trial ${ }^{99}$ was undertaken with the MRA spironolactone in patients with severe HF.

- In RALES, 1663 patients with an EF $\leq 35 \%$ and in NYHA functional class III (having been in class IV within the past 6 months) were randomized to placebo or spironolactone 25$50 \mathrm{mg}$ once daily added to conventional treatment. At the time this trial was conducted, beta-blockers were not widely used to treat $\mathrm{HF}$, and only $11 \%$ were treated with a beta-blocker.

- Treatment with spironolactone led to an RRR in death of $30 \%$ and an RRR in HF hospitalization of $35 \%$ within an average of 2 years of starting treatment. These benefits were additional
Table I4 Evidence-based doses of disease-modifying drugs used in key randomized trials in heart failure (or after myocardial infarction)

\begin{tabular}{|c|c|c|}
\hline & Starting dose (mg) & Target dose (mg) \\
\hline \multicolumn{3}{|l|}{ ACE inhibitor } \\
\hline Captoprila & 6.25 t.i.d. & 50 t.i.d. \\
\hline Enalapril & 2.5 b.i.d. & 10-20 b.i.d. \\
\hline Lisinopril $^{b}$ & $2.5-5.0$ o.d. & 20-35 o.d. \\
\hline Ramipril & 2.5 o.d. & 5 b.i.d. \\
\hline Trandolapril ${ }^{a}$ & 0.5 o.d. & 4 o.d. \\
\hline \multicolumn{3}{|l|}{ Beta-blocker } \\
\hline Bisoprolol & 1.25 o.d. & 10 o.d. \\
\hline Carvedilol & 3.125 b.i.d. & $25-50$ b.i.d. \\
\hline Metoprolol succinate (CR/XL) & 12.5/25 o.d. & 200 o.d. \\
\hline Nebivololc & 1.25 o.d. & 10 o.d. \\
\hline \multicolumn{3}{|l|}{ ARB } \\
\hline Candesartan & 4 or 8 o.d. & 32 o.d. \\
\hline Valsartan & 40 b.i.d. & 160 b.i.d. \\
\hline Losartan, & 50 o.d. & 150 o.d. \\
\hline \multicolumn{3}{|l|}{ MRA } \\
\hline Eplerenone & 25 o.d. & 50 o.d. \\
\hline Spironolactone & 25 o.d. & 25-50 o.d. \\
\hline
\end{tabular}

$\mathrm{ACE}=$ angiotensin-converting enzyme; $\mathrm{ARB}=$ angiotensin receptor blocker; b.i.d. = bis in die (twice daily); MRA = mineralocorticoid receptor antagonist; o.d. = omni die (once every day); t.i.d. = ter in die (three times daily). andicates an ACE inhibitor where the dosing target is derived from post-myocardial infarction trials.

Indicates drugs where a higher dose has been shown to reduce morbiditymortality compared with a lower dose of the same drug, but there is no substantive placebo-controlled randomized controlled trial and the optimum dose is uncertain.

Indicates a treatment not shown to reduce cardiovascular or all-cause mortality in patients with heart failure or after acute mycocardial infarction (or shown to be non-inferior to a treatment that does).

to those gained with conventional treatment, including an ACE inhibitor.

- The ARR in mortality (after a mean of 2 years of treatment) in patients with severe HF was $11.4 \%$, equating to an NNT (for 2 years to postpone one death) of 9.

- More recently the EMPHASIS-HF trial ${ }^{100}$ was undertaken in patients with systolic HF and mild symptoms.

- In EMPHASIS-HF, 2737 patients aged $\geq 55$ years with NYHA functional class II symptoms and an EF $\leq 30 \%$ ( $\leq 35 \%$ if the QRS duration was $>130 \mathrm{~ms}$ ) were enrolled. Patients had to have either experienced a cardiovascular hospitalization within the previous 6 months or have an elevated plasma natriuretic peptide concentration and be treated with an ACE inhibitor, ARB, or both, and a beta-blocker.

- Treatment with eplerenone (up to $50 \mathrm{mg}$ once daily) led to an RRR of $37 \%$ in cardiovascular death or HF hospitalization. Reductions were also seen in rates of death from any cause (24\%), cardiovascular death (24\%), hospitalization for any reason (23\%), and HF hospitalization (42\%). These benefits 
were obtained within an average of 21 months of starting treatment and were additional to those gained with conventional treatment, including an ACE inhibitor and beta-blocker.

- The ARR in the primary composite mortality-morbidity endpoint in patients with mild symptoms was $7.7 \%$, equating to an NNT (for an average of 21 months to postpone one event) of 13 . The ARR in mortality was $3 \%$, equating to an NNT of 33.

- These findings are supported by another RCT [Eplerenone Post-Acute Myocardial Infarction Heart Failure Efficacy and Survival Study (EPHESUS)], which enrolled 6632 patients 3-14 days after acute myocardial infarction with an $E F \leq 40 \%$ and
HF or diabetes. ${ }^{107}$ Patients were randomized to placebo or eplerenone 25-50 mg once daily added to conventional treatment including an ACE inhibitor/ARB (87\%) and a beta-blocker (75\%). Treatment with eplerenone led to an RRR in death of $15 \%$.

- Spironolactone and eplerenone can cause hyperkalaemia and worsening renal function, which were uncommon in the RCTs, but may occur more frequently in ordinary clinical practice, especially in the elderly. Both should only be used in patients with adequate renal function and a normal serum potassium concentration; if either is used, serial monitoring of serum electrolytes and renal function is mandatory.

\section{Other treatments with less-certain benefits in patients with symptomatic (NYHA class II-IV) systolic heart failure}

\begin{tabular}{|c|c|c|c|}
\hline Recommendations & Class $^{\mathrm{a}}$ & Level $^{b}$ & $\operatorname{Ref}^{c}$ \\
\hline \multicolumn{4}{|l|}{ ARB } \\
\hline $\begin{array}{l}\text { Recommended to reduce the risk of HF hospitalization and the risk of premature death in patients with an } \mathrm{EF} \leq 40 \% \\
\text { and unable to tolerate an ACE inhibitor because of cough (patients should also receive a beta-blocker and an MRA). }\end{array}$ & I & $\mathbf{A}$ & 108,109 \\
\hline $\begin{array}{l}\text { Recommended to reduce the risk of HF hospitalization in patients with an EF } \leq 40 \% \text { and persisting symptoms (NYHA } \\
\text { class II-IV) despite treatment with an ACE inhibitor and a beta-blocker who are unable to tolerate an MRA. }\end{array}$ & I & $\mathbf{A}$ & 110,111 \\
\hline \multicolumn{4}{|l|}{ Ivabradine } \\
\hline $\begin{array}{l}\text { Should be considered to reduce the risk of HF hospitalization in patients in sinus rhythm with an } E F \leq 35 \% \text {, a heart rate } \\
\text { remaining } \geq 70 \text { b.p.m., and persisting symptoms (NYHA class II-IV) despite treatment with an evidence-based dose of } \\
\text { beta-blocker (or maximum tolerated dose below that), ACE inhibitor (or ARB), and an MRA (or ARB).e }\end{array}$ & Ila & B & 112 \\
\hline $\begin{array}{l}\text { May be considered to reduce the risk of } \mathrm{HF} \text { hospitalization in patients in sinus rhythm with an } \mathrm{EF} \leq 35 \% \text { and a heart } \\
\text { rate } \geq 70 \text { b.p.m. who are unable to tolerate a beta-blocker. Patients should also receive an } \mathrm{ACE} \text { inhibitor (or ARB) } \\
\text { and an MRA (or ARB). }\end{array}$ & Illb & C & - \\
\hline \multicolumn{4}{|l|}{ Digoxin } \\
\hline $\begin{array}{l}\text { May be considered to reduce the risk of HF hospitalization in patients in sinus rhythm with an } E F \leq 45 \% \text { who are } \\
\text { unable to tolerate a beta-blocker (ivabradine is an alternative in patients with a heart rate } \geq 70 \text { b.p.m.). Patients should } \\
\text { also receive an ACE inhibitor (or ARB) and an MRA (or ARB). }\end{array}$ & Ilb & B & 113 \\
\hline $\begin{array}{l}\text { May be considered to reduce the risk of } \mathrm{HF} \text { hospitalization in patients with an } \mathrm{EF} \leq 45 \% \text { and persisting symptoms } \\
\text { (NYHA class II-IV) despite treatment with a beta-blocker, ACE inhibitor (or ARB), and an MRA (or ARB). }\end{array}$ & Ilb & B & 113 \\
\hline \multicolumn{4}{|l|}{ H-ISDN } \\
\hline $\begin{array}{l}\text { May be considered as an alternative to an } \mathrm{ACE} \text { inhibitor or } \mathrm{ARB} \text {, if neither is tolerated, to reduce the risk of } \mathrm{HF} \\
\text { hospitalization and risk of premature death in patients with an } \mathrm{EF} \leq 45 \% \text { and dilated } \mathrm{LV} \text { (or } \mathrm{EF} \leq 35 \% \text { ). Patients should } \\
\text { also receive a beta-blocker and an MRA. }\end{array}$ & Ilb & $\mathbf{B}$ & 114,115 \\
\hline $\begin{array}{l}\text { May be considered to reduce the risk of HF hospitalization and risk of premature death in patients in patients with an } \\
E F \leq 45 \% \text { and dilated LV (or EF } \leq 35 \% \text { ) and persisting symptoms (NYHA class II-IV) despite treatment with a } \\
\text { beta-blocker,ACE inhibitor (or ARB), and an MRA (or ARB). }\end{array}$ & Illb & $\mathbf{B}$ & 116 \\
\hline $\begin{array}{l}\text { An n-3 PUFA preparation may be considered to reduce the risk of death and the risk of } \\
\text { cardiovascular hospitalization in patients treated with an ACE inhibitor (or ARB), } \\
\text { beta-blocker, and an MRA (or ARB). }\end{array}$ & Illb & $\mathbf{B}$ & 117 \\
\hline
\end{tabular}

$\mathrm{ACE}=$ angiotensin-converting enzyme; $\mathrm{ARB}=$ angiotensin receptor blocker; CHARM-Added $=$ Candesartan in Heart Failure: Assessment of Reduction in Mortality and Morbidity-Added; $\mathrm{EF}=$ ejection fraction; $\mathrm{HF}=$ heart failure; $\mathrm{H}-\mathrm{ISDN}=$ hydralazine and isosorbide dinitrate; $\mathrm{MRA}=$ mineralocorticoid receptor antagonist; $\mathrm{NYHA}=\mathrm{New}$ York Heart Association; PUFA = polyunsaturated fatty acid.

${ }^{a}$ Class of recommendation.

bLevel of evidence.

'References.

In the CHARM-Added trial, candesartan also reduced cardiovascular mortality.

eEuropean Medecines Agency has approved ivabradine for use in patients with a heart rate $\geq 75$ b.p.m.

fPreparation studied in cited trial; the GISSI-HF trial had no EF limit. 
- Spironolactone can also cause breast discomfort and enlargement in men ( $10 \%$ compared with $1 \%$ on placebo, in RALES $^{99}$ ); this side effect is infrequent with eplerenone.

Practical guidance on how to use MRAs is given in Appendix $E^{102}$

\subsubsection{Other treatments recommended in selected patients with systolic heart failure}

This section describes other treatments that are valuable in patients with systolic HF. They have not, however, been shown clearly to reduce all-cause mortality [or in the case of hydralazine and isosorbide dinitrate $(\mathrm{H}-\mathrm{ISDN})$, this has only been clearly shown in African-Americans]. Most of these drugs have shown convincing benefits in terms of symptom reduction, HF hospitalization, or both, and are useful alternative or additional treatments in patients with HF.

\subsubsection{Angiotensin receptor blockers}

ARBs remain recommended as an alternative in patients intolerant of an ACE inhibitor. ${ }^{109,109}$ However, ARBs are no longer the firstchoice recommendation in patients with $\mathrm{HF}$ and an $\mathrm{EF} \leq 40 \%$ who remain symptomatic despite optimal treatment with an ACE inhibitor and beta-blocker. This is because in EMPHASIS-HF, eplerenone led to a larger reduction in morbidity-mortality than seen in the ARB 'add-on' trials discussed below, and because in both the Randomized Aldactone Evaluation Study (RALES) and EMPHASIS-HF, MRA treatment reduced all-cause mortality, whereas ARB 'add-on' treatment did not.

\section{Key evidence}

- Two key placebo-controlled RCTs [Valsartan Heart Failure Trial (Val-HeFT) and CHARM-Added] randomized $\sim 7600$ patients with mild to severely symptomatic HF to placebo or an ARB (valsartan and candesartan), added to an ACE inhibitor (in 93\% of patients in Val-HeFT and all patients in CHARM-Added) ${ }^{110,111}$ In addition, $35 \%$ of patients in Val-HeFT and $55 \%$ in CHARM-Added were treated with a beta-blocker.

- Each of these two trials showed that ARB treatment reduced the risk of HF hospitalization (RRR $24 \%$ in Val-HeFT and $17 \%$ in CHARM-Added) but not all-cause hospitalization. There was a $16 \%$ RRR in the risk of cardiovascular death with candesartan in CHARM-Added. These benefits were additional to those gained with conventional treatment, including a diuretic, digoxin, an ACE inhibitor, and a beta-blocker (but few patients were taking an MRA).

- The ARR in the primary composite mortality-morbidity endpoint in patients with mild to moderate HF was $4.4 \%$, equating to an NNT (for an average of 41 months to postpone one event) of 23 in CHARM-Added. The equivalent figures for Val-HeFT were ARR 3.3\% and NNT 30 (over an average of 23 months).

- The CHARM trials and Val-HeFT also showed that ARBs improve symptoms and quality of life. Other trials showed that these agents improve exercise capacity.

- CHARM-Alternative was a placebo-controlled RCT with candesartan in 2028 patients with an LVEF $\leq 40 \%$, intolerant of an ACE inhibitor. Treatment with candesartan resulted in an RRR of cardiovascular or HF hospitalization of $23 \%$ (ARR 7\%, NNT
14 , over 34 months of follow-up). ${ }^{108}$ Valsartan was also beneficial in the subset of patients in Val-HeFT not treated with an ACE inhibitor. ${ }^{109}$

- Another trial [Evaluation of Losartan In The Elderly (ELITE) ${ } \mathrm{I}^{118}$ ] failed to show that losartan $50 \mathrm{mg}$ daily was as effective as captopril $50 \mathrm{mg}$ three times daily. However, a subsequent RCT [Heart failure Endpoint evaluation of Angiotensin II Antagonist Losartan (HEAAL) ${ }^{119}$ ] showed that $150 \mathrm{mg}$ daily of losartan was superior to $50 \mathrm{mg}$ daily, supporting the similar findings of the Assessment of Treatment with Lisinopril And Survival (ATLAS) trial with the ACE inhibitor lisinopril-see above. In HEAAL there was an RRR of $10 \%$ in death or HF hospitalization in the high-dose losartan group $(P=0.027)$ over a median follow-up of 4.7 years. The results from these two trials, ATLAS $^{90}$ and HEAAL, ${ }^{119}$ indicate that more benefit is obtained from using higher doses of renin-angiotensin system blockers and underscore the importance of attaining, if possible, the target doses proven to be of benefit in the key RCTs.

- Additional support for the use of ARBs comes from the Valsartan In Acute myocardial infarction trial (VALIANT), ${ }^{120}$ an RCT in which 14703 patients with HF, LV systolic dysfunction, or both after acute myocardial infarction were assigned to treatment with captopril, valsartan, or the combination. Valsartan was found to be non-inferior to captopril. In a similar trial [Optimal Therapy in Myocardial infarction with the Angiotensin II Antagonist Losartan (OPTIMAAL) ${ }^{121}$ ], losartan $50 \mathrm{mg}$ once daily did not demonstrate non-inferiority when compared with captopril.

Practical guidance on how to use an $A R B$ is given in Appendix $\mathrm{C}^{102}$

\subsubsection{Ivabradine}

Ivabradine is a drug that inhibits the $\mathrm{I}_{f}$ channel in the sinus node. Its only known pharmacological effect is to slow the heart rate in patients in sinus rhythm (it does not slow the ventricular rate in AF).

\section{Key evidence}

- The Systolic Heart failure treatment with the $I_{f}$ inhibitor ivabradine Trial (SHIFT) enrolled 6588 patients in NYHA functional class II-IV, sinus rhythm with a rate of $\geq 70$ b.p.m., and an EF $\leq 35 \%$. $^{112}$ Patients were also required to have had a HF hospitalization in the previous 12 months. They were randomized to ivabradine (up-titrated to a maximal dosage of $7.5 \mathrm{mg}$ twice daily) or placebo, added to a diuretic (in 84\%), digoxin (22\%), an ACE inhibitor (79\%), an ARB (14\%), a beta-blocker (90\%), and an MRA (60\%). Only $26 \%$ of patients were, however, on full-dose beta-blocker. The median follow-up was 23 months. The RRR in the primary composite outcome of cardiovascular death or HF hospitalization was 18\% $(P<0.0001)$; the reduction in cardiovascular death (or all-cause death) was not significant, but the RRR in HF hospitalization was $26 \%$. The ARR in the primary composite mortality-morbidity endpoint was $4.2 \%$, equating to an NNT (for an average of 23 months to postpone one event) of 24. Ivabradine also improved LV function and quality of life. 
- Five per cent of patients on ivabradine had symptomatic bradycardia compared with $1 \%$ of the placebo group $(P<0.0001)$. Visual side effects (phosphenes) were reported by $3 \%$ of patients on ivabradine and $1 \%$ on placebo $(P<0.0001)$.

- Additional safety evidence for ivabradine comes from the MorBidity-mortality EvAlUaTion of the $I_{f}$ inhibitor ivabradine in patients with coronary disease and left ventricULar dysfunction (BEAUTIFUL) trial, an RCT in which 10917 patients with coronary heart disease and an EF $<40 \%$ were assigned to treatment with ivabradine $7.5 \mathrm{mg}$ twice daily or placebo and followed for a median of 19 months. Although ivabradine did not reduce the primary outcome of cardiovascular death, myocardial infarction, or HF hospitalization, it was well tolerated. ${ }^{122}$

\subsubsection{Digoxin and other digitalis glycosides}

In patients with symptomatic HF and AF, digoxin may be used to slow a rapid ventricular rate, although other treatments are preferred (see Section 10.1).

Digoxin may also be used in patients in sinus rhythm with symptomatic HF and an LVEF $\leq 40 \%$ as recommended below, based on the evidence summarized below. ${ }^{113}$

Key evidence

- A single large morbidity-mortality RCT [Digitalis Investigation Group (DIG)] has been undertaken with digoxin in patients with symptomatic HF and a low EF. ${ }^{113}$

- In the DIG trial, 6800 patients with an EF $\leq 45 \%$ and in NYHA functional class II-IV were randomized to placebo or digoxin ( $0.25 \mathrm{mg}$ once daily), added to a diuretic and an ACE inhibitor. This trial was performed before beta-blockers were widely used for HF. ${ }^{113}$

- Treatment with digoxin did not alter all-cause mortality but did lead to an RRR for hospital admission for worsening HF of $28 \%$ within an average of 3 years of starting treatment. The absolute ARR was $7.9 \%$, equating to an NNT (for 3 years to postpone one patient admission) of 13 .

- These findings are supported by a meta-analysis of smaller trials suggesting that digoxin can improve symptoms and prevent deterioration. $^{123}$

- Digoxin can cause atrial and ventricular arrhythmias, particularly in the context of hypokalaemia, and serial monitoring of serum electrolytes and renal function is mandatory.

- The efficacy and safety of other digitalis glycosides such as digitoxin have not been studied properly in heart failure.

\subsubsection{Combination of hydralazine and isosorbide dinitrate}

In one relatively small RCT conducted exclusively in men (and before ACE inhibitor or beta-blockers were used to treat HF), this vasodilator combination led to a borderline reduction in mortality when compared with placebo. ${ }^{114-116}$ In a subsequent RCT, the addition of H-ISDN to conventional therapy (ACE inhibitor, beta-blocker, and MRA) reduced morbidity and mortality (and improved symptoms) in African-Americans with HF. ${ }^{116}$ The selected patient population studied, relatively small RCT size, and early termination (for mortality benefit) have left uncertainty about the real value of this combination therapy, especially in nonblack patients.

Key evidence

- There are two placebo-controlled (V-HeFT-I and A-HeFT) RCTs and one active-controlled (V-HeFT-II) RCT with H-ISDN. ${ }^{114-116}$

- In V-HeFT-I, 642 men were randomized to placebo, prazosin, or $\mathrm{H}$-ISDN added to a diuretic and digoxin. ${ }^{114}$ No patients were treated with a beta-blocker or an ACE inhibitor (and the use of MRAs was not documented). Mortality rates were not different in the placebo and prazosin groups. With H-ISDN, there was a trend to a reduction in all-cause mortality during the overall period of follow-up (mean 2.3 years): RRR 22\%; ARR 5.3\%; NNT 19. H-ISDN increased exercise capacity and LVEF compared with placebo.

- In A-HeFT, 1050 African-American men and women in NYHA class III or IV were randomized to placebo or H-ISDN, added to a diuretic (in 90\%), digoxin (60\%), an ACE inhibitor (70\%), an ARB (17\%), a beta-blocker (74\%), and spironolactone (39\%). ${ }^{116}$ The initial dose of treatment was $20 \mathrm{mg}$ ISDN/ $37.5 \mathrm{mg}$ hydralazine thrice daily, increasing to a target of $40 \mathrm{mg} / 75 \mathrm{mg}$ thrice daily. The trial was discontinued prematurely, after a median follow-up of 10 months, because of a significant reduction in mortality (RRR 43\%; ARR 4.0\%; NNT 25). $\mathrm{H}$-ISDN also reduced the risk of HF hospitalization (RRR $33 \%)$ and improved quality of life.

- In V-HeFT-II, 804 men, mainly in NYHA class II or III, were randomized to enalapril or H-ISDN, added to a diuretic and digoxin. ${ }^{115}$ No patients were treated with a beta-blocker. There was a trend in the H-ISDN group to an increase in allcause mortality during the overall period of follow-up (mean 2.5 years): relative increase in risk was $28 \%$.

- The most common adverse effects with H-ISDN in these trials were headache, dizziness/hypotension, and nausea. Arthralgia leading to discontinuation or reduction in dose of H-ISDN occurred in $5-10 \%$ of patients in V-HeFT I and II and a sustained increase in antinuclear antibody in $2-3 \%$ of patients (but lupuslike syndrome was rare).

\subsubsection{Omega-3 polyunsaturated fatty acids}

The small treatment effect of $n-3$ polyunsaturated fatty acids (PUFAs) in the Gruppo Italiano per lo Studio della Sopravvivenza nell'Infarto miocardico-heart failure (GISSI-HF) trial was only detected after covariate adjustment in the statistical analysis and there was no effect on HF hospitalization. ${ }^{117}$ The effect of $n-3$ PUFAs after myocardial infarction is uncertain.

\section{Key evidence}

- In the GISSI-HF PUFA trial, 6975 patients with NYHA class II-IV symptoms and an EF $\leq 40 \%$ (or if $>40 \%$, HF hospitalization in the previous year) were randomized to placebo or $1 \mathrm{~g}$ daily of an $n-3$ PUFA preparation in addition to standard therapy includ- 
ing an ACE inhibitor/ARB in 94\%, beta-blocker in 65\%, and spironolactone in $39 \%{ }^{117}$ The median follow-up was 3.9 years. $n-3$ PUFA treatment led to an RRR of $8 \%$ in the co-primary composite outcome of death or cardiovascular hospitalization in an adjusted analysis (adjusted $P=0.009$ ). There was no reduction in HF hospitalization, but there was a 10\% RRR in cardiovascular mortality (adjusted $P=0.045$ ) and 7\% RRR in cardiovascular hospitalization (adjusted $P=0.026$ ).

- These findings are supported by one post-myocardial infarction RCT (GISSI-Prevenzione ${ }^{124}$ ) but not by another (OMEGA ${ }^{125}$ ). In GISSI-Prevenzione, involving 11324 patients enrolled after a recent ( $\leq 3$ months) myocardial infarction, patients received placebo or $1 \mathrm{~g}$ daily of $n-3$ PUFA. $n-3$ PUFA treatment led to an RRR of $10 \%$ in the primary composite outcome of death, myocardial infarction, or stroke (largely driven by a reduction in cardiovascular death).

- OMEGA randomized 3851 patients 3-14 days after acute myocardial infarction to placebo or $1 \mathrm{~g} n$-3 PUFA daily for 1 year. Outcomes did not differ between treatment groups.

- $n-3$ PUFA preparations differ in composition and the dose may be important.

- The main adverse effects of $n-3$ PUFAs reported in these trials were nausea and other minor gastrointestinal disturbances.

\subsection{Treatments not recommended (unproven benefit)}

\subsubsection{3-Hydroxy-3-methylglutaryl-coenzyme A reductase} inhibitors ('statins')

Although there is a wealth of robust evidence supporting the value of statins in patients with atherosclerotic (arterial) disease, most trials excluded patients with HF (because it was uncertain that they would benefit ${ }^{126}$ ). Two recent trials studied statin treatment specifically in patients with chronic HF and did not demonstrate convincing evidence of benefit (although there was little evidence of harm). ${ }^{127,128}$ Despite the evidence in other areas of cardiovascular medicine, the evidence does not therefore support the initiation of statins in most patients with chronic HF.

Key evidence

- The Controlled Rosuvastatin Multinational Trial in Heart Failure (CORONA) and GISSI-HF compared rosuvastatin with placebo in patients with symptomatic HF. ${ }^{127,128}$

- CORONA enrolled 5011 older patients ( $\geq 60$ years) with symptomatic HF (NYHA class II-IV) of ischaemic aetiology with an $\mathrm{EF} \leq 40 \%$, felt by the investigator not to require cholesterollowering therapy. Rosuvastatin did not reduce the primary endpoint (cardiovascular death, myocardial infarction, or stroke) or all-cause mortality. ${ }^{127}$

- The GISSI-HF statin trial enrolled 4574 patients with symptomatic HF (NYHA class II-IV) of ischaemic and non-ischaemic aetiology. Patients had an EF $\leq 40 \%$ (or if $>40 \%$, HF hospitalization in the previous year) and were randomized to placebo or rosuvastatin $10 \mathrm{mg}$ daily, in addition to standard therapy including an
ACE inhibitor/ARB in 94\%, beta-blocker in 63\% and spironolactone in $40 \%$. The median follow-up was 3.9 years. The co-primary endpoints of all-cause mortality and the composite of all-cause death or cardiovascular hospitalization were not reduced by rosuvastatin.

\subsubsection{Renin inhibitors}

One direct renin inhibitor (aliskiren) is currently being evaluated in two morbidity-mortality RCTs. It is not presently recommended as an alternative to an ACE inhibitor or ARB. ${ }^{129,130}$

\subsubsection{Oral anticoagulants}

Other than in patients with AF (both HF-REF and HF-PEF), there is no evidence that an oral anticoagulant reduces mortality-morbidity compared with placebo or aspirin (see Section 10.1). ${ }^{130 a}$

\subsection{Treatments not recommended (believed to cause harm)}

Treatments (or combinations of treatments) that may cause harm in patients with symptomatic (NYHA class II-IV) systolic heart failure

\begin{tabular}{|l|l|l|l|}
\hline Recommendations & Class $^{\mathrm{a}}$ & Level $^{\mathrm{b}}$ & Ref $^{\mathrm{c}}$ \\
\hline $\begin{array}{l}\text { Thiazolidinediones (glitazones) } \\
\text { should not be used as they } \\
\text { cause worsening HF and increase } \\
\text { the risk of HF hospitalization. }\end{array}$ & III & A & I3I-I33 \\
\hline $\begin{array}{l}\text { Most CCBs (with the exception } \\
\text { of amlodipine and felodipine) } \\
\text { should not be used as they have } \\
\text { a negative inotropic effect and can } \\
\text { cause worsening HF. }\end{array}$ & III & B & I34 \\
\hline $\begin{array}{l}\text { NSAIDs and COX-2 inhibitors } \\
\text { should be avoided if possible as } \\
\text { they may cause sodium and water } \\
\text { retention, worsening renal function } \\
\text { and worsening HF. }\end{array}$ & III & B & I35, I36 \\
\hline $\begin{array}{l}\text { The addition of an ARB } \\
\text { (or renin inhibitor) to the } \\
\text { combination of an ACE inhibitor AND } \\
\text { a mineralocorticoid antagonist is } \\
\begin{array}{l}\text { NOT recommended } \\
\text { because of the risk of renal } \\
\text { dysfunction and hyperkalaemia. }\end{array}\end{array}$ & III & C & - \\
\hline
\end{tabular}

$\mathrm{ACE}=$ angiotensin-converting enzyme; $\mathrm{ARB}=$ angiotensin receptor blocker $\mathrm{CCB}=$ calcium-channel blocker; $\mathrm{COX}=$ cyclo-oxygenase; $\mathrm{EF}=$ ejection fraction; $\mathrm{HF}=$ heart failure; NSAID = non-steroidal anti-inflammatory drug; NYHA = New York Heart Association.

${ }^{a}$ Class of recommendation.

'Level of evidence.

'References. 


\subsection{Diuretics}

The effects of diuretics on mortality and morbidity have not been studied in patients with HF, unlike ACE inhibitors, betablockers, and MRAs (and other treatments). However, diuretics relieve dyspnoea and oedema and are recommended for this reason in patients with signs and symptoms of congestion, irrespective of EF.

Loop diuretics produce a more intense and shorter diuresis than thiazides, which cause a more gentle and prolonged diuresis. Thiazides may be less effective in patients with reduced kidney function. Loop diuretics are usually preferred to thiazides in HF-REF although they act synergistically and the combination may be used (usually on a temporary basis) to treat resistant oedema.

The aim of using diuretics is to achieve and maintain euvolaemia (the patient's 'dry weight') with the lowest achievable dose. This means that the dose must be adjusted, particularly after restoration of dry body weight, to avoid the risk of dehydration leading to hypotension and renal dysfunction. This may reduce cardiac output in patients with HF-PEF and often needlessly prevents the use of (or achievement of the target dose of) other disease-modifying therapies such as ACE inhibitors (or ARBs) and MRAs in patients with HF-REF. Many patients

Table 16 Doses of diuretics commonly used to treat heart failure (with and without a preserved ejection fraction, chronic and acute)

\begin{tabular}{|c|c|c|c|c|}
\hline Diuretics & \multicolumn{2}{|c|}{ Initial dose (mg) } & \multicolumn{2}{|c|}{ Usual daily dose (mg) } \\
\hline \multicolumn{5}{|l|}{ Loop diuretics $^{a}$} \\
\hline Furosemide & \multicolumn{2}{|l|}{$20-40$} & \multicolumn{2}{|l|}{$40-240$} \\
\hline Bumetanide & \multicolumn{2}{|l|}{$0.5-1.0$} & \multicolumn{2}{|l|}{$1-5$} \\
\hline Torasemide & \multicolumn{2}{|l|}{$5-10$} & \multicolumn{2}{|l|}{$10-20$} \\
\hline \multicolumn{5}{|l|}{ Thiazides $^{b}$} \\
\hline Bendroflumethiazide & \multicolumn{2}{|l|}{2.5} & \multicolumn{2}{|l|}{$2.5-10$} \\
\hline Hydrochlorothiazide & \multicolumn{2}{|l|}{25} & \multicolumn{2}{|c|}{$12.5-100$} \\
\hline Metolazone & \multicolumn{2}{|l|}{2.5} & \multicolumn{2}{|l|}{$2.5-10$} \\
\hline Indapamide ${ }^{c}$ & \multicolumn{2}{|l|}{2.5} & \multicolumn{2}{|l|}{$2.5-5$} \\
\hline \multicolumn{5}{|c|}{ Potassium-sparing diuretics ${ }^{d}$} \\
\hline & $\begin{array}{l}+\mathrm{ACEi} / \\
\mathrm{ARB}\end{array}$ & $\begin{array}{l}\text {-ACEi/ } \\
\text { ARB }\end{array}$ & $\begin{array}{l}+ \text { ACEi/ } \\
\text { ARB }\end{array}$ & $\begin{array}{l}\text {-ACEi/ } \\
\text { ARB }\end{array}$ \\
\hline $\begin{array}{l}\text { Spironolactone/ } \\
\text { eplerenone }\end{array}$ & $12.5-25$ & 50 & 50 & $100-200$ \\
\hline Amiloride & 2.5 & 5 & $5-10$ & $10-20$ \\
\hline Triamterene & 25 & 50 & 100 & 200 \\
\hline
\end{tabular}

$\mathrm{ACE}$ = angiontensin-converting enzyme inhibitor; $\mathrm{ARB}=$ angiotensin receptor blocker.

${ }^{a}$ Oral or intravenous; dose might need to be adjusted according to volume status/ weight; excessive doses may cause renal impairment and ototoxicity.

${ }^{b}$ Do not use thiazides if estimated glomerular filtration rate $<30 \mathrm{~mL} / \mathrm{min}$, except when prescribed synergistically with loop diuretics.

'Indapamide is a non-thiazide sulfonamide.

${ }^{\mathrm{d}} \mathrm{A}$ mineralocorticoid antagonist (MRA) i.e. spironolactone/eplerenone is always preferred. Amiloride and triamterene should not be combined with an MRA. can be trained to self-adjust their diuretic dose, based on monitoring of symptoms/signs of congestion and daily weight measurements.

Practical guidance on the use of diuretics is given in Appendix $F$ and the doses of commonly used diuretics are shown in Table 16.

Use of potassium-sparing diuretics and potassium supplements

- If a potassium-losing diuretic is used with the combination of an ACE inhibitor and an MRA (or ARB), potassium replacement is usually not required.

- Serious hyperkalaemia may occur if potassium-sparing diuretics or supplements are taken in addition to the combination of an ACE inhibitor (or ARB) and MRA.

- The use of all three of an ACE inhibitor, MRA and ARB is not recommended.

\section{Pharmacological treatment of heart failure with 'preserved' ejection fraction (diastolic heart failure)}

No treatment has yet been shown, convincingly, to reduce morbidity and mortality in patients with HF-PEF. Diuretics are used to control sodium and water retention and relieve breathlessness and oedema as in HF-REF. Adequate treatment of hypertension and myocardial ischaemia is also considered to be important, as is control of the ventricular rate in patients with AF (see Section 11). Two very small studies ( $<30$ patients each) have shown that the heart rate-limiting calcium-channel blocker (CCB) verapamil may improve exercise capacity and symptoms in these patients. ${ }^{137,138}$ Rate-limiting CCBs may also be useful for ventricular rate control in patients with $\mathrm{AF}$ and in the treatment of hypertension and myocardial ischaemia (which is not the case in patients with HF-REF where their negative inotropic action can be dangerous). Beta-blockers may also be used to control the ventricular rate in patients with HF-PEF and AF.

The drugs that should be avoided in HF-REF (see Section 7.4) should also be avoided in HF-PEF, with the exception of CCBs.

The key mortality-morbidity trials to date are:

- The 3023-patient Candesartan in Heart Failure: Assessment of Reduction in Mortality and Morbidity (CHARM)-Preserved trial, which showed no reduction in the primary composite endpoint (cardiovascular death or HF hospitalization). ${ }^{139}$

- The 850-patient Perindopril for Elderly People with Chronic Heart failure trial (PEP-CHF), which showed no reduction in the primary composite endpoint of death or HF hospitalization. $^{140}$

- The 4128 patient Irbesartan in heart failure with preserved systolic function trial (I-Preserve) which showed no reduction in the primary composite outcome of death or cardiovascular 
hospitalization (specifically, HF, myocardial infarction, unstable angina, arrhythmia, or stroke). ${ }^{141}$

\section{Non-surgical device treatment of heart failure with reduced ejection fraction (systolic heart failure)}

This section discusses the use of ICDs and CRT. While no new ICD RCT has completed since publication of the 2008 guidelines, ${ }^{1}$ there have been several important RCTs using CRT that have changed the recommendations (see below). Other technologies including a wearable defibrillator vest ${ }^{142}$ and implantable monitors (either 'stand-alone' or incorporated into other devices) are of research interest, but do not yet have enough evidence behind them to support guideline recommendations.

\subsection{Implantable cardioverter-defibrillator}

Approximately half of the deaths in patients with HF, especially in those with milder symptoms, occur suddenly and unexpectedly, and many, if not most, of these are related to ventricular arrhythmias (whereas others may be related to bradycardia and asystole). Prevention of sudden death is therefore an important goal in HF. While the key disease-modifying neurohumoral antagonists mentioned earlier reduce the risk of sudden death, they do not abort it. Specific antiarrhythmic drugs do not decrease this risk (and may even increase it). ${ }^{143}$ For this reason, ICDs have an important role to play in reducing the risk of death from ventricular arrhythmias.

\subsubsection{Secondary prevention of sudden cardiac death Key evidence}

ICDs reduce mortality in survivors of cardiac arrest and in patients with sustained symptomatic ventricular arrhythmias. Consequently, an ICD is recommended in such patients, irrespective of EF, with good functional status, a life expectancy of $>1$ year, and where the intent is to increase survival. ${ }^{144,147}$

\subsubsection{Primary prevention of sudden cardiac death} Key evidence

- The Sudden Cardiac Death in Heart Failure Trial (SCD-HeFT) enrolled 2521 patients with non-ischaemic dilated cardiomyopathy or ischaemic HF, no prior symptomatic ventricular arrhythmia, and an EF $\leq 35 \%$ who were in NYHA functional class II or III. These patients were randomized to placebo, amiodarone, or an ICD, in addition to conventional treatment including an ACE inhibitor or ARB (96\%) and a beta-blocker (69\%); MRA use was not reported. ${ }^{149}$

- ICD treatment led to an RRR in death of $23 \%(P=0.007)$ over a median follow-up of 45.5 months. This benefit was additional to that gained with conventional treatment, including an ACE inhibitor and a beta-blocker. Amiodarone did not reduce mortality.
Recommendations for the use of implanted cardioverter defibrillators in patients with heart failure

\begin{tabular}{|l|c|c|c|}
\hline Recommendations & Class $^{\text {a }}$ & Level $^{\mathbf{b}}$ & Ref $^{\text {C }}$ \\
\hline $\begin{array}{l}\text { Secondary prevention } \\
\text { An ICD is recommended in } \\
\text { a patient with a ventricular } \\
\text { arrhythmia causing } \\
\text { haemodynamic instability, who }\end{array}$ & & \\
is expected to survive for \\
$>$ I year with good functional \\
status, to reduce the risk of \\
sudden death.
\end{tabular}

$\mathrm{HF}=$ heart failure; ICD = implantable cardioverter defibrillator; NYHA $=$ New York Heart Association.

${ }^{a}$ Class of recommendation.

bLevel of evidence.

${ }^{\mathrm{c}}$ References.

- The ARR in mortality with an ICD was $6.9 \%$, equating to an NNT (for 45.5 months to postpone one death) of 14 .

- Additional support for the use of ICDs comes from the Multicenter Automatic Defibrillator Implantation Trial II (MADIT-II), ${ }^{148}$ an RCT in which patients with a prior myocardial infarction and an EF $\leq 30 \%$ (59\% of which were in NYHA class II or III) were assigned to receive either conventional treatment or conventional treatment plus an ICD. Use of an ICD led to a 31\% RRR in mortality. Two other RCTs showed no benefit in patients treated with an ICD early ( $\leq 40$ days) after myocardial infarction. ${ }^{150,151}$ This is why ICD use in patients with coronary heart disease receives level of evidence $A$, but only in patients $>40$ days after acute myocardial infarction.

- There is less evidence in patients with non-ischaemic HF, with one moderate sized trial [Defibrillators in Non-ischemic Cardiomyopathy Treatment Evaluation (DEFINITE), $n=458$ ] showing only a non-significant trend to a reduction in mortality; hence the evidence level of $B .^{152}$

- ICD implantation should be considered only after a sufficient period of optimization of medical therapy (at least 3 months) and only if the EF remains persistently low. 
- ICD therapy is not indicated in patients in NYHA class IV with severe, drug-refractory, symptoms who are not candidates for CRT, a ventricular assist device, or cardiac transplantation (because such patients have a very limited life expectancy and are more likely to die from pump failure).

- Patients should be counselled as to the purpose of an ICD and the complications related to its use (predominantly inappropriate shocks). ${ }^{153}$

- If HF deteriorates, deactivation of a patient's ICD may be considered after appropriate discussion with the patient and caregiver(s).

\subsection{Cardiac resynchronization therapy}

Two large RCTs have shown that CRT is of benefit in patients with mild (NYHA class II) symptoms ${ }^{154,155}$ as well as in those who are more severely symptomatic. ${ }^{156,157}$ There is little doubt that patients expected to survive with good functional status for $>1$ year should receive CRT if they are in sinus rhythm, their LVEF is low ( $\leq 30 \%)$, QRS duration is markedly prolonged ( $\geq 150 \mathrm{~ms}$ ), and an ECG shows a left bundle branch morphology, irrespective of symptom severity. There is less consensus about patients with right bundle branch block or interventricular conduction delay (based on subgroup analyses) and those in AF (because most trials excluded these patients and because a high ventricular rate will prevent resychronization). Another area of debate is what to do in an HF-REF patient without an indication for CRT who needs a conventional pacemaker. ${ }^{158}$ The possibility that patients with a QRS duration of $<120 \mathrm{~ms}$ may have 'mechanical dyssynchrony' (detectable by imaging) and might benefit from CRT is another area of research interest but remains to be proven. ${ }^{159,160}$

Recommendations for the use of CRT where the evidence is strong-patients in sinus rhythm with NYHA functional class III and ambulatory class IV heart failure and a persistently reduced ejection fraction, despite optimal pharmacological therapy

\begin{tabular}{|c|c|c|c|}
\hline Recommendations & Class $^{a}$ & Level $^{\mathrm{b}}$ & $\operatorname{Ref}^{c}$ \\
\hline \multicolumn{4}{|l|}{ LBBB QRS morphology } \\
\hline $\begin{array}{l}\text { CRT-P/CRT-D is recommended in patients in sinus rhythm with a QRS duration of } \geq 120 \mathrm{~ms} \text {, LBBB QRS morphology, } \\
\text { and an EF } \leq 35 \% \text {, who are expected to survive with good functional status for }>1 \text { year, to reduce the risk of HF } \\
\text { hospitalization and the risk of premature death. }\end{array}$ & $\mathbf{I}$ & $\mathbf{A}$ & 156,157 \\
\hline \multicolumn{4}{|l|}{ Non-LBBB QRS morphology } \\
\hline $\begin{array}{l}\text { CRT-P/CRT-D should be considered in patients in sinus rhythm with a QRS duration of } \geq 150 \mathrm{~ms} \text {, irrespective of QRS } \\
\text { morphology, and an } \mathrm{EF} \leq 35 \% \text {, who are expected to survive with good functional status for }>1 \text { year, to reduce the risk } \\
\text { of HF hospitalization and the risk of premature death. }\end{array}$ & Ila & $\mathbf{A}$ & 156,157 \\
\hline
\end{tabular}

CRT-D = cardiac resynchronization therapy defibrillator; CRT-P = cardiac resynchronization therapy pacemaker; $E F=$ ejection fraction; $\mathrm{HF}=$ heart failure; $\mathrm{LBBB}=$ left bundle branch block; NYHA = New York Heart Association.

${ }^{a}$ Class of recommendation.

bevel of evidence.

${ }^{\mathrm{c}}$ References.

Recommendations for the use of CRT where the evidence is strong-patients in sinus rhythm with NYHA functional class II heart failure and a persistently reduced ejection fraction, despite optimal pharmacological therapy

\begin{tabular}{|c|c|c|c|}
\hline Recommendations & Class $^{a}$ & Level $^{b}$ & $\operatorname{Ref}^{c}$ \\
\hline \multicolumn{4}{|l|}{ LBBB QRS morphology } \\
\hline $\begin{array}{l}\text { CRT, preferably CRT-D is recommended in patients in sinus rhythm with a } Q R S \text { duration of } \geq 130 \mathrm{~ms} \text {, LBBB QRS } \\
\text { morphology, and an } \mathrm{EF} \leq 30 \% \text {, who are expected to survive for }>\text { I year with good functional status, to reduce the risk } \\
\text { of } \mathrm{HF} \text { hospitalization and the risk of premature death. }\end{array}$ & I & $\mathbf{A}$ & 154,155 \\
\hline \multicolumn{4}{|l|}{ Non-LBBB QRS morphology } \\
\hline $\begin{array}{l}\text { CRT, preferably CRT-D should be considered in patients in sinus rhythm with a QRS duration of } \geq 150 \mathrm{~ms} \text {, irrespective } \\
\text { of QRS morphology, and an } \mathrm{EF} \leq 30 \% \text {, who are expected to survive for }>I \text { year with good functional status, to reduce } \\
\text { the risk of HF hospitalization and the risk of premature death. }\end{array}$ & Ila & $\mathbf{A}$ & 154,155 \\
\hline
\end{tabular}

CRT-D = cardiac resynchronization therapy defibrillator; EF = ejection fraction; HF = heart failure; LBBB = left bundle branch block; NYHA = New York Heart Association ${ }^{\mathrm{a} C l a s s}$ of recommendation.

bLevel of evidence.

'References. 


\subsubsection{Recommendations for cardiac resynchronization therapy where the evidence is certain}

Key evidence supporting the use of cardiac resynchronization therapy

Moderate to severely symptomatic heart failure

- Two key placebo-controlled RCTs [Comparison of Medical Therapy, Pacing, and Defibrillation in Heart Failure (COMPANION) and Cardiac Resynchronization in Heart Failure Study (CARE-HF)] randomized 2333 patients with moderate to severely symptomatic HF (NYHA class III or IV) to either optimal medical therapy or optimal medical therapy plus CRT. ${ }^{156,157}$ Patients in COMPANION were required to be in sinus rhythm, to have an $\mathrm{EF} \leq 35 \%$ and a QRS duration of at least $120 \mathrm{~ms}$, and a HF hospitalization or equivalent in the preceding year. Patients in CARE-HF were required to be in sinus rhythm and to have an $E F \leq 35 \%$, a QRS duration $\geq 120 \mathrm{~ms}$ (if the QRS duration was $120-149 \mathrm{~ms}$ other echocardiographic criteria for dyssynchrony had to be met), and an LV end-diastolic dimension of at least $30 \mathrm{~mm}$ (indexed to height).

- Each of these two trials showed that CRT reduced the risk of death from any cause and hospital admission for worsening HF [RRR in death of $24 \%$ with a CRT-pacemaker (CRT-P) and of $36 \%$ with CRT-defibrillator (CRT-D) in COMPANION and of $36 \%$ with CRT-P in CARE-HF]. In CARE-HF, the RRR in HF hospitalization with CRT-P was $52 \%$. These benefits were additional to those gained with conventional treatment, including a diuretic, digoxin, an ACE inhibitor, a beta-blocker, and an MRA.

- The ARR with CRT-D in the composite outcome of cardiovascular death or cardiovascular hospitalization in COMPANION was $8.6 \%$, equating to an NNT (over a median duration of follow-up of $\sim 16$ months) to postpone one event of 12 . The corresponding figures for CRT-P in CARE-HF (over a mean follow-up of 29 months) were an ARR of $16.6 \%$ and an NNT of 6 .

- These trials also showed that CRT improves symptoms, quality of life, and ventricular function. Other trials showed that these agents improve exercise capacity.

- Because these severely symptomatic patients have much to gain and because there was no subgroup of patients that clearly did not benefit from CRT, individuals in NYHA functional class III and IV have been given the broadest indication for CRT.

Mild to moderately symptomatic HF

- Two key placebo-controlled RCTs randomized 3618 patients with mild (MADIT-CRT, 15\% NYHA class I and 85\% NYHA class II) to moderately [Resynchronization/Defibrillation for Ambulatory Heart Failure Trial (RAFT), 80\% NYHA class II and 20\% NYHA class III] symptomatic HF to either optimal medical therapy plus an ICD or optimal medical therapy plus a CRT-D. ${ }^{154,155}$ Patients in MADIT-CRT were required to have an $\mathrm{EF} \leq 30 \%$, a QRS duration $\geq 130 \mathrm{~ms}$, and to be in sinus rhythm. Patients in RAFT were required to have an EF $\leq 30 \%$ and a QRS duration $\geq 120 \mathrm{~ms}$ ( $13 \%$ of enrolled patients had AF with a well-controlled ventricular rate).
- Each of these two trials showed that CRT reduced the risk of the primary composite endpoint of death or HF hospitalization (HF event in MADIT-CRT) (RRR of $34 \%$ in MADIT-CRT and $25 \%$ in RAFT). There was a $25 \%$ reduction in all-cause mortality in RAFT $(P=0.003)$, but mortality was not reduced in MADIT-CRT. These benefits were additional to those gained with conventional treatment, including a diuretic, digoxin, an ACE inhibitor, a beta-blocker, an MRA, and an ICD.

- The ARR in the primary composite mortality-morbidity endpoint in MADIT-CRT was $8.1 \%$, equating to an NNT (for an average of 2.4 years to postpone one event) of 12 . The equivalent figures for RAFT were ARR 7.1\% and NNT 14 (over an average of 40 months).

- These trials also showed that CRT improves symptoms, quality of life, and ventricular function. Other trials showed that these agents improve exercise capacity.

- Both MADIT-CRT and RAFT showed a significant treatment-bysubgroup interaction whereby QRS duration modified the treatment effect (CRT appeared more effective in patients with a QRS $\geq 150 \mathrm{~ms}$ ) and patients with LBBB also seemed to obtain more benefit than those with right bundle branch block or an interventricular conduction defect (these groups overlap considerably, as patients with LBBB are more likely to have a QRS duration $\geq 150 \mathrm{~ms}$ ). These findings are supported by echocardiographic analyses. ${ }^{161}$ For these reasons, in patients with milder symptoms, CRT is recommended only in those with either a QRS duration $\geq 150 \mathrm{~ms}$ or $\geq 130 \mathrm{~ms}$ plus an LBBB pattern.

\subsubsection{Recommendations for cardiac resynchronization therapy where the evidence is uncertain}

Two commonly encountered clinical situations where there is little robust evidence for (or against) CRT are AF and when a patient with a reduced EF has an indication for conventional pacing and no other indication for CRT.

\section{Atrial fibrillation}

One small, single-blind study [Multisite Stimulation in Cardiomyopathies (MUSTIC)] included 59 HF-REF patients with persistent/permanent AF, a slow ventricular rate necessitating permanent ventricular pacing, and a paced QRS duration $\geq 200 \mathrm{~ms}^{162}$ The study had a crossover design (3 months conventional pacing vs. 3 months CRT). There was a high drop-out rate (42\%) and there was no difference in the primary endpoint of 6-min walk distance. The key large RCTs of CRT all excluded patients in AF, with the exception of RAFT. ${ }^{158}$ RAFT included 229 patients with permanent AF or flutter either with a controlled ventricular rate ( $\leq 60$ b.p.m. at rest and $\leq 90$ b.p.m. during a 6-min walk test) or with planned AV junction ablation. Further analysis did not show a significant interaction between baseline rhythm and treatment effect, but this subgroup represented only a small proportion of the overall population. Other data suggesting that patients with AF (without AV nodal ablation) may benefit from CRT are limited by being observational in nature. ${ }^{163}$

Patients with an indication for conventional pacing

All the major RCTs of CRT, with the exception of RAFT, excluded patients with a conventional indication for pacing. RAFT included 
Recommendations for the use of CRT where the evidence is uncertain-patients with symptomatic HF (NYHA functional class II-IV) and a persistently reduced EF despite optimal pharmacological therapy and in AF or with a conventional pacing indication

\begin{tabular}{|c|c|c|c|}
\hline Recommendations & Class $^{a}$ & Level $^{\mathrm{b}}$ & $\operatorname{Ref}^{c}$ \\
\hline \multicolumn{4}{|l|}{ Patients in permanent AF } \\
\hline $\begin{array}{l}\text { CRT-P/CRT-D may be considered in patients in NYHA functional class III or ambulatory class IV with a QRS duration } \\
\geq I 20 \text { ms and an EF } \leq 35 \% \text {, who are expected to survive with good functional status for }>I \text { year, to reduce the risk of } \\
\text { HF worsening if: } \\
\text { - The patient requires pacing because of an intrinsically slow ventricular rate } \\
\text { - The patient is pacemaker dependent as a result of AV nodal ablation } \\
\text { - The patient's ventricular rate is } \leq 60 \text { b.p.m. at rest and } \leq 90 \text { b.p.m. on exercise. }\end{array}$ & $\begin{array}{l}\text { Ilb } \\
\text { Ila } \\
\text { Ilb }\end{array}$ & $\begin{array}{l}\text { C } \\
\text { B } \\
\text { C }\end{array}$ & $\begin{array}{c}- \\
163 a \\
-\end{array}$ \\
\hline \multicolumn{4}{|l|}{ Patients with an indication for conventional pacing and no other indication for CRT } \\
\hline $\begin{array}{l}\text { In patients who are expected to survive with good functional status for }>\text { I year: } \\
\text { - CRT should be considered in those in NYHA functional class III or IV with an EF } \leq 35 \% \text {, irrespective of QRS } \\
\text { duration, to reduce the risk of worsening of HF } \\
\text { - CRT may be considered in those in NYHA functional class II with an EF } \leq 35 \% \text {, irrespective of QRS duration, to } \\
\text { reduce the risk of worsening of HF. }\end{array}$ & $\begin{array}{l}\text { Ila } \\
\text { Ilb }\end{array}$ & $\begin{array}{l}\mathrm{C} \\
\mathrm{C}\end{array}$ & $\begin{array}{l}- \\
-\end{array}$ \\
\hline
\end{tabular}

CRT-D = cardiac resynchronization therapy defibrillator; CRT-P = cardiac resynchronization therapy pacemaker; EF = ejection fraction; HF $=$ heart failure; NYHA = New York Heart Association.

${ }^{\mathrm{a}}$ Class of recommendation.

'Level of evidence.

${ }^{\mathrm{c}}$ References.

135 patients with a paced QRS duration $\geq 200 \mathrm{~ms}$, a subgroup too small for meaningful analysis. ${ }^{155}$ Conventional right ventricular pacing, however, alters the normal sequence of cardiac activation in a similar way to LBBB, and experimental and observational data suggest that this may lead to deterioration in LV systolic function. ${ }^{164,165}$ It is on this basis that CRT is recommended as an alternative to conventional right ventricular pacing in patients with HF-REF who have a standard indication for pacing or who require a generator change or revision of a conventional pacemaker.

\section{Arrhythmias, bradycardia, and atrioventricular block in patients with heart failure with reduced ejection fraction and heart failure with preserved ejection fraction}

The management of arrhythmias is discussed in other ESC guidelines, ${ }^{143,166}$ and this section focuses only on aspects that are particularly relevant to patients with HF.

\subsection{Atrial fibrillation}

AF is the most common arrhythmia in HF; it increases the risk of thrombo-embolic complications (particularly stroke) and may lead to worsening of symptoms. Whether AF is an independent predictor of mortality is less certain, as is whether it can cause systolic HF ('tachycardiomyopathy').

AF should be classified and managed according to the current AF guidelines (i.e. first episode, paroxysmal, persistent, long- standing persistent, or permanent), recognizing the uncertainty about the actual duration of the episode and about previous undetected episodes. ${ }^{166}$

The following issues need to be considered in patients with HF and AF, especially a first episode of AF or paroxysmal AF:

- Identification of correctable causes (e.g. hyperthyroidism, electrolyte disorders, uncontrolled hypertension, mitral valve disease).

- Identification of potential precipitating factors (e.g. recent surgery, chest infection or exacerbation of chronic pulmonary disease/asthma, acute myocardial ischaemia, alcohol binge) as this may determine whether a rhythm-control strategy is preferred to a rate-control strategy.

- Assessment for thromboembolism prophylaxis.

\subsubsection{Rate control}

An approach to controlling the ventricular rate in patients with HF and AF is shown in Figure 3. Recommendations for stepwise use of individual treatments in patients with HF-REF are given below.

For rate control in patients with HF-REF, a beta-blocker is preferred over digoxin as the latter does not provide rate control during exercise. ${ }^{167}$ Furthermore, beta-blockers have favourable effects on mortality and morbidity in systolic HF per se (see above). The combination of digoxin and a beta-blocker is more effective than a beta-blocker alone in controlling the ventricular rate at rest. ${ }^{168}$

In patients with HF-PEF, rate-limiting CCBs (verapamil and diltiazem) are an effective alternative to a beta-blocker (but their use is not recommended in patients with HF-REF as their negative inotropic action may further depresses LV systolic function). ${ }^{134,167}$ 


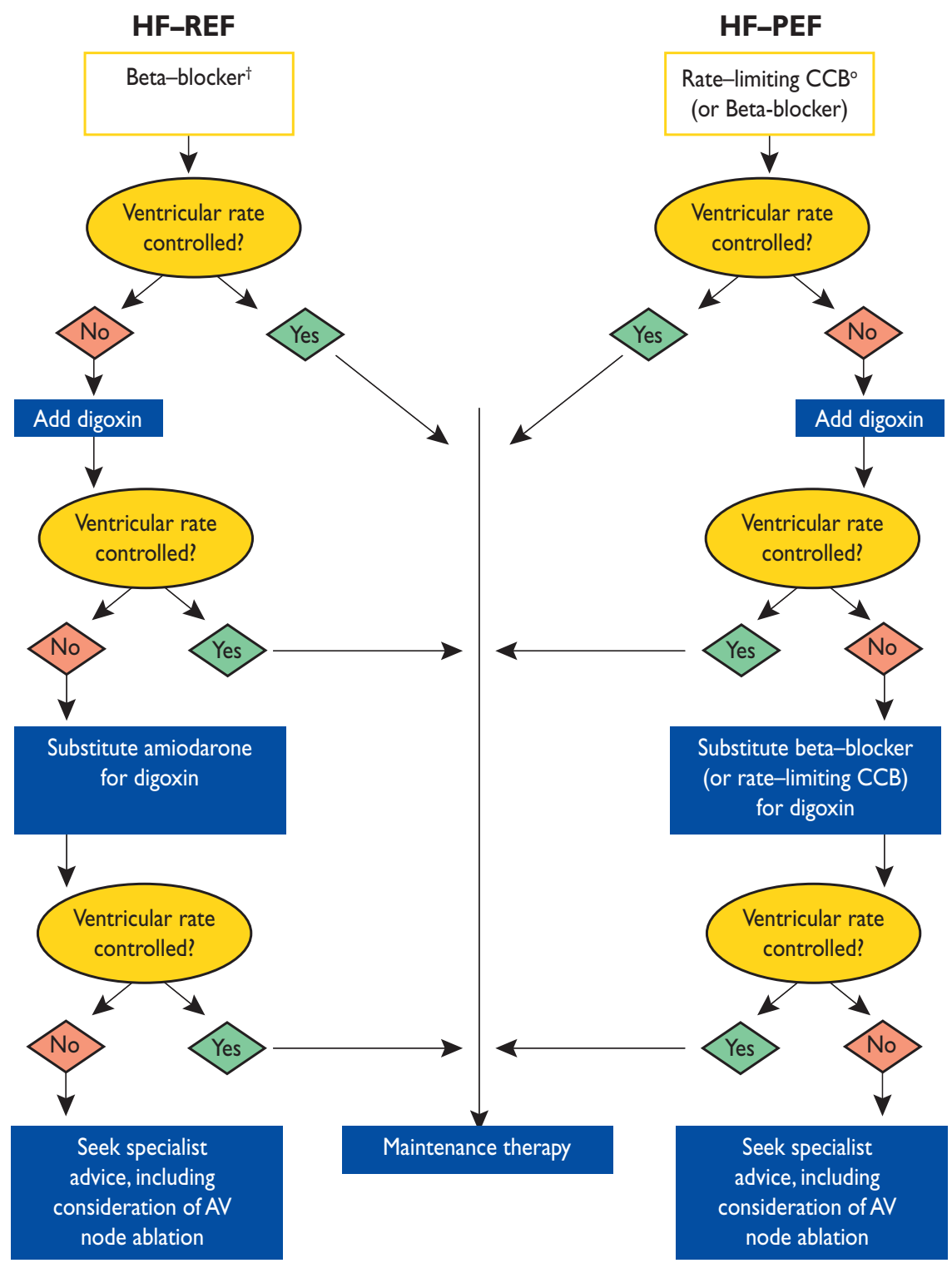

*Thrombo-embolism prophylaxis should also be considered in parallel.

†Beta-blocker treatment can cause worsening in acutely decompensated patients with HF-REF (see section on acute heart failure).

${ }^{\circ}$ Rate-limiting CCBs should be avoided in HF-REF.

$\mathrm{AV}=$ atrioventricular; $\mathrm{CCB}=$ calcium-channel blocker; HF-PEF = heart failure with preserved ejection fraction; $\mathrm{HF}-\mathrm{REF}=$ heart failure with reduced ejection fraction.

Figure 3 Recommendations for controlling the ventricular rate in patients with heart failure and persistent/permanent atrial fibrillation and no evidence of acute decompensation*.

The combination of digoxin and a rate-limiting CCB is more effective than a CCB alone in controlling the ventricular rate at rest. ${ }^{169}$

Assessment of control of the ventricular rate on exertion requires either ambulatory ECG monitoring or measurement of the rate during moderate exercise. The optimum ventricular rate in patients with $\mathrm{HF}$ and $\mathrm{AF}$ is uncertain because the one RCT comparing strict with lenient rate control included very few patients with $\mathrm{HF}^{170}$ In the Atrial Fibrillation and Congestive Heart Failure (AF-CHF) study (which showed similar outcomes for a ratecontrol compared with a rhythm-control strategy) the target rate was $<80$ b.p.m. at rest and $<110$ b.p.m. during a 6 -min walk test. ${ }^{171}$

In extreme cases, $\mathrm{AV}$ node ablation and pacing may be required; in this situation in patients with systolic HF, CRT may be considered instead of conventional pacing (see Section 9.2). ${ }^{164}$

\subsubsection{Rhythm control}

In patients with chronic HF, a rhythm-control strategy (including pharmacological or electrical cardioversion) has not been demonstrated to be superior to a rate-control strategy in reducing 
Recommendations for controlling the ventricular rate in patients with symptomatic HF (NYHA functional class II-IV), LV systolic dysfunction, persistent/permanent AF and no evidence of acute decompensation

\begin{tabular}{|c|c|c|c|}
\hline Recommendations & Class $^{\mathbf{a}}$ & Level $^{\mathrm{b}}$ & $\operatorname{Ref}^{\mathrm{C}}$ \\
\hline \multicolumn{4}{|l|}{ Step I: A beta-blocker } \\
\hline $\begin{array}{l}\text { A beta-blocker is recommended as the preferred first-line treatment to control the ventricular rate because of the } \\
\text { associated benefits of this treatment (reducing the risk of hospitalization for worsening HF and reducing the risk of } \\
\text { premature death). }\end{array}$ & $\mathbf{I}$ & A & $92-98$ \\
\hline \multicolumn{4}{|l|}{ Alternative Step I treatment } \\
\hline (i) Digoxin is recommended in patients unable to tolerate a beta-blocker & $\mathbf{I}$ & B & 113 \\
\hline (ii) Amiodarone may be considered in patients unable to tolerate a beta-blocker or digoxin. & Illb & C & - \\
\hline $\begin{array}{l}\text { (iii) AV node ablation and pacing (possibly CRT) may be considered in patients unable to tolerate any of a beta-blocker, } \\
\text { digoxin, or amiodarone. }\end{array}$ & Illb & C & - \\
\hline \multicolumn{4}{|l|}{ Step 2: Digoxin } \\
\hline $\begin{array}{l}\text { Digoxin is recommended as the preferred second drug, in addition to a beta-blocker, to control the ventricular rate in } \\
\text { patients with an inadequate response to a beta-blocker. }\end{array}$ & $\mathbf{I}$ & $\mathbf{B}$ & 113 \\
\hline \multicolumn{4}{|l|}{ Alternative Step 2 treatment } \\
\hline $\begin{array}{l}\text { (i) Amiodarone may be considered in addition to either a beta-blocker or digoxin (but not both) to control the } \\
\text { ventricular rate in patients with an inadequate response and unable to tolerate the combination of both a beta-blocker } \\
\text { and digoxin. }\end{array}$ & Ilb & C & - \\
\hline $\begin{array}{l}\text { (ii) AV node ablation and pacing (possibly CRT) may be considered in patients with an inadequate response to two of } \\
\text { three of a beta-blocker, digoxin and amiodarone. }\end{array}$ & Ilb & C & - \\
\hline $\begin{array}{l}\text { No more than two of three of a beta-blocker, digoxin, and amiodarone (or any other drug suppressing cardiac } \\
\text { conduction) should be considered because of the risk of severe bradycardia, third-degree AV block, and asystole. }\end{array}$ & Illa & C & - \\
\hline
\end{tabular}

$\mathrm{AF}=$ atrial fibrillation; $\mathrm{AV}=$ atrioventricular; $\mathrm{EF}=$ ejection fraction; $\mathrm{HF}=$ heart failure; $\mathrm{LV}=$ left ventricular; NYHA = New York Heart Association.

${ }^{\mathrm{a} C l a s s}$ of recommendation.

bevel of evidence.

${ }^{c}$ References.

mortality or morbidity. ${ }^{171}$ This strategy is probably best reserved for patients with a reversible secondary cause of AF (e.g. hyperthyroidism) or an obvious precipitant (e.g. recent pneumonia) and in patients who cannot tolerate AF after optimization of rate control and $\mathrm{HF}$ therapy. Amiodarone is the only antiarrhythmic that should be used in patients with systolic HF. ${ }^{172,173}$ The role of catheter ablation as a rhythm control strategy in $\mathrm{HF}$ is at present uncertain. ${ }^{174,175}$

In patients with AHF, emergency cardioversion may be required to correct profound haemodynamic instability (see Section 12.2).

\subsubsection{Thrombo-embolism prophylaxis}

Thrombo-embolism prophylaxis in patients with $\mathrm{HF}$ and AF should be based on the Cardiac failure, Hypertension, Age $\geq 75$ (Doubled), Diabetes, Stroke (Doubled)-Vascular disease, Age 65-74 and Sex category (Female) $\left(\mathrm{CHA}_{2} \mathrm{DS}_{2}\right.$-VASc) score (see Table 17), in keeping with the 2010 ESC AF guidelines. ${ }^{166,179}$ Most patients with systolic HF will have a risk score consistent with a firm indication for (score $\geq 2$ ), or preference for, an oral anticoagulant (score $=1$ ), although bleeding risk must also be considered (see below).

The Hypertension, Abnormal renal/liver function (1 point each), Stroke, Bleeding history or predisposition, Labile INR, Elderly
(>65), Drugs/alcohol concomitantly (1 point each) (HAS-BLED score) (Table 18) is recommended to assess bleeding risk, in keeping with the 2010 ESC AF guidelines. ${ }^{166,180}$ A substantial proportion of patients with HF will have a score $\geq 3$, indicating that careful consideration should be given before prescribing an oral anticoagulant and that regular review is needed (and correctable risk factors addressed) if an oral anticoagulant is given.

Some new anticoagulant drugs such as the oral direct thrombin inhibitors and oral factor $\mathrm{Xa}$ inhibitors are contraindicated in severe renal impairment (creatinine clearance $<30 \mathrm{~mL} / \mathrm{min}$ ). ${ }^{181-}$ 183 This is clearly a concern in many patients with HF and, if these drugs are used, serial monitoring of renal function is required. There is no known way to reverse the anticoagulant action of these new drugs.

\subsection{Ventricular arrhythmias}

Ventricular arrhythmias are frequent in HF patients, particularly in those with a dilated left ventricle and reduced EF. Ambulatory ECG recording detects premature ventricular complexes in virtually all HF patients, and episodes of asymptomatic, non-sustained ventricular tachycardia are common. ${ }^{143}$ Historical studies have suggested that 'complex ventricular arrhythmias' (frequent premature ventricular complexes and non-sustained ventricular 
Recommendations for a rhythm control-management strategy in patients with AF, symptomatic HF (NYHA functional class II-IV), and LV systolic dysfunction and no evidence of acute decompensation

\begin{tabular}{|l|c|c|c|}
\hline Recommendations & Class $^{\mathbf{a}}$ & Level $^{\mathbf{b}}$ & Ref $^{\mathbf{C}}$ \\
\hline $\begin{array}{l}\text { Electrical cardioversion or } \\
\text { pharmacological cardioversion } \\
\text { with amiodarone may be } \\
\text { considered in patients with } \\
\text { persisting symptoms and/or } \\
\text { signs of HF, despite optimum } \\
\text { pharmacological treatment } \\
\text { and adequate control of the } \\
\text { ventricular rate, to improve } \\
\text { clinical/symptomatic status. }\end{array}$ & Ilb & C & - \\
\hline $\begin{array}{l}\text { Amiodarone may be } \\
\text { considered prior to (and } \\
\text { following) successful electrical } \\
\text { cardioversion to maintain } \\
\text { sinus rhythm. }\end{array}$ & Ilb & C & - \\
\hline $\begin{array}{l}\text { Dronedarone is not } \\
\text { recommended because of } \\
\text { an increased risk of hospital } \\
\text { admissions for cardiovascular } \\
\text { causes and an increased risk of } \\
\text { premature death. }\end{array}$ & III & A & I76, I77 \\
\hline $\begin{array}{l}\text { Class I antiarrhythmic agents } \\
\text { are not recommended } \\
\text { because of an increased risk of } \\
\text { premature death. }\end{array}$ & III & \\
\hline
\end{tabular}

$A F=$ atrial fibrillation; $E F=$ ejection fraction; $H F=$ heart failure; $L V=$ left ventricular; NYHA = New York Heart Association.

${ }^{\mathrm{a}}$ Class of recommendation.

bevel of evidence.

'References.

tachycardia) are associated with a poor outcome in HF. Certain recommendations from the American College of Cardiology/ American Heart Association/ESC guidelines on the management of ventricular arrhythmias and sudden death, which may be particularly relevant to patients with HF, are summarized below. The role of catheter ablation in patients with HF other than as an adjunct in the treatment of refractory ventricular arrhythmias is uncertain. $^{186}$ The reader is also referred to the section on ICDs (Section 9.1).

\subsection{Symptomatic bradycardia and atrioventricular block}

Although the indications for pacing in patients with HF are similar to those in other patients, as described in the ESC guidelines on pacing, ${ }^{165}$ there are issues specific to $\mathrm{HF}$, including:

- Before implanting a conventional pacemaker in a patient with HF-REF, consider whether there is an indication for an ICD, CRT-P, or CRT-D (see Sections 9.1 and 9.2).
Table 17 Assessment of stroke risk in patients with atrial fibrillation

\begin{tabular}{|c|c|}
\hline \multicolumn{2}{|l|}{$\mathrm{CHA}_{2} \mathrm{DS}_{2}-\mathrm{VASc}$} \\
\hline Congestive HF or LVEF $\leq 40 \%$ & 1 \\
\hline Hypertension & I \\
\hline Age $\geq 75$ years & 2 \\
\hline Diabetes mellitus & I \\
\hline Stroke, transient ischaemic attack, or thrombo-embolism & 2 \\
\hline $\begin{array}{l}\text { Vascular disease (previous myocardial infarction, peripheral } \\
\text { artery disease, or aortic plaque) }\end{array}$ & 1 \\
\hline Age $65-74$ years & I \\
\hline Sex category (i.e. female sex) & 1 \\
\hline Maximum score & 9 \\
\hline \multicolumn{2}{|l|}{$\mathrm{CHA}_{2} \mathrm{DS}_{2}-\mathrm{VASc}$ score $=0$ : recommend no antithrombotic therapy. } \\
\hline \multicolumn{2}{|c|}{$\begin{array}{l}\mathrm{CHA}_{2} \mathrm{DS}_{2}-\mathrm{VASc} \text { score }=1 \text { : recommend antithrombotic therapy with oral } \\
\text { anticoagulation or antiplatelet therapy, but preferably oral anticoagulation }\end{array}$} \\
\hline $\mathrm{CHA}_{2} \mathrm{DS}_{2}$-VASc score $=2$ : recommend oral anticoagulation. & \\
\hline
\end{tabular}

$\mathrm{CHA}_{2} \mathrm{DS}_{2}-\mathrm{VASc}=$ Cardiac failure, Hypertension, Age $\geq 75$ (Doubled), Diabetes, Stroke (Doubled), Vascular disease, Age 65-74, and Sex category (Female); HF = heart failure; LVEF = left ventricular ejection fraction.

Table 18 Assessment of bleeding risk in patients with atrial fibrillation

\begin{tabular}{|c|c|}
\hline \multicolumn{2}{|l|}{ HAS-BLED } \\
\hline Hypertension (systolic blood pressure $>160 \mathrm{mmHg}$ ) & 1 \\
\hline Abnormal renal and liver function (I point each) & I or 2 \\
\hline Stroke & I \\
\hline Bleeding tendency or predisposition & I \\
\hline Labile international normalized ratio (if on warfarin) & 1 \\
\hline Elderly (e.g. age > 65 years) & I \\
\hline $\begin{array}{l}\text { Drugs (e.g. concomitant aspirin, NSAID) or alcohol } \\
\text { (I point each) }\end{array}$ & I or 2 \\
\hline Maximum score & 9 \\
\hline \multicolumn{2}{|c|}{$\begin{array}{l}\text { A HAS-BLED score } \geq 3 \text { suggests that caution is warranted when } \\
\text { prescribing oral anticoagulation and regular review is recommended. }\end{array}$} \\
\hline
\end{tabular}

HAS-BLED = Hypertension, Abnormal renal/liver function (1 point each), Stroke, Bleeding history or predisposition, Labile international normalized ratio, Elderly $(>65)$, Drugs/alcohol concomitantly (1 point each); NSAID = non-steroidal anti-inflammatory drug.

- Because right ventricular pacing may induce dyssynchrony and worsen symptoms, CRT should be considered instead of conventional pacing in patients with HF-REF (see Section 9.2). 
Recommendations for the prevention of thromboembolism in patients with symptomatic HF (NYHA functional class IIIV) and paroxysmal or persistent/permanent AF

\begin{tabular}{|c|c|c|c|}
\hline Recommendations & Class $^{a}$ & Level $^{\mathrm{b}}$ & $\operatorname{Ref}^{c}$ \\
\hline $\begin{array}{l}\text { The } \mathrm{CHA}_{2} \mathrm{DS}_{2}-\mathrm{VASC} \text { and HAS-BLED scores (Tables } 17 \text { and } 18 \text { ) are recommended to determine the likely risk-benefit } \\
\text { (thrombo-embolism prevention vs. risk of bleeding) of oral anticoagulation. }\end{array}$ & I & B & 179,180 \\
\hline $\begin{array}{l}\text { An oral anticoagulant is recommended for all patients with paroxysmal or persistent/permanent } A F \text { and a } \\
\mathrm{CHA}_{2} \mathrm{DS}_{2}-\mathrm{VASc} \text { score } \geq 1 \text {, without contraindications, and irrespective of whether a rate- or rhythm-management } \\
\text { strategy is used (including after successful cardioversion). }\end{array}$ & I & $\mathbf{A}$ & 184 \\
\hline $\begin{array}{l}\text { In patients with } A F \text { of } \geq 48 \mathrm{~h} \text { duration, or when the known duration of } A F \text { is unknown, an oral anticoagulant is } \\
\text { recommended at a therapeutic dose for } \geq 3 \text { weeks prior to electrical or pharmacological cardioversion. }\end{array}$ & I & C & - \\
\hline $\begin{array}{l}\text { Intravenous heparin or } \mathrm{LMWH} \text { is recommended for patients who have not been treated with an anticoagulant and } \\
\text { require urgent electrical or pharmacological cardioversion. }\end{array}$ & I & C & - \\
\hline $\begin{array}{l}\text { Alternative to i.v. heparin or LMWH } \\
\text { A TOE-guided strategy may be considered for patients who have not been treated with an anticoagulant and require } \\
\text { urgent electrical or pharmacological cardioversion. }\end{array}$ & Ilb & C & - \\
\hline $\begin{array}{l}\text { Combination of an oral anticoagulant and an antiplatelet agent is not recommended in patients with chronic ( }>12 \\
\text { months after an acute event) coronary or other arterial disease, because of a high risk of serious bleeding. Single } \\
\text { therapy with an oral anticoagulant is preferred after } 12 \text { months. }\end{array}$ & III & $\mathbf{A}$ & 185 \\
\hline
\end{tabular}

$\mathrm{AF}=$ atrial fibrillation; $\mathrm{CHA}_{2} \mathrm{DS}_{2}-\mathrm{VASc}=$ Cardiac failure, Hypertension, Age $\geq 75$ (Doubled), Diabetes, Stroke (Doubled), Vascular disease, Age $65-74$ and Sex category (Female); EF = ejection fraction; HAS-BLED = Hypertension, Abnormal renal/liver function (1 point each), Stroke, Bleeding history or predisposition, Labile international normalized ratio, Elderly (>65), Drugs/alcohol concomitantly (1 point each); HF = heart failure; i.v. = intravenous; LMWH = low molecular weight heparin; LV = left ventricular; $\mathrm{NYHA}=$ New York Heart Association; TOE = transoesophageal echocardiography.

${ }^{a}$ Class of recommendation.

bevel of evidence.

'References.

\section{Recommendations for the management of ventricular arrhythmias in heart failure}

\begin{tabular}{|c|c|c|c|}
\hline Recommendations & Class $^{\mathrm{a}}$ & Level $^{\mathrm{b}}$ & $\operatorname{Ref}^{c}$ \\
\hline $\begin{array}{l}\text { It is recommended that potential aggravating/precipitating factors (e.g. electrolyte disorders, use of proarrhythmic } \\
\text { drugs, myocardial ischaemia) should be sought and corrected in patients with ventricular arrhythmias. }\end{array}$ & I & C & - \\
\hline $\begin{array}{l}\text { It is recommended that treatment with an ACE inhibitor (or ARB), beta-blocker, and MRA should be optimized in } \\
\text { patients with ventricular arrhythmias. }\end{array}$ & I & $\mathbf{A}$ & $87-100$ \\
\hline $\begin{array}{l}\text { It is recommended that coronary revascularization is considered in patients with ventricular arrhythmias and coronary } \\
\text { artery disease (see Section 13.2). }\end{array}$ & I & C & - \\
\hline $\begin{array}{l}\text { It is recommended that an ICD is implanted in a patient with symptomatic or sustained ventricular arrhythmia } \\
\text { (ventricular tachycardia or ventricular fibrillation), reasonable functional status, and in whom a goal of treatment is to } \\
\text { improve survival. }\end{array}$ & I & $\mathbf{A}$ & $144-149$ \\
\hline $\begin{array}{l}\text { Amiodarone is recommended in patients with an ICD, who continue to have symptomatic ventricular arrhythmias or } \\
\text { recurrent shocks despite optimal treatment and device re-programming. }\end{array}$ & I & C & - \\
\hline $\begin{array}{l}\text { Catheter ablation is recommended in patients with an ICD who continue to have ventricular arrhythmias causing } \\
\text { recurrent shocks not preventable by optimal treatment device re-programming and amiodarone. }\end{array}$ & I & C & - \\
\hline $\begin{array}{l}\text { Amiodarone may be considered as a treatment to prevent recurrence of sustained symptomatic ventricular } \\
\text { arrhythmias in otherwise optimally treated patients in whom an ICD is not considered appropriate. }\end{array}$ & Illb & C & - \\
\hline $\begin{array}{l}\text { Routine use of amiodarone is not recommended in patients with non-sustained ventricular arrhythmias because of } \\
\text { lack of benefit and potential drug toxicity. }\end{array}$ & III & $\mathbf{A}$ & 172,173 \\
\hline $\begin{array}{l}\text { Other antiarrhythmic drugs (particularly class IC agents and dronedarone) should not be used in patients with systolic } \\
\text { HF because of safety concerns (worsening HF, proarrhythmia, and death). }\end{array}$ & III & $\mathbf{A}$ & 176,178 \\
\hline
\end{tabular}

$\mathrm{ACE}=$ angiotensin-converting enzyme; $\mathrm{ARB}=$ angiotensin receptor blocker; $\mathrm{HF}=$ heart failure; ICD = implantable cardioverter-defibrillator; $\mathrm{MRA}=$ mineralocorticoid receptor antagonist.

${ }^{\mathrm{a}}$ Class of recommendation.

bLevel of evidence.

${ }^{c}$ References. 
- Physiological pacing to maintain an adequate chronotropic response and maintain atrial-ventricular coordination with a DDD system is preferable to $\mathrm{VVI}$ pacing in patients with both HF-REF and HF-PEF. ${ }^{165}$

- Pacing solely in order to permit initiation or titration of betablocker therapy in the absence of a conventional indication is not recommended.

\section{Importance and management of other co-morbidity in heart failure with reduced ejection fraction and heart failure with preserved ejection fraction}

\subsection{Heart failure and co-morbidities}

Co-morbidities are important in patients with HF for four main reasons. First, co-morbidities may affect the use of treatments for HF (e.g. it may not be possible to use renin-angiotensin system inhibitors is some patients with renal dysfunction) (see Section 7.2). Secondly, the drugs used to treat co-morbidities may cause worsening of HF (e.g. NSAIDs given for arthritis) (see Section 7.4). Thirdly, the drugs used to treat HF and those used to treat co-morbidities may also interact with one another [e.g. beta-blockers and beta-agonists for chronic obstructive pulmonary disease (COPD) and asthma] and reduce patient adherence. Lastly, most co-morbidities are associated with worse clinical status and are predictors of poor prognosis in HF (e.g. diabetes). This has led to some co-morbidities themselves becoming targets for treatment (e.g. anaemia). ${ }^{187}$

Management of co-morbidities is a key component of the holistic care of patients with HF (see Section 14).

\subsection{Anaemia}

Anaemia (defined as a haemoglobin concentration $<13 \mathrm{~g} / \mathrm{dL}$ in men and $<12 \mathrm{~g} / \mathrm{dL}$ in women) is common in HF, particularly in hospitalized patients. It is more frequent in women, the elderly, and in patients with renal impairment. Anaemia is associated with more symptoms, worse functional status, greater risk of HF hospitalization, and reduced survival. A standard diagnostic work-up should be undertaken in anaemic patients. Correctable causes should be treated in the usual way, although no definite aetiology is identified in many patients. Correction of iron deficiency using i.v. iron has been specifically studied in patients with HF (see Section 11.14). The value of erythropoietin-stimulating agents as a treatment for anaemia of unknown aetiology is unknown but is currently being tested in a large mortalitymorbidity RCT. ${ }^{187}$

\subsection{Angina}

Beta-blockers are effective agents for angina as well as an essential treatment for systolic HF. Certain other effective antianginal drugs have been studied in large numbers of patients with systolic HF and shown to be safe (e.g. amlodipine, ${ }^{188,189}$ ivabradine, ${ }^{112,122}$ and nitrates $\left.^{114-116}\right)$. The safety of other antianginal agents such as nicorandil and ranolazine is uncertain, while other drugs, specifically dilatiazem and verapamil, are thought to be unsafe in patients with HF-REF (although they may be used in HF-PEF). ${ }^{134}$ Percutaneous and surgical revascularization are alternative approaches to the treatment of angina (see Section 13). Coronary artery bypass graft surgery may reduce morbidity and mortality in patients with HF-REF.

\subsection{Asthma: see chronic obstructive pulmonary disease}

See Section 11.7.

\subsection{Cachexia}

A generalized process, wasting all body compartments [i.e. lean tissue (skeletal muscle), fat tissue (energy reserves), and bone tissue (osteoporosis)], may occur in $10-15 \%$ of patients with $\mathrm{HF}$, especially those with HF-REF. This serious complication is associated with worse symptoms and functional capacity, more frequent hospitalization, and decreased survival. Cachexia is specifically defined as involuntary non-oedematous weight loss $\geq 6 \%$ of total body weight within the previous 6-12 months. ${ }^{192}$ The causes are uncertain, but may include poor nutrition, malabsorption, impaired calorie and protein balance, hormone resistance, pro-inflammatory immune activation, neurohormonal derangements, and reduced anabolic drive. Potential treatments include appetite stimulants, exercise training, and anabolic agents (insulin, anabolic steroids) in combination with the application of nutritional supplements, although none is of proven benefit and their safety is unknown.

\subsection{Cancer}

Certain chemotherapeutic agents can cause (or aggravate) LV systolic dysfunction and HF. The best recognized of these are the anthracyclines (e.g. doxorubicin) and trastuzumab. ${ }^{193,194}$ Dexrazoxane may confer some cardioprotection in patients receiving anthracyclines. Pre- and post-evaluation of EF is essential in patients receiving cardiotoxic chemotherapy, as detailed elsewhere. ${ }^{193,194}$ Patients developing LV systolic dysfunction should not receive further chemotherapy and should receive standard treatment for HF-REF. Mediastinal irradiation can also lead to a variety of long-term cardiac complications, although the less frequent use of high-dose, wide-field radiotherapy has led to a decline in these problems.

\subsection{Chronic obstructive pulmonary disease}

COPD and asthma may cause diagnostic difficulties, especially in HF-PEF. ${ }^{24,25}$ These conditions are associated with worse functional status and a worse prognosis. Beta-blockers are contraindicated in asthma but not in COPD, although a selective beta-1 adrenoceptor antagonist (i.e. bisoprolol, metoprolol succinate, or nebivolol) is preferred. ${ }^{195}$ Oral corticosteroids cause sodium and water retention, potentially leading to worsening of HF, but this is not believed to be a problem with inhaled corticosteroids. COPD is an independent predictor of worse outcomes in HF. 
Recommendations for the pharmacological treatment of stable angina pectoris in patients with symptomatic HF (NYHA functional class II-IV) and LV systolic dysfunction

\begin{tabular}{|c|c|c|c|}
\hline Recommendations & Class $^{\mathrm{a}}$ & Level $^{\mathrm{b}}$ & $\operatorname{Ref}^{\mathrm{C}}$ \\
\hline \multicolumn{4}{|l|}{ Step I: A beta-blocker } \\
\hline $\begin{array}{l}\text { A beta-blocker is recommended as the preferred first-line treatment to relieve angina because of the associated } \\
\text { benefits of this treatment (reducing the risk of HF hospitalization and the risk of premature death). }\end{array}$ & $\mathbf{I}$ & $\mathbf{A}$ & $92-98$ \\
\hline \multicolumn{4}{|l|}{ Alternatives to a beta-blocker: } \\
\hline $\begin{array}{l}\text { (i) Ivabradine should be considered in patients in sinus rhythm who cannot tolerate a beta-blocker, to relieve angina } \\
\text { (effective antianginal treatment and safe in HF). }\end{array}$ & Ila & $\mathbf{A}$ & 112,122 \\
\hline $\begin{array}{l}\text { (ii) An oral or transcutaneous nitrate should be considered in patients unable to tolerate a beta-blocker, to relieve } \\
\text { angina (effective antianginal treatment and safe in HF). }\end{array}$ & Illa & $\mathbf{A}$ & $114-116$ \\
\hline $\begin{array}{l}\text { (iii) Amlodipine should be considered in patients unable to tolerate a beta-blocker, to relieve angina (effective } \\
\text { antianginal treatment and safe in HF). }\end{array}$ & Ila & $\mathbf{A}$ & 188,189 \\
\hline $\begin{array}{l}\text { (iv) Nicorandil may be considered in patients unable to tolerate a beta-blocker, to relieve angina (effective antianginal } \\
\text { treatment but safety in HF uncertain). }\end{array}$ & Illb & C & - \\
\hline $\begin{array}{l}\text { (v) Ranolazine may be considered in patients unable to tolerate a beta-blocker, to relieve angina (effective antianginal } \\
\text { treatment but safety in HF uncertain). }\end{array}$ & Illb & C & - \\
\hline \multicolumn{4}{|l|}{ Step 2: Add a second anti-anginal drug } \\
\hline \multicolumn{4}{|c|}{ The following may be added to a beta-blocker (or alternative)-taking account of the combinations not recommended below. } \\
\hline $\begin{array}{l}\text { The addition of ivabradine is recommended when angina persists despite treatment with a beta-blocker (or alternative), } \\
\text { to relieve angina (effective antianginal treatment and safe in HF). }\end{array}$ & I & $\mathbf{A}$ & 112,122 \\
\hline $\begin{array}{l}\text { The addition of an oral or transcutaneous nitrate is recommended when angina persists despite treatment with a } \\
\text { beta-blocker (or alternative), to relieve angina (effective antianginal treatment and safe in HF). }\end{array}$ & I & $\mathbf{A}$ & $114-116$ \\
\hline $\begin{array}{l}\text { The addition of amlodipine is recommended when angina persists despite treatment with a beta-blocker (or alternative), } \\
\text { to relieve angina (effective antianginal treatment and safe in HF). }\end{array}$ & 1 & A & 188,189 \\
\hline $\begin{array}{l}\text { The addition of nicorandil may be considered when angina persists despite treatment with a beta-blocker (or alternative), } \\
\text { to relieve angina (effective antianginal treatment but safety in HF uncertain). }\end{array}$ & Illb & C & - \\
\hline $\begin{array}{l}\text { The addition of ranolazine may be considered when angina persists despite treatment with a beta-blocker (or alternative), } \\
\text { to relieve angina (effective antianginal treatment but safety in HF uncertain). }\end{array}$ & Illb & C & - \\
\hline \multicolumn{4}{|l|}{ Step 3: Coronary revascularization } \\
\hline $\begin{array}{l}\text { Coronary revascularization is recommended when angina persists despite treatment with two antianginal drugs } \\
\text { (see Section 13). }\end{array}$ & 1 & $\mathbf{A}$ & 190,191 \\
\hline $\begin{array}{l}\text { Alternatives to coronary revascularization: } \\
\text { A third antianginal drug from those listed above may be considered when angina persists despite treatment with } \\
\text { two antianginal drugs (excluding the combinations not recommended below). }\end{array}$ & Illb & C & - \\
\hline \multicolumn{4}{|l|}{ The following are NOT recommended } \\
\hline (i) Combination of any of ivabradine, ranolazine, and nicorandil because of unknown safety. & III & C & - \\
\hline (ii) Combination of nicorandil and a nitrate (because of lack of additional efficacy). & III & C & - \\
\hline Diltiazem or verapamil are not recommended because of their negative inotropic action and risk of worsening $\mathrm{HF}$ & III & B & 134 \\
\hline
\end{tabular}

$E F=$ ejection fraction; $H F=$ heart failure; $L V$, left ventricular; NYHA = New York Heart Association.

${ }^{\mathrm{a}}$ Class of recommendation.

bevel of evidence.

'References.

\subsection{Depression}

Depression is common and is associated with worse clinical status and a poor prognosis in HF. It may also contribute to poor adherence and social isolation. A high index of suspicion is needed to make the diagnosis, especially in the elderly. Routine screening using a validated questionnaire is good practice. Psychosocial intervention and pharmacological treatment are helpful. Selective serotonin reuptake inhibitors are thought to be safe, whereas tricyclic antidepressants are not because they may cause hypotension, worsening HF, and arrhythmias. ${ }^{196}$

\subsection{Diabetes}

Dysglycaemia and diabetes are very common in HF, and diabetes is associated with poorer functional status and worse prognosis. 
Diabetes may be prevented by treatment with ARBs and possibly ACE inhibitors. ${ }^{197}$ Beta-blockers are not contraindicated in diabetes and are as effective in improving outcome in diabetic patients as in non-diabetic individuals, although different beta-blockers may have different effects on glycaemic indices. ${ }^{198}$ Thiazolidinediones (glitazones) cause sodium and water retention and increased risk of worsening HF and hospitalization, and should be avoided (see recommendations, Section 7.4). ${ }^{131-133}$ Metformin is not recommended in patients with severe renal or hepatic impairment because of the risk of lactic acidosis, but is widely (and apparently safely) used in other patients with HF. ${ }^{199}$ The safety of newer antidiabetic drugs in $\mathrm{HF}$ is unknown.

\subsection{Erectile dysfunction}

Erectile dysfunction should be treated in the usual way; phosphodiesterase $V$ inhibitors are not contraindicated other than in patients taking nitrates. Indeed short-term studies have shown that these agents have favourable haemodynamic and other effects in patients with HF-REF. ${ }^{200}$ There are, however, reports of phosphodiesterase $\mathrm{V}$ inhibitors causing worsening LV outflow tract obstruction in patients with hypertrophic cardiomyopathy, which may be a concern in some patients with HF-PEF.

\subsection{Gout}

Hyperuricaemia and gout are common in HF and may be caused or aggravated by diuretic treatment. Hyperuricaemia is associated with a worse prognosis in HF-REF. ${ }^{80}$ Xanthine oxidase inhibitors (allopurinol, oxypurinol) may be used to prevent gout, although their safety in HF-REF is uncertain. ${ }^{201}$ Gout attacks are better treated by colchicine than with NSAIDs (although colchicine should not be used in patients with very severe renal dysfunction and may cause diarrhoea). Intra-articular corticosteroids are an alternative for monoarticular gout, but systemic corticosteroids cause sodium and water retention.

\subsection{Hyperlipidaemia}

Elevated low-density lipoprotein cholesterol is uncommon in HF-REF; patients with advanced HF-REF often have low concentrations of low-density lipoprotein, which is associated with a worse prognosis. Rosuvastatin did not reduce the primary composite mortality-morbidity endpoints in two large RCTs in HF. ${ }^{127,128}$

\subsection{Hypertension}

Hypertension is associated with an increased risk of developing HF; antihypertensive therapy markedly reduces the incidence of HF (with an exception of alpha-adrenoceptor blockers, which are less effective than other antihypertensives in preventing HF). ${ }^{202}$ Negatively inotropic CCBs (i.e. diltiazem and verapamil) should not be used to treat hypertension in patients with HF-REF (but are believed to be safe in HF-PEF), and moxonidine should also be avoided in patients with HF-REF as it increased mortality in patients in one $\mathrm{RCT}^{203}$ If blood pressure is not controlled with an ACE inhibitor (or ARB), a beta-blocker, MRA, and diuretic, hydralazine and amlodipine (or felodipine ${ }^{204}$ ), are additional

Recommendations for the treatment of hypertension in patients with symptomatic HF (NYHA functional class II-IV) and LV systolic dysfunction

\begin{tabular}{|c|c|c|c|}
\hline Recommendations & Class $^{\mathrm{a}}$ & Level $^{b}$ & $\operatorname{Ref}^{c}$ \\
\hline \multicolumn{4}{|l|}{ Step I } \\
\hline $\begin{array}{l}\text { One or more of an ACE inhibitor (or ARB), beta-blocker, and MRA is recommended as first-, second-, and third-line } \\
\text { therapy, respectively, because of their associated benefits (reducing the risk of HF hospitalization and reducing the risk } \\
\text { of premature death). }\end{array}$ & $\mathbf{I}$ & A & $87,108-111$ \\
\hline \multicolumn{4}{|l|}{ Step 2} \\
\hline $\begin{array}{l}\text { A thiazide diuretic (or if the patient is treated with a thiazide diuretic, switching to a loop diuretic) is recommended } \\
\text { when hypertension persists despite treatment with a combination of as many as possible of an ACE inhibitor (or ARB), } \\
\text { beta-blocker, and MRA. }\end{array}$ & I & C & - \\
\hline \multicolumn{4}{|l|}{ Step 3} \\
\hline $\begin{array}{l}\text { Amlodipine is recommended when hypertension persists despite treatment with a combination of as many as possible } \\
\text { of an ACE inhibitor (or ARB), beta-blocker, MRA, and diuretic. }\end{array}$ & I & $\mathbf{A}$ & 188,189 \\
\hline $\begin{array}{l}\text { Hydralazine is recommended when hypertension persists despite treatment with a combination of as many as possible } \\
\text { of an ACE inhibitor (or ARB), beta-blocker, MRA, and diuretic. }\end{array}$ & I & A & $114-116$ \\
\hline $\begin{array}{l}\text { Felodipine should be considered when hypertension persists despite treatment with a combination of as many as } \\
\text { possible of an ACE inhibitor (or ARB), beta-blocker, MRA, and diuretic. }\end{array}$ & Ila & B & 204 \\
\hline Moxonidine is NOT recommended because of safety concerns (increased mortality). & III & B & 203 \\
\hline $\begin{array}{l}\text { Alpha-adrenoceptor antagonists are NOT recommended because of safety concerns (neurohumoral activation, fluid } \\
\text { retention, worsening HF). }\end{array}$ & III & A & $\begin{array}{l}202,206 \\
207\end{array}$ \\
\hline
\end{tabular}

$\mathrm{ACE}=$ angiotensin-converting enzyme; $\mathrm{ARB}=$ angiotensin receptor blocker; $\mathrm{HF}=$ heart failure; $\mathrm{LV}=$ left ventricular; $\mathrm{LVEF}=$ left ventricular ejection fraction; $\mathrm{MRA}=$ mineralocorticoid receptor antagonist; NYHA $=$ New York Heart Association.

${ }^{\mathrm{a}}$ Class of recommendation.

b Level of evidence.

'References. 
blood pressure-lowering agents shown to be safe in systolic HF. The blood pressure targets recommended in hypertension guidelines $^{205}$ are applicable to HF.

In patients with AHF, i.v. nitrates (or sodium nitroprusside) are recommended to lower blood pressure (see Section 12).

\subsection{Iron deficiency}

Iron deficiency may contribute to muscle dysfunction in HF and causes anaemia. In a single RCT, 459 patients with NYHA class II or III systolic HF, a haemoglobin concentration between 9.5 and $13.5 \mathrm{~g} / \mathrm{dL}$, and iron deficiency (see below) were randomized 2:1 to i.v. ferric carboxymaltose or saline. In this trial, iron deficiency was diagnosed when serum ferritin was $<100 \mu / L$ or when the ferritin concentration was between 100 and $299 \mu \mathrm{g} / \mathrm{L}$ and transferrin saturation was $<20 \% .{ }^{208}$ Over 6 months of treatment, iron therapy improved self-reported patient global assessment and NYHA class (as well as 6-min walk distance and health-related quality of life) and may be considered as a treatment for these patients. The effect of treating iron deficiency in HF-PEF and the long-term safety of iron therapy in HF is unknown.

\subsection{Kidney dysfunction and cardiorenal syndrome}

The GFR is reduced in most patients with HF, especially if advanced, and renal function is a powerful independent predictor of prognosis in HF. Renin-angiotensin-aldosterone blockers (ACE inhibitors, renin inhibitors, ARBs, and MRAs) frequently cause a fall in GFR, although any reduction is usually small and should not lead to treatment discontinuation unless marked (see Appendix C). Conversely, an immediate and large fall in GFR should raise the suspicion of renal artery stenosis. Sodium and water depletion (due to the excessive diuresis or fluid loss due to vomiting or diarrhoea) and hypotension are well recognized causes of renal dysfunction, but less well known is that volume overload, right heart failure, and renal venous congestion may also cause renal dysfunction. Other causes of kidney dysfunction are prostatic obstruction and nephrotoxic drugs such as NSAIDs and certain antibiotics (e.g. trimethoprim and gentamicin), all of which should be considered (and corrected or avoided) in HF patients with worsening renal function. Thiazide diuretics may be less effective in patients with a very low eGFR, and certain renally excreted drugs (e.g. digoxin, insulin, and low molecular weight heparin) may accumulate in patients with renal impairment. Sometimes the term 'cardiorenal syndrome' is used to describe concurrent heart and renal failure (and 'cardiorenal-anaemia syndrome' if there is concomitant anaemia). ${ }^{209}$

Chronic or acute renal dysfunction is a particular problem in patients with AHF, and is discussed further in that section (see Section 12).

\subsection{Obesity}

Obesity is a risk factor for HF and complicates its diagnosis because it causes dyspnoea, effort intolerance, and ankle swelling, and may result in poor-quality echocardiographic images. Obese individuals also have reduced natriuretic peptide levels. Obesity is more common in HF-PEF than in HF-REF, although it is possible that misdiagnosis may explain at least some of this difference in prevalence. Obesity should be managed as recommended in other guidelines. ${ }^{210}$

\subsection{Prostatic obstruction}

Alpha-adrenoceptor blockers cause hypotension, and sodium and water retention, and may not be safe in systolic HF (see Section 11.13). ${ }^{202,206,207}$ For these reasons, 5-alpha reductase inhibitors are generally preferred. Prostatic obstruction should be ruled out in men with deteriorating renal function.

\subsection{Renal dysfunction}

See Section 11.15.

\subsection{Sleep disturbance and sleep-disordered breathing}

Patients with HF frequently have sleep disturbance; the causes are many, including pulmonary congestion (leading to orthopnea and paroxysmal nocturnal dyspnoea) and diuretic therapy causing nocturnal diuresis. Anxiety and other psychological problems can also lead to insomnia, and reviewing sleep history is part of the holistic care of patients with HF (see Section 14). Up to one-third of patients with HF have sleep-disordered breathing. ${ }^{211,212}$ Sleep apnoea is of concern in patients with HF because it leads to intermittent hypoxaemia, hypercapnia, and sympathetic excitation. Obstructive sleep apnoea also causes recurrent episodes of negative intrathoracic pressure and increases in LV afterload. It is more common in patients who are obese and whose sleeping partners report that the patient snores or exhibits daytime somnolence (the patient may not be aware of these). However, not all patients with obstructive sleep apnoea are obese. The prevalence of central sleep apnoea (including Cheyne-Stokes respiration) in HF is uncertain and may have declined since the widespread use of betablockers and CRT. Screening for and the diagnosis and treatment of sleep apnoea is discussed in detail elsewhere. ${ }^{211,212}$ Diagnosis currently requires overnight polysomnography. Nocturnal oxygen supplementation, continuous positive airway pressure, bi-level positive airway pressure, and adaptive servo-ventilation may be used to treat nocturnal hypoxaemia.

\section{Acute heart failure}

Acute heart failure (AHF) is the term used to describe the rapid onset of, or change in, symptoms and signs of HF. It is a lifethreatening condition that requires immediate medical attention and usually leads to urgent admission to hospital. In most cases, AHF arises as a result of deterioration in patients with a previous diagnosis of HF (either HF-REF or HF-PEF), and all of the aspects of chronic management described in these guidelines apply fully to these patients. AHF may also be the first presentation of HF ('de novo' AHF). AHF may be caused by an abnormality of any aspect of cardiac function (Appendix A). In patients with pre-existing HF there is often a clear precipitant or trigger (e.g. an arrhythmia or discontinuation of diuretic therapy in a patient with HF-REF and volume overload or severe hypertension in patients with HF-PEF) (Table 19). The 'acuteness' may 
Table 19 Precipitants and causes of acute heart failure

\begin{tabular}{|l|}
\hline Events usually leading to rapid deterioration \\
\hline - Rapid arrhythmia or severe bradycardia/conduction disturbance \\
\hline - Acute coronary syndrome \\
\hline $\begin{array}{l}\text { - Mechanical complication of acute coronary syndrome (e.g. rupture of } \\
\text { interventricular septum, mitral valve chordal rupture, right ventricular } \\
\text { infarction) }\end{array}$ \\
\hline - Acute pulmonary embolism \\
\hline - Hypertensive crisis \\
\hline - Cardiac tamponade \\
\hline - Aortic dissection \\
\hline - Surgery and perioperative problems \\
\hline - Peripartum cardiomyopathy \\
\hline Events usually leading to less rapid deterioration \\
\hline - Infection (including infective endocarditis) \\
\hline - Exacerbation of COPD/asthma \\
\hline - Anaemia \\
\hline - Kidney dysfunction \\
\hline - Non-adherence to diet/drug therapy \\
\hline $\begin{array}{l}\text { - latrogenic causes (e.g. prescription of an NSAID or corticosteroid; } \\
\text { drug interactions) }\end{array}$ \\
\hline $\begin{array}{l}\text { - Arrhythmias, bradycardia, and conduction disturbances not leading to } \\
\text { sudden, severe change in heart rate }\end{array}$ \\
\hline - Uncontrolled hypertension \\
\hline - Hypothyroidism or hyperthyroidism \\
\hline - Alcohol and drug abuse \\
\hline
\end{tabular}

$\mathrm{AHF}=$ acute heart failure; $\mathrm{COPD}=$ chronic obstructive pulmonary disease; NSAID $=$ non-steroidal anti-inflammatory drug.

vary, with many patients describing a period of days or even weeks of deterioration (e.g. increasing breathlessness or oedema) but others developing HF within hours to minutes (e.g. in association with an acute myocardial infarction). Patients may present with a spectrum of conditions ranging from lifethreatening pulmonary oedema or cardiogenic shock to a condition characterized, predominantly, by worsening peripheral oedema.

Diagnosis and treatment are usually carried out in parallel, especially in patients who are particularly unwell, and management must be initiated promptly. Close monitoring of the patient's vital functions is essential during the initial evaluation and treatment (see Sections 12.3 and 12.4) and some patients are best managed in an intensive or coronary care unit. Although the immediate goals of treatment are to improve symptoms and stabilize the patient's haemodynamic condition, longer term management, including post-discharge care, is also particularly important to prevent recurrences and improve prognosis in HF-REF. Pre- and post-discharge care should follow the recommendations outlined elsewhere in these guidelines, where applicable.

\subsection{Initial assessment and monitoring of patients}

Three parallel assessments must be made during the initial evaluation of the patient, aided by the investigations listed in Figure 4.

(i) Does the patient have HF or is there an alternative cause for their symptoms and signs (e.g. chronic lung disease, anaemia, kidney failure, or pulmonary embolism)?

(ii) If the patient does have HF, is there a precipitant and does it require immediate treatment or correction (e.g. an arrhythmia or acute coronary syndrome)?

(iii) Is the patient's condition immediately life-threatening because of hypoxaemia or hypotension leading to underperfusion of the vital organs (heart, kidneys, and brain)?

\subsection{Treatment of acute heart failure}

Often treatment must be administered in parallel with the diagnostic work-up (see treatment algorithm, Figure 5). Although not 'evidence based' in the same way as treatments for chronic HF, the key drugs are oxygen, diuretics, and vasodilators. Opiates and inotropes are used more selectively, and mechanical support of the circulation is required only rarely. Non-invasive ventilation is used commonly in many centres, but invasive ventilation is required in only a minority of patients.

Systolic blood pressure, heart rhythm and rate, saturation of peripheral oxygen $\left(\mathrm{SpO}_{2}\right)$ using a pulse oximeter, and urine output should be monitored on a regular and frequent basis until the patient is stabilized (see also Sections 12.3 and 12.4).

\subsubsection{Pharmacological therapy}

12.2.1.1 Acute management

Oxygen

Oxygen may be given to treat hypoxaemia $\left(\mathrm{SpO}_{2}<90 \%\right)$, which is associated with an increased risk of short-term mortality. Oxygen should not be used routinely in non-hypoxaemic patients as it causes vasoconstriction and a reduction in cardiac output. 224

\section{Diuretics}

Most patients with dyspnoea caused by pulmonary oedema obtain rapid symptomatic relief from administration of an i.v. diuretic, as a result of both an immediate venodilator action and subsequent removal of fluid. The optimum dose and route of administration (bolus or continuous infusion) are uncertain. A recent, small, prospective RCT compared 12-hourly bolus injection with continuous infusion and low-dose (equal to pre-existing oral dose) with highdose ( $\times 2.5$ times previous oral dose) using a $2 \times 2$ factorial design. ${ }^{213}$ There was no difference between either of the treatment comparisons for the co-primary endpoints (patient global assessment of symptoms and change in serum creatinine). Compared with the low-dose strategy, the high-dose strategy was, however, associated with greater improvement in a number of secondary outcomes (including dyspnoea) but at the expense of more transient worsening of renal function.

In patients with resistant peripheral oedema (and ascites), a combination of a loop and a thiazide (e.g. bendroflumethiazide) 


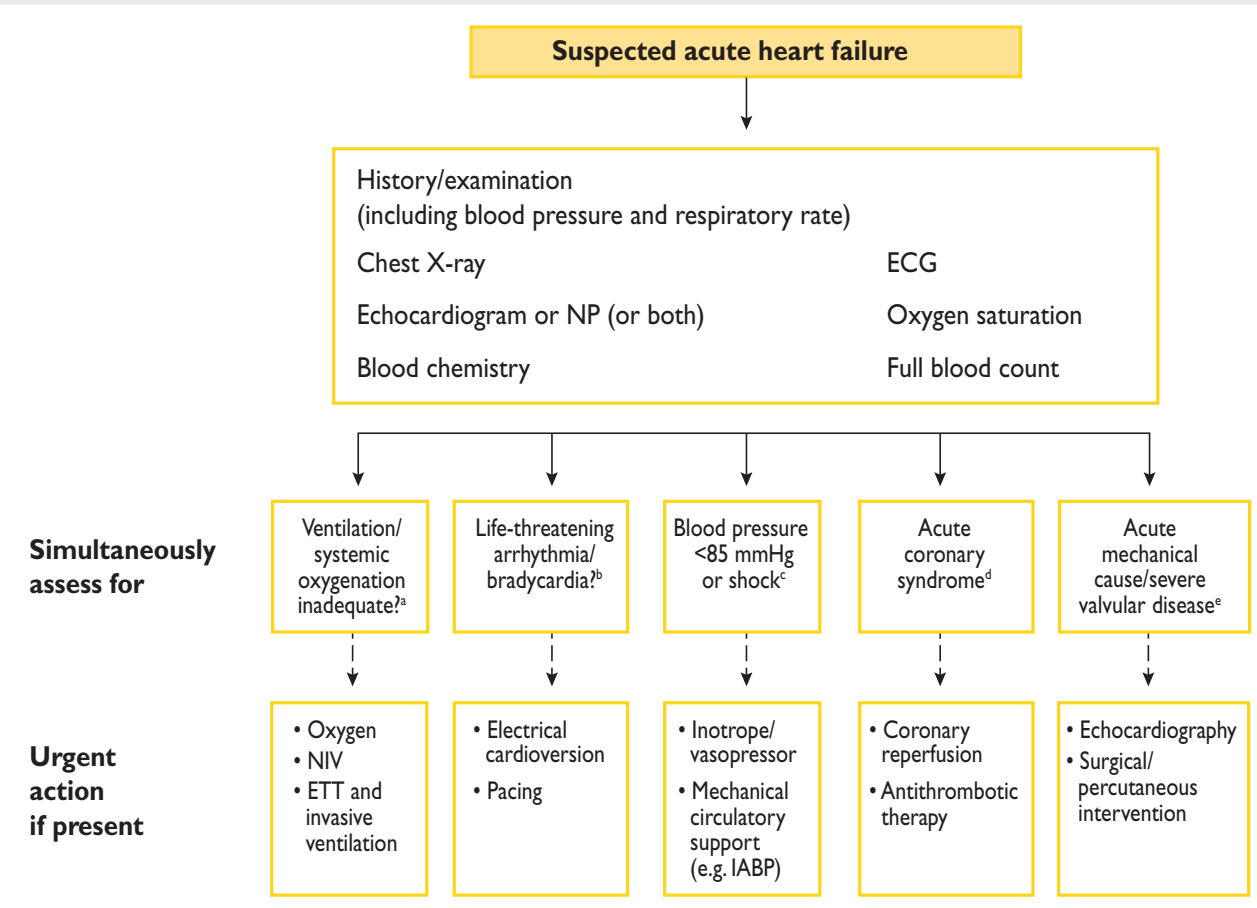

$E C G$ = electrocardiogram; $E T T$ = endotracheal tube; IABP = intra-aortic balloon pump; NIV = non-invasive ventilation; NP = natriuretic peptide. ${ }^{2}$ For example, respiratory distress, confusion $\mathrm{SpO}_{2}<90 \%$, or $\mathrm{PaO}_{2}<60 \mathrm{mmHg}(8.0 \mathrm{kPa})$.

'For example, ventricular tachycardia, third-degree atrioventricular block.

'Reduced peripheral and vital organ perfusion-patients often have cold skin and urine output $\leq 15 \mathrm{ml} / \mathrm{h}$ and/or disturbance of consciousness.

'Percutaneous coronary revascularization (or thrombolysis) indicated if ST-segment elevation or new left bundle branch block.

eVasodilators should be used with great caution, and surgery should be considered for certain acute mechanical complications (e.g. inter-ventricular septal rupture, mitral valve papillary muscle rupture).

Figure 4 Initial assessment of patient with suspected acute heart failure. ECG = electrocardiogram; ETT=endotracheal tube; $\mathrm{IABP}=$ intra-aortic balloon pump; NIV = non-invasive ventilation; NP = natriuretic peptide.

or thiazide-like diuretic (metolazone) may be needed to achieve an adequate diuresis (see Appendix F). ${ }^{225,226}$ This potent combination is usually only needed for a few days and requires careful monitoring to avoid hypokalaemia, renal dysfunction, and hypovolaemia.

\section{Opiates}

Opiates such as morphine may be useful in some patients with acute pulmonary oedema as they reduce anxiety and relieve distress associated with dyspnoea. Opiates are also thought to be venodilators, reducing preload, and may also reduce sympathetic drive. Conversely, opiates induce nausea (necessitating the concomitant administration of an antiemetic, one of which, cyclizine, ${ }^{227}$ has vasoconstrictor activity) and depress respiratory drive, potentially increasing the need for invasive ventilation.

\section{Vasodilators}

Although vasodilators such as nitroglycerine (Table 20) reduce preload and afterload and increase stroke volume, there is no robust evidence that they relieve dyspnoea or improve other clinical outcomes. ${ }^{218,220}$ Vasodilators are probably most useful in patients with hypertension and should be avoided in patients with a systolic blood pressure $<110 \mathrm{mmHg}$. Excessive falls in
Table 20 Intravenous vasodilators used to treat acute heart failure

\begin{tabular}{|l|l|l|l|}
\hline Vasodilator & Dosing & $\begin{array}{l}\text { Main side } \\
\text { effects }\end{array}$ & Other \\
\hline Nitroglycerine & $\begin{array}{l}\text { Start with } 10-20 \mu g / \mathrm{min}, \\
\text { increase up to } \\
200 \mu \mathrm{g} / \mathrm{min}\end{array}$ & $\begin{array}{l}\text { Hypotension, } \\
\text { headache }\end{array}$ & $\begin{array}{l}\text { Tolerance on } \\
\text { continuous } \\
\text { use }\end{array}$ \\
\hline $\begin{array}{l}\text { Isosorbide } \\
\text { dinitrate }\end{array}$ & $\begin{array}{l}\text { Start with I } \mathrm{mg} / \mathrm{h}, \\
\text { increase up to } 10 \mathrm{mg} / \mathrm{h}\end{array}$ & $\begin{array}{l}\text { Hypotension, } \\
\text { headache }\end{array}$ & $\begin{array}{l}\text { Tolerance on } \\
\text { continuous } \\
\text { use }\end{array}$ \\
\hline Nitroprusside & $\begin{array}{l}\text { Start with } 0.3 \mu \mathrm{g} / \mathrm{kg} / \mathrm{min} \\
\text { and increase up to } \\
5 \mu g / \mathrm{kg} / \mathrm{min}\end{array}$ & $\begin{array}{l}\text { Hypotension, } \\
\text { isocyanate } \\
\text { toxicity }\end{array}$ & $\begin{array}{l}\text { Light } \\
\text { sensitive }\end{array}$ \\
\hline Nesiritide ${ }^{\mathrm{a}}$ & $\begin{array}{l}\text { Bolus } 2 \mu \mathrm{g} / \mathrm{kg}+ \\
\text { infusion } 0.01 \mu g / \mathrm{kg} / \mathrm{min}\end{array}$ & Hypotension & \\
\hline
\end{tabular}

${ }^{a}$ Not available in many European Society of Cardiology countries.

blood pressure should also be avoided because hypotension is associated with higher mortality in patients with AHF. Vasodilators should be used with caution in patients with significant mitral or aortic stenosis. 


\section{Nesiritide}

Nesiritide - a human BNP that acts mainly as a vasodilator-was recently shown to reduce dyspnoea by a small but statistically significant amount when added to conventional treatment (mainly diuretic). ${ }^{228}$

\section{Inotropes}

Use of an inotrope such as dobutamine (Table 21) should usually be reserved for patients with such severe reduction in cardiac output that vital organ perfusion is compromised. Such patients are almost always hypotensive ('shocked'). Inotropes cause sinus tachycardia and may induce myocardial ischaemia and arrhythmias. There is long-standing concern that they may increase mortality. There is pharmacological rationale to use levosimendan (or a phosphodiesterase III inhibitor such as milrinone) if it is felt necessary to counteract the effect of a beta-blocker.

\section{Vasopressors}

Drugs with prominent peripheral arterial vasoconstrictor action such as norepinephrine (Table 21) are sometimes given to severely ill patients with marked hypotension. These agents are given to raise blood pressure and redistribute cardiac output from the extremities to the vital organs. However, this is at the expense of an increase in LV afterload, and these agents have adverse effects similar to those of inotropes (and the most commonly used of these agents, norepinephrine and epinephrine, have inotropic activity). Their use should be restricted to patients with persistent hypoperfusion despite adequate cardiac filling pressures.

Table 2 I Drugs used to treat acute heart failure that are positive inotropes or vasopressors or both

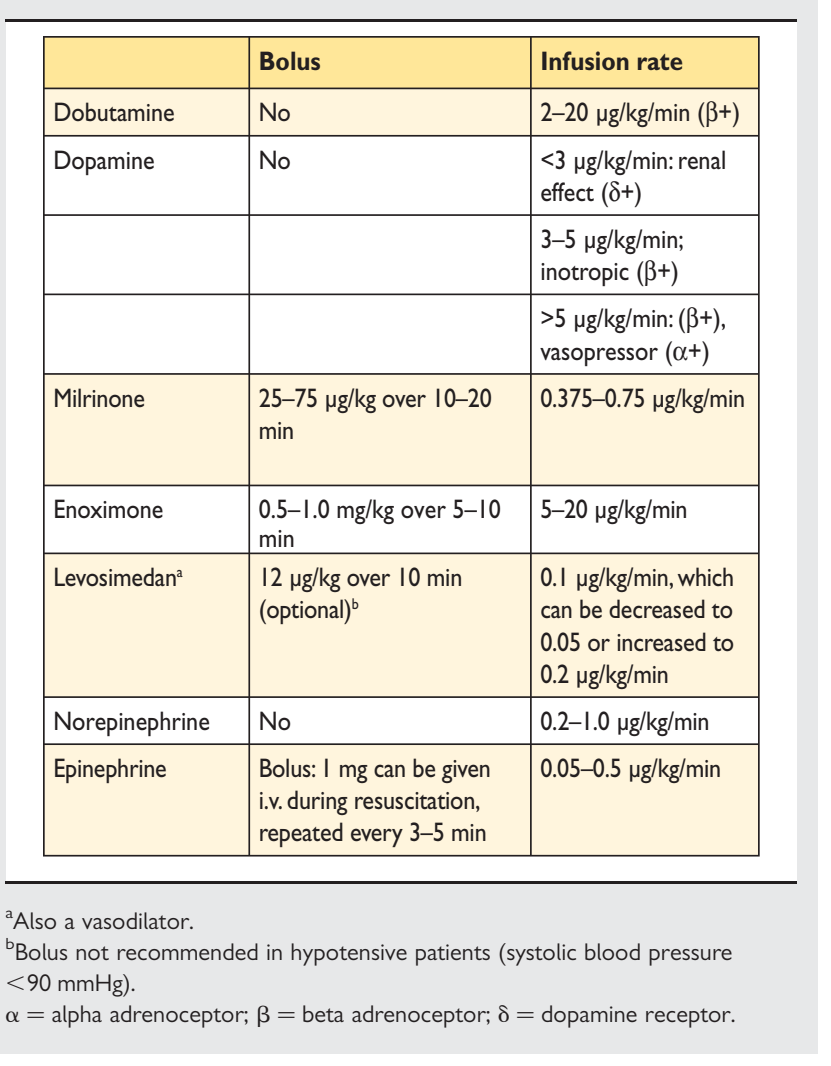

\section{Dopamine}

In large doses (>5 $\mu \mathrm{g} / \mathrm{kg} / \mathrm{min})$ dopamine has inotropic and vasoconstrictor activity. At lower doses $(<3 \mu \mathrm{g} / \mathrm{kg} / \mathrm{min})$ dopamine may have a selective renal arterial vasodilator activity and promote natriuresis, although this is uncertain. Dopamine may cause hypoxaemia. ${ }^{229}$ Arterial oxygen saturation should be monitored, and supplemental oxygen administrated as required.

\section{Other pharmacological therapy}

Thrombo-embolism prophylaxis with heparin or another anticoagulant should be used, unless contraindicated or unnecessary (because of existing treatment with oral anticoagulants). ${ }^{214-216}$ Tolvaptan (a vasopressin $V_{2}$-receptor antagonist) may be used to treat patients with resistant hyponatraemia (thirst and dehydration are recognized adverse effects). ${ }^{230}$

\subsubsection{After stabilization}

Angiotensin-converting enzyme inhibitorlangiotensin receptor blocker In patients with reduced EF not already receiving an ACE inhibitor (or ARB), this treatment should be started as soon as possible, blood pressure and renal function permitting (see recommendations in Section 7.2.1 and Appendix C). The dose should be up-titrated as far as possible before discharge, and a plan made to complete dose up-titration after discharge.

\section{Beta-blocker}

In patients with reduced EF not already receiving a beta-blocker, this treatment should be started as soon as possible after stabilization, blood pressure and heart rate permitting (see recommendations in Section 7.1 and Appendix D). The dose should be up-titrated as far as possible before discharge, and a plan made to complete dose up-titration after discharge. It has been shown that beta-blocker treatment may be continued in many patients during an episode of decompensation and started safely before discharge after an episode of decompensation.

\section{Mineralocorticoid (aldosterone) receptor antagonist}

In patients with reduced EF not already receiving an MRA, this treatment should be started as soon as possible, renal function and potassium permitting (see recommendations in Section 7.2 and Appendix E). As the dose of MRA used to treat HF has a minimal effect on blood pressure, even relatively hypotensive patients may be started on this therapy during admission. The dose should be up-titrated as far as possible before discharge, and a plan made to complete dose up-titration after discharge.

\section{Digoxin}

In patients with reduced EF, digoxin may be used to control the ventricular rate in AF, especially if it has not been possible to up-titrate the dose of beta-blocker. Digoxin may also provide symptom benefit and reduce the risk of HF hospitalization in patients with severe systolic HF (see recommendations in Section 7.2.6).

\subsubsection{Non-pharmacological/non-device therapy}

It is common to restrict sodium intake to $<2 \mathrm{~g} /$ day and fluid intake to $<1.5-2.0 \mathrm{~L} /$ day, especially (the latter in hyponatraemic 


\section{Recommendations for the treatment of patients with acute heart failure}

\begin{tabular}{|c|c|c|c|}
\hline Recommendations & Class $^{\mathrm{a}}$ & Level $^{\mathrm{b}}$ & $\operatorname{Ref}^{C}$ \\
\hline \multicolumn{4}{|l|}{ Patients with pulmonary congestion/oedema without shock } \\
\hline $\begin{array}{l}\text { An i.v. loop diuretic is recommended to improve breathlessness and relieve congestion. Symptoms, urine output, renal } \\
\text { function, and electrolytes should be monitored regularly during use of i.v. diuretic. }\end{array}$ & I & B & 213 \\
\hline $\begin{array}{l}\text { High-flow oxygen is recommended in patients with a capillary oxygen saturation }<90 \% \text { or } \mathrm{PaO}_{2}<60 \mathrm{mmHg}(8.0 \mathrm{kPa}) \\
\text { to correct hypoxaemia. }\end{array}$ & I & C & - \\
\hline $\begin{array}{l}\text { Thrombo-embolism prophylaxis (e.g. with LMWH) is recommended in patients not already anticoagulated and with } \\
\text { no contraindication to anticoagulation, to reduce the risk of deep venous thrombosis and pulmonary embolism. }\end{array}$ & I & A & $214-216$ \\
\hline $\begin{array}{l}\text { Non-invasive ventilation (e.g. CPAP) should be considered in dyspnoeic patients with pulmonary oedema and a } \\
\text { respiratory rate }>20 \text { breaths/min to improve breathlessness and reduce hypercapnia and acidosis. Non-invasive } \\
\text { ventilation can reduce blood pressure and should not generally be used in patients with a systolic blood pressure } \\
<85 \mathrm{mmHg} \text { (and blood pressure should be monitored regularly when this treatment is used). }\end{array}$ & Ila & B & 217 \\
\hline $\begin{array}{l}\text { An i.v. opiate (along with an antiemetic) should be considered in particularly anxious, restless, or distressed patients to } \\
\text { relieve these symptoms and improve breathlessness. Alertness and ventilatory effort should be monitored frequently } \\
\text { after administration because opiates can depress respiration. }\end{array}$ & Ila & C & - \\
\hline $\begin{array}{l}\text { An i.v. infusion of a nitrate should be considered in patients with pulmonary congestion/oedema and a systolic } \\
\text { blood pressure }>110 \mathrm{mmHg} \text {, who do not have severe mitral or aortic stenosis, to reduce pulmonary capillary wedge } \\
\text { pressure and systemic vascular resistance. Nitrates may also relieve dyspnoea and congestion. Symptoms and blood } \\
\text { pressure should be monitored frequently during administration of i.v. nitrates. }\end{array}$ & Ila & B & 218,219 \\
\hline $\begin{array}{l}\text { An i.v. infusion of sodium nitroprusside may be considered in patients with pulmonary congestion/oedema and a } \\
\text { systolic blood pressure >110 mmHg, who do not have severe mitral or aortic stenosis, to reduce pulmonary capillary } \\
\text { wedge pressure and systemic vascular resistance. Caution is recommended in patients with acute myocardial infarction. } \\
\text { Nitroprusside may also relieve dyspnoea and congestion. Symptoms and blood pressure should be monitored } \\
\text { frequently during administration of i.v. nitroprusside. }\end{array}$ & Illb & B & 220 \\
\hline $\begin{array}{l}\text { Inotropic agents are NOT recommended unless the patient is hypotensive (systolic blood pressure }<85 \mathrm{mmHg} \text { ), } \\
\text { hypoperfused, or shocked because of safety concerns (atrial and ventricular arrhythmias, myocardial ischaemia, and death). }\end{array}$ & III & C & - \\
\hline \multicolumn{4}{|l|}{ Patients with hypotension, hypoperfusion or shock } \\
\hline $\begin{array}{l}\text { Electrical cardioversion is recommended if an atrial or ventricular arrhythmia is thought to be contributing to the } \\
\text { patient's haemodynamic compromise in order to restore sinus rhythm and improve the patient's clinical condition. }\end{array}$ & I & C & - \\
\hline $\begin{array}{l}\text { An i.v. infusion of an inotrope (e.g. dobutamine) should be considered in patients with hypotension (systolic blood } \\
\text { pressure }<85 \mathrm{mmHg} \text { ) and/or hypoperfusion to increase cardiac output, increase blood pressure, and improve } \\
\text { peripheral perfusion. The ECG should be monitored continuously because inotropic agents can cause arrhythmias and } \\
\text { myocardial ischaemia. }\end{array}$ & Ila & C & - \\
\hline $\begin{array}{l}\text { Short-term mechanical circulatory support should be considered (as a 'bridge to recovery') in patients remaining } \\
\text { severely hypoperfused despite inotropic therapy and with a potentially reversible cause (e.g. viral myocarditis) or } \\
\text { a potentially surgically correctable cause (e.g. acute interventricular septal rupture). }\end{array}$ & Ila & C & - \\
\hline $\begin{array}{l}\text { An i.v. infusion of levosimendan (or a phosphodiesterase inhibitor) may be considered to reverse the effect of } \\
\text { beta-blockade if beta-blockade is thought to be contributing to hypoperfusion. The ECG should be monitored } \\
\text { continuously because inotropic agents can cause arrhythmias and myocardial ischaemia, and, as these agents are also } \\
\text { vasodilators, blood pressure should be monitored carefully. }\end{array}$ & Ilb & C & - \\
\hline $\begin{array}{l}\text { A vasopressor (e.g. dopamine or norepinephrine) may be considered in patients who have cardiogenic shock, despite } \\
\text { treatment with an inotrope, to increase blood pressure and vital organ perfusion. The ECG should be monitored as } \\
\text { these agents can cause arrhythmias and/or myocardial ischaemia. Intra-arterial blood pressure measurement should } \\
\text { be considered. }\end{array}$ & Ilb & C & - \\
\hline $\begin{array}{l}\text { Short-term mechanical circulatory support may be considered (as a 'bridge to decision') in patients deteriorating } \\
\text { rapidly before a full diagnostic and clinical evaluation can be made. }\end{array}$ & Illb & C & - \\
\hline \multicolumn{4}{|l|}{ Patients with an ACS } \\
\hline $\begin{array}{l}\text { Immediate primary } \mathrm{PCl} \text { (or CABG in selected cases) is recommended if there is an ST elevation or a new LBBB ACS } \\
\text { in order to reduce the extent of myocyte necrosis and reduce the risk of premature death. }\end{array}$ & I & A & 221 \\
\hline $\begin{array}{l}\text { Alternative to } P C I \text { or } C A B G \text { : } \\
\text { Intravenous thrombolytic therapy is recommended, if PCI/CABG cannot be performed, if there is ST-segment } \\
\text { elevation or new } L B B B \text {, to reduce the extent of myocyte necrosis and reduce the risk of premature death. }\end{array}$ & I & A & 222 \\
\hline $\begin{array}{l}\text { Early } \mathrm{PCl} \text { (or CABG in selected patients) is recommended if there is non-ST elevation ACS in order to reduce the risk } \\
\text { of recurrent } \mathrm{ACS} \text {. Urgent revascularization is recommended if the patient is haemodynamically unstable. }\end{array}$ & I & A & 221 \\
\hline $\begin{array}{l}\text { Eplerenone is recommended to reduce the risk of death and subsequent cardiovascular hospitalization in patients with } \\
\text { an } \mathrm{EF} \leq 40 \% \text {. }\end{array}$ & I & B & 107 \\
\hline
\end{tabular}




\section{Recommendations for the treatment of patients with acute heart failure (Cont.)}

\begin{tabular}{|c|c|c|c|c|}
\hline & Recommendations & Class $^{\mathrm{a}}$ & Level $^{\mathrm{b}}$ & $\operatorname{Ref}^{c}$ \\
\hline & \multicolumn{4}{|l|}{ Patients with an ACS } \\
\hline & $\begin{array}{l}\text { An } \mathrm{ACE} \text { inhibitor (or } \mathrm{ARB} \text { ) is recommended in patients with an } \mathrm{EF} \leq 40 \% \text {, after stabilization, to reduce the risk of death, } \\
\text { recurrent myocardial infarction, and hospitalization for HF. }\end{array}$ & I & A & 101 \\
\hline & $\begin{array}{l}\text { A beta-blocker is recommended in patients with an } \mathrm{EF} \leq 40 \% \text {, after stabilization, to reduce the risk of death and } \\
\text { recurrent myocardial infarction. }\end{array}$ & I & B & 223 \\
\hline & $\begin{array}{l}\text { An i.v. opiate (along with an antiemetic) should be considered in patients with ischaemic chest pain to relieve this } \\
\text { symptom (and improve breathlessness). Alertness and ventilatory effort should be monitored frequently after } \\
\text { administration because opiates can depress respiration. }\end{array}$ & Ila & C & - \\
\hline & \multicolumn{4}{|l|}{ Patients with AF and a rapid ventricular rate } \\
\hline & $\begin{array}{l}\text { Patients should be fully anticoagulated (e.g. with i.v. heparin), if not already anticoagulated and with no contraindication } \\
\text { to anticoagulation, as soon as AF is detected to reduce the risk of systemic arterial embolism and stroke. }\end{array}$ & $\mathbf{I}$ & A & 184 \\
\hline & $\begin{array}{l}\text { Electrical cardioversion is recommended in patients haemodynamically compromised by AF and in whom urgent } \\
\text { restoration of sinus rhythm is required to improve the patient's clinical condition rapidly. }\end{array}$ & I & C & - \\
\hline & $\begin{array}{l}\text { Electrical cardioversion or pharmacological cardioversion with amiodarone should be considered in patients when } \\
\text { a decision is made to restore sinus rhythm non-urgently ('rhythm control' strategy). This strategy should only be } \\
\text { employed in patients with a first episode of AF of < } 48 \mathrm{~h} \text { duration (or in patients with no evidence of left atrial } \\
\text { appendage thrombus on TOE). }\end{array}$ & I & C & - \\
\hline & Intravenous administration of a cardiac glycoside should be considered for rapid control of the ventricular rate. & I & C & - \\
\hline & $\begin{array}{l}\text { Dronedarone is not recommended because of safety concerns (increased risk of hospital admission for cardiovascular } \\
\text { causes and an increased risk of premature death), particularly in patients with an } \mathrm{EF} \leq 40 \% \text {. }\end{array}$ & III & A & 176 \\
\hline & $\begin{array}{l}\text { Class I antiarrhythmic agents are not recommended because of safety concerns (increased risk of premature death), } \\
\text { particularly in patients with LV systolic dysfunction. }\end{array}$ & III & $\mathbf{A}$ & 178 \\
\hline & \multicolumn{4}{|l|}{ Patients with severe bradycardia or heart block } \\
\hline & $\begin{array}{l}\text { Pacing is recommended in patients haemodynamically compromised by severe bradycardia or heart block to improve } \\
\text { the patient's clinical condition. }\end{array}$ & I & C & - \\
\hline $\begin{array}{l}\text { CPAP }=\mathrm{cC} \\
\mathrm{LMWH}= \\
\text { echocardio } \\
{ }^{\mathrm{a}} \text { Class of } \mathrm{r} \\
{ }^{\mathrm{b}} \text { Level of e } \\
{ }^{\mathrm{c}} \text { Reference }\end{array}$ & $\begin{array}{l}\text { jiotensin-converting enzyme; } \mathrm{ACS}=\text { acute coronary syndrome; } \mathrm{AF}=\text { atrial fibrillation; } \mathrm{ARB}=\text { angiotensin receptor } \\
\text { ontinuous positive airway pressure; } \mathrm{ECG}=\text { electrocardiogram; } \mathrm{EF}=\text { ejection fraction; } \mathrm{HF}=\text { heart failure; i.v. = intra } \\
\text { low molecular weight heparin; } \mathrm{LV}=\text { left ventricular; } \mathrm{PaO}_{2}=\text { partial pressure of oxygen; } \mathrm{PCl}=\text { percutaneous coron } \\
\text { graphy. } \\
\text { ecommendation. } \\
\text { vidence. }\end{array}$ & enous; $L$ & $=$ left & branc \\
\hline
\end{tabular}

patients) during the initial management of an acute episode of HF associated with volume overload, although there is no firm evidence to support this practice.

\subsubsection{Ventilation}

\section{Non-invasive ventilation}

Continuous positive airway pressure (CPAP) and non-invasive positive pressure ventilation (NIPPV) relieve dyspnoea and improve certain physiological measures (e.g. oxygen saturation) in patients with acute pulmonary oedema. However, a recent large RCT showed that neither type of non-invasive ventilation reduced mortality or the rate of endotracheal intubation when compared with standard therapy, including nitrates (in $90 \%$ of patients) and opiates (in $51 \%$ of patients). ${ }^{217}$ This result is in contrast to the findings of meta-analyses of earlier, smaller studies.

Non-invasive ventilation may be used as adjunctive therapy to relieve symptoms in patients with pulmonary oedema and severe respiratory distress or who fail to improve with pharmacological therapy. Contraindications include hypotension, vomiting, possible pneumothorax, and depressed consciousness.
Endotracheal intubation and invasive ventilation

The primary indication for endotracheal intubation and invasive ventilation is respiratory failure leading to hypoxaemia, hypercapnia, and acidosis. Physical exhaustion, diminished consciousness, and inability to maintain or protect the airway are other reasons to consider intubation and ventilation.

\subsubsection{Mechanical circulatory support} Intra-aortic balloon pump

The conventional indications for an intra-aortic balloon pump (IABP) are to support the circulation before surgical correction of specific acute mechanical problems (e.g. interventricular septal rupture and acute mitral regurgitation), during severe acute myocarditis and in selected patients with acute myocardial ischaemia or infarction before, during, and after percutaneous or surgical revascularization. There is no good evidence that an IABP is of benefit in other causes of cardiogenic shock. ${ }^{231}$ More recently, balloon pumps (and other types of short-term, temporary circulatory support) have been used to bridge patients until implantation of a ventricular assist device or heart transplantation (see Section 13.5). 


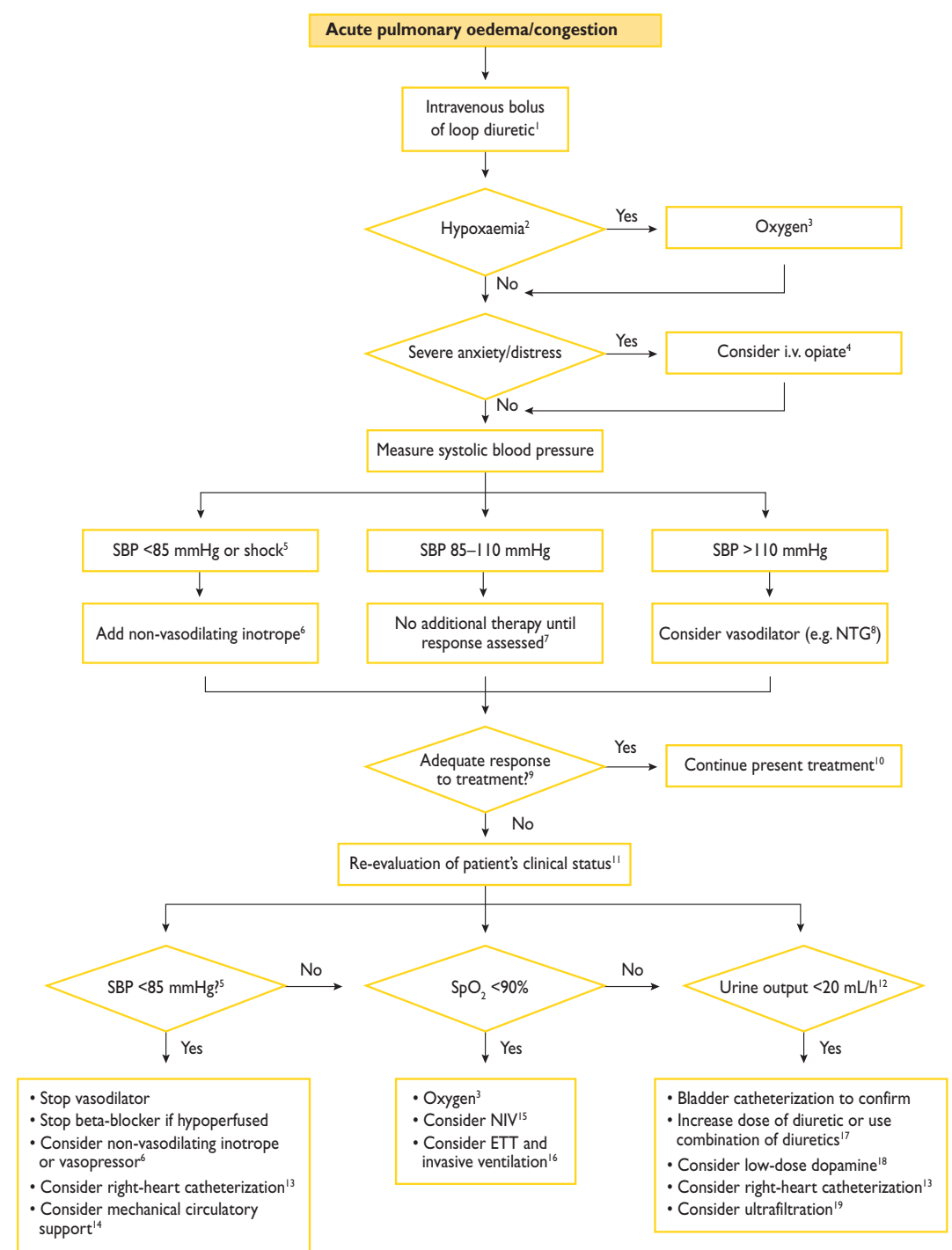

$\mathrm{CPAP}=$ continuous positive airway pressure; $\mathrm{ETT}=$ endotracheal tube; i.v. $=$ intravenous; $\mathrm{NIPPV}=$ non-invasive positive pressure ventilation; NIV = non-invasive ventilation NTG = nitroglycerine; $\mathrm{PaO}_{2}=$ partial pressure of oxygen; $\mathrm{SBP}=$ systolic blood pressure; $\mathrm{SpO}_{2}=$ saturation of peripheral oxygen.

'In patients' already taking diuretic, 2.5 times existing oral dose recommended. Repeat as needed. 2Pulse oximeter oxygen saturation $<90 \%$ or $\mathrm{PaO}_{2}<60 \mathrm{mmHg}(<8.0 \mathrm{kPa})$

${ }^{3}$ Usually start with $40-60 \%$ oxygen, titrating to $\mathrm{SpO}_{2}>90 \%$; caution required in patients at risk of $\mathrm{CO}_{2}$ retention.

${ }^{4}$ For example, 4-8 mg of morphine plus $10 \mathrm{mg}$ of metoclopramide; observe for respiratory depression. Repeat as needed.

${ }^{5}$ Cold skin, low pulse volume, poor urine output, confusion, myocardial ischaemia.

${ }^{6}$ For example, start an i.v. infusion of dobutamine $2.5 \mu \mathrm{g} / \mathrm{kg} / \mathrm{min}$, doubling dose every $15 \mathrm{~min}$ according to response or tolerability (dose titration usually limited by excessive tachycardia, arrhythmias, or ischaemia).A dose $>20 \mu \mathrm{g} / \mathrm{kg} / \mathrm{min}$ is rarely needed. Even dobutamine may have mild vasodilator activity as a result of beta-2 adrenoceptor stimulation. 'Patient should be kept under regular observation (symptoms, heart rate/rhythm, $\mathrm{SpO}_{2}, \mathrm{SBP}$, urine output) until stabilized and recovered.

${ }^{8}$ For example, start i.v. infusion at $10 \mu \mathrm{g} / \mathrm{min}$ and doubled every $10 \mathrm{~min}$ according to response and tolerability (usually dose up-titration is limited by hypotension).

A dose of $>100 \mu \mathrm{g} / \mathrm{min}$ is rarely needed.

${ }^{9} \mathrm{An}$ adequate response includes reduction in dyspnoea and adequate diuresis $(>100 \mathrm{~mL} / \mathrm{h}$ urine production in first $2 \mathrm{~h})$, accompanied by an increase in oxygen saturation

(if hypoxaemic) and, usually, reduction in heart and respiratory rate (which should occur in I-2 h). Peripheral blood flow may also increase as indicated by a reduction in skin vasoconstriction, an increase in skin temperature, and improvement in skin colour. There may also be a decrease in lung crackles.

${ }^{10}$ Once the patient is comfortable and a stable diuresis has been established, withdrawal of i.v. therapy can be considered (with substitution of oral diuretic treatment).

"Assess for symptoms relevant to HF (dyspnoea, orthopnoea, paroxysmal nocturnal dyspnoea), associated co-morbidity (e.g. chest pain due to myocardial ischaemia), and

treatment-related adverse effects (e.g. symptomatic hypotension).Assess for signs of peripheral and pulmonary congestion/oedema, heart rate and rhythm, blood pressure, peripheral perfusion, respiratory rate, and respiratory effort. An ECG (rhythm/ischaemia and infarction) and blood chemistry/haematology (anaemia, electrolyte disturbances, kidney failure) should also be examined. Pulse oximetry (or arterial blood gas measurements) should be checked and echocardiography performed (if not already carried out).

${ }^{12}$ Less than $100 \mathrm{~mL} / \mathrm{h}$ over $\mathrm{I}-2 \mathrm{~h}$ is an inadequate initial response to i.v. diuretic (confirm is inadequate by catheterizing bladder).

${ }^{13}$ In patients with persistently low blood pressure/shock, consider alternative diagnoses (e.g. pulmonary embolism), acute mechanical problems, and severe valve disease (particularly aortic stenosis). Pulmonary artery catheterization may identify patients with an inadequate left ventricular filling pressure (and characterize the patient's haemodynamic pattern, enabling more precise tailoring of vasoactive therapy).

${ }^{14} \mathrm{An}$ intra-aortic balloon pump or other mechanical circulatory support should be considered in patients without contraindications.

${ }^{15}$ CPAP or NIPPV (see Section 12.2.2.I) should be considered in patients without contraindications.

${ }^{16}$ Consider endotracheal intubation and invasive ventilation if worsening hypoxaemia, failing respiratory effort, increasing confusion, etc.

I7Double dose of loop diuretic up to equivalent of furosemide $500 \mathrm{mg}$ (doses of $250 \mathrm{mg}$ and above should be given by infusion over $4 \mathrm{~h}$ ).

${ }^{18}$ If no response to doubling of dose of diuretic despite adequate left ventricular filling pressure (either inferred or measured directly) start i.v. infusion of dopamine $2.5 \mu \mathrm{g} / \mathrm{kg} / \mathrm{min}$. Higher doses are not recommended to enhance diuresis.

${ }^{19}$ If steps 17 and 18 do not result in an adequate diuresis and the patient remains in pulmonary oedema, venovenous isolated ultrafiltration should be considered.

Figure 5 Algorithm for management of acute pulmonary oedema/congestion. 
Ventricular assist devices

Ventricular assist devices and other forms of mechanical circulatory support (MCS) may be used as a 'bridge to decision' or longer term in selected patients (see Section 13.5).

\subsubsection{Ultrafiltration}

Venovenous isolated ultrafiltration is sometimes used to remove fluid in patients with $\mathrm{HF}^{232}$ although is usually reserved for those unresponsive or resistant to diuretics.

\subsection{Invasive monitoring}

\subsubsection{Intra-arterial line}

Insertion of an intra-arterial line should only be considered in patients with persistent HF and a low systolic blood pressure despite treatment.

\subsubsection{Pulmonary artery catheterization}

Right heart catheterization does not have a general role in the management of AHF, but may help in the treatment of a minority of selected patients with acute (and chronic) HF. ${ }^{233}$ Pulmonary artery catheterization should only be considered in patients: (i) who are refractory to pharmacological treatment; (ii) who are persistently hypotensive; (iii) in whom LV filling pressure is uncertain; or (iv) who are being considered for cardiac surgery. A primary concern is to ensure that hypotension (and worsening renal function) is not due to inadequate LV filling pressure, in which case diuretic and vasodilator therapy should be reduced (and volume replacement may be required). Conversely, a high LV filling pressure and/or systemic vascular resistance may suggest an alternative pharmacological strategy (e.g. inotropic or vasodilator therapy), depending on blood pressure. Measurement of pulmonary vascular resistance (and its reversibility) is a routine part of the surgical work-up before cardiac transplantation.

\subsection{Monitoring after stabilization}

Heart rate, rhythm, blood pressure, and oxygen saturation should be monitored continuously for at least the first $24 \mathrm{~h}$ of admission, and frequently thereafter. Symptoms relevant to HF (e.g. dyspnoea) and related to the adverse effects of treatments used (e.g. dizziness) should be assessed at least daily. Fluid intake and output, weight, and the jugular venous pressure and extent of pulmonary and peripheral oedema (and ascites if present) should be measured daily to evaluate the correction of volume overload. Blood urea nitrogen, creatinine, potassium, and sodium should be monitored daily during i.v. therapy and when renin-angiotensin-aldosterone system antagonists are being initiated or if the dose of any of these drugs is changed.

\subsection{Other in-patient assessments}

After initial treatment of the acute episode, every patient should be assessed for possible causes of HF (if the HF is new) and precipitants of worsening (if the HF has previously been diagnosed). The focus is detection of reversible or treatable causes (Table 19).

\subsection{Readiness for discharge}

Before discharge is contemplated, the acute episode of HF should have resolved and, in particular, congestion should be absent and a
Table 22 Goals of treatment in acute heart failure

\begin{tabular}{|l|}
\hline Immediate (ED/ICU/CCU) \\
\hline - Treat symptoms \\
\hline - Restore oxygenation \\
\hline - Improve haemodynamics and organ perfusion \\
\hline - Limit cardiac and renal damage \\
\hline - Prevent thrombo-embolism \\
\hline - Minimize ICU length of stay \\
\hline Intermediate (in hospital) \\
\hline - Stabilize patient and optimize treatment strategy \\
\hline - Initiate and up-titrate disease-modifying pharmacological therapy \\
\hline - Consider device therapy in appropriate patients \\
\hline - Identify aetiology and relevant co-morbidities \\
\hline Pre-discharge and long-term management \\
\hline - Plan follow-up strategy \\
\hline - Enrol in disease management programme, educate, and initiate \\
appropriate lifestyle adjustments \\
\hline - Plan to up-titrate/optimize dose of disease-modifying drugs \\
\hline - Ensure assessed for appropriate device therapy \\
\hline - Prevent early readmission \\
\hline - Improve symptoms, quality of life, and survival \\
\hline
\end{tabular}

$\mathrm{CCU}=$ coronary care unit; $\mathrm{ED}=$ emergency department; $\mathrm{ICU}=$ intensive care unit.

stable oral diuretic regimen established for at least $48 \mathrm{~h}^{234-236}$ Long-term disease-modifying therapy (including a beta-blocker) should be optimized as much as possible and appropriate education provided to the patient and family/caregivers. Pre- and postdischarge management should follow the standards of care laid out by the Heart Failure Association. ${ }^{236}$ The goals of treatment during the different stages of management of patients with HF are summarized in Table 22.

\subsection{Special patient populations}

\subsubsection{Patients with a concomitant acute coronary syndrome}

Patients with a concomitant acute coronary syndrome should be assessed and treated according to the current acute coronary syndrome guidelines. ${ }^{237,238}$ They should undergo coronary angiography and revascularization as appropriate. This should be undertaken as an urgent procedure in patients with haemodynamic instability and as an emergency procedure in those in cardiogenic shock. If haemodynamic instability persists despite optimal medical treatment, an IABP should be inserted before coronary angiography and revascularization. Persistent haemodynamic instability may also be caused by mechanical complications of infarction (e.g. mitral valve papillary muscle rupture), which may be identified using echocardiography and may require urgent corrective surgery. 


\subsubsection{Isolated right ventricular failure}

New-onset isolated right ventricular failure may occur secondarily to an acute coronary syndrome (and is managed as described above) and following massive pulmonary embolism (see pulmonary embolism guidelines ${ }^{239}$ ). In both situations, diuretics and vasodilators should be used cautiously or avoided so as not to reduce right ventricular filling.

Progressive isolated right ventricular failure may occur in patients with pulmonary hypertension. Type $\mathrm{V}$ phosphodiesterase inhibitors, endothelin antagonists, and prostacyclin analogues may help by decreasing pulmonary arterial resistance (see guidelines ${ }^{240}$ ).

\subsubsection{Acute heart failure with 'cardiorenal syndrome'}

Acutely worsening HF, or its treatment, or both may cause acute worsening of renal function (the so-called 'type 1 cardiorenal syndrome') in up to one-third of patients, and is associated with worse survival and prolonged hospitalization. ${ }^{209}$ An acute renocardiac syndrome (the so-called 'type 3 cardiorenal syndrome'), characterized by worsening cardiac function secondary to volume overload resulting from acute kidney injury, may also occur, but is less common. The main management issues with these patients are that renal dysfunction may limit the use of renin-angiotensin-aldosterone system blockers and that progressive uraemia and volume overload may necessitate renal replacement therapy. Often these patients are best cared for jointly with a nephrologist.

\subsubsection{Perioperative acute heart failure}

AHF may occur in patients before (e.g. because of pre-operative infarction), during ('failure to wean'), and after (mechanical complications and pericardial tamponade must be excluded) cardiac surgery. The specialized management of this group of patients is described in detail elsewhere ${ }^{241}$ and may involve use of mechanical support, including extracorporeal membrane oxygenation (ECMO).

\subsubsection{Peripartum cardiomyopathy}

A high index of suspicion is needed to avoid late diagnosis of this serious condition, the management of which is described in detail in a Heart Failure Association statement and elsewhere. ${ }^{242,243}$

\subsubsection{Adult congenital heart disease}

Patients with adult congenital heart disease (ACHD) are a very heterogeneous patient population. The diagnosis and management of $\mathrm{HF}$ in these patients can be very complex, and close collaboration with a tertiary referral centre is mandatory.

Patients with ACHD may present with HF due to a reduced systemic LVEF, reduced systemic right ventricular EF, or isolated subpulmonary right ventricular failure (see Section 12.7.2). Patients with univentricular hearts, either unoperated or palliated by a Fontan procedure, are particularly difficult to evaluate and treat. CMR and cardiopulmonary exercise testing are especially valuable in their assessment, but the acquisition and interpretation of data require special expertise. ${ }^{66,244}$

There is a lack of multicentre RCTs to guide the treatment of HF in patients with ACHD. There are, however, a number of general empirical principles of management: (i) residual (post-repair) or new haemodynamic lesions should always be sought first; (ii) the value of ACE inhibitors, ARBs, and beta-blockers in ACHD is controversial and these drugs may even be harmful in certain patients, e.g. those with a Fontan circulation (see ESC guidelines ${ }^{245}$ ); (iii) pulmonary arterial vasodilators may be useful in certain patients with pulmonary hypertension (see ESC guidelines ${ }^{240}$ ); (iv) the role of CRT is unknown; and (v) heart transplantation is an option but may be precluded by factors such as complex cardiovascular anatomy, and renal and hepatic dysfunction.

\section{Coronary revascularization and surgery, including valve surgery, ventricular assist devices, and transplantation}

\subsection{Coronary revascularization}

Surgical (and percutaneous) coronary revascularization is indicated for the relief of angina pectoris in patients with either HF-REF or HF-PEF, and surgical coronary revascularization is indicated for 'prognostic' reasons in other patients with severe CAD, particularly those with three-vessel disease or left-main stenosis. The detailed indications for coronary revascularization are covered elsewhere. ${ }^{71}$

This section focuses on recent developments relevant to HF. The Surgical Treatment for Ischemic Heart Failure (STICH) trial addressed the broader role of surgical revascularization in patients with HF-REF and less severe CAD. ${ }^{191}$ Patients with an $E F \leq 35 \%$ and $C A D$ who were suitable for surgery were randomized to coronary artery bypass graft (CABG) plus medical therapy or medical therapy alone. The patients enrolled were young (average age 60 years), predominantly male $(88 \%)$, and were in NYHA class I (11\%), II (52\%), or III (34\%). Their Canadian Cardiovascular Society angina class was 0 in $36 \%$, I in $16 \%$, II in $43 \%$, III in $4 \%$, and IV in 1\%. Most patients had twovessel (31\%) or three-vessel (60\%) CAD, and 68\% had a severe proximal left anterior descending stenosis; very few (2\%) had a left-main stenosis. The primary outcome (all-cause death) was not reduced by CABG. CABG did, however, reduce the secondary outcomes of cardiovascular death (RRR 19\%) and death from any cause or cardiovascular hospitalization (RRR 26\%). This trial may therefore extend the indication for CABG to 'STICH-like' patients with two-vessel CAD, including a left anterior descending stenosis, who are otherwise suitable for surgery and expected to survive $>1$ year with good functional status.

The benefit-risk balance for CABG in patients without angina/ ischaemia or without viable myocardium remains uncertain. Patients with $>10 \%$ of dysfunctional but viable LV myocardium may be more likely to benefit from myocardial revascularization (and those with $\leq 10 \%$ less likely to benefit) although this approach to patient selection for revascularization is unproven. Several noninvasive techniques can be used to assess myocardial viability (Table 7). Nuclear imaging has a high sensitivity, whereas techniques evaluating contractile reserve have lower sensitivity but higher specificity. CMR is excellent for assessing the transmural extent of scar, but is not better at detecting viability or predicting recovery of wall motion.

The choice between percutaneous coronary intervention and CABG should be made by the Heart Team, including a HF specialist, and be based on the extent of CAD, expected completeness of 


\section{Recommendations for myocardial revascularization in patients with chronic HF and systolic LV dysfunction}

\begin{tabular}{|c|c|c|c|}
\hline Recommendations & Class $^{a}$ & Level $^{\mathrm{b}}$ & $\operatorname{Ref}^{c}$ \\
\hline $\begin{array}{l}\text { CABG is recommended } \\
\text { for patients with angina and } \\
\text { significant left main stenosis, } \\
\text { who are otherwise suitable } \\
\text { for surgery and expected to } \\
\text { survive }>\text { I year with good } \\
\text { functional status, to reduce the } \\
\text { risk of premature death. }\end{array}$ & I & C & - \\
\hline $\begin{array}{l}\text { CABG is recommended } \\
\text { for patients with angina and } \\
\text { two- or three-vessel coronary } \\
\text { disease, including a left } \\
\text { anterior descending stenosis, } \\
\text { who are otherwise suitable } \\
\text { for surgery and expected to } \\
\text { survive >I year with good } \\
\text { functional status, to reduce } \\
\text { the risk of hospitalization for } \\
\text { cardiovascular causes and the } \\
\text { risk of premature death from } \\
\text { cardiovascular causes. }\end{array}$ & I & B & 191 \\
\hline $\begin{array}{l}\text { Alternative to CABG: } \\
P C I \text { may be considered as } \\
\text { an alternative to } C A B G \\
\text { in the above categories of } \\
\text { patients unsuitable for } \\
\text { surgery. }\end{array}$ & Ilb & c & - \\
\hline $\begin{array}{l}\mathrm{CABG} \text { and } \mathrm{PCl} \text { are NOT } \\
\text { recommended in patients } \\
\text { without angina AND without } \\
\text { viable myocardium. }\end{array}$ & III & C & - \\
\hline $\begin{array}{l}\mathrm{BG}=\text { coronary artery bypass gra } \\
=\text { left ventricular; } \mathrm{PCl}=\text { percutan } \\
\text { ass of recommendation. } \\
\text { vel of evidence. } \\
\text { ferences. }\end{array}$ & $\begin{array}{l}E F=\text { eje } \\
\text { pus coror }\end{array}$ & $\begin{array}{l}\text { n fraction; } \\
\text { interventi }\end{array}$ & \\
\hline
\end{tabular}

revascularization, associated valvular disease, and the presence of co-morbidities.

\subsection{Ventricular reconstruction}

The value of surgical ventricular reconstruction during which scar tissue is removed from the LV wall, with the aim of restoring a more physiological LV volume and shape, is uncertain and was not shown to be of benefit in $\mathrm{STICH} .{ }^{246}$ This technique is not recommended for routine use and is discussed further in the revascularization guidelines. ${ }^{71}$ External containment devices are not recommended.

\subsection{Valvular surgery}

Valvular heart disease may cause or aggravate HF. This section briefly addresses problems particularly relevant to HF, and the reader is referred to the recent ESC/European Association for Cardio-Thoracic Surgery guidelines on valvular disease for more information. $^{247}$

\subsubsection{Aortic stenosis}

The main concern in patients with LV systolic dysfunction is the entity of 'low-flow, low-gradient' aortic stenosis (valve area $<1 \mathrm{~cm}^{2}$, EF $<40 \%$, mean gradient $<40 \mathrm{mmHg}$ ) because some may have severe aortic stenosis and others 'pseudo-aortic stenosis' (i.e. where the low flow across the aortic valve is not caused by a severe fixed obstruction but by low stroke volume). In such individuals, low-dose dobutamine stress echocardiography may help differentiate between these two types of patient and provide information about contractile reserve which is of prognostic importance. In patients with severe aortic stenosis and a low EF, individuals with contractile reserve have a lower operative mortality and better long-term prognosis.

If the mean gradient is $>40 \mathrm{mmHg}$, there is theoretically no lower EF limit for aortic valve replacement in symptomatic patients with severe aortic stenosis. However, substantial recovery of LV function is only likely when the reduced EF is caused by excessive afterload and is not due to scar.

Medical treatment should be optimized, although vasodilators (ACE inhibitors, ARBs, renin inhibitors, CCBs, hydralazine, and nitrates) may cause substantial hypotension in patients with severe aortic stenosis and should only be used with great caution. Optimization of treatment should not delay surgical decision-making. In patients not medically fit for surgery (e.g. because of severe pulmonary disease), transcatheter aortic valve replacement should be considered. ${ }^{248,249}$

\subsubsection{Aortic regurgitation}

Aortic valve repair or replacement is recommended in all symptomatic patients and in asymptomatic patients with severe aortic regurgitation and an $\mathrm{EF}<50 \%$, who are otherwise fit for surgery. Surgery should also be considered in patients with severe aortic regurgitation and an LV end-diastolic diameter $>70 \mathrm{~mm}$ or end-systolic diameter $>50 \mathrm{~mm}$ (or $>25 \mathrm{~mm} / \mathrm{m}^{2}$ body surface area if small stature). ${ }^{31}$ Surgery is indicated to reduce the risk of death, and HF and LV function usually improve after aortic valve repair.

It is important not to confuse mild to moderate aortic incompetence secondary to LV dilatation with LV dilatation and systolic dysfunction due to primary severe aortic regurgitation.

\subsubsection{Mitral regurgitation}

Assessment of mitral regurgitation is complex, particularly in patients with systolic dysfunction (and assessment of systolic function is complicated in the presence of mitral regurgitation-see Section 4.1). Differentiating between primary and secondary mitral regurgitation is crucial (see below).

The decision to recommend surgery should take account of symptoms, age, concurrent AF, reduced LV systolic function, pulmonary hypertension, and the suitability of the valve for repair, which are the most important predictors of post-operative outcome.

\section{Primary (organic) mitral regurgitation}

In primary mitral regurgitation due to flail leaflets, an LV endsystolic diameter $\geq 40 \mathrm{~mm}$ is associated with increased mortality whether the patient is treated medically or surgically. When the $\mathrm{EF}$ is $<30 \%$, a durable surgical repair may improve symptoms, 
although its effect on survival is unknown. In this situation, the decision to operate should take account of response to medical therapy, co-morbidity, and the likelihood that the valve can be repaired (rather than replaced).

\section{Secondary mitral regurgitation}

This occurs because LV enlargement and remodelling lead to reduced leaflet closing. Effective medical therapy leading to reverse remodelling of the LV may reduce functional mitral regurgitation, and every effort should be made to optimize medical treatment in these patients.

Ischaemic mitral regurgitation is a particular type of secondary mitral regurgitation that may be more suitable for surgical repair. As it is often a dynamic condition, stress testing is important in its evaluation. An exercise-induced increase of effective regurgitant orifice ( $\geq 13 \mathrm{~mm}^{2}$ ) is associated with a worse prognosis. Combined valve and coronary surgery should be considered in symptomatic patients with LV systolic dysfunction, coronary arteries suitable for revascularization, and evidence of viability. Predictors of late failure of valve repair include large interpapillary muscle distance, severe posterior mitral leaflet tethering, and marked LV dilatation (LV end-diastolic diameter $>65 \mathrm{~mm}$ ). In these patients, mitral valve replacement, rather than repair, may be advisable. In the presence of AF, atrial ablation and left atrial appendage closure may be considered at the time of mitral valve surgery.

The role of isolated mitral valve surgery in patients with severe functional mitral regurgitation and severe LV systolic dysfunction who cannot be revascularized or have non-ischaemic cardiomyopathy is questionable, and in most patients conventional medical and device therapy are preferred. In selected cases, repair may be considered in order to avoid or postpone transplantation.

In patients with an indication for valve repair but judged inoperable or at unacceptably high surgical risk, percutaneous edge-to-edge repair may be considered in order to improve symptoms. $^{250}$

\subsection{Heart transplantation}

Heart transplantation is an accepted treatment for end-stage HF. $^{251,252}$ Although controlled trials have never been conducted, there is consensus that transplantation-provided that proper selection criteria are applied-significantly increases survival, exercise capacity, quality of life, and return to work compared with conventional treatment.

Apart from the shortage of donor hearts, the main challenges in transplantation are the consequences of the limited effectiveness and complications of immunosuppressive therapy in the long term (i.e. antibody-mediated rejection, infection, hypertension, renal failure, malignancy, and coronary artery vasculopathy). The indications for and contraindications to heart transplantation are summarized in Table 23.

\subsection{Mechanical circulatory support}

MCS is an umbrella term describing a number of different technologies used to provide both short- and longer term assistance in patients with either chronic HF or AHF. A variety of terms have been used to describe the use of these technologies (Table 24). ${ }^{211,253}$ The most experience is with MCS in end-stage
Table 23 Heart transplantation: indications and contraindications

\begin{tabular}{|c|c|}
\hline \multirow[t]{3}{*}{$\begin{array}{l}\text { Patients to } \\
\text { consider }\end{array}$} & $\begin{array}{l}\text { End-stage heart failure with severe symptoms, } \\
\text { a poor prognosis, and no remaining alternative } \\
\text { treatment options }\end{array}$ \\
\hline & $\begin{array}{l}\text { Motivated, well informed, and emotionally } \\
\text { stable }\end{array}$ \\
\hline & $\begin{array}{l}\text { Capable of complying with the intensive } \\
\text { treatment required post-operatively }\end{array}$ \\
\hline \multirow[t]{12}{*}{ Contraindications } & Active infection \\
\hline & $\begin{array}{l}\text { Severe peripheral arterial or cerebrovascular } \\
\text { disease }\end{array}$ \\
\hline & Current alcohol or drug abuse \\
\hline & Treated cancer in previous 5 years \\
\hline & Unhealed peptic ulcer \\
\hline & Recent thrombo-embolism \\
\hline & $\begin{array}{l}\text { Significant renal failure (e.g. creatinine clearance } \\
<50 \mathrm{~mL} / \mathrm{min} \text { ) }\end{array}$ \\
\hline & Significant liver disease \\
\hline & Systemic disease with multiorgan involvement \\
\hline & $\begin{array}{l}\text { Other serious co-morbidity with poor } \\
\text { prognosis }\end{array}$ \\
\hline & Emotional instability or untreated mental illness \\
\hline & $\begin{array}{l}\text { High, fixed pulmonary vascular resistance } \\
(>4-5 \text { Wood Units and mean transpulmonary } \\
\text { gradient }>15 \mathrm{mmHg})\end{array}$ \\
\hline
\end{tabular}

$\mathrm{HF}=$ heart failure

Table 24 Terms describing various uses of mechanical circulatory support (MCS)

\begin{tabular}{|l|l|}
\hline $\begin{array}{l}\text { Bridge to } \\
\text { decision (BTD): }\end{array}$ & $\begin{array}{l}\text { Use of MCS in patients with drug-refractory acute } \\
\text { circulatory collapse and at immediate risk of death } \\
\text { to sustain life until a full clinical evaluation can be } \\
\text { completed and additional therapeutic options can } \\
\text { be evaluated. }\end{array}$ \\
\hline $\begin{array}{l}\text { Bridge to } \\
\text { candidacy (BTC): }\end{array}$ & $\begin{array}{l}\text { Use of MCS to improve end-organ function in } \\
\text { order to make an ineligible patient eligible for } \\
\text { transplantation. }\end{array}$ \\
\hline $\begin{array}{l}\text { Bridge to } \\
\text { transplantation } \\
\text { (BTT): }\end{array}$ & $\begin{array}{l}\text { Use of MCS to keep a patient at high risk of death } \\
\text { before transplantation alive until a donor organ } \\
\text { becomes available. }\end{array}$ \\
\hline $\begin{array}{l}\text { Bridge to } \\
\text { recovery (BTR): }\end{array}$ & $\begin{array}{l}\text { Use of MCS to keep patient alive until intrinsic } \\
\text { cardiac function recovers sufficiently to remove MCS. }\end{array}$ \\
\hline $\begin{array}{l}\text { Destination } \\
\text { therapy (DT): }\end{array}$ & $\begin{array}{l}\text { Long-term use of MCS as an alternative to } \\
\text { transplantation in patients with end-stage heart } \\
\text { failure ineligible for transplantation. }\end{array}$ \\
\hline
\end{tabular}

MCS = mechanical circulatory support. 
HF, initially as bridge to transplantation (BTT), but more recently as destination therapy (DT).

\subsubsection{End-stage heart failure}

For selected patients with end-stage HF, transplantation remains the gold-standard treatment, with good long-term survival. However, because of the increasing numbers of patients with endstage HF, limited organ donation, and technological advances, MCS with an LV assist device (LVAD) or bi-ventricular assist device (BiVAD) is increasingly seen as an alternative for some of these individuals. Initially MCS was used as a short-term BTT treatment (Table 24), but is now being used long-term, as so-called 'destination therapy (DT)', in patients not eligible for transplantation. Ventricular assist devices may ultimately become a more general alternative to transplantation, as current 2- to 3-year survival rates in carefully selected patients receiving the latest continuous flow devices are much better than with medical therapy only. ${ }^{254,255}$ Patients receiving these devices also have a posttransplant survival rate similar to those not requiring bridging. However, despite technological improvements, bleeding, thromboembolism (both of which can cause stroke), infection, and device failure remain significant problems; these issues, plus the high cost of devices and implantation, have limited their wider use. It is recommended that such devices are only implanted and managed at tertiary heart failure centres with appropriately trained, specialist HF physicians and surgeons. Ideally these centres should also undertake transplantation.

In some patients, LV reverse remodelling and functional improvement during MCS permit removal of the ventricular assist devices ('bridge-to-recovery, BTR)'. This outcome may occur in some patients with non-ischaemic cardiomyopathy, but is more likely in patients with an acute fulminant, but reversible, cause of HF such as acute myocarditis. ${ }^{256}$ Another concept is using MCS to permit recovery of end-organ dysfunction, so-called 'bridge to candidacy (BTC)', which may allow ineligible patients to become eligible for transplantation. The difficult decision to withdraw MCS may need to be made if the patient does not become eligible and DT is not possible.

\section{Table 25 Patients potentially eligible for implantation} of a ventricular assist device

\begin{tabular}{|l|}
\hline $\begin{array}{l}\text { Patients with }>2 \text { months of severe symptoms despite optimal medical } \\
\text { and device therapy and more than one of the following: }\end{array}$ \\
\hline - $\mathrm{LVEF}<25 \%$ and, if measured, peak $\mathrm{VO}_{2}<12 \mathrm{~mL} / \mathrm{kg} / \mathrm{min}$ \\
\hline - $\geq 3 \mathrm{HF}$ hospitalizations in previous 12 months without an obvious \\
precipitating cause
\end{tabular}

$\mathrm{Cl}=$ cardiac index; $\mathrm{HF}=$ heart failure; i.v. = intravenous; $\mathrm{LVEF}=$ left ventricular ejection fraction; PCWP = pulmonary capillary wedge pressure; SBP = systolic blood pressure.

\section{Recommendations for surgical implantation of LVADs} in patients with systolic heart failure

\begin{tabular}{|c|c|c|c|}
\hline Recommendations & Class $^{a}$ & Level $^{\mathrm{b}}$ & $\operatorname{Ref}^{\mathrm{C}}$ \\
\hline $\begin{array}{l}\text { An LVAD or BiVAD is } \\
\text { recommended in selected } \\
\text { patients }{ }^{d} \text { with end-stage HF } \\
\text { despite optimal pharmacological } \\
\text { and device treatment and who } \\
\text { are otherwise suitable for heart } \\
\text { transplantation, to improve } \\
\text { symptoms and reduce the } \\
\text { risk of HF hospitalization for } \\
\text { worsening HF and to reduce } \\
\text { the risk of premature death } \\
\text { while awaiting transplantation. }\end{array}$ & I & $\mathbf{B}$ & $\begin{array}{c}254,255 \\
258\end{array}$ \\
\hline $\begin{array}{l}\text { An LVAD should be considered } \\
\text { in highly selected patients }{ }^{d} \text { who } \\
\text { have end-stage HF despite } \\
\text { optimal pharmacological and } \\
\text { device therapy and who are } \\
\text { not suitable for heart } \\
\text { transplantation, but are } \\
\text { expected to survive }>\text { I year } \\
\text { with good functional status, to } \\
\text { improve symptoms, and reduce } \\
\text { the risk of HF hospitalization } \\
\text { and of premature death. }\end{array}$ & Ila & B & 254 \\
\hline
\end{tabular}

BiVAD = bi-ventricular assist device; $\mathrm{HF}=$ heart failure; $\mathrm{LVAD}=$ left ventricular assist device.

${ }^{\mathrm{a}}$ Class of recommendation.

bevel of evidence.

'References.

'See text and Table 25.

Typically, patients with end-stage HF considered for MCS are on continuous inotropic support (Table 25). ${ }^{211,253,257}$ Evaluation of right ventricular function is crucial as post-operative right ventricular failure greatly increases perioperative mortality and reduces survival to, and after, transplantation. Consequently, BiVAD, rather than LVAD, support should be considered for BTT in patients with biventricular failure or at high risk of developing right ventricular failure after LVAD implantation. Referral before right ventricular failure develops is preferable. Indeed, earlier ventricular assist device implantation in less severely ill patients (e.g. with an EF $<25 \%$, peak oxygen consumption $<12 \mathrm{~mL} / \mathrm{kg} / \mathrm{min}$, and only requiring intermittent inotropic support), and before right ventricular or multiorgan failure develops, leads to better surgical outcomes.

Patients with active infection, severe renal, pulmonary, or hepatic dysfunction, or uncertain neurological status after cardiac arrest or due to cardiogenic shock are not usually candidates for BTT or DT, but may be candidates for BTC.

\subsubsection{Acute heart failure}

In addition to ventricular assist devices, other forms of short-term, temporary MCS may be used in selected patients with AHF, including intra-aortic balloon counterpulsation, other percutaneous cardiac support, and ECMO. In addition to the uses described 
above, MCS, particularly ECMO, can be used as a "bridge to decision (BTD)' in patients with acute and rapidly deteriorating HF where full evaluation has not been possible and in whom death will occur without MCS. However, the difficult decision to withdraw MCS may need to be made if the patient is not eligible for conventional corrective surgery or longer term MCS.

\section{Holistic management, including exercise training and multidisciplinary management programmes, patient monitoring, and palliative care}

Non-pharmacological non-device/surgical interventions used in the management of HF (both HF-REF and HF-PEF) are summarized in

\section{Recommendations for exercise prescription and multidisciplinary management}

\begin{tabular}{|l|c|c|c|}
\hline Recommendations & Class $^{\mathbf{a}}$ & Level $^{\mathbf{b}}$ & Ref $^{\mathrm{c}}$ \\
\hline $\begin{array}{l}\text { It is recommended that regular } \\
\text { aerobic exercise is encouraged } \\
\text { in patients with heart failure to } \\
\text { improve functional capacity and } \\
\text { symptoms. }\end{array}$ & I & A & 262,263 \\
\hline $\begin{array}{l}\text { It is recommended that patients } \\
\text { with heart failure are enrolled } \\
\text { in a multidisciplinary-care } \\
\text { management programme to } \\
\text { reduce the risk of heart failure } \\
\text { hospitalization. }\end{array}$ & I & A & $236,259,264$ \\
\hline
\end{tabular}

${ }^{a}$ Class of recommendation

bLevel of evidence.

'References.
Tables 26 and 27, and detailed practical recommendations on their use have been published by the Heart Failure Association. ${ }^{259}$ There is no evidence that most of these improve mortality or morbidity, and some long-cherished approaches may not be beneficial, e.g. advice to restrict sodium intake and self-management counselling. ${ }^{260,261}$ For this reason, these interventions have not been given a recommendation with an evidence level. The exceptions are implementation of care in a multidisciplinary framework and exercise training, both of which are discussed further below.

\subsection{Exercise training}

Several systematic reviews and meta-analyses of small studies have shown that physical conditioning by exercise training improves exercise tolerance, health-related quality of life, and HF hospitalization rates in patients with HF. Recently, a single large RCT [Heart Failure: A Controlled Trial Investigating Outcomes of Exercise Training (HF-ACTION)] investigated the effects of exercise training in 2331 relatively young (mean age 59 years) medically stable patients with mild to moderately severe symptoms (NYHA class II 63\% and class III 35\%) and an EF $\leq 35 \% .{ }^{262}$ The intervention comprised 36 supervised sessions in the initial 3 months followed by home-based training. The median follow-up was 30 months. In an adjusted analysis, exercise training led to an $11 \%$ reduction in the primary composite outcome of all-cause mortality or all-cause hospitalization (unadjusted $P=0.13$; adjusted $P=0.03$ ). There was also a $15 \%$ RRR in a secondary composite outcome of cardiovascular death or HF hospitalization (unadjusted $P=0.06$; adjusted $P=0.03$ ). There was no reduction in mortality, and no safety concerns were raised. Adherence to exercise declined substantially after the period of supervised training.

Collectively, the evidence suggests that physical training is beneficial in HF, although typical elderly patients were not enrolled in many studies and the optimum exercise 'prescription' is uncertain. Furthermore, the single large trial showed a borderline treatment effect that was only obtained with a very intensive intervention that may not be practical to deliver in every centre. Exercise training is

Table 26 Characteristics and components of management programmes for patients with heart failure with reduced ejection fraction and heart failure with preserved ejection fraction

\begin{tabular}{|l|l|}
\hline Characteristics & Should employ a multidisciplinary approach (cardiologists, primary care physicians, nurses, pharmacists, etc.) \\
\cline { 2 - 3 } & Should target high-risk symptomatic patients \\
\hline & Should include competent and professionally educated staff \\
\hline Components & Optimized medical and device management \\
\hline & Adequate patient education, with special emphasis on adherence and self-care \\
\hline & Patient involvement in symptom monitoring and flexible diuretic use \\
\hline Follow-up after discharge (regular clinic and/or home-based visits; possibly telephone support or remote monitoring) \\
\hline & Increased access to healthcare (through in-person follow-up and by telephone contact; possibly through remote monitoring) \\
\hline & Facilitated access to care during episodes of decompensation \\
\hline & $\begin{array}{l}\text { Assessment of (and appropriate intervention in response to) an unexplained increase in weight, nutritional status, functional } \\
\text { status, quality of life, and laboratory findings }\end{array}$ \\
\hline & Access to advanced treatment options \\
\hline & Provision of psychosocial support to patients and family and/or caregivers \\
\hline
\end{tabular}


Table 27 Essential topics that should be covered during patient education, and the skills and self-care behaviours that should be taught in relation to these topics.

\begin{tabular}{|c|c|}
\hline Educational topic & Patient skills and self-care behaviours \\
\hline Definition and aetiology & - Understand the cause of heart failure and why symptoms occur \\
\hline Prognosis & - Understand important prognostic factors and make realistic decisions \\
\hline \multirow{5}{*}{$\begin{array}{l}\text { Symptom monitoring } \\
\text { and self-care }\end{array}$} & - Monitor and recognize signs and symptoms \\
\hline & - Record daily weight and recognize rapid weight gain \\
\hline & - Know how and when to notify healthcare provider \\
\hline & $\begin{array}{l}\text { - In the case of increasing dyspnoea or oedema or a sudden unexpected weight gain of }>2 \mathrm{~kg} \text { in } 3 \text { days, patients may } \\
\text { increase their diuretic dose and/or alert their healthcare team }\end{array}$ \\
\hline & $\begin{array}{l}\text { - Use flexible diuretic therapy if appropriate and recommended after appropriate education and provision of detailed } \\
\text { instructions }\end{array}$ \\
\hline \multirow{2}{*}{$\begin{array}{l}\text { Pharmacological } \\
\text { treatment }\end{array}$} & - Understand indications, dosing, and effects of drugs \\
\hline & - Recognize the common side effects of each drug prescribed \\
\hline \multirow[t]{2}{*}{ Adherence } & - Understand the importance of following treatment recommendations and maintaining motivation to follow treatment plan \\
\hline & $\begin{array}{l}\text { - Sodium restriction may help control the symptoms and signs of congestion in patients with symptomatic heart failure } \\
\text { classes III and IV }\end{array}$ \\
\hline \multirow[t]{3}{*}{ Diet } & $\begin{array}{l}\text { - Avoid excessive fluid intake: fluid restriction of } \mathrm{I} .5-2 \mathrm{~L} / \text { day may be considered in patients with severe heart failure to relieve } \\
\text { symptoms and congestion. Restriction of hypotonic fluids may improve hyponatraemia. Routine fluid restriction in all } \\
\text { patients with mild to moderate symptoms is probably not of benefit. Weight-based fluid restriction }(30 \mathrm{~mL} / \mathrm{kg} \text { body weight, } \\
35 \mathrm{~mL} / \mathrm{kg} \text { if body weight }>85 \mathrm{~kg} \text { ) may cause less thirst }\end{array}$ \\
\hline & - Monitor and prevent malnutrition \\
\hline & - Eat healthily and keep a healthy weight (see Section II) \\
\hline Alcohol & $\begin{array}{l}\text { - Modest intake of alcohol: abstinence is recommended in patients with alcohol-induced cardiomyopathy. Otherwise, normal } \\
\text { alcohol guidelines apply ( } 2 \text { units per day in men or I unit per day in women). I unit is } 10 \mathrm{~mL} \text { of pure alcohol (e.g. I glass of } \\
\text { wine, I/2 pint of beer, I measure of spirit) }\end{array}$ \\
\hline Smoking and drugs & - Stop smoking and/or taking illicit drugs \\
\hline \multirow[t]{3}{*}{ Exercise } & - Understand the benefits of exercise \\
\hline & - Perform exercise training regularly \\
\hline & - Be reassured and comfortable about physical activity \\
\hline \multirow[t]{2}{*}{ Travel and leisure } & - Prepare travel and leisure activities according to physical capacity \\
\hline & $\begin{array}{l}\text { - When travelling, carry a written report of medical history and current medication regimen and carry extra medication. } \\
\text { Monitor and adapt fluid intake particularly during flights and in hot climates. Beware adverse reactions to sun exposure with } \\
\text { certain medications (e.g. amiodarone) }\end{array}$ \\
\hline Sexual activity & $\begin{array}{l}\text { - Be reassured about engaging in sex and discuss problems with healthcare professionals. Stable patients can undertake normal } \\
\text { sexual activity that does not provoke undue symptoms. For treatment of erectile dysfunction, see Section II.I0 }\end{array}$ \\
\hline Immunization & - Receive immunization against influenza and pneumococcal disease according to local guidelines and practice \\
\hline \multirow{2}{*}{$\begin{array}{l}\text { Sleep and breathing } \\
\text { disorders }\end{array}$} & - Recognize preventive behaviour such as reducing weight in obese patients, smoking cessation, and abstinence from alcohol \\
\hline & - Learn about treatment options if appropriate \\
\hline \multirow[t]{2}{*}{ Psychosocial aspects } & $\begin{array}{l}\text { - Understand that depressive symptoms and cognitive dysfunction are common in patients with heart failure and the } \\
\text { importance of social support }\end{array}$ \\
\hline & - Learn about treatment options if appropriate \\
\hline
\end{tabular}

discussed in more detail in a recent Heart Failure Association consensus paper. ${ }^{263}$

\subsection{Organization of care and multidisciplinary management programmes}

The goal of management of HF is to provide a 'seamless' system of care, embracing both the community and hospital, to ensure that the management of every patient is optimal, from the beginning to the end of their healthcare journey. The standards of care that patients with HF should expect have been published by the Heart Failure Association. ${ }^{236}$ To achieve this goal, other services, such as cardiac rehabilitation and palliative care, must be integrated into the overall provision for patients with HF. Fundamental to the delivery of this complete package of care are multidisciplinary management programmes designed to improve outcomes through structured follow-up with patient education, optimization of medical treatment, psychosocial support, and improved access to care. ${ }^{264}$ Key to the success of these programmes is coordination of care along the continuum of HF and throughout the chain-of-care delivered by the various services within the healthcare system. This 
necessitates close collaboration between HF practitioners (cardiologists and HF nurses) and experts in allied health professions, including pharmacists, dieticians, physiotherapists, psychologists, primary care providers, and social workers. Although the content and structure of HF management programmes may vary in different countries and healthcare settings, the components shown in Tables 26 and 27 are recommended.

\subsection{Serial natriuretic peptide measurement}

High natriuretic peptide concentrations are associated with a poor prognosis, and a fall in peptide levels correlates with a better prognosis. However, several RCTs that evaluated natriuretic peptideguided treatment (intensifying treatment in order to lower peptide levels) have given conflicting results. ${ }^{265}$ It is uncertain whether outcome is better using this approach than by simply optimizing treatment (combinations and doses of drugs, devices) according to guidelines.

\subsection{Remote monitoring (using an implanted device)}

Management adapted in response to monitoring thoracic impedance (as an indirect measure of intrathoracic fluid) has not been shown to improve outcomes. ${ }^{266}$ Treatment adjusted in response to pulmonary artery pressure measured using an implanted monitor did reduce hospital admission for HF in one RCT, ${ }^{267}$ but the general applicability of this approach is uncertain and a guideline recommendation is not yet possible.

\subsection{Remote monitoring (no implanted device)}

The optimum approach to non-invasive remote monitoring is uncertain, and RCTs performed to date have given inconsistent results and do not yet support a guideline recommendation. ${ }^{268}$

\subsection{Structured telephone support}

Although a meta-analysis of RCTs suggests that structured telephone support in addition to conventional care may reduce the risk of hospitalization in patients with HF, few individual RCTs showed this benefit, and the evidence is not robust enough to support a guideline recommendation. ${ }^{268,269}$

\subsection{Palliative/supportive/end-of-life care}

HF has an unpredictable disease trajectory and it is often difficult to identify a specific time point to consider palliative care. Features that should trigger consideration of palliative care are listed in Tables 28 and 29. At this point in a patient's disease trajectory, the focus should be on improvement in quality of life, control of symptoms, early detection, and treatment of episodes of deterioration, and on pursuing a holistic approach to patient care, encompassing physical, psychological, social, and spiritual well-being. Liaison between the specialist palliative care service and the HF team and/or the primary care physician, using a shared-care approach, is required in order to address and coordinate the patients' care optimally. Palliative care has been discussed in detail in a position paper from the Heart Failure Association. ${ }^{270}$
Table 28 Patients in whom palliative care should be considered

\begin{tabular}{|l|}
\hline $\begin{array}{l}\text { - Frequent admission to hospital or other serious episodes of } \\
\text { decompensation despite optimized treatment }\end{array}$ \\
\hline - Heart transplantation and mechanical circulatory support ruled out \\
\hline - Chronic poor quality of life with NYHA class IV symptoms \\
\hline - Cardiac cachexia/low serum albumin \\
\hline - Dependence in most activities of daily living \\
\hline - Clinically judged to be close to the end of life \\
\hline
\end{tabular}

NYHA $=$ New York Heart Association.

Table 29 Key components of palliative care service

- Frequent assessment of patient's physical, psychological, and spiritual needs

- Focus on complete symptom relief from both HF and other co-morbidities

- Advanced care planning, taking account of preferences for place of death and resuscitation (which may include deactivating ICD)

$\mathrm{HF}=$ heart failure; $\mathrm{ICD}=$ implantable cardioverter-defibrillator.

\section{Gaps in evidence}

Clinicians responsible for managing patients with HF must frequently make treatment decisions without adequate evidence or a consensus of expert opinion. The following is a shortlist of selected, common issues that deserve to be addressed in future clinical research.

\subsection{Diagnosis}

The diagnosis of HF-PEF remains a particular challenge, and the optimum approach incorporating symptoms, signs, imaging, biomarkers, and other investigations is uncertain.

Strain/speckle imaging - value in diagnostic and prognostic assessment of both HF-REF and HF-PEF?

Diastolic stress test-value in diagnosis of HF-PEF?

\subsection{Co-morbidity}

The long-term safety and efficacy of many treatments for comorbidities are unknown, but are of great interest and importance.

Anaemia - erythropoiesis-stimulating agents, iron?

Depression-selective serotonin reuptake inhibitors, cognitive therapy?

Diabetes - metformin, GLP-1 agonists/analogues, DPP IV inhibitors, SGLT-2 inhibitors?

Sleep-disordered breathing-positive airways pressure therapies? 


\subsection{Non-pharmacological, non-interventional therapy}

Salt restriction-is it effective and safe?

Cardiac cachexia - is there an effective and safe treatment?

\subsection{Pharmacological therapy}

Digoxin-efficacy and safety in modern era of pharmacological and device therapy?

Hydralazine and ISDN-efficacy and safety in non-black patients?

Renin inhibition - is it an effective and safe alternative to/addition to ACE inhibition?

New oral anticoagulants - efficacy and safety compared with aspirin in patients in sinus rhythm?

Clopidogrel and other novel antiplatelet agents-efficacy and safety compared with aspirin in patients in sinus rhythm?

Dual neprilysin/angiotensin receptor inhibitors-efficacy and safety compared with an ACE inhibitor?

\subsection{Devices}

CRT - the efficacy and safety of CRT remains unknown in certain groups of patients.
- patients with a normal QRS duration but echocardiographic dyssynchrony?

- patients with RBBB and IVCD?

- patients in AF?

LVADs - the long-term efficacy and safety of LVADs as an alternative to heart transplantation or medical therapy remains uncertain

Remote monitoring-the long-term efficacy and safety of the various remote monitoring strategies available remain uncertain

\subsection{Acute heart failure}

The treatment of acute heart failure remains largely opinion-based with little good evidence to guide therapy.

Intravenous nitrates - efficacy and safety still uncertain.

Levosimendan - efficacy and safety still uncertain.

Omecamtiv mecarbil-is it effective and safe?

Ultrafiltration-efficacy and safety unknown.

\subsection{End-of-life care}

What is the optimum palliative care package?

When should palliative care be started?

The CME text 'European Guidelines on cardiovascular disease prevention in clinical practice (version 2012)' is accredited by the European Board for Accreditation in Cardiology (EBAC). EBAC works according to the quality standards of the European Accreditation Council for Continuing Medical Education (EACCME), which is an institution of the European Union of Medical Specialists (UEMS). In compliance with EBAC/EACCME guidelines, all authors participating in this programme have disclosed potential conflicts of interest that might cause a bias in the article. The Organizing Committee is responsible for ensuring that all potential conflicts of interest relevant to the programme are declared to the participants prior to the CME activities.

CME questions for this article are available at: European Heart Journal http://www.oxforde-learning.com/eurheartj and European Society of Cardiology http://www.escardio. EBAC org/guidelines.

\section{References}

1. Dickstein K, Cohen-Solal A, Filippatos G, McMurray J], Ponikowski P, Poole-Wilson PA, Stromberg A, van Veldhuisen DJ, Atar D, Hoes AW, Keren A, Mebazaa A, Nieminen M, Priori SG, Swedberg K. ESC guidelines for the diagnosis and treatment of acute and chronic heart failure 2008: the Task Force for the diagnosis and treatment of acute and chronic heart failure 2008 of the European Society of Cardiology. Developed in collaboration with the Heart Failure Association of the ESC (HFA) and endorsed by the European Society of Intensive Care Medicine (ESICM). Eur J Heart Fail 2008; 10:933-989.

2. Davie AP, Francis CM, Caruana L, Sutherland GR, McMurray JJ. Assessing diagnosis in heart failure: which features are any use? QJM 1997;90:335-339.

3. Mant J, Doust J, Roalfe A, Barton P, Cowie MR, Glasziou P, Mant D, McManus RJ, Holder R, Deeks J, Fletcher K, Qume M, Sohanpal S, Sanders S, Hobbs FD. Systematic review and individual patient data meta-analysis of diagnosis of heart failure, with modelling of implications of different diagnostic strategies in primary care. Health Technol Assess 2009;13:1-207, iii.

4. Oudejans I, Mosterd A, Bloemen JA, Valk MJ, van Velzen E, Wielders JP, Zuithoff NP, Rutten FH, Hoes AW. Clinical evaluation of geriatric outpatients with suspected heart failure: value of symptoms, signs, and additional tests. Eur J Heart Fail 2011;13:518-527.

5. Fonseca C. Diagnosis of heart failure in primary care. Heart Fail Rev 2006;11 95-107.

6. Kelder JC, Cramer MJ, van Wijngaarden J, van Tooren R, Mosterd A, Moons KG Lammers JW, Cowie MR, Grobbee DE, Hoes AW. The diagnostic value of physical examination and additional testing in primary care patients with suspected heart failure. Circulation 2011:124:2865-2873.
7. Borlaug BA, Paulus WJ. Heart failure with preserved ejection fraction: pathophysiology, diagnosis, and treatment. Eur Heart J 2011;32:670-679.

8. Paulus WJ, Tschope C, Sanderson JE, Rusconi C, Flachskampf FA, Rademakers FE, Marino P, Smiseth OA, De Keulenaer G, Leite-Moreira AF, Borbely A, Edes I, Handoko ML, Heymans S, Pezzali N, Pieske B, Dickstein K, Fraser AG, Brutsaert DL. How to diagnose diastolic heart failure: a consensus statement on the diagnosis of heart failure with normal left ventricular ejection fraction by the Heart Failure and Echocardiography Associations of the European Society of Cardiology. Eur Heart J 2007;28:2539-2550.

9. Marwick TH, Raman SV, Carrio I, Bax JJ. Recent developments in heart failure imaging. JACC Cardiovasc Imaging 2010;3:429-439.

10. Paterson DI, O'Meara E, Chow BJ, Ukkonen H, Beanlands RS. Recent advances in cardiac imaging for patients with heart failure. Curr Opin Cardiol 2011;26: $132-143$

11. McMurray JJ, Clinical practice. Systolic heart failure. N Engl J Med 2010;362 228-238.

12. Chen J, Normand SL, Wang Y, Krumholz HM. National and regional trends in heart failure hospitalization and mortality rates for Medicare beneficiaries, 1998-2008. JAMA 2011;306:1669-1678.

13. Dunlay SM, Redfield MM, Weston SA, Therneau TM, Hall Long K, Shah ND Roger VL. Hospitalizations after heart failure diagnosis a community perspective. J Am Coll Cardiol 2009;54:1695-1702.

14. Khot UN, Jia G, Moliterno DJ, Lincoff AM, Khot MB, Harrington RA, Topol EJ. Prognostic importance of physical examination for heart failure in non-ST-elevation acute coronary syndromes: the enduring value of Killip classification. JAMA 2003;290:2174-2181.

15. Mosterd A, Hoes AW. Clinical epidemiology of heart failure. Heart 2007;93: $1137-1146$. 
16. Ackerman MJ, Priori SG, Willems S, Berul C, Brugada R, Calkins H, Camm AJ, Ellinor PT, Gollob M, Hamilton R, Hershberger RE, Judge DP, Le Marec H, McKenna WJ, Schulze-Bahr E, Semsarian C, Towbin JA, Watkins H, Wilde A, Wolpert C, Zipes DP. HRS/EHRA expert consensus statement on the state of genetic testing for the channelopathies and cardiomyopathies: this document was developed as a partnership between the Heart Rhythm Society (HRS) and the European Heart Rhythm Association (EHRA). Heart Rhythm 2011;8: $1308-1339$.

17. Hogg K, Swedberg K, McMurray J. Heart failure with preserved left ventricular systolic function; epidemiology, clinical characteristics, and prognosis. I Am Coll Cardiol 2004;43:317-327.

18. Lam CS, Donal E, Kraigher-Krainer E, Vasan RS. Epidemiology and clinical course of heart failure with preserved ejection fraction. Eur J Heart Fail 2011;13:18-28.

19. Meta-analysis Global Group in Chronic Heart Failure (MAGGIC). The survival of patients with heart failure with preserved or reduced left ventricular ejection fraction: an individual patient data meta-analysis. Eur Heart / 2012;33:1750-1757.

20. Shah AM, Mann DL. In search of new therapeutic targets and strategies for heart failure: recent advances in basic science. Lancet 2011;378:704-712.

21. Stewart S, Maclntyre K, Hole DJ, Capewell S, McMurray JJ. More 'malignant' than cancer? Five-year survival following a first admission for heart failure. Eur J Heart Fail 2001;3:315-322

22. Stewart S, Ekman I, Ekman T, Oden A, Rosengren A. Population impact of heart failure and the most common forms of cancer: a study of 1162309 hospital cases in Sweden (1988 to 2004). Circ Cardiovasc Qual Outcomes 2010;3:573-580.

23. Jhund PS, Macintyre K, Simpson CR, Lewsey JD, Stewart S, Redpath A, Chalmers JW, Capewell S, McMurray JJ. Long-term trends in first hospitalization for heart failure and subsequent survival between 1986 and 2003: a population study of 5.1 million people. Circulation 2009;119:515-523.

24. Rutten FH, Moons KG, Cramer MJ, Grobbee DE, Zuithoff NP, Lammers JW, Hoes AW. Recognising heart failure in elderly patients with stable chronic obstructive pulmonary disease in primary care: cross sectional diagnostic study. BMJ 2005;331:1379.

25. Hawkins NM, Petrie MC, Jhund PS, Chalmers GW, Dunn FG, McMurray JJ. Heart failure and chronic obstructive pulmonary disease: diagnostic pitfalls and epidemiology. Eur J Heart Fail 2009;11:130-139.

26. Daniels LB, Clopton P, Bhalla V, Krishnaswamy P, Nowak RM, McCord J, Hollander JE, Duc P, Omland T, Storrow AB, Abraham WT, Wu AH, Steg PG, Westheim A, Knudsen CW, Perez A, Kazanegra R, Herrmann HC, McCullough PA, Maisel AS. How obesity affects the cut-points for B-type natriuretic peptide in the diagnosis of acute heart failure. Results from the Breathing Not Properly Multinational Study. Am Heart J 2006;151:999-1005.

27. Rudski LG, Lai WW, Afilalo J, Hua L, Handschumacher MD, Chandrasekaran K, Solomon SD, Louie EK, Schiller NB. Guidelines for the echocardiographic assessment of the right heart in adults: a report from the American Society of Echocardiography endorsed by the European Association of Echocardiography, a registered branch of the European Society of Cardiology, and the Canadian Society of Echocardiography. J Am Soc Echocardiogr 2010;23:685-713; quiz $786-688$.

28. Dokainish H, Nguyen JS, Bobek J, Goswami R, Lakkis NM. Assessment of the American Society of Echocardiography-European Association of Echocardiography guidelines for diastolic function in patients with depressed ejection fraction: an echocardiographic and invasive haemodynamic study. Eur J Echocardiogr 2011;12:857-864.

29. Kirkpatrick JN, Vannan MA, Narula J, Lang RM. Echocardiography in heart failure: applications, utility, and new horizons. J Am Coll Cardiol 2007;50:381-396.

30. Lancellotti P, Moura L, Pierard LA, Agricola E, Popescu BA, Tribouilloy C, Hagendorff A, Monin JL, Badano L, Zamorano JL. European Association of Echocardiography recommendations for the assessment of valvular regurgitation. Part 2: mitral and tricuspid regurgitation (native valve disease). Eur J Echocardiogr 2010;11:307-332.

31. Lancellotti P, Tribouilloy C, Hagendorff A, Moura L, Popescu BA, Agricola E, Monin JL, Pierard LA, Badano L, Zamorano JL. European Association of Echocardiography recommendations for the assessment of valvular regurgitation. Part 1: aortic and pulmonary regurgitation (native valve disease). Eur J Echocardiogr 2010; 11:223-244.

32. Popescu BA, Andrade MJ, Badano LP, Fox KF, Flachskampf FA, Lancellotti P, Varga A, Sicari R, Evangelista A, Nihoyannopoulos P, Zamorano JL, Derumeaux G, Kasprzak JD, Roelandt JR. European Association of Echocardiography recommendations for training, competence, and quality improvement in echocardiography. Eur J Echocardiogr 2009;10:893-905.

33. Nagueh SF, Bhatt R, Vivo RP, Krim SR, Sarvari SI, Russell K, Edvardsen T, Smiseth OA, Estep JD. Echocardiographic evaluation of hemodynamics in patients with decompensated systolic heart failure. Circ Cardiovasc Imaging 2011;4:220-227.
34. Sicari R, Nihoyannopoulos P, Evangelista A, Kasprzak J, Lancellotti P, Poldermans D, Voigt JU, Zamorano JL. Stress echocardiography expert consensus statement: European Association of Echocardiography (EAE) (a registered branch of the ESC). Eur J Echocardiogr 2008;9:415-437.

35. Davie AP, Francis CM, Love MP, Caruana L, Starkey IR, Shaw TR, Sutherland GR, McMurray JJ. Value of the electrocardiogram in identifying heart failure due to left ventricular systolic dysfunction. BMJ 1996;312:222.

36. Thomas JT, Kelly RF, Thomas SJ, Stamos TD, Albasha K, Parrillo JE, Calvin JE. Utility of history, physical examination, electrocardiogram, and chest radiograph for differentiating normal from decreased systolic function in patients with heart failure. Am J Med 2002;112:437-445.

37. Khunti K, Squire I, Abrams KR, Sutton AJ. Accuracy of a 12-lead electrocardiogram in screening patients with suspected heart failure for open access echocardiography: a systematic review and meta-analysis. Eur J Heart Fail 2004;6: 571-576.

38. Madias JE. Why recording of an electrocardiogram should be required in every inpatient and outpatient encounter of patients with heart failure. Pacing Clin Electrophysiol 2011;34:963-967.

39. Ewald B, Ewald D, Thakkinstian A, Attia J. Meta-analysis of B type natriuretic peptide and $\mathrm{N}$-terminal pro $\mathrm{B}$ natriuretic peptide in the diagnosis of clinical heart failure and population screening for left ventricular systolic dysfunction. Intern Med J 2008;38:101-113.

40. Doust JA, Glasziou PP, Pietrzak E, Dobson AJ. A systematic review of the diagnostic accuracy of natriuretic peptides for heart failure. Arch Intern Med 2004; 164:1978-1984.

41. Zaphiriou A, Robb S, Murray-Thomas T, Mendez G, Fox K, McDonagh T, Hardman SM, Dargie HJ, Cowie MR. The diagnostic accuracy of plasma BNP and NTproBNP in patients referred from primary care with suspected heart failure: results of the UK natriuretic peptide study. Eur J Heart Fail 2005;7: 537-541.

42. Maisel A, Mueller C, Adams K Jr, Anker SD, Aspromonte N, Cleland JG, Cohen-Solal A, Dahlstrom U, DeMaria A, Di Somma S, Filippatos GS, Fonarow GC, Jourdain P, Komajda M, Liu PP, McDonagh T, McDonald K, Mebazaa A, Nieminen MS, Peacock WF, Tubaro M, Valle R, Vanderhyden M, Yancy CW, Zannad F, Braunwald E. State of the art: using natriuretic peptide levels in clinical practice. Eur J Heart Fail 2008;10:824-839.

43. Fuat A, Murphy JJ, Hungin AP, Curry J, Mehrzad AA, Hetherington A, Johnston JI, Smellie WS, Duffy V, Cawley P. The diagnostic accuracy and utility of a B-type natriuretic peptide test in a community population of patients with suspected heart failure. Br J Gen Pract 2006;56:327-333.

44. Yamamoto K, Burnett JC Jr, Bermudez EA, Jougasaki M, Bailey KR, Redfield MM. Clinical criteria and biochemical markers for the detection of systolic dysfunction. J Card Fail 2000;6:194-200.

45. Cowie MR, Struthers AD, Wood DA, Coats AJ, Thompson SG, Poole-Wilson PA, Sutton GC. Value of natriuretic peptides in assessment of patients with possible new heart failure in primary care. Lancet 1997;350: 1349-1353.

46. Krishnaswamy P, Lubien E, Clopton P, Koon J, Kazanegra R, Wanner E, Gardetto N, Garcia A, DeMaria A, Maisel AS. Utility of B-natriuretic peptide levels in identifying patients with left ventricular systolic or diastolic dysfunction. Am J Med 2001;111:274-279.

47. Kelder JC, Cowie MR, McDonagh TA, Hardman SM, Grobbee DE, Cost B, Hoes AW. Quantifying the added value of BNP in suspected heart failure in general practice: an individual patient data meta-analysis. Heart 2011;97: 959-963.

48. Kelder JC, Cramer MJ, Verweij WM, Grobbee DE, Hoes AW. Clinical utility of three B-type natriuretic peptide assays for the initial diagnostic assessment of new slow-onset heart failure. J Card Fail 2011;17:729-734.

49. Gustafsson F, Steensgaard-Hansen F, Badskjaer J, Poulsen AH, Corell P, Hildebrandt $\mathrm{P}$. Diagnostic and prognostic performance of $\mathrm{N}$-terminal proBNP in primary care patients with suspected heart failure. J Card Fail 2005;11: S15-S20.

50. Nielsen OW, Rasmussen V, Christensen NJ, Hansen JF. Neuroendocrine testing in community patients with heart disease: plasma $\mathrm{N}$-terminal proatrial natriuretic peptide predicts morbidity and mortality stronger than catecholamines and heart rate variability. Scand J Clin Lab Invest 2004;64:619-628.

51. Maisel A, Mueller C, Nowak R, Peacock WF, Landsberg JW, Ponikowski P, Mockel M, Hogan C, Wu AH, Richards M, Clopton P, Filippatos GS, Di Somma S, Anand I, Ng L, Daniels LB, Neath SX, Christenson R, Potocki M, McCord J, Terracciano G, Kremastinos D, Hartmann O, von Haehling S, Bergmann A, Morgenthaler NG, Anker SD. Mid-region pro-hormone markers for diagnosis and prognosis in acute dyspnea: results from the BACH (Biomarkers in Acute Heart Failure) trial. J Am Coll Cardiol 2010;55:2062-2076.

52. Schwitter J. Extending the frontiers of cardiac magnetic resonance. Circulation 2008;118:109-112. 
53. Gebker R, Schwitter J, Fleck E, Nagel E. How we perform myocardial perfusion with cardiovascular magnetic resonance. J Cardiovasc Magn Reson 2007;9: 539-547.

54. Beller GA, Heede RC. SPECT imaging for detecting coronary artery disease and determining prognosis by noninvasive assessment of myocardial perfusion and myocardial viability. I Cardiovasc Transl Res 2011;4:416-424.

55. Leong DP, De Pasquale CG, Selvanayagam JB. Heart failure with normal ejection fraction: the complementary roles of echocardiography and CMR imaging. JACC Cardiovasc Imaging 2010;3:409-420.

56. Myerson SG. Valvular and hemodynamic assessment with CMR. Heart Fail Clin 2009;5:389-400, vi-vii.

57. Raman SV, Simonetti OP. The CMR examination in heart failure. Heart Fail Clin 2009;5:283-300, v

58. Sheikine Y, Di Carli MF. Integrated PET/CT in the assessment of etiology and viability in ischemic heart failure. Curr Heart Fail Rep 2008;5:136-142.

59. Miller JM, Rochitte CE, Dewey M, Arbab-Zadeh A, Niinuma H, Gottlieb I, Paul N, Clouse ME, Shapiro EP, Hoe J, Lardo AC, Bush DE, de Roos A, Cox C, Brinker J, Lima JA. Diagnostic performance of coronary angiography by 64-row CT. N Engl J Med 2008;359:2324-2336.

60. Beanlands RS, Nichol G, Huszti E, Humen D, Racine N, Freeman M, Gulenchyn KY, Garrard L, deKemp R, Guo A, Ruddy TD, Benard F, Lamy A, Iwanochko RM. F-18-fluorodeoxyglucose positron emission tomography imaging-assisted management of patients with severe left ventricular dysfunction and suspected coronary disease: a randomized, controlled trial (PARR-2). J Am Coll Cardiol 2007;50:2002-2012.

61. Lang RM, Bierig M, Devereux RB, Flachskampf FA, Foster E, Pellikka PA, Picard MH, Roman MJ, Seward J, Shanewise J, Solomon S, Spencer KT, St John Sutton M, Stewart W. Recommendations for chamber quantification. Eur J Echocardiogr 2006;7:79-108.

62. Lang RM, Badano LP, Tsang W, Adams DH, Agricola E, Buck T, Faletra FF, Franke A, Hung J, de Isla LP, Kamp O, Kasprzak JD, Lancellotti P, Marwick TH, McCulloch ML, Monaghan MJ, Nihoyannopoulos P, Pandian NG, Pellikka PA, Pepi M, Roberson DA, Shernan SK, Shirali GS, Sugeng L, Ten Cate FJ, Vannan MA, Zamorano JL, Zoghbi WA. EAE/ASE Recommendations for Image Acquisition and Display Using Three-Dimensional Echocardiography. Eur Heart J Cardiovasc Imaging 2012; 13:1-46.

63. Nagueh SF, Appleton CP, Gillebert TC, Marino PN, Oh JK, Smiseth OA, Waggoner AD, Flachskampf FA, Pellikka PA, Evangelisa A. Recommendations for the evaluation of left ventricular diastolic function by echocardiography. Eur J Echocardiogr 2009;10:165-193.

64. Nagueh SF, Middleton KJ, Kopelen HA, Zoghbi WA, Quinones MA. Doppler tissue imaging: a noninvasive technique for evaluation of left ventricular relaxation and estimation of filling pressures. J Am Coll Cardiol 1997;30:1527-1533.

65. Schwitter J, Arai AE. Assessment of cardiac ischaemia and viability: role of cardiovascular magnetic resonance. Eur Heart J 2011;32:799-809.

66. Kilner PJ, Geva T, Kaemmerer H, Trindade PT, Schwitter J, Webb GD. Recommendations for cardiovascular magnetic resonance in adults with congenital heart disease from the respective working groups of the European Society of Cardiology. Eur Heart J 2010;31:794-805.

67. Luchinger R, Schwitter J, Bruder O. Safety of CMR. In: Schwitter J, ed. CMR Update 2012. 2nd ed. Lausanne; p. 31-51. ISBN: 978-3-033-01674-3.

68. Bruder O, Schneider S, Nothnagel D, Pilz G, Lombardi M, Sinha A, Wagner A, Dill T, Frank H, van Rossum A, Schwitter J, Nagel E, Senges J, Sabin G, Sechtem $U$, Mahrholdt $H$. Acute adverse reactions to gadolinium-based contrast agents in CMR: multicenter experience with 17,767 patients. from the EuroCMR Registry. J Am Coll Cardiol-Cardiovasc Imaging 2011;4:1171-1176.

69. Sheikine Y, Di Carli MF. Integrated PET/CT in the assessment of etiology and viability in ischemic heart failure. Curr Heart Fail Rep 2008;5:136-142.

70. Tonino PA, De Bruyne B, Pijls NH, Siebert U, Ikeno F, van' t Veer M, Klauss $V$, Manoharan G, Engstrom T, Oldroyd KG, Ver Lee PN, MacCarthy PA, Fearon WF. Fractional flow reserve versus angiography for guiding percutaneous coronary intervention. N Engl J Med 2009;360:213-224.

71. Wijns W, Kolh P, Danchin N, Di Mario C, Falk V, Folliguet T, Garg S, Huber K, James S, Knuuti J, Lopez-Sendon J, Marco J, Menicanti L, Ostojic M, Piepoli MF, Pirlet C, Pomar JL, Reifart N, Ribichini FL, Schalij MJ, Sergeant P, Serruys PW, Silber S, Sousa Uva M, Taggart D. Guidelines on myocardial revascularization. Eur Heart J 2010;31:2501-2555.

72. Cooper LT, Baughman KL, Feldman AM, Frustaci A, Jessup M, Kuhl U, Levine GN, Narula J, Starling RC, Towbin J, Virmani R. The role of endomyocardial biopsy in the management of cardiovascular disease: a scientific statement from the American Heart Association, the American College of Cardiology, and the European Society of Cardiology Endorsed by the Heart Failure Society of America and the Heart Failure Association of the European Society of Cardiology. Eur Heart J 2007;28:3076-3093.
73. Arena R, Myers J, Guazzi M. Cardiopulmonary exercise testing is a core assessment for patients with heart failure. Congest Heart Fail 2011;17:115-119.

74. Wedel H, McMurray JJ, Lindberg M, Wikstrand J, Cleland JG, Cornel JH, Dunselman P, Hjalmarson A, Kjekshus J, Komajda M, Kuusi T, Vanhaecke J, Waagstein F. Predictors of fatal and non-fatal outcomes in the Controlled Rosuvastatin Multinational Trial in Heart Failure (CORONA): incremental value of apolipoprotein $\mathrm{A}-1$, high-sensitivity $\mathrm{C}$-reactive peptide and $\mathrm{N}$-terminal pro B-type natriuretic peptide. Eur J Heart Fail 2009;11:281-291.

75. Allen LA, Felker GM, Pocock S, McMurray JJ, Pfeffer MA, Swedberg K, Wang D, Yusuf S, Michelson EL, Granger CB. Liver function abnormalities and outcome in patients with chronic heart failure: data from the Candesartan in Heart Failure: Assessment of Reduction in Mortality and Morbidity (CHARM) program. Eur J Heart Fail 2009;11:170-177.

76. Jackson CE, Solomon SD, Gerstein HC, Zetterstrand S, Olofsson B Michelson EL, Granger CB, Swedberg K, Pfeffer MA, Yusuf S, McMurray JJ. Albuminuria in chronic heart failure: prevalence and prognostic importance. Lancet 2009;374:543-550.

77. Felker GM, Allen LA, Pocock SJ, Shaw LK, McMurray J], Pfeffer MA, Swedberg K, Wang D, Yusuf S, Michelson EL, Granger CB. Red cell distribution width as a novel prognostic marker in heart failure: data from the CHARM Program and the Duke Databank. J Am Coll Cardiol 2007;50:40-47.

78. Pocock SJ, Wang D, Pfeffer MA, Yusuf S, McMurray JJ, Swedberg KB, Ostergren J, Michelson EL, Pieper KS, Granger CB. Predictors of mortality and morbidity in patients with chronic heart failure. Eur Heart J 2006;27:65-75.

79. Komajda M, Carson PE, Hetzel S, McKelvie R, McMurray J, Ptaszynska A, Zile MR, Demets D, Massie BM. Factors associated with outcome in heart failure with preserved ejection fraction: findings from the Irbesartan in Heart Failure with Preserved Ejection Fraction Study (I-PRESERVE). Circ Heart Fail 2011;4:27-35

80. Ketchum ES, Levy WC. Establishing prognosis in heart failure: a multimarker approach. Prog Cardiovasc Dis 2011;54:86-96.

81. Stewart S, Jenkins A, Buchan S, McGuire A, Capewell S, McMurray JJ. The current cost of heart failure to the National Health Service in the UK. Eur J Heart Fail 2002;4:361-371.

82. Masson S, Latini R, Anand IS, Barlera S, Angelici L, Vago T, Tognoni G, Cohn JN. Prognostic value of changes in $\mathrm{N}$-terminal pro-brain natriuretic peptide in Val-HeFT (Valsartan Heart Failure Trial). J Am Coll Cardiol 2008;52:997-1003.

83. Wong M, Staszewsky L, Latini R, Barlera S, Volpi A, Chiang YT, Benza RL, Gottlieb SO, Kleemann TD, Rosconi F, Vandervoort PM, Cohn JN. Valsartan benefits left ventricular structure and function in heart failure: Val-HeFT echocardiographic study. J Am Coll Cardiol 2002;40:970-975.

84. Ekman I, Cleland JG, Andersson B, Swedberg K. Exploring symptoms in chronic heart failure. Eur J Heart Fail 2005;7:699-703.

85. Packer M, Narahara KA, Elkayam U, Sullivan JM, Pearle DL, Massie BM, Creager MA. Double-blind, placebo-controlled study of the efficacy of flosequinan in patients with chronic heart failure. Principal Investigators of the REFLECT Study. J Am Coll Cardiol 1993;22:65-72.

86. Cowley AJ, Stainer K, Wynne RD, Rowley JM, Hampton JR. Comparison of the effects of captopril and enoximone in patients with severe heart failure: a placebo controlled double-blind study. Int J Cardiol 1989;24:311-316.

87. Effects of enalapril on mortality in severe congestive heart failure. Results of the Cooperative North Scandinavian Enalapril Survival Study (CONSENSUS). The CONSENSUS Trial Study Group. N Engl / Med 1987;316:1429-1435.

88. Effect of enalapril on survival in patients with reduced left ventricular ejection fractions and congestive heart failure. The SOLVD Investigators. N Engl J Med 1991;325:293-302.

89. Garg R, Yusuf S. Overview of randomized trials of angiotensin-converting enzyme inhibitors on mortality and morbidity in patients with heart failure. Collaborative Group on ACE Inhibitor Trials. JAMA 1995;273:1450-1456.

90. Packer M, Poole-Wilson PA, Armstrong PW, Cleland JG, Horowitz JD, Massie BM, Ryden L, Thygesen K, Uretsky BF. Comparative effects of low and high doses of the angiotensin-converting enzyme inhibitor, lisinopril, on morbidity and mortality in chronic heart failure. ATLAS Study Group. Circulation 1999; 100:2312-2318.

91. The SOLVD Investigators. Effect of enalapril on mortality and the development of heart failure in asymptomatic patients with reduced left ventricular ejection fractions. N Engl J Med 1992;327:685-691.

92. The Cardiac Insufficiency Bisoprolol Study II (CIBIS-II): a randomised trial. Lancet 1999;353:9-13

93. Effect of metoprolol CR/XL in chronic heart failure: Metoprolol CR/XL Randomised Intervention Trial in Congestive Heart Failure (MERIT-HF). Lancet 1999 353:2001-2007.

94. Hjalmarson A, Goldstein S, Fagerberg B, Wedel H, Waagstein F, Kjekshus J, Wikstrand J, El Allaf D, Vitovec J, Aldershvile J, Halinen M, Dietz R, Neuhaus KL, Janosi A, Thorgeirsson G, Dunselman PH, Gullestad L, Kuch J, 
Herlitz J, Rickenbacher P, Ball S, Gottlieb S, Deedwania P. Effects of controlled-release metoprolol on total mortality, hospitalizations, and well-being in patients with heart failure: the Metoprolol CR/XL Randomized Intervention Trial in congestive heart failure (MERIT-HF). MERIT-HF Study Group. JAMA 2000;283:1295-1302.

95. Packer M, Coats AJ, Fowler MB, Katus HA, Krum H, Mohacsi P, Rouleau JL, Tendera M, Castaigne A, Roecker EB, Schultz MK, DeMets DL. Effect of carvedilol on survival in severe chronic heart failure. N Engl J Med 2001;344: 1651-1658.

96. Packer M, Fowler MB, Roecker EB, Coats AJ, Katus HA, Krum H, Mohacsi P, Rouleau JL, Tendera M, Staiger C, Holcslaw TL, Amann-Zalan I, DeMets DL. Effect of carvedilol on the morbidity of patients with severe chronic heart failure: results of the carvedilol prospective randomized cumulative survival (COPERNICUS) study. Circulation 2002;106:2194-2199.

97. Flather MD, Shibata MC, Coats AJ, Van Veldhuisen DJ, Parkhomenko A, Borbola J, Cohen-Solal A, Dumitrascu D, Ferrari R, Lechat P, Soler-Soler J, Tavazzi L, Spinarova L, Toman J, Bohm M, Anker SD, Thompson SG, Poole-Wilson PA. Randomized trial to determine the effect of nebivolol on mortality and cardiovascular hospital admission in elderly patients with heart failure (SENIORS). Eur Heart J 2005;26:215-225.

98. Packer M, Bristow MR, Cohn JN, Colucci WS, Fowler MB, Gilbert EM, Shusterman $\mathrm{NH}$. The effect of carvedilol on morbidity and mortality in patients with chronic heart failure. U.S. Carvedilol Heart Failure Study Group. N Engl J Med 1996;334:1349-1355.

99. Pitt B, Zannad F, Remme WJ, Cody R, Castaigne A, Perez A, Palensky J, Wittes J. The effect of spironolactone on morbidity and mortality in patients with severe heart failure. Randomized Aldactone Evaluation Study Investigators. N Engl / Med 1999;341:709-717.

100. Zannad F, McMurray JJ, Krum H, van Veldhuisen DJ, Swedberg K, Shi H, Vincent J, Pocock SJ, Pitt B. Eplerenone in patients with systolic heart failure and mild symptoms. N Engl J Med 2011;364:11-21.

101. Flather MD, Yusuf S, Kober L, Pfeffer M, Hall A, Murray G, Torp-Pedersen C, Ball S, Pogue J, Moye L, Braunwald E. Long-term ACE-inhibitor therapy in patients with heart failure or left-ventricular dysfunction: a systematic overview of data from individual patients. ACE-Inhibitor Myocardial Infarction Collaborative Group. Lancet 2000;355:1575-1581.

102. McMurray J, Cohen-Solal A, Dietz R, Eichhorn E, Erhardt L, Hobbs FD, Krum H, Maggioni A, McKelvie RS, Pina IL, Soler-Soler J, Swedberg K. Practical recommendations for the use of ACE inhibitors, beta-blockers, aldosterone antagonists and angiotensin receptor blockers in heart failure: putting guidelines into practice. Eur J Heart Fail 2005; 7:710-721.

103. Beta-Blocker Evaluation of Survival Trial Investigators. A trial of the beta-blocker bucindolol in patients with advanced chronic heart failure. N Engl J Med 2001; 344:1659-1667.

104. Poole-Wilson PA, Swedberg K, Cleland JG, Di Lenarda A, Hanrath P, Komajda M, Lubsen J, Lutiger B, Metra M, Remme WJ, Torp-Pedersen C, Scherhag A, Skene A. Comparison of carvedilol and metoprolol on clinical outcomes in patients with chronic heart failure in the Carvedilol Or Metoprolol European Trial (COMET): randomised controlled trial. Lancet 2003;362:7-13.

105. Krum H, Roecker EB, Mohacsi P, Rouleau JL, Tendera M, Coats AJ, Katus HA, Fowler MB, Packer M. Effects of initiating carvedilol in patients with severe chronic heart failure: results from the COPERNICUS Study. JAMA 2003;289: $712-718$.

106. Jondeau G, Neuder Y, Eicher JC, Jourdain P, Fauveau E, Galinier M, Jegou A, Bauer F, Trochu JN, Bouzamondo A, Tanguy ML, Lechat P. B-CONVINCED: Beta-blocker CONtinuation Vs. INterruption in patients with Congestive heart failure hospitalizED for a decompensation episode. Eur Heart J 2009;30: 2186-2192.

107. Pitt B, Remme W, Zannad F, Neaton J, Martinez F, Roniker B, Bittman R, Hurley S, Kleiman J, Gatlin M. Eplerenone, a selective aldosterone blocker, in patients with left ventricular dysfunction after myocardial infarction. $N$ Engl J Med 2003;348:1309-1321.

108. Granger CB, McMurray JJ, Yusuf S, Held P, Michelson EL, Olofsson B, Ostergren J, Pfeffer MA, Swedberg K. Effects of candesartan in patients with chronic heart failure and reduced left-ventricular systolic function intolerant to angiotensin-converting-enzyme inhibitors: the CHARM-Alternative trial. Lancet 2003;362:772-776.

109. Maggioni AP, Anand I, Gottlieb SO, Latini R, Tognoni G, Cohn JN. Effects of valsartan on morbidity and mortality in patients with heart failure not receiving angiotensin-converting enzyme inhibitors. J Am Coll Cardiol 2002;40:1414-1421.

110. Cohn JN, Tognoni G. A randomized trial of the angiotensin-receptor blocker valsartan in chronic heart failure. N Engl J Med 2001;345:1667-1675.

111. McMurray JJ, Ostergren J, Swedberg K, Granger CB, Held P, Michelson EL, Olofsson B, Yusuf S, Pfeffer MA. Effects of candesartan in patients with chronic heart failure and reduced left-ventricular systolic function taking angiotensin-converting-enzyme inhibitors: the CHARM-Added trial. Lancet 2003;362:767-771.

112. Swedberg K, Komajda M, Bohm M, Borer JS, Ford I, Dubost-Brama A, Lerebours G, Tavazzi L. Ivabradine and outcomes in chronic heart failure (SHIFT): a randomised placebo-controlled study. Lancet 2010;376:875-885.

113. The effect of digoxin on mortality and morbidity in patients with heart failure. The Digitalis Investigation Group. N Engl J Med 1997;336:525-533.

114. Cohn JN, Archibald DG, Ziesche S, Franciosa JA, Harston WE, Tristani FE, Dunkman WB, Jacobs W, Francis GS, Flohr KH, for the Veterans Administration Cooperative Study Group. Effect of vasodilator therapy on mortality in chronic congestive heart failure. Results of a Veterans Administration Cooperative Study. N Engl J Med 1986;314:1547-1552

115. Cohn JN, Johnson G, Ziesche S, Cobb F, Francis G, Tristani F, Smith R, Dunkman WB, Loeb $H$, Wong M, Bhat G, Goldman S, Fletcher RD, Doherty J, Hughes CV, Carson P, Cintron G, Shabetai R, Haakenson C. A comparison of enalapril with hydralazine-isosorbide dinitrate in the treatment of chronic congestive heart failure. N Engl J Med 1991;325:303-310.

116. Taylor AL, Ziesche S, Yancy C, Carson P, D'Agostino R Jr, Ferdinand K, Taylor M, Adams K, Sabolinski M, Worcel M, Cohn JN. Combination of isosorbide dinitrate and hydralazine in blacks with heart failure. N Engl J Med 2004;351: 2049-2057.

117. Tavazzi L, Maggioni AP, Marchioli R, Barlera S, Franzosi MG, Latini R, Lucci D, Nicolosi GL, Porcu M, Tognoni G. Effect of $n-3$ polyunsaturated fatty acids in patients with chronic heart failure (the GISSI-HF trial): a randomised, doubleblind, placebo-controlled trial. Lancet 2008;372:1223-1230.

118. Pitt B, Poole-Wilson PA, Segal R, Martinez FA, Dickstein K, Camm AJ, Konstam MA, Riegger G, Klinger GH, Neaton J, Sharma D, Thiyagarajan B. Effect of losartan compared with captopril on mortality in patients with symptomatic heart failure: randomised trial-the Losartan Heart Failure Survival Study ELITE II. Lancet 2000;355:1582-1587.

119. Konstam MA, Neaton JD, Dickstein K, Drexler H, Komajda M, Martinez FA, Riegger GA, Malbecq W, Smith RD, Guptha S, Poole-Wilson PA. Effects of highdose versus low-dose losartan on clinical outcomes in patients with heart failure (HEAAL study): a randomised, double-blind trial. Lancet 2009;374:1840-1848.

120. Pfeffer MA, McMurray JJ, Velazquez EJ, Rouleau JL, Kober L, Maggioni AP, Solomon SD, Swedberg K, Van de Werf F, White H, Leimberger JD, Henis M, Edwards S, Zelenkofske S, Sellers MA, Califf RM. Valsartan, captopril, or both in myocardial infarction complicated by heart failure, left ventricular dysfunction, or both. N Engl J Med 2003;349:1893-1906.

121. Dickstein K, Kjekshus J. Effects of losartan and captopril on mortality and morbidity in high-risk patients after acute myocardial infarction: the OPTIMAAL randomised trial. Optimal Trial in Myocardial Infarction with Angiotensin II Antagonist Losartan. Lancet 2002;360:752-760.

122. Fox K, Ford I, Steg PG, Tendera M, Ferrari R. Ivabradine for patients with stable coronary artery disease and left-ventricular systolic dysfunction (BEAUTIFUL): a randomised, double-blind, placebo-controlled trial. Lancet 2008;372:807-816.

123. Hood WB Jr, Dans AL, Guyatt GH, Jaeschke R, McMurray JJ. Digitalis for treatment of congestive heart failure in patients in sinus rhythm: a systematic review and meta-analysis. J Card Fail 2004;10:155-164.

124. Dietary supplementation with $n-3$ polyunsaturated fatty acids and vitamin $E$ after myocardial infarction: results of the GISSI-Prevenzione trial. Gruppo Italiano per lo Studio della Sopravvivenza nell'Infarto miocardico. Lancet 1999;354:447-455.

125. Rauch B, Schiele R, Schneider S, Diller F, Victor N, Gohlke H, Gottwik M, Steinbeck G, Del Castillo U, Sack R, Worth H, Katus H, Spitzer W, Sabin G, Senges J. OMEGA, a randomized, placebo-controlled trial to test the effect of highly purified omega-3 fatty acids on top of modern guideline-adjusted therapy after myocardial infarction. Circulation 2010;122:2152-2159.

126. Reiner Z, Catapano AL, De Backer G, Graham I, Taskinen MR, Wiklund O, Agewall S, Alegria E, Chapman MJ, Durrington P, Erdine S, Halcox J, Hobbs R, Kjekshus J, Filardi PP, Riccardi G, Storey RF, Wood D, Bax J, Vahanian A, Auricchio A, Baumgartner H, Ceconi C, Dean V, Deaton C, Fagard R, Filippatos G, Funck-Brentano C, Hasdai D, Hoes A, Kearney P, Knuuti J, Kolh P, McDonagh T, Moulin C, Poldermans D, Popescu BA, Sechtem U, Sirnes PA, Tendera M, Torbicki A, Vardas P, Widimsky P, Windecker S, Berkenboom G, De Graaf J, Descamps O, Gotcheva N, Griffith K, Guida GF, Gulec S, Henkin Y, Huber K, Kesaniemi YA, Lekakis J, Manolis AJ, Marques-Vidal P, Masana L, McMurray J, Mendes M, Pagava Z, Pedersen T, Prescott E, Rato Q, Rosano G, Sans S, Stalenhoef A, Tokgozoglu L, Viigimaa M, Wittekoek ME, Zamorano JL. ESC/EAS Guidelines for the management of dyslipidaemias: the Task Force for the management of dyslipidaemias of the European Society of Cardiology (ESC) and the European Atherosclerosis Society (EAS). Eur Heart J 2011;32:1769-1818.

127. Kjekshus J, Apetrei E, Barrios V, Bohm M, Cleland JG, Cornel JH, Dunselman P, Fonseca C, Goudev A, Grande P, Gullestad L, Hjalmarson A, Hradec J, Janosi A, Kamensky G, Komajda M, Korewicki J, Kuusi T, Mach F, Mareev V, McMurray JJ, 
Ranjith N, Schaufelberger M, Vanhaecke J, van Veldhuisen DJ, Waagstein F, Wedel $\mathrm{H}$, Wikstrand J. Rosuvastatin in older patients with systolic heart failure. N Engl J Med 2007;357:2248-2261.

128. Tavazzi L, Maggioni AP, Marchioli R, Barlera S, Franzosi MG, Latini R, Lucci D, Nicolosi GL, Porcu M, Tognoni G. Effect of rosuvastatin in patients with chronic heart failure (the GISSI-HF trial): a randomised, double-blind, placebocontrolled trial. Lancet 2008;372:1231-1239.

129. Krum H, Massie B, Abraham WT, Dickstein K, Kober L, McMurray J], Desai A, Gimpelewicz C, Kandra A, Reimund B, Rattunde H, Armbrecht J. Direct renin inhibition in addition to or as an alternative to angiotensin converting enzyme inhibition in patients with chronic systolic heart failure: rationale and design of the Aliskiren Trial to Minimize OutcomeS in Patients with HEart failuRE (ATMOSPHERE) study. Eur J Heart Fail 2011;13:107-114.

130. Gheorghiade M, Albaghdadi M, Zannad F, Fonarow GC, Bohm M, Gimpelewicz C, Botha J, Moores S, Lewis EF, Rattunde H, Maggioni A. Rationale and design of the multicentre, randomized, double-blind, placebo-controlled Aliskiren Trial on Acute Heart Failure Outcomes (ASTRONAUT). Eur J Heart Fail 2011;13:100-106.

130a. Homma S, Thompson JL, Pullicino PM, Levin B, Freudenberger RS, Teerlink JR, Ammon SE, Graham S, Sacco RL, Mann DL, Mohr JP, Massie BM, Labovitz AJ, Anker SD, Lok DJ, Ponikowski P, Estol C], Lip GY, Di Tullio MR, Sanford AR, Mejia V, Gabriel AP, Del Valle ML, Buchsbaum R; the WARCEF Investigators. Warfarin and aspirin in patients with heart failure and sinus rhythm. $N$ Engl J Med 2012; Published online ahead of print 2 May 2012. PubMed PMID: 22551105.

131. Komajda M, McMurray JJ, Beck-Nielsen H, Gomis R, Hanefeld M, Pocock SJ, Curtis PS, Jones NP, Home PD. Heart failure events with rosiglitazone in type 2 diabetes: data from the RECORD clinical trial. Eur Heart J 2010;31:824-831.

132. Hernandez AV, Usmani A, Rajamanickam A, Moheet A. Thiazolidinediones and risk of heart failure in patients with or at high risk of type 2 diabetes mellitus: a meta-analysis and meta-regression analysis of placebo-controlled randomized clinical trials. Am J Cardiovasc Drugs 2011;11:115-128.

133. Erdmann E, Charbonnel B, Wilcox RG, Skene AM, Massi-Benedetti M, Yates J, Tan M, Spanheimer R, Standl E, Dormandy JA. Pioglitazone use and heart failure in patients with type 2 diabetes and preexisting cardiovascular disease: data from the PROactive study (PROactive 08). Diabetes Care 2007;30: 2773-2778.

134. Goldstein RE, Boccuzzi SJ, Cruess D, Nattel S. Diltiazem increases late-onset congestive heart failure in postinfarction patients with early reduction in ejection fraction. The Adverse Experience Committee; and the Multicenter Diltiazem Postinfarction Research Group. Circulation 1991;83:52-60.

135. Mamdani M, Juurlink DN, Lee DS, Rochon PA, Kopp A, Naglie G, Austin PC, Laupacis A, Stukel TA. Cyclo-oxygenase-2 inhibitors versus non-selective nonsteroidal anti-inflammatory drugs and congestive heart failure outcomes in elderly patients: a population-based cohort study. Lancet 2004;363:1751-1756.

136. Huerta C, Varas-Lorenzo C, Castellsague J, Garcia Rodriguez LA. Non-steroidal anti-inflammatory drugs and risk of first hospital admission for heart failure in the general population. Heart 2006;92:1610-1615.

137. Setaro JF, Zaret BL, Schulman DS, Black HR, Soufer R. Usefulness of verapamil for congestive heart failure associated with abnormal left ventricular diastolic filling and normal left ventricular systolic performance. Am J Cardiol 1990;66: 981-986.

138. Hung MJ, Cherng WJ, Kuo LT, Wang CH. Effect of verapamil in elderly patients with left ventricular diastolic dysfunction as a cause of congestive heart failure. Int J Clin Pract 2002;56:57-62.

139. Yusuf S, Pfeffer MA, Swedberg K, Granger CB, Held P, McMurray JJ, Michelson EL, Olofsson B, Ostergren J. Effects of candesartan in patients with chronic heart failure and preserved left-ventricular ejection fraction: the CHARM-Preserved Trial. Lancet 2003;362:777-781.

140. Cleland JG, Tendera M, Adamus J, Freemantle N, Polonski L, Taylor J. The perindopril in elderly people with chronic heart failure (PEP-CHF) study. Eur Heart J 2006;27:2338-2345.

141. Massie BM, Carson PE, McMurray JJ, Komajda M, McKelvie R, Zile MR, Anderson S, Donovan M, Iverson E, Staiger C, Ptaszynska A. Irbesartan in patients with heart failure and preserved ejection fraction. N Engl J Med 2008; 359:2456-2467.

142. Chung MK, Szymkiewicz SJ, Shao M, Zishiri E, Niebauer MJ, Lindsay BD, Tchou PJ. Aggregate national experience with the wearable cardioverterdefibrillator: event rates, compliance, and survival. J Am Coll Cardiol 2010;56: 194-203.

143. Zipes DP, Camm AJ, Borggrefe M, Buxton AE, Chaitman B, Fromer M, Gregoratos G, Klein G, Moss AJ, Myerburg RJ, Priori SG, Quinones MA, Roden DM, Silka MJ, Tracy C, Blanc JJ, Budaj A, Dean V, Deckers JW, Despres C, Dickstein K, Lekakis J, McGregor K, Metra M, Morais J, Osterspey A, Tamargo JL, Zamorano JL, Smith SC Jr, Jacobs AK, Adams CD,
Antman EM, Anderson JL, Hunt SA, Halperin JL, Nishimura R, Ornato JP, Page RL, Riegel B. ACC/AHA/ESC 2006 guidelines for management of patients with ventricular arrhythmias and the prevention of sudden cardiac death-executive summary: a report of the American College of Cardiology/American Heart Association Task Force and the European Society of Cardiology Committee for Practice Guidelines (Writing Committee to Develop Guidelines for Management of Patients with Ventricular Arrhythmias and the Prevention of Sudden Cardiac Death) Developed in collaboration with the European Heart Rhythm Association and the Heart Rhythm Society. Eur Heart J 2006;27:2099-2140.

144. A comparison of antiarrhythmic-drug therapy with implantable defibrillators in patients resuscitated from near-fatal ventricular arrhythmias. The Antiarrhythmics versus Implantable Defibrillators (AVID) Investigators. N Engl J Med 1997;337:1576-1583.

145. Kuck KH, Cappato R, Siebels J, Ruppel R. Randomized comparison of antiarrhythmic drug therapy with implantable defibrillators in patients resuscitated from cardiac arrest: the Cardiac Arrest Study Hamburg (CASH). Circulation 2000;102:748-754.

146. Connolly SJ, Gent M, Roberts RS, Dorian P, Roy D, Sheldon RS, Mitchell LB, Green MS, Klein GJ, O'Brien B. Canadian implantable defibrillator study (CIDS): a randomized trial of the implantable cardioverter defibrillator against amiodarone. Circulation 2000;101:1297-1302.

147. Oseroff O, Retyk E, Bochoeyer A. Subanalyses of secondary prevention implantable cardioverter-defibrillator trials: antiarrhythmics versus implantable defibrillators (AVID), Canadian Implantable Defibrillator Study (CIDS), and Cardiac Arrest Study Hamburg (CASH). Curr Opin Cardiol 2004;19:26-30.

148. Moss AJ, Hall WJ, Cannom DS, Daubert JP, Higgins SL, Klein H, Levine JH, Saksena S, Waldo AL, Wilber D, Brown MW, Heo M. Improved survival with an implanted defibrillator in patients with coronary disease at high risk for ventricular arrhythmia. Multicenter Automatic Defibrillator Implantation Trial Investigators. N Engl J Med 1996;335:1933-1940.

149. Bardy GH, Lee KL, Mark DB, Poole JE, Packer DL, Boineau R, Domanski M, Troutman C, Anderson J, Johnson G, McNulty SE, Clapp-Channing N, Davidson-Ray LD, Fraulo ES, Fishbein DP, Luceri RM, Ip JH. Amiodarone or an implantable cardioverter-defibrillator for congestive heart failure. $N$ Engl J Med 2005;352:225-237.

150. Hohnloser SH, Kuck KH, Dorian P, Roberts RS, Hampton JR, Hatala R, Fain E, Gent M, Connolly SJ. Prophylactic use of an implantable cardioverterdefibrillator after acute myocardial infarction. N Engl J Med 2004;351: $2481-2488$

151. Steinbeck G, Andresen D, Seidl K, Brachmann J, Hoffmann E, Wojciechowski D, Kornacewicz-Jach Z, Sredniawa B, Lupkovics G, Hofgartner F, Lubinski A, Rosenqvist M, Habets A, Wegscheider K, Senges J. Defibrillator implantation early after myocardial infarction. N Engl J Med 2009;361:1427-1436.

152. Kadish A, Dyer A, Daubert JP, Quigg R, Estes NA, Anderson KP, Calkins H, Hoch D, Goldberger J, Shalaby A, Sanders WE, Schaechter A, Levine JH. Prophylactic defibrillator implantation in patients with nonischemic dilated cardiomyopathy. N Engl J Med 2004;350:2151-2158.

153. Stewart GC, Weintraub JR, Pratibhu PP, Semigran MJ, Camuso JM, Brooks K, Tsang SW, Anello MS, Nguyen VT, Lewis EF, Nohria A, Desai AS, Givertz MM, Stevenson LW. Patient expectations from implantable defibrillators to prevent death in heart failure. J Card Fail 2010;16:106-113.

154. Moss AJ, Hall WJ, Cannom DS, Klein H, Brown MW, Daubert JP, Estes NA 3rd, Foster E, Greenberg H, Higgins SL, Pfeffer MA, Solomon SD, Wilber D, Zareba W. Cardiac-resynchronization therapy for the prevention of heart-failure events. N Engl J Med 2009;361:1329-1338.

155. Tang AS, Wells GA, Talajic M, Arnold MO, Sheldon R, Connolly S, Hohnloser SH, Nichol G, Birnie DH, Sapp JL, Yee R, Healey JS, Rouleau JL. Cardiac-resynchronization therapy for mild-to-moderate heart failure. N Engl J Med 2010;363:2385-2395.

156. Bristow MR, Saxon LA, Boehmer J, Krueger S, Kass DA, De Marco T, Carson P, DiCarlo L, DeMets D, White BG, DeVries DW, Feldman AM. Cardiac-resynchronization therapy with or without an implantable defibrillator in advanced chronic heart failure. N Engl J Med 2004;350:2140-2150.

157. Cleland JG, Daubert JC, Erdmann E, Freemantle N, Gras D, Kappenberger L, Tavazzi L. The effect of cardiac resynchronization on morbidity and mortality in heart failure. N Engl J Med 2005;352:1539-1549.

158. Dickstein K, Vardas PE, Auricchio A, Daubert JC, Linde C, McMurray J, Ponikowski P, Priori SG, Sutton R, van Veldhuisen DJ. 2010 focused update of ESC Guidelines on device therapy in heart failure: an update of the 2008 ESC Guidelines for the diagnosis and treatment of acute and chronic heart failure and the 2007 ESC Guidelines for cardiac and resynchronization therapy. Developed with the special contribution of the Heart Failure Association and the European Heart Rhythm Association. Eur J Heart Fail 2010;12:1143-1153. 
159. Beshai JF, Grimm RA, Nagueh SF, Baker JH 2nd Beau SL, Greenberg SM, Pires LA, Tchou PJ. Cardiac-resynchronization therapy in heart failure with narrow QRS complexes. N Engl J Med 2007;357:2461-2471.

160. Chung ES, Leon AR, Tavazzi L, Sun JP, Nihoyannopoulos P, Merlino J, Abraham WT, Ghio S, Leclercq C, Bax Jj, Yu CM, Gorcsan J 3rd, St John Sutton M, De Sutter J, Murillo J. Results of the Predictors of Response to CRT (PROSPECT) trial. Circulation 2008;117:2608-2616.

161. Linde C, Abraham WT, Gold MR, St John Sutton M, Ghio S, Daubert C. Randomized trial of cardiac resynchronization in mildly symptomatic heart failure patients and in asymptomatic patients with left ventricular dysfunction and previous heart failure symptoms. J Am Coll Cardiol 2008;52:1834-1843.

162. Leclercq C, Walker S, Linde C, Clementy J, Marshall AJ, Ritter P, Djiane P, Mabo P, Levy T, Gadler F, Bailleul C, Daubert JC. Comparative effects of permanent biventricular and right-univentricular pacing in heart failure patients with chronic atrial fibrillation. Eur Heart J 2002;23:1780-1787.

163. Wilton SB, Leung AA, Ghali WA, Faris P, Exner DV. Outcomes of cardiac resynchronization therapy in patients with versus those without atrial fibrillation: a systematic review and meta-analysis. Heart Rhythm 2011;8:1088-1094.

163a. Ganesan AN, Brooks AG, Roberts-Thomson KC, Lau DH, Kalman JM, Sanders P. Role of AV nodal ablation in cardiac resynchronization in patients with coexistent atrial fibrillation and heart failure. A systematic review. J Am Coll Cardiol 2012;59:719-726.

164. Tops LF, Schalij MJ, Bax JJ. The effects of right ventricular apical pacing on ventricular function and dyssynchrony implications for therapy. J Am Coll Cardiol 2009;54:764-776.

165. Vardas PE, Auricchio A, Blanc J], Daubert JC, Drexler H, Ector H, Gasparini M, Linde C, Morgado FB, Oto A, Sutton R, Trusz-Gluza M. Guidelines for cardiac pacing and cardiac resynchronization therapy: the Task Force for Cardiac Pacing and Cardiac Resynchronization Therapy of the European Society of Cardiology. Developed in collaboration with the European Heart Rhythm Association. Eur Heart J 2007;28:2256-2295.

166. Camm AJ, Kirchhof P, Lip GY, Schotten U, Savelieva I, Ernst S, Van Gelder IC, Al-Attar N, Hindricks G, Prendergast B, Heidbuchel H, Alfieri O, Angelini A, Atar D, Colonna P, De Caterina R, De Sutter J, Goette A, Gorenek B, Heldal M, Hohloser SH, Kolh P, Le Heuzey JY, Ponikowski P, Rutten FH. Guidelines for the management of atrial fibrillation: the Task Force for the Management of Atrial Fibrillation of the European Society of Cardiology (ESC). Eur Heart J 2010;31:2369-2429.

167. Lewis RV, McMurray J, McDevitt DG. Effects of atenolol, verapamil, and xamoterol on heart rate and exercise tolerance in digitalised patients with chronic atrial fibrillation. J Cardiovasc Pharmacol 1989;13:1-6.

168. Khand AU, Rankin AC, Martin W, Taylor J, Gemmell I, Cleland JG. Carvedilol alone or in combination with digoxin for the management of atrial fibrillation in patients with heart failure? J Am Coll Cardiol 2003;42:1944-1951.

169. Lewis RV, Laing E, Moreland TA, Service E, McDevitt DG. A comparison of digoxin, diltiazem and their combination in the treatment of atrial fibrillation. Eur Heart J 1988;9:279-283.

170. Van Gelder IC, Groenveld HF, Crijns HJ, Tuininga YS, Tijssen JG, Alings AM, Hillege HL, Bergsma-Kadijk JA, Cornel JH, Kamp O, Tukkie R, Bosker HA, Van Veldhuisen DJ, Van den Berg MP. Lenient versus strict rate control in patients with atrial fibrillation. N Engl J Med 2010;362:1363-1373.

171. Roy D, Talajic M, Nattel S, Wyse DG, Dorian P, Lee KL, Bourassa MG, Arnold JM, Buxton AE, Camm AJ, Connolly SJ, Dubuc M, Ducharme A, Guerra PG, Hohnloser SH, Lambert J, Le Heuzey JY, O'Hara G, Pedersen OD, Rouleau JL, Singh BN, Stevenson LW, Stevenson WG, Thibault B, Waldo AL. Rhythm control versus rate control for atrial fibrillation and heart failure. N Engl J Med 2008;358:2667-2677.

172. Piepoli M, Villani GQ, Ponikowski P, Wright A, Flather MD, Coats AJ. Overview and meta-analysis of randomised trials of amiodarone in chronic heart failure. Int J Cardiol 1998;66:1-10.

173. Effect of prophylactic amiodarone on mortality after acute myocardial infarction and in congestive heart failure: meta-analysis of individual data from 6500 patients in randomised trials. Amiodarone Trials Meta-Analysis Investigators. Lancet 1997;350:1417-1424.

174. Khan MN, Jais P, Cummings J, Di Biase L, Sanders P, Martin DO, Kautzner J, Hao S, Themistoclakis S, Fanelli R, Potenza D, Massaro R, Wazni O, Schweikert R, Saliba W, Wang P, Al-Ahmad A, Beheiry S, Santarelli P, Starling RC, Dello Russo A, Pelargonio G, Brachmann J, Schibgilla V, Bonso A, Casella M, Raviele A, Haissaguerre M, Natale A. Pulmonary-vein isolation for atrial fibrillation in patients with heart failure. N Engl J Med 2008;359: 1778-1785

175. MacDonald MR, Connelly DT, Hawkins NM, Steedman T, Payne J, Shaw M, Denvir M, Bhagra S, Small S, Martin W, McMurray J], Petrie MC. Radiofrequency ablation for persistent atrial fibrillation in patients with advanced heart failure and severe left ventricular systolic dysfunction: a randomised controlled trial. Heart 2011;97:740-747.

176. Kober L, Torp-Pedersen C, McMurray JJ, Gotzsche O, Levy S, Crijns H, Amlie J, Carlsen J. Increased mortality after dronedarone therapy for severe heart failure. N Engl J Med 2008;358:2678-2687.

177. Connolly SJ, Camm AJ, Halperin JL, Joyner C, Alings M, Amerena J, Atar D, Avezum A, Blomstrom P, Borggrefe M, Budaj A, Chen SA, Ching CK, Commerford P, Dans A, Davy JM, Delacretaz E, Di Pasquale G, Diaz R, Dorian P, Flaker G, Golitsyn S, Gonzalez-Hermosillo A, Granger CB, Heidbuchel H, Kautzner J, Kim JS, Lanas F, Lewis BS, Merino JL, Morillo C, Murin J, Narasimhan C, Paolasso E, Parkhomenko A, Peters NS, Sim KH, Stiles MK, Tanomsup S, Toivonen L, Tomcsanyi J, Torp-Pedersen C, Tse HF, Vardas P, Vinereanu D, Xavier D, Zhu J, Zhu JR, Baret-Cormel L, Weinling E, Staiger C, Yusuf S, Chrolavicius S, Afzal R, Hohnloser SH. Dronedarone in highrisk permanent atrial fibrillation. N Engl J Med 2011;365:2268-2276.

178. Echt DS, Liebson PR, Mitchell LB, Peters RW, Obias-Manno D, Barker AH, Arensberg D, Baker A, Friedman L, Greene HL, Huther ML, Richardson DW, the CAST Investigators. Mortality and morbidity in patients receiving encainide, flecainide, or placebo. The Cardiac Arrhythmia Suppression Trial. N Engl J Med 1991;324:781-788.

179. Lip GY, Nieuwlaat R, Pisters R, Lane DA, Crijns HJ. Refining clinical risk stratification for predicting stroke and thromboembolism in atrial fibrillation using a novel risk factor-based approach: the Euro Heart Survey on atrial fibrillation. Chest 2010;137:263-272.

180. Pisters R, Lane DA, Nieuwlaat R, de Vos CB, Crijns HJ, Lip GY. A novel userfriendly score (HAS-BLED) to assess 1-year risk of major bleeding in patients with atrial fibrillation: the Euro Heart Survey. Chest 2010;138:1093-1100.

181. Connolly SJ, Ezekowitz MD, Yusuf S, Eikelboom J, Oldgren J, Parekh A, Pogue J, Reilly PA, Themeles E, Varrone J, Wang S, Alings M, Xavier D, Zhu J, Diaz R, Lewis BS, Darius H, Diener HC, Joyner CD, Wallentin L. Dabigatran versus warfarin in patients with atrial fibrillation. N Engl J Med 2009;361:1139-1151.

182. Granger CB, Alexander JH, McMurray JJ, Lopes RD, Hylek EM, Hanna M, Al-Khalidi HR, Ansell J, Atar D, Avezum A, Bahit MC, Diaz R, Easton JD, Ezekowitz JA, Flaker G, Garcia D, Geraldes M, Gersh BJ, Golitsyn S, Goto S, Hermosillo AG, Hohnloser SH, Horowitz J, Mohan P, Jansky P, Lewis BS, Lopez-Sendon JL, Pais P, Parkhomenko A, Verheugt FW, Zhu J, Wallentin L. Apixaban versus warfarin in patients with atrial fibrillation. N Engl J Med 2011; 365:981-992.

183. Patel MR, Mahaffey KW, Garg J, Pan G, Singer DE, Hacke W, Breithardt G, Halperin JL, Hankey G], Piccini JP, Becker RC, Nessel CC, Paolini JF, Berkowitz SD, Fox KA, Califf RM. Rivaroxaban versus warfarin in nonvalvular atrial fibrillation. N Engl J Med 2011;365:883-891.

184. Hart RG, Benavente O, McBride R, Pearce LA. Antithrombotic therapy to prevent stroke in patients with atrial fibrillation: a meta-analysis. Ann Intern Med 1999;131:492-501.

185. Larson RJ, Fisher ES. Should aspirin be continued in patients started on warfarin? J Gen Intern Med 2004;19:879-886.

186. Aliot EM, Stevenson WG, Almendral-Garrote JM, Bogun F, Calkins $\mathrm{CH}$, Delacretaz E, Bella PD, Hindricks G, Jais P, Josephson ME, Kautzner J, Kay GN, Kuck KH, Lerman BB, Marchlinski F, Reddy V, Schalij MJ, Schilling R, Soejima K, Wilber D. EHRA/HRS Expert Consensus on Catheter Ablation of Ventricular Arrhythmias: developed in a partnership with the European Heart Rhythm Association (EHRA), a Registered Branch of the European Society of Cardiology (ESC), and the Heart Rhythm Society (HRS); in collaboration with the American College of Cardiology (ACC) and the American Heart Association (AHA). Europace 2009;11:771-817.

187. McMurray J], Anand IS, Diaz R, Maggioni AP, O'Connor C, Pfeffer MA, Polu KR, Solomon SD, Sun Y, Swedberg K, Tendera M, van Veldhuisen DJ, Wasserman SM, Young JB. Design of the Reduction of Events with Darbepoetin alfa in Heart Failure (RED-HF): a phase III, anaemia correction, morbiditymortality trial. Eur J Heart Fail 2009;11:795-801.

188. Packer M, O'Connor CM, Ghali JK, Pressler ML, Carson PE, Belkin RN, Miller AB, Neuberg GW, Frid D, Wertheimer JH, Cropp AB, DeMets DL. Effect of amlodipine on morbidity and mortality in severe chronic heart failure. Prospective Randomized Amlodipine Survival Evaluation Study Group. N Engl J Med 1996;335:1107-1114.

189. Wijeysundera HC, Hansen MS, Stanton E, Cropp AS, Hall C, Dhalla NS, Ghali J, Rouleau JL. Neurohormones and oxidative stress in nonischemic cardiomyopathy: relationship to survival and the effect of treatment with amlodipine. Am Heart J 2003;146:291-297.

190. Yusuf S, Zucker D, Peduzzi P, Fisher LD, Takaro T, Kennedy JW, Davis K, Killip T, Passamani E, Norris R, Mathur V, Varnauskas E, Chalmers TC. Effect of coronary artery bypass graft surgery on survival: overview of 10 -year results from randomised trials by the Coronary Artery Bypass Graft Surgery Trialists Collaboration. Lancet 1994;344:563-570. 
191. Velazquez EJ, Lee KL, Deja MA, Jain A, Sopko G, Marchenko A, Ali IS, Pohost G, Gradinac S, Abraham WT, Yii M, Prabhakaran D, Szwed H, Ferrazzi P, Petrie MC, O'Connor CM, Panchavinnin P, She L, Bonow RO, Rankin GR, Jones RH, Rouleau JL. Coronary-artery bypass surgery in patients with left ventricular dysfunction. N Engl J Med 2011;364:1607-1616.

192. Akashi YJ, Springer J, Anker SD. Cachexia in chronic heart failure: prognostic implications and novel therapeutic approaches. Curr Heart Fail Rep 2005;2: 198-203.

193. Eschenhagen T, Force T, Ewer MS, de Keulenaer GW, Suter TM, Anker SD, Avkiran M, de Azambuja E, Balligand JL, Brutsaert DL, Condorelli G, Hansen A, Heymans S, Hill JA, Hirsch E, Hilfiker-Kleiner D, Janssens S, de Jong S, Neubauer G, Pieske B, Ponikowski P, Pirmohamed M, Rauchhaus M, Sawyer D, Sugden PH, Wojta J, Zannad F, Shah AM. Cardiovascular side effects of cancer therapies: a position statement from the Heart Failure Association of the European Society of Cardiology. Eur J Heart Fail 2011;13:1-10.

194. Jones AL, Barlow M, Barrett-Lee PJ, Canney PA, Gilmour IM, Robb SD, Plummer C], Wardley AM, Verrill MW. Management of cardiac health in trastuzumab-treated patients with breast cancer: updated United Kingdom National Cancer Research Institute recommendations for monitoring. $\mathrm{Br} J$ Cancer 2009;100:684-692.

195. Dungen HD, Apostolovic S, Inkrot S, Tahirovic E, Topper A, Mehrhof F, Prettin C, Putnikovic B, Neskovic AN, Krotin M, Sakac D, Lainscak M, Edelmann F, Wachter R, Rau T, Eschenhagen T, Doehner W, Anker SD, Waagstein F, Herrmann-Lingen C, Gelbrich G, Dietz R. Titration to target dose of bisoprolol vs. carvedilol in elderly patients with heart failure: the CIBIS-ELD trial. Eur J Heart Fail 2011;13:670-680.

196. O'Connor CM, Jiang W, Kuchibhatla M, Silva SG, Cuffe MS, Callwood DD, Zakhary B, Stough WG, Arias RM, Rivelli SK, Krishnan R. Safety and efficacy of sertraline for depression in patients with heart failure: results of the SADHART-CHF (Sertraline Against Depression and Heart Disease in Chronic Heart Failure) trial. J Am Coll Cardiol 2010;56:692-699.

197. McMurray JJ, Holman RR, Haffner SM, Bethel MA, Holzhauer B, Hua TA, Belenkov Y, Boolell M, Buse JB, Buckley BM, Chacra AR, Chiang FT, Charbonnel B, Chow CC, Davies MJ, Deedwania P, Diem P, Einhorn D, Fonseca V, Fulcher GR, Gaciong Z, Gaztambide S, Giles T, Horton E, Ilkova $H$, Jenssen $T$, Kahn SE, Krum H, Laakso M, Leiter LA, Levitt NS, Mareev V, Martinez F, Masson C, Mazzone T, Meaney E, Nesto R, Pan C, Prager R, Raptis SA, Rutten GE, Sandstroem H, Schaper F, Scheen A, Schmitz O, Sinay I, Soska V, Stender S, Tamas G, Tognoni G, Tuomilehto J, Villamil AS, Vozar J, Califf RM. Effect of valsartan on the incidence of diabetes and cardiovascular events. N Engl J Med 2010;362:1477-1490.

198. Bakris GL, Fonseca V, Katholi RE, McGill JB, Messerli FH, Phillips RA, Raskin P, Wright JT, Oakes R, Lukas MA, Anderson KM, Bell DSH; for the GEMINI Investigators. Metabolic Effects of carvedilol vs metoprolol in patients with type 4 diabetes mellitus and hypertension — a randomized contolled trial. JAMA 2004; 292:2227-2236.

199. MacDonald MR, Eurich DT, Majumdar SR, Lewsey JD, Bhagra S, Jhund PS, Petrie MC, McMurray JJ, Petrie JR, McAlister FA. Treatment of type 2 diabetes and outcomes in patients with heart failure: a nested case-control study from the U.K. General Practice Research Database. Diabetes Care 2010;33: 1213-1218.

200. Guazzi M, Vicenzi M, Arena R, Guazzi MD. PDE5 inhibition with sildenafil improves left ventricular diastolic function, cardiac geometry, and clinical status in patients with stable systolic heart failure: results of a 1-year, prospective, randomized, placebo-controlled study. Circ Heart Fail 2011;4:8-17.

201. Hare JM, Mangal B, Brown J, Fisher C Jr, Freudenberger R, Colucci WS, Mann DL, Liu P, Givertz MM, Schwarz RP. Impact of oxypurinol in patients with symptomatic heart failure. Results of the OPT-CHF study. J Am Coll Cardiol 2008;51:2301-2309.

202. Major cardiovascular events in hypertensive patients randomized to doxazosin vs chlorthalidone: the antihypertensive and lipid-lowering treatment to prevent heart attack trial (ALLHAT). ALLHAT Collaborative Research Group. JAMA 2000;283:1967-1975.

203. Cohn JN, Pfeffer MA, Rouleau J, Sharpe N, Swedberg K, Straub M, Wiltse C, Wright TJ. Adverse mortality effect of central sympathetic inhibition with sustained-release moxonidine in patients with heart failure (MOXCON). Eur J Heart Fail 2003;5:659-667.

204. Cohn JN, Ziesche S, Smith R, Anand I, Dunkman WB, Loeb H, Cintron G, Boden W, Baruch L, Rochin P, Loss L. Effect of the calcium antagonist felodipine as supplementary vasodilator therapy in patients with chronic heart failure treated with enalapril: V-HeFT III. Vasodilator-Heart Failure Trial (V-HeFT) Study Group. Circulation 1997;96:856-863.

205. Mancia G, De Backer G, Dominiczak A, Cifkova R, Fagard R, Germano G, Grassi G, Heagerty AM, Kjeldsen SE, Laurent S, Narkiewicz K, Ruilope L, Rynkiewicz A, Schmieder RE, Struijker Boudier HA, Zanchetti A, Vahanian A,
Camm J, De Caterina R, Dean V, Dickstein K, Filippatos G, Funck-Brentano C, Hellemans I, Kristensen SD, McGregor K, Sechtem U, Silber S, Tendera M, Widimsky P, Zamorano JL, Erdine S, Kiowski W, Agabiti-Rosei E, Ambrosioni E, Lindholm LH, Manolis A, Nilsson PM, Redon J, Struijker-Boudier HA, Viigimaa M, Adamopoulos S, Bertomeu V, Clement D, Farsang C, Gaita D, Lip G, Mallion JM, Manolis AJ, O’Brien E, Ponikowski P, Ruschitzka F, Tamargo J, van Zwieten P, Waeber B, Williams B, Zamorano JL, The task force for the management of arterial hypertension of the European Society of Hypertension, The task force for the management of arterial hypertension of the European Society of Cardiology. 2007 Guidelines for the management of arterial hypertension: The Task Force for the Management of Arterial Hypertension of the European Society of Hypertension (ESH) and of the European Society of Cardiology (ESC). Eur Heart J 2007;28:1462-1536.

206. Dorszewski A, Gohmann E, Dorszewski B, Werner GS, Kreuzer H, Figulla HR. Vasodilation by urapidil in the treatment of chronic congestive heart failure in addition to angiotensin-converting enzyme inhibitors is not beneficial: results of a placebo-controlled, double-blind study. J Card Fail 1997;3:91-96.

207. Bayliss J, Norell MS, Canepa-Anson R, Reid C, Poole-Wilson P, Sutton G. Clinical importance of the renin-angiotensin system in chronic heart failure: double blind comparison of captopril and prazosin. Br Med J (Clin Res Ed) 1985;290: 1861-1865.

208. Anker SD, Comin Colet J, Filippatos G, Willenheimer R, Dickstein K, Drexler H, Luscher TF, Bart B, Banasiak W, Niegowska J, Kirwan BA, Mori C, von Eisenhart Rothe B, Pocock S], Poole-Wilson PA, Ponikowski P. Ferric carboxymaltose in patients with heart failure and iron deficiency. N Engl J Med 2009;361: 2436-2448.

209. Ronco C, McCullough P, Anker SD, Anand I, Aspromonte N, Bagshaw SM, Bellomo R, Berl T, Bobek I, Cruz DN, Daliento L, Davenport A, Haapio M, Hillege H, House AA, Katz N, Maisel A, Mankad S, Zanco P, Mebazaa A, Palazzuoli A, Ronco F, Shaw A, Sheinfeld G, Soni S, Vescovo G, Zamperetti N, Ponikowski P; Acute Dialysis Quality Initiative (ADQI) consensus group. Cardio-renal syndromes: report from the consensus conference of the acute dialysis quality initiative. Eur Heart J 2010;31:703-711.

210. Perk J, De Backer G, Gohlke H, Graham I, Reiner Z, Verschuren M, Albus C, Benlian P, Boysen G, Cifkova R, Deaton C, Ebrahim S, Fisher M, Germano G, Hobbs R, Hoes A, Karadeniz S, Mezzani A, Prescott E, Ryden L, Scherer M, Syvänne M, Scholte Op, Reimer WJ, Vrints C, Wood D, Zamorano JL, Zannad F. European Guidelines on cardiovascular disease prevention in clinical practice (version 2012): The Fifth Joint Task Force of the European Society of Cardiology and Other Societies on Cardiovascular Disease Prevention in Clinical Practice (constituted by representatives of nine societies and by invited experts) *Developed with the special contribution of the European Association for Cardiovascular Prevention \& Rehabilitation (EACPR). Eur Heart J 2012;33: $1635-1701$.

211. McKelvie RS, Moe GW, Cheung A, Costigan J, Ducharme A, Estrella-Holder E, Ezekowitz JA, Floras J, Giannetti N, Grzeslo A, Harkness K, Heckman GA, Howlett JG, Kouz S, Leblanc K, Mann E, O'Meara E, Rajda M, Rao V, Simon J, Swiggum E, Zieroth S, Arnold JM, Ashton T, D'Astous M, Dorian P, Haddad H, Isaac DL, Leblanc MH, Liu P, Sussex B, Ross HJ. The 2011 Canadian Cardiovascular Society heart failure management guidelines update: focus on sleep apnea, renal dysfunction, mechanical circulatory support, and palliative care. Can J Cardiol 2011;27:319-338.

212. Kasai T, Bradley TD. Obstructive sleep apnea and heart failure: pathophysiologic and therapeutic implications. J Am Coll Cardiol 2011;57:119-127.

213. Felker GM, Lee KL, Bull DA, Redfield MM, Stevenson LW, Goldsmith SR, LeWinter MM, Deswal A, Rouleau JL, Ofili EO, Anstrom KJ, Hernandez AF, McNulty SE, Velazquez EJ, Kfoury AG, Chen HH, Givertz MM, Semigran MJ, Bart BA, Mascette AM, Braunwald E, O'Connor CM. Diuretic strategies in patients with acute decompensated heart failure. N Engl J Med 2011;364: 797-805.

214. Alikhan R, Cohen AT, Combe S, Samama MM, Desjardins L, Eldor A, Janbon C, Leizorovicz A, Olsson CG, Turpie AG. Prevention of venous thromboembolism in medical patients with enoxaparin: a subgroup analysis of the MEDENOX study. Blood Coagul Fibrinolysis 2003;14:341-346.

215. Kleber FX, Witt C, Vogel G, Koppenhagen K, Schomaker U, Flosbach CW. Randomized comparison of enoxaparin with unfractionated heparin for the prevention of venous thromboembolism in medical patients with heart failure or severe respiratory disease. Am Heart J 2003;145:614-621.

216. Tebbe U, Schellong SM, Haas S, Gerlach HE, Abletshauser C, Sieder C, Bramlage $\mathrm{P}$, Riess $\mathrm{H}$. Certoparin versus unfractionated heparin to prevent venous thromboembolic events in patients hospitalized because of heart failure: a subgroup analysis of the randomized, controlled CERTIFY study. Am Heart J 2011;161:322-328. 
217. Gray A, Goodacre S, Newby DE, Masson M, Sampson F, Nicholl J. Noninvasive ventilation in acute cardiogenic pulmonary edema. N Engl J Med 2008;359: $142-151$.

218. Cotter G, Metzkor E, Kaluski E, Faigenberg Z, Miller R, Simovitz A, Shaham O, Marghitay D, Koren M, Blatt A, Moshkovitz Y, Zaidenstein R, Golik A. Randomised trial of high-dose isosorbide dinitrate plus low-dose furosemide versus high-dose furosemide plus low-dose isosorbide dinitrate in severe pulmonary oedema. Lancet 1998;351:389-393.

219. Intravenous nesiritide vs nitroglycerin for treatment of decompensated congestive heart failure: a randomized controlled trial. JAMA 2002;287:1531-1540.

220. Cohn JN, Franciosa JA, Francis GS, Archibald D, Tristani F, Fletcher R, Montero A, Cintron G, Clarke J, Hager D, Saunders R, Cobb F, Smith R, Loeb $H$, Settle $H$. Effect of short-term infusion of sodium nitroprusside on mortality rate in acute myocardial infarction complicated by left ventricular failure: results of a Veterans Administration cooperative study. N Engl J Med 1982; 306:1129-1135.

221. Mehta SR, Cannon CP, Fox KA, Wallentin L, Boden WE, Spacek R, Widimsky P, McCullough PA, Hunt D, Braunwald E, Yusuf S. Routine vs selective invasive strategies in patients with acute coronary syndromes: a collaborative meta-analysis of randomized trials. JAMA 2005;293:2908-2917.

222. Indications for fibrinolytic therapy in suspected acute myocardial infarction: collaborative overview of early mortality and major morbidity results from all randomised trials of more than 1000 patients. Fibrinolytic Therapy Trialists' (FTT) Collaborative Group. Lancet 1994;343:311-322.

223. Dargie HJ. Effect of carvedilol on outcome after myocardial infarction in patients with left-ventricular dysfunction: the CAPRICORN randomised trial. Lancet 2001;357:1385-1390.

224. Park JH, Balmain S, Berry C, Morton JJ, McMurray JJ. Potentially detrimental cardiovascular effects of oxygen in patients with chronic left ventricular systolic dysfunction. Heart 2010;96:533-538.

225. Rosenberg J, Gustafsson F, Galatius S, Hildebrandt PR. Combination therapy with metolazone and loop diuretics in outpatients with refractory heart failure: an observational study and review of the literature. Cardiovasc Drugs Ther 2005; 19:301-306.

226. Channer KS, McLean KA, Lawson-Matthew P, Richardson M. Combination diuretic treatment in severe heart failure: a randomised controlled trial. $\mathrm{Br}$ Heart J 1994; 71:146-150.

227. Tan LB, Bryant S, Murray RG. Detrimental haemodynamic effects of cyclizine in heart failure. Lancet 1988;1:560-561.

228. O'Connor CM, Starling RC, Hernandez AF, Armstrong PW, Dickstein K, Hasselblad V, Heizer GM, Komajda M, Massie BM, McMurray J], Nieminen MS, Reist CJ, Rouleau JL, Swedberg K, Adams KF Jr, Anker SD, Atar D, Battler A, Botero R, Bohidar NR, Butler J, Clausell N, Corbalan R, Costanzo MR, Dahlstrom U, Deckelbaum LI, Diaz R, Dunlap ME, Ezekowitz JA, Feldman D, Felker GM, Fonarow GC, Gennevois D, Gottlieb SS, Hill JA, Hollander JE, Howlett JG, Hudson MP, Kociol RD, Krum H, Laucevicius A, Levy WC, Mendez GF, Metra M, Mittal S, Oh BH, Pereira NL, Ponikowski P, Tang WH, Tanomsup S, Teerlink JR, Triposkiadis F, Troughton RW, Voors AA, Whellan DJ, Zannad F, Califf RM. Effect of nesiritide in patients with acute decompensated heart failure. N Engl J Med 2011;365:32-43.

229. van de Borne P, Oren R, Somers VK. Dopamine depresses minute ventilation in patients with heart failure. Circulation 1998;98:126-131.

230. Gheorghiade M, Konstam MA, Burnett JC Jr, Grinfeld L, Maggioni AP, Swedberg K, Udelson JE, Zannad F, Cook T, Ouyang J, Zimmer C, Orlandi C. Short-term clinical effects of tolvaptan, an oral vasopressin antagonist, in patients hospitalized for heart failure: the EVEREST Clinical Status Trials. JAMA 2007;297: $1332-1343$.

231. Sjauw KD, Engstrom AE, Vis MM, van der Schaaf RJ, Baan J Jr, Koch KT, de Winter RJ, Piek JJ, Tijssen JG, Henriques JP. A systematic review and meta-analysis of intra-aortic balloon pump therapy in ST-elevation myocardial infarction: should we change the guidelines? Eur Heart J 2009;30:459-468.

232. Costanzo MR, Saltzberg MT, Jessup M, Teerlink JR, Sobotka PA. Ultrafiltration is associated with fewer rehospitalizations than continuous diuretic infusion in patients with decompensated heart failure: results from UNLOAD. J Card Fail 2010; 16:277-284

233. Shah MR, Hasselblad V, Stevenson LW, Binanay C, O'Connor CM, Sopko G, Califf RM. Impact of the pulmonary artery catheter in critically ill patients: meta-analysis of randomized clinical trials. JAMA 2005;294:1664-1670.

234. Shepperd S, McClaran J, Phillips CO, Lannin NA, Clemson LM, McCluskey A, Cameron ID, Barras SL. Discharge planning from hospital to home. Cochrane Database Syst Rev 2010;(1):CD000313.

235. Phillips CO, Wright SM, Kern DE, Singa RM, Shepperd S, Rubin HR. Comprehensive discharge planning with postdischarge support for older patients with congestive heart failure: a meta-analysis. JAMA 2004;291:1358-1367.
236. McDonagh TA, Blue L, Clark AL, Dahlstrom U, Ekman I, Lainscak M, McDonald K, Ryder M, Stromberg A, Jaarsma T. European Society of Cardiology Heart Failure Association Standards for delivering heart failure care. Eur J Heart Fail 2011;13:235-241.

237. Hamm CW, Bassand JP, Agewall S, Bax J, Boersma E, Bueno H, Caso P, Dudek D, Gielen S, Huber K, Ohman M, Petrie MC, Sonntag F, Uva MS, Storey RF, Wijns W, Zahger D, Bax J), Auricchio A, Baumgartner H, Ceconi C, Dean V, Deaton C, Fagard R, Funck-Brentano C, Hasdai D, Hoes A, Knuuti J, Kolh P, McDonagh T, Moulin C, Poldermans D, Popescu BA, Reiner Z, Sechtem U, Sirnes PA, Torbicki A, Vahanian A, Windecker S, Achenbach S, Badimon L, Bertrand M, Botker HE, Collet JP, Crea F, Danchin N, Falk E, Goudevenos J, Gulba D, Hambrecht R, Herrmann J, Kastrati A, Kjeldsen K, Kristensen SD, Lancellotti P, Mehilli J, Merkely B, Montalescot G, Neumann FJ, Neyses L, Perk J, Roffi M, Romeo F, Ruda M, Swahn E, Valgimigli M, Vrints CJ, Widimsky P. ESC Guidelines for the management of acute coronary syndromes in patients presenting without persistent ST-segment elevation: the Task Force for the management of acute coronary syndromes (ACS) in patients presenting without persistent ST-segment elevation of the European Society of Cardiology (ESC). Eur Heart J 2011;32:2999-3054.

238. Van de Werf F, Bax J, Betriu A, Blomstrom-Lundqvist C, Crea F, Falk V, Filippatos G, Fox K, Huber K, Kastrati A, Rosengren A, Steg PG, Tubaro M, Verheugt F, Weidinger F, Weis M; Committee for Practice Guidelines (CPG). Management of acute myocardial infarction in patients presenting with persistent ST-segment elevation: the Task Force on the Management of ST-Segment Elevation Acute Myocardial Infarction of the European Society of Cardiology. Eur Heart J 2008;29:2909-2945.

239. Torbicki A, Perrier A, Konstantinides S, Agnelli G, Galie N, Pruszczyk P, Bengel F, Brady AJ, Ferreira D, Janssens U, Klepetko W, Mayer E, Remy-Jardin M, Bassand JP. Guidelines on the diagnosis and management of acute pulmonary embolism: the Task Force for the Diagnosis and Management of Acute Pulmonary Embolism of the European Society of Cardiology (ESC). Eur Heart J 2008;29: 2276-2315.

240. Galie N, Hoeper MM, Humbert M, Torbicki A, Vachiery JL, Barbera JA, Beghetti M, Corris P, Gaine S, Gibbs JS, Gomez-Sanchez MA, Jondeau G, Klepetko W, Opitz C, Peacock A, Rubin L, Zellweger M, Simonneau G. Guidelines for the diagnosis and treatment of pulmonary hypertension: the Task Force for the Diagnosis and Treatment of Pulmonary Hypertension of the European Society of Cardiology (ESC) and the European Respiratory Society (ERS), endorsed by the International Society of Heart and Lung Transplantation (ISHLT). Eur Heart J 2009;30:2493-2537.

241. Mebazaa A, Pitsis AA, Rudiger A, Toller W, Longrois D, Ricksten SE, Bobek I, De Hert S, Wieselthaler G, Schirmer U, von Segesser LK, Sander M, Poldermans D, Ranucci M, Karpati PC, Wouters P, Seeberger M, Schmid ER, Weder W, Follath F. Clinical review: practical recommendations on the management of perioperative heart failure in cardiac surgery. Crit Care 2010;14:201.

242. Sliwa K, Hilfiker-Kleiner D, Petrie MC, Mebazaa A, Pieske B, Buchmann E, Regitz-Zagrosek V, Schaufelberger M, Tavazzi L, van Veldhuisen DJ, Watkins H, Shah AJ, Seferovic PM, Elkayam U, Pankuweit S, Papp Z, Mouquet F, McMurray JJ. Current state of knowledge on aetiology, diagnosis, management, and therapy of peripartum cardiomyopathy: a position statement from the Heart Failure Association of the European Society of Cardiology Working Group on peripartum cardiomyopathy. Eur J Heart Fail 2010;12: 767-778.

243. European Society of Gynecology; Association for European Paediatric Cardiology; German Society for Gender Medicine; Authors/Task Force Members, Regitz-Zagrosek V, Blomstrom Lundqvist C, Borghi C, Cifkova R, Ferreira R, Foidart JM, Gibbs JS, Gohlke-Baerwolf C, Gorenek B, lung B, Kirby M, Maas $\mathrm{AH}$, Morais J, Nihoyannopoulos P, Pieper PG, Presbitero P, Roos-Hesselink JW, Schaufelberger M, Seeland U, Torracca L; ESC Committee for Practice Guidelines, Bax J, Auricchio A, Baumgartner H, Ceconi C, Dean V, Deaton C, Fagard R, Funck-Brentano C, Hasdai D, Hoes A, Knuuti J, Kolh P, McDonagh T, Moulin C, Poldermans D, Popescu BA, Reiner Z, Sechtem U, Sirnes PA, Torbicki A, Vahanian A, Windecker S; Document Reviewers, Baumgartner $\mathrm{H}$, Deaton C, Aguiar C, Al-Attar N, Garcia AA, Antoniou A, Coman I, Elkayam U, Gomez-Sanchez MA, Gotcheva N, Hilfiker-Kleiner D, Kiss RG, Kitsiou A, Konings KT, Lip GY, Manolis A, Mebaaza A, Mintale I, Morice MC, Mulder BJ, Pasquet A, Price S, Priori SG, Salvador MJ, Shotan A, Silversides CK, Skouby SO, Stein JI, Tornos P, Vejlstrup N, Walker F, Warnes C. ESC Guidelines on the management of cardiovascular diseases during pregnancy: the Task Force on the Management of Cardiovascular Diseases during Pregnancy of the European Society of Cardiology (ESC). Eur Heart J 2011;32:3147-3197.

244. Diller GP, Dimopoulos K, Okonko D, Li W, Babu-Narayan SV, Broberg CS, Johansson B, Bouzas B, Mullen MJ, Poole-Wilson PA, Francis DP, Gatzoulis MA. Exercise intolerance in adult congenital heart disease: 
comparative severity, correlates, and prognostic implication. Circulation 2005; 112:828-835.

245. Baumgartner H, Bonhoeffer P, De Groot NM, de Haan F, Deanfield JE, Galie N, Gatzoulis MA, Gohlke-Baerwolf C, Kaemmerer H, Kilner P, Meijboom F, Mulder BJ, Oechslin E, Oliver JM, Serraf A, Szatmari A, Thaulow E, Vouhe PR, Walma E. ESC Guidelines for the management of grown-up congenital heart disease (new version 2010). Eur Heart J 2010;31:2915-2957.

246. Jones RH, Velazquez EJ, Michler RE, Sopko G, Oh JK, O'Connor CM, Hill JA, Menicanti L, Sadowski Z, Desvigne-Nickens P, Rouleau JL, Lee KL. Coronary bypass surgery with or without surgical ventricular reconstruction. $N$ Engl J Med 2009;360:1705-1717.

247. Vahanian A, Alfieri O, Andreotti F, Antunes MJ, Barón-Esquivias G, Baumgartner H, Borger MA, Carrel TP, De Bonis M, Evangelista A, Falk V, lung B, Lancellotti P, Pierard L, Price S, Schaefers H-J, Schuler G, Stepinska J, Swedberg K, Takkenberg J, Von Oppell UO, Windecker S, Zamorano JL, Zembala M. Guidelines on the Management of Valvular Heart Disease (Version 2012). The Joint Task Force on the Management of Valvular Heart Disease of the European Society of Cardiology (ESC) and the European Association for Cardio-Thoracic Surgery (EACTS). Eur Heart J 2012; doi:10.1093/eurheartj/ehs109, in press.

248. Smith CR, Leon MB, Mack MJ, Miller DC, Moses JW, Svensson LG, Tuzcu EM, Webb JG, Fontana GP, Makkar RR, Williams M, Dewey T, Kapadia S, Babaliaros V, Thourani VH, Corso P, Pichard AD, Bavaria JE, Herrmann HC, Akin J], Anderson WN, Wang D, Pocock SJ. Transcatheter versus surgical aorticvalve replacement in high-risk patients. N Engl J Med 2011;364:2187-2198.

249. Smith CR, Leon MB, Mack MJ, Miller C, Moses JW, Svensson LG, Tuzcu M, Webb JG, Fontana GP, Makkar RR, WIlliams M, Dewey T, Kapadia S, Babaliaros V, Thourani VH, Corso P, Pichard AD, Bavaria JE, Herrmann HC, Akin J, Anderson WN, Wang D, Pocock SJ; for the PARTNER Trial Investigators. Transcatheter versus surgical aortic-valve replacement in high-risk patients. $N$ Eng J Med 2011;364:2187-98.

250. Feldman T, Kar S, Rinaldi M, Fail P, Hermiller J, Smalling R, Whitlow PL, Gray W, Low R, Herrmann HC, Lim S, Foster E, Glower D. Percutaneous mitral repair with the MitraClip system: safety and midterm durability in the initial EVEREST (Endovascular Valve Edge-to-Edge REpair Study) cohort. J Am Coll Cardiol 2009;54:686-694.

251. Banner NR, Bonser RS, Clark AL, Clark S, Cowburn PJ, Gardner RS, Kalra PR, McDonagh T, Rogers CA, Swan L, Parameshwar J, Thomas HL, Williams SG. UK guidelines for referral and assessment of adults for heart transplantation. Heart 2011;97:1520-1527.

252. Mehra MR, Kobashigawa J, Starling R, Russell S, Uber PA, Parameshwar J, Mohacsi P, Augustine S, Aaronson K, Barr M. Listing criteria for heart transplantation: International Society for Heart and Lung Transplantation guidelines for the care of cardiac transplant candidates-2006. J Heart Lung Transplant 2006;25: 1024-1042.

253. Shah KB, Tang DG, Cooke RH, Harton S, Flattery M, Katlaps G], Kasirajan V, Hess ML. Implantable mechanical circulatory support: demystifying patients with ventricular assist devices and artificial hearts. Clin Cardiol 2011;34:147-152.

254. Rose EA, Gelijns AC, Moskowitz AJ, Heitjan DF, Stevenson LW, Dembitsky W, Long JW, Ascheim DD, Tierney AR, Levitan RG, Watson JT, Meier P, Ronan NS, Shapiro PA, Lazar RM, Miller LW, Gupta L, Frazier OH, Desvigne-Nickens P, $\mathrm{Oz}$ MC, Poirier VL. Long-term use of a left ventricular assist device for end-stage heart failure. N Engl J Med 2001;345:1435-1443.

255. Slaughter MS, Rogers JG, Milano CA, Russell SD, Conte JV, Feldman D, Sun B, Tatooles AJ, Delgado RM 3rd, Long JW, Wozniak TC, Ghumman W, Farrar DJ, Frazier $\mathrm{OH}$. Advanced heart failure treated with continuous-flow left ventricular assist device. N Engl J Med 2009;361:2241-2251.

256. Birks EJ, Tansley PD, Hardy J, George RS, Bowles CT, Burke M, Banner NR, Khaghani A, Yacoub $\mathrm{MH}$. Left ventricular assist device and drug therapy for the reversal of heart failure. N Engl J Med 2006;355:1873-1884.
257. Khazanie P, Rogers JG. Patient selection for left ventricular assist devices. Congest Heart Fail 2011;17:227-234.

258. Pagani FD, Miller LW, Russell SD, Aaronson KD, John R, Boyle AJ, Conte JV, Bogaev RC, MacGillivray TE, Naka Y, Mancini D, Massey HT, Chen L, Klodell CT, Aranda JM, Moazami N, Ewald GA, Farrar DJ, Frazier OH. Extended mechanical circulatory support with a continuous-flow rotary left ventricular assist device. J Am Coll Cardiol 2009;54:312-321.

259. Lainscak M, Blue L, Clark AL, Dahlstrom U, Dickstein K, Ekman I, McDonagh T, McMurray JJ, Ryder M, Stewart S, Stromberg A, Jaarsma T. Self-care management of heart failure: practical recommendations from the Patient Care Committee of the Heart Failure Association of the European Society of Cardiology. Eur J Heart Fail 2011;13:115-126.

260. Paterna S, Gaspare P, Fasullo S, Sarullo FM, Di Pasquale P. Normal-sodium diet compared with low-sodium diet in compensated congestive heart failure: is sodium an old enemy or a new friend? Clin Sci (Lond) 2008;114:221-230.

261. Powell LH, Calvin JE Jr, Richardson D, Janssen I, Mendes de Leon CF, Flynn KJ, Grady KL, Rucker-Whitaker CS, Eaton C, Avery E. Self-management counseling in patients with heart failure: the heart failure adherence and retention randomized behavioral trial. JAMA 2010;304:1331-1338.

262. O'Connor CM, Whellan DJ, Lee KL, Keteyian SJ, Cooper LS, Ellis SJ, Leifer ES, Kraus WE, Kitzman DW, Blumenthal JA, Rendall DS, Miller NH, Fleg JL, Schulman KA, McKelvie RS, Zannad F, Piña IL; HF-ACTION Investigators. Efficacy and safety of exercise training in patients with chronic heart failure: HFACTION randomized controlled trial. JAMA 2009;301:1439-1450.

263. Piepoli MF, Conraads V, Corra U, Dickstein K, Francis DP, Jaarsma T, McMurray J, Pieske B, Piotrowicz E, Schmid JP, Anker SD, Solal AC, Filippatos GS, Hoes AW, Gielen S, Giannuzzi P, Ponikowski PP. Exercise training in heart failure: from theory to practice. A consensus document of the Heart Failure Association and the European Association for Cardiovascular Prevention and Rehabilitation. Eur J Heart Fail 2011;13:347-357.

264. Sochalski J, Jaarsma T, Krumholz HM, Laramee A, McMurray JJ, Naylor MD, Rich MW, Riegel B, Stewart S. What works in chronic care management: the case of heart failure. Health Aff 2009;28:179-189.

265. Porapakkham P, Zimmet H, Billah B, Krum H. B-type natriuretic peptide-guided heart failure therapy: a meta-analysis. Arch Intern Med 2010;170:507-514.

266. van Veldhuisen DJ, Braunschweig F, Conraads V, Ford I, Cowie MR, Jondeau G, Kautzner J, Aguilera RM, Lunati M, Gerritse B, Borggrefe M. Intrathoracic impedance monitoring, audible patient alerts, and outcome in patients with heart failure. Circulation 2011;124:1719-1726.

267. Abraham WT, Adamson PB, Bourge RC, Aaron MF, Costanzo MR, Stevenson LW, Strickland W, Neelagaru S, Raval N, Krueger S, Weiner S, Shavelle D, Jeffries B, Yadav JS. Wireless pulmonary artery haemodynamic monitoring in chronic heart failure: a randomised controlled trial. Lancet 2011;377: 658-666.

268. Anker SD, Koehler F, Abraham WT. Telemedicine and remote management of patients with heart failure. Lancet 2011;378:731-739.

269. Inglis SC, Clark RA, McAlister FA, Stewart S, Cleland JG. Which components of heart failure programmes are effective? A systematic review and meta-analysis of the outcomes of structured telephone support or telemonitoring as the primary component of chronic heart failure management in 8323 patients: Abridged Cochrane Review. Eur J Heart Fail 2011;13:1028-1040.

270. Jaarsma T, Beattie JM, Ryder M, Rutten FH, McDonagh T, Mohacsi P, Murray SA, Grodzicki T, Bergh I, Metra M, Ekman I, Angermann C, Leventhal M, Pitsis A, Anker SD, Gavazzi A, Ponikowski P, Dickstein K, Delacretaz E, Blue L, Strasser F, McMurray J. Palliative care in heart failure: a position statement from the palliative care workshop of the Heart Failure Association of the European Society of Cardiology. Eur J Heart Fail 2009;11:433-443. 


\section{Appendix}

Appendix A: Aetiology of heart failure

There is no agreed or satisfactory classification for the causes of HF, with much overlap between potential categories

Myocardial disease

I. Coronary artery disease

2. Hypertension ${ }^{2}$

3. Cardiomyopathy

a. Familial

i. Hypertrophic

ii. Dilated

iii. Arrhythmogenic right ventricular cardiomyopathy

iv. Restrictive

v. Left ventricular non-compaction

b. Acquired ${ }^{c}$

i. Myocarditis (inflammatory cardiomyopathy)

Infective

- Bacterial

- Spirochaetal

- Fungal

- Protozoal

- Parasitic

- Rickettsia

- Viral

Immune-mediated

- Tetanus toxoid, vaccines, serum sickness

- Drugs

- Lymphocytic/giant cell myocarditis

- Sarcoidosis

- Autoimmune

Toxic

- Eosinophilic (Churg-Strauss)

- Drugs (e.g. chemotherapy, cocaine)

- Alcohol

- Heavy metals (copper, iron, lead)

ii. Endocrine/nutritional

- Phaeochromocytoma

- Vitamin deficiency (e.g. thiamine)

- Selenium deficiency

- Hypophosphataemia

- Hypocalcaemia

iii. Pregnancy

iv. Infiltration

- Amyloidosis

- Malignancy

Valvular heart disease

Mitral

Aortic

Tricuspid

Pulmonary

\section{Pericardial disease}

Constrictive pericarditis

Pericardial effusion

Endocardial disease

- Endomyocardial diseases with hypereosinophilia [hypereosinophilic syndromes (HES)]

- Endomyocardial disease without hypereosinophilia [e.g. endomyocardial fibrosis (EMF)]

- Endocardial fibroelastosis

Congenital heart disease

Arrhythmia

Tachyarrhythmia

Atrial

Ventricular

Bradyarrhythymia

Sinus node dysfunction

Conduction disorders

- Atrioventricular block

High output states

- Anaemia

- Sepsis

- Thyrotoxicosis

- Paget's disease

- Arteriovenous fistula

Volume overload

- Renal failure

- latrogenic (e.g. post-operative fluid infusion)

$\mathrm{AV}=$ atrioventricular; $\mathrm{HF}=$ heart failure.

aoth peripheral arterial and myocardial factors contribute to the development of heart failure.

'Other inherited diseases may have cardiac effects. e.g. Fabry disease. 
Appendix B: Prognostic variables in heart failure

A very large number of variables have been shown to relate to outcome in HF (and new prognostic markers are regularly identified). This table lists some of the more commonly described prognostic variables.

\section{Demographics, history, and physical examination}

Age, sex, ethnicity NYHA class, body mass index.

Signs of congestion, increased jugular venous pressure, third heart sound, low systolic blood pressure, higher heart rate.

Diabetes mellitus, renal dysfunction, depression, COPD

Ischaemic aetiology, history of myocardial infarction.

\section{Routine laboratory tests}

Serum sodium

Liver enzymes, bilirubin

Serum creatinine/creatinine clearance/eGFR

$\mathrm{BUN} /$ urea and markers of tubular injury

Serum albumin

Uric acid

Haemoglobin

Red cell distribution width

Troponin I/T

Urinary albumin creatinine ratio

Neurohormones, cytokines, and related factors ${ }^{a}$

Plasma renin activity

Angiotensin II

Aldosterone

Catecholamines

(Big) endothelin- 1

Adrenomedullin

Natriuretic peptides ${ }^{b}$

Vasopressin/Co-peptin

Cytokines

sST-2

Galectin-3

Collagen markers

\section{Electrical variables}

QRS width

LV hypertrophy

Atrial fibrillation

Complex ventricular arrhythmias

Heart rate variability

\section{Imaging variables}

LV internal dimensions and fractional shortening

Cardiothoracic ratio on chest X-ray

Wall motion index (various ${ }^{c}$ )

Ejection fraction

Left atrial size

Restrictive filling pattern/short deceleration time

Right ventricular function (various ${ }^{c}$ )

Inflammation (contrast-enhanced CMR), iron content (in thalassaemia: CMR)

Amyloidosis (contrast kinetics in CMR)

Ischaemia and viability imaging, arrhythmogenic substrates

Exercise test/haemodynamic variables (rest/exercise)

$\mathrm{VO}$

$\mathrm{VE} / \mathrm{VCO}_{2}$ slope

Max/peak (normal $>20 \mathrm{~mL} / \mathrm{kg} / \mathrm{min}^{\mathrm{d}}$ )

6-min walk distance (normal $>600 \mathrm{~m}^{\circ}$ )

Cardiac index (normal $>2.5 \mathrm{~L} / \mathrm{min} / \mathrm{m}^{2}$ )

$\mathrm{LV}$ end-diastolic pressure/pulmonary artery wedge pressure (normal $<12 \mathrm{mmHg}$ )

BUN = blood urea nitrogen; $\mathrm{CMR}$ = cardiac magenetic resonance; $\mathrm{COPD}=$ chronic obstructive pulmonary disease; eGFR = estimated glomerular filtration rate;

$\mathrm{HF}=$ heart failure; LV = left ventricular; NYHA = New York Heart Association; sST-2 = soluble ST-2; VO2 = peak oxygen consumption.

${ }^{2}$ This list is not intended to be comprehensive and other circulating factors may also be associated with prognosis.

bVarious peptides including $\mathrm{C}$-terminal, $\mathrm{N}$-terminal, and mid-regional are predictive of outcome.

cVarious measures/classifications can be used, and no single threshold for normal/abnormal can be given

${ }^{d}$ Functional capacity varies greatly according to prior fitness, age, and sex; values given are a guideline for older ( $>65$ years) adults. 
Appendix C: Practical guidance on the use of angiotensin-convering enzyme inhibitors

(or an angiotensin II receptor blocker) in patients with systolic heart failure ${ }^{\mathrm{a}}$

WHY?

To improve symptoms and exercise capacity, reduce the risk of HF hospitalization, and increase survival

IN WHOM AND WHEN?

Indications

Potentially all patients with $\mathrm{HF}$ and an $\mathrm{EF} \leq 40 \%$

First-line treatment (along with beta-blockers and an MRA) in patients with NYHA class II-IV HF; start as early as possible in the course of disease.

ACE inhibitors are also of benefit in patients with asymptomatic LV systolic dysfunction (NYHA class I)

Contraindications

History of angioedema

Known bilateral renal artery stenosis

Pregnancy/risk of pregnancy

Cautions/seek specialist advice

Significant hyperkalaemia $\left(\mathrm{K}^{+}>5.0 \mathrm{mmol} / \mathrm{L}\right)$

Significant renal dysfunction (creatinine $>221 \mu \mathrm{mol} / \mathrm{L}[>2.5 \mathrm{mg} / \mathrm{dL}]$ or eGFR $<30 \mathrm{~mL} / \mathrm{min} / 1.73 \mathrm{~m}^{2}$ )

Symptomatic or severe asymptomatic hypotension (systolic blood pressure $<90 \mathrm{mmHg}$ )

Drug interactions to look out for

$\mathrm{K}^{+}$supplements/ $\mathrm{K}^{+}$-sparing diuretics, e.g. amiloride and triamterene (beware combination preparations with furosemide), MRAs and renin inhibitors ${ }^{c}$ NSAIDs ${ }^{d}$

Trimethoprim/trimethoprim-sulfamethoxazole

'Low-salt' substitutes with a high $\mathrm{K}^{+}$content

WHERE?

In the community for most patients

Exceptions-see Cautions/see specialist advice

WHICH ACE INHIBITOR AND WHAT DOSE? - see Table 14

HOW TO USE?

Check renal function and electrolytes

Start with a low dose (see Table 14)

Double the dose at not less than 2-week intervals in the community. More rapid dose up-titration may be carried out in patients in hospital or who are otherwise closely monitored, tolerability permitting

Aim for target dose (see above) or, failing that, the highest tolerated dose

Remember: some ACE inhibitor (or ARB) is better than no ACE inhibitor

Re-check blood chemistry (urea/BUN, creatinine, $\mathrm{K}^{+}$) I-2 weeks after initiation and I-2 weeks after final dose titration

Monitor blood chemistry 4 monthly thereafter

When to stop up-titration, reduce dose, stop treatment-see PROBLEM SOLVING

A specialist HF nurse may assist with education of the patient, follow-up (in person or by telephone), biochemical monitoring and dose up-titration

\section{ADVICE TO PATIENT}

Explain expected benefits

Treatment is given to improve symptoms, to prevent worsening of HF leading to hospital admission, and to increase survival

Symptoms improve within a few weeks to a few months after starting treatment

Advise patients to report principal adverse effects, (i.e. dizziness/symptomatic hypotension, cough)-see PROBLEM SOLVING

Advise patients to avoid NSAIDs ${ }^{d}$ not prescribed by a physician (i.e. purchased over-the-counter) and salt substitutes high

in $\mathrm{K}^{+}$-see PROBLEM SOLVING

PROBLEM SOLVING

Asymptomatic low blood pressure

Doses not usually require any change in therapy

Symptomatic hypotension

Dizziness/light headedness is common and often improves with time-patients should be reassured

Reconsider need for nitrates, calcium-channel blockers, ${ }^{e}$ and other vasodilators and reduce dose/stop, if posible

If no signs of symptoms of congestion, consider reducing diuretic dose

Cough

If these measures do not solve problem, seek specialist advice

Cough is common in patients with HF, many of whom have smoking-related lung disease

Cough is also a symptom of pulmonary oedema, which should be excluded when a new worsening cough develops

ACE inhibitor-induced cough does not always require treatment discontinuation

When a troublesome cough does develop (e.g. one stopping the patient from sleeping) and can be proved to be due to ACE inhibition (i.e. recurs

after ACE inhibitor withdrawal and re-challenge), substitution of an ARB is recommended

Worsening renal function and hyperkalaemia

Some rise in urea (BUN), creatinine, and potassium is to be expected after an ACE inhibitor; if an increase is small and asymptomatic, no action is necessary

An increase in creatinine of up to $50 \%$ above baseline, or $266 \mu \mathrm{mol} / \mathrm{L}(3 \mathrm{mg} / \mathrm{dL}) / \mathrm{eGFR}<25 \mathrm{~mL} / \mathrm{min} / 1.73 \mathrm{~m}^{2}$, whichever is the smaller, is acceptable

An increase in potassium to $\leq 5.5 \mathrm{mmol} / \mathrm{L}$ is acceptable

If urea, creatinine, or potassium does rise excessively, consider stopping concomitant nephrotoxic drugs (e.g. NSAIDs ${ }^{d}$ ) and other potassium

supplements or retaining agents (triamterene, amiloride) and, if no signs of congestion, reducing the dose of diuretic

If greater rises in creatinine or potassium than those outlined above persist despite adjustment of concomitant medications, the dose of the ACE

inhibitor (or ARB) should be halved and blood chemistry re-checked within I-2 weeks; if there is still an unsatisfactory response, specialist advice

should be sought

If potassium rises to $>5.5 \mathrm{mmol} / \mathrm{L}$ or creatinine increases by $>100 \%$ or to $>310 \mu \mathrm{mol} / \mathrm{L}(3.5 \mathrm{mg} / \mathrm{dL}) / \mathrm{eGFR}<20 \mathrm{~mL} / \mathrm{min} / 1.73 \mu \mathrm{m}^{2}$, the ACE inhibitor

(or ARB) should be stopped and specialist advice sought

Blood chemistry should be monitored frequently and serially until potassium and creatinine have plateaued

$\mathrm{ACE}=$ angiotensin-converting enzyme; $\mathrm{ARB}=$ angiotensin receptor blocker; $\mathrm{BUN}=$ blood urea nitrogen; $\mathrm{EF}=$ ejection fraction; $\mathrm{HF}$, heart failure; $\mathrm{LV}=$ left ventricular;

MRA = mineralocorticoid receptor antagonist; NSAID = non-steroidal anti-inflammatory drug; NYHA $=$ New York Heart Association

Note: it is very rarely necessary to stop an ACE inhibitor (or ARB), and clinical deterioration is likely if treatment is withdrawn. Ideally, specialist advice should be sought before The

aThe recommendations in this table represent expert opinion based upon relevant clinical trials (drugs, titration schedules, target doses, patient monitoring, treatment benefits, and

reported adverse effects) and clinical experience.

'The safety of an ARB in patients developing angioedema with an ACE inhibitor is uncertain.

Renin inhibitors are not recommended in heart failure.

${ }^{\mathrm{A}}$ Avoid NSAIDs unless essential.

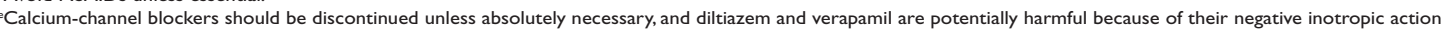




\section{WHY? \\ To improve symptoms, reduce the risk of HF hospitalization and increase survival}

Appendix D: Practical guidance on the use of beta-blockers in patients with systolic heart failure ${ }^{\mathrm{a}}$

\section{IN WHOM AND WHEN?}

Indications

Potentially all patients with stable mild or moderate systolic $\mathrm{HF}(\mathrm{EF} \leq 40 \%)$; patients with severe HF also benefit from beta-blockers but treatment should be started under the care of a specialist

First-line treatment, along with an ACE inhibitor and an MRA, in patients with stabilized HF; start as early as possible in the course of disease

Contraindications

Asthma (COPD is not a contraindication)

Second- or third-degree AV block (in the absence of a permanent pacemaker)

Cautions/seek specialist advice

Severe (NYHA class IV) HF

Current or recent ( $<4$ weeks) exacerbation of HF (e.g. hospital admission with worsening HF), heart block, or heart rate $<60$ b.p.m.

Persisting signs of congestion, hypotension/low blood pressure (systolic $<90 \mathrm{mmHg}$ ), raised jugular venous pressure, ascites, marked peripheral oedematry to relieve congestion and achieve 'euvolaemia' before starting beta-blocker

Drug interactions to look out for (because of risk of bradycardia/atrio ventricular block)

Verapamil, diltiazem (should be discontinued) ${ }^{\mathrm{b}}$

Digoxin, amiodarone, ivabradine

\section{WHERE?}

In the community in stable patients (NYHA class IV/severe HF patients and those with a current/recent exacerbation should be referred for specialist advice) In patients hospitalized with worsening HF-after stabilizing, relieving congestion, and, if possible, restoring 'euvolaemia'(but ideally before discharge).

Other exceptions-see Cautions/see specialist advice

\section{WHICH BETA-BLOCKER AND WHAT DOSE? - see Table $14^{c}$}

\section{HOW TO USE?}

Start with a low dose (see Table 14)

Double the dose at not less than 2-week intervals (slower up-titration may be needed in some patients)

Aim for target dose (see above) or, failing that, the highest tolerated dose

Remember: some beta-blocker is better than no beta-blocker

Monitor heart rate, blood pressure, and clinical status (symptoms, signs-especially signs of congestion, body weight)

When to stop up-titration, reduce dose, stop treatment-see PROBLEM SOLVING

A specialist HF nurse may assist with education of the patient, follow-up (in person or by telephone), and dose up-titration

\section{ADVICE TO PATIENT}

Explain expected benefits (see WHY?) and mention possibility of temporary adverse effects

Treatment is given to improve symptoms, to prevent worsening of HF leading to hospital admission, and to increase survival

Symptomatic improvement may develop slowly after starting treatment, sometimes taking 3-6 months or longer

Temporary symptomatic deterioration may occur during initiation or up-titration phase; in the long term, beta-blockers improve well-being

Advise patient to report deterioration (see PROBLEM SOLVING) and that deterioration (tiredness, fatigue, breathlessness) can usually be easily managed

by adjustment of other medication; patients should be advised not to stop beta-blocker therapy without consulting the physician

To detect and to treat deterioration early, patients should be encouraged to weigh themselves daily (after waking, before dressing, after voiding, before eating) and to increase their diuretic dose should their weight increase, persistently (>2 days), by $>1.5-2.0 \mathrm{~kg}^{\mathrm{d}}$

PROBLEM SOLVING

Worsening symptoms or signs (e.g. increasing dyspnoea, fatigue, oedema, weight gain)

If increasing congestion, increase dose of diuretic or halve dose of beta-blocker (if increasing diuretic dose does not work)

If marked fatigue (or bradycardia-see below), halve dose of beta-blocker (rarely necessary); review patient in I-2 weeks; if not improved, seek specialist advice

If serious deterioration, halve dose of beta-blocker or stop this treatment (rarely necessary); seek specialist advice

Low heart rate

If $<50$ b.p.m. and worsening symptoms, halve dose of beta-blocker, or, if severe deterioration, stop beta-blocker (rarely necessary)

Review need for other heart rate-slowing drugs (e.g. digoxin, amiodarone, diltiazem, or verapamil ${ }^{b}$ )

Arrange electrocardiogram to exclude heart block

Seek specialist advice

Asymptomatic low blood pressure

Does not usually require any change in therapy

Symptomatic hypotension

If dizziness, light headedness, or confusion and a low blood pressure, reconsider need for nitrates, calcium-channel blockers, ${ }^{b}$ and other vasodilators and reduce/stop, if possible

If no signs or symptoms of congestion, consider reducing diuretic dose

If these measures do not solve problem, seek specialist advice

$\mathrm{ACE}=$ angiotensin-converting enzyme; $\mathrm{AV}=$ atrioventricular; $\mathrm{COPD}=$ chronic obstructive pulmonary disease; $\mathrm{HF}$, heart failure; $\mathrm{LV}=$ left ventricular

MRA = mineralocorticoid receptor antagonist; NSAID = non-steroidal anti-inflammatory drug; NYHA = New York Heart Association.

Note: beta-blockers should not be stopped suddenly unless absolutely necessary (there is a risk of a 'rebound' increase in myocardial ischaemia or infarction and arrhythmias). Ideally, specialist advice should be sought before treatment discontinuation.

aThe recommendations in this table represent expert opinion based upon relevant clinical trials (drugs, titration schedules, target doses, patient monitoring, treatment benefits, and reported adverse effects) and clinical experience.

bCalcium-channel blockers should be discontinued unless absolutely necessary, and diltiazem and verapamil are potentially harmful because of their negative inotropic effect.

cMetoprolol tartrate should not be used in preference to an evidence-based beta-blocker in HF.

dThis is generally good advice for all patients with HF. 


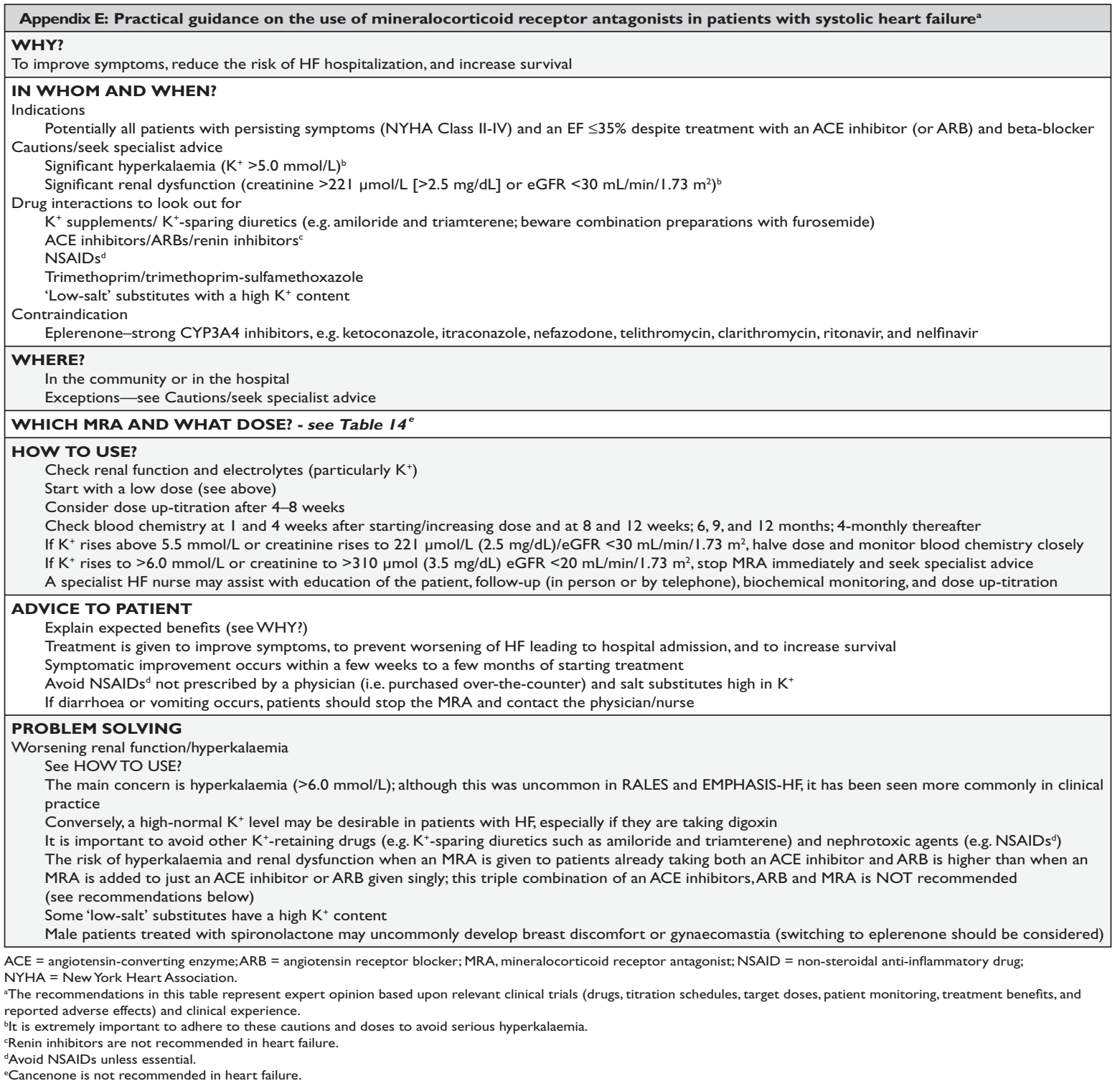


Appendix F: Practical guidance on the use of diuretics in patients with heart failure

(with a reduced or preserved ejection fraction)

WHY?

To relieve breathlessness and oedema in patients with symptoms and signs of congestion

\section{IN WHOM AND WHEN?}

Indications

Potentially all patients with symptoms and signs of congestion, irrespective of EF

Should always be used in combination with an ACE inhibitor (or ARB), beta-blocker, and an MRA in patients with a reduced EF

Use minimum dose necessary to maintain euvolaemia-the patient's 'dry weight' (i.e. to keep the patient free of symptoms and signs of congestion)

Dose may need to be increased or decreased according to the patient's volume status; patients can be educated and trained to alter their own diuretic dose, according to need (based on symptoms, signs and weight changes-see Section 14)

Contraindications

Not indicated if the patient has never had symptoms or signs of congestion

Known allergic reaction/other adverse reaction (drug-specific)

Cautions/seek specialist advice

Significant hypokalaemia $\left(\mathrm{K}^{+} \leq 3.5 \mathrm{mmol} / \mathrm{L}\right)$-may be made worse by diuretic

Significant renal dysfunction (creatinine $>221 \mu \mathrm{mol} / \mathrm{L}[>2.5 \mathrm{mg} / \mathrm{dL}]$ or eGFR $<30 \mathrm{~mL} / \mathrm{min} / 1.73 \mathrm{~m}^{2}$ )-may be made worse by diuretic or patient may not respond to diuretic (especially thiazide diuretic)

Symptomatic or severe asymptomatic hypotension (systolic blood pressure $<90 \mathrm{mmHg}$ )-may be made worse by diuretic-induced hypovolaemia

Drug interactions to look out for

Combination with ACE inhibitor ARB or renin inhibitors ${ }^{b}$-risk of hypotension (usually not a problem)

Combination with other diuretics (e.g. loop plus thiazide)-risk of hypovolaemia, hypotension, hypokalaemia, and renal impairment NSAIDsc-may attenuate effect of diuretic

\section{WHERE?}

In the community for most patients

\section{WHICH DIURETIC AND WHAT DOSE? - see Table 16}

\section{HOW TO USE?}

Check renal function and electrolytes

Start with a low dose (see Table 16)

Adjust dose according to symptoms and signs of congestion, blood pressure, and renal function

Re-check blood chemistry I-2 weeks after initiation and after any increase in dose (urea/BUN, creatinine, $\mathrm{K}^{+}$)

When to stop up-titration, reduce dose, stop treatment-see PROBLEM SOLVING

A specialist HF nurse may assist with education of the patient, follow-up (in person or by telephone), biochemical monitoring, and dose adjustment (including patient training in dose adjustment)

\section{ADVICE TO PATIENT}

\section{Explain expected benefits}

Symptoms improve quickly-usually within days of starting treatment

Advise patients to report principal adverse effects (e.g. thirst) (avoid excessive consumption of hypotonic fluids, which can cause hyponatraemia) and dizziness/symptomatic hypotension-see PROBLEM SOLVING

Advise patients to avoid NSAIDs ${ }^{b}$ not prescribed by a physician (i.e. purchased over-the-counter)-may cause diuretic resistance and renal impairment Patient may be trained to adjust dose based on symptoms, signs, and changes in weight (if regular weighing)

Dose may need to be decreased if fluid loss (e.g. due to diarrhoea/vomiting, excessive sweating)

\section{PROBLEM SOLVING}

Asymptomatic low blood pressure

Dose may be reduced if no symptoms or signs of congestion

Symptomatic hypotension

Causing dizziness/light headedness-reduce dose if no symptoms or signs of congestion

Reconsider need for nitrates, CCBs, ${ }^{d}$ and other vasodilators

If these measures do not solve problem, seek specialist advice

Hypokalaemia/hypomagnaesaemia

Increase ACE inhibitor/ARB dose, add MRA, potassium supplements; magnesium supplements

Hyponatraemia

Volume depleted: stop thiazide or switch to loop diuretic, if possible; reduce dose/stop loop diuretics if possible; volume overloaded: fluid restriction; increase dose of loop diuretic; consider AVP antagonist (e.g. tolvaptan if available); i.v. inotropic support; consider ultrafiltration

Hyperuricaemia/gout

Consider allopurinol prophylaxis; for symptomatic gout use colchicine for pain relief; avoid NSAIDs

Hypovolaemia/dehydration

Assess volume status; consider diuretic dosage reduction

Insufficient diuretic response/diuretic resistance

Check compliance and fluid intake; increase dose of diuretic; consider switching from furosemide to bumetanide or torasemide; add MRA/increase dose of MRA; combine loop diuretic and thiazide/metolazone; administer loop diuretic twice (or more times) daily or on empty stomach/consider short-term i.v. infusion of loop diuretic; consider ultrafiltration

Renal impairment (rising creatinine/BUN-urea)

Check for hypovolaemia/dehydration; exclude use of other nephrotoxic agents, e.g. NSAIDs, trimethoprim; withhold MRA; if using concomitant loop and thiazide diuretic stop thiazide diuretic; consider reducing dose of ACE inhibitor/ARB; consider haemofiltration/dialysis

$\mathrm{ACE}=$ angiotensin-converting enzyme; $\mathrm{ARB}=$ angiotensin receptor blocker; $\mathrm{AVP}=$ arginine vasopressin; $\mathrm{BUN}=$ blood urea nitrogen; $\mathrm{CCBs}=$ calcium-channel blockers;

$\mathrm{EF}=$ ejection fraction; $\mathrm{HF}=$ heart failure; i.v. = intravenous; $\mathrm{MRA}=$ mineralocorticoid receptor antagonist; NSAIDs = non-steroidal anti-inflammatory drugs.

asually only needed for a short period-careful monitoring of blood chemistry is essential.

${ }^{B}$ Renin inhibitors are not recommended in heart failure.

'Avoid NSAIDs unless essential.

${ }^{\mathrm{d}} \mathrm{CCBs}$ should be discontinued in patients with systolic HF unless absolutely necessary, and diltiazem and verapamil are potentially harmful in patients with systolic heart failure because

of their negative inotropic action. 